\title{
ANÁLISE DAS RELAÇÕES ENTRE ENERGIA, MOMENTUM, TAXA DE PRECIPITACÃO E REFLETIVIDADE DO RADAR: UMA APLICAÇẪO AO ESTUDO DA EROSÃO
}

\author{
CLAUDIA SONIA WAGNER
}

Orientador: Prof. Dr. OSWALDO MASSAMBANI

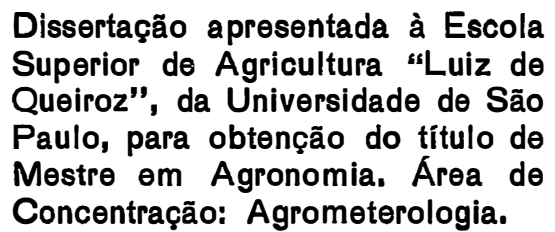

PIRACICABA

Estado de São Paulo - Brasil

Novembro - 1986 
. $i j i$.

Aos meus pais 


\section{AGRADECIMENTOS}

Ao Imstintuto de Pesquirsas Meteorológincas da thilversidade de Banrou, nas pessoas do Diretor Dr. Roherto $\mathbb{Z}$ ïcemite Callheïros e Prof.

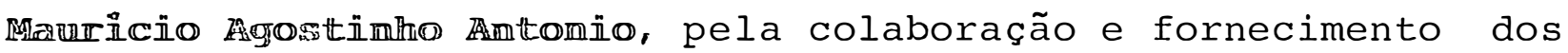
dados disdrométricos, sem os quais este trabalho não teria sido realizado.

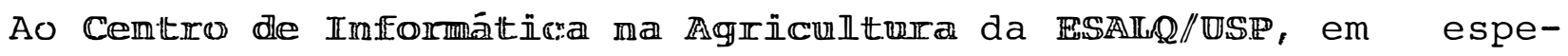
cial a José Celso $\mathbb{C}$. de Abreu e a Carlos matiolin, pela ajuda e desenvolvimento do programa para cálculo dos dados.

Ao Prof.Dr. Oswalldo Massambarnin, pela orientação e interesse demonstrado.

Ao Dr. Frramci.sco luombardi Neto da Seção de Comservação do Solo do IIAC, pelo incentivo dado.

Ao Dr. Chringtïam Roth pelo primeiro estímulo dado.

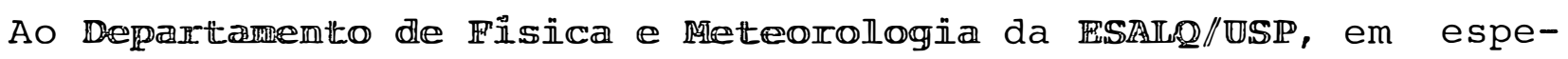

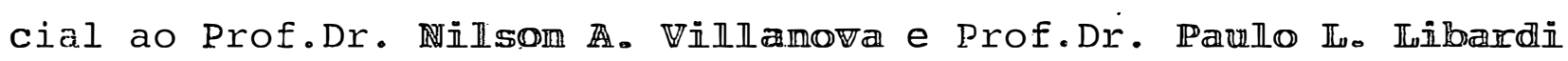
pela atenção dispensada. 


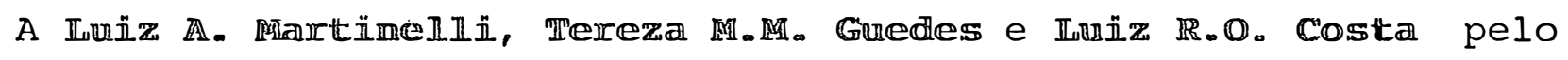
apoio concedido.

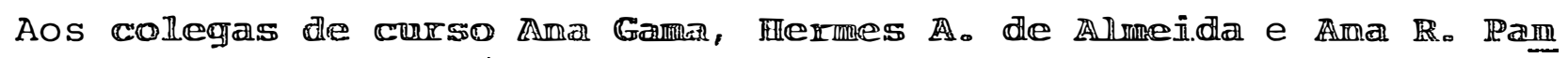
Ånro pelas horas agradáveis de estudo.

Ao CNIPG, CAMPES e $\mathbb{E}$ APPESP pelos auxílio-bolsa concedidos. 


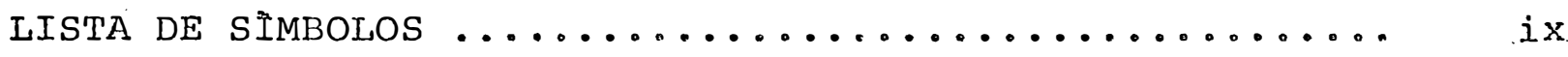

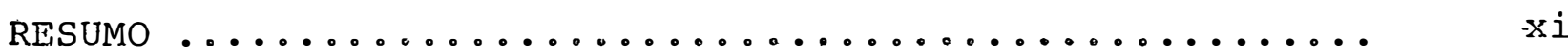

SUMMARY $\ldots \ldots \ldots \ldots \ldots \ldots \ldots \ldots \ldots \ldots \ldots \ldots \ldots \ldots \ldots \ldots \ldots \ldots \ldots$

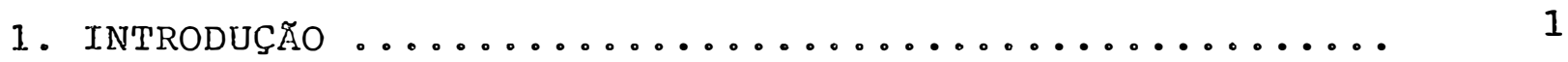

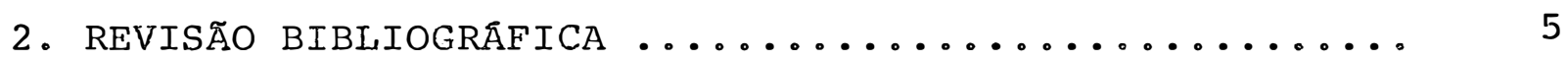

2.1. Distribuição do tamanho de gotas ........... 5

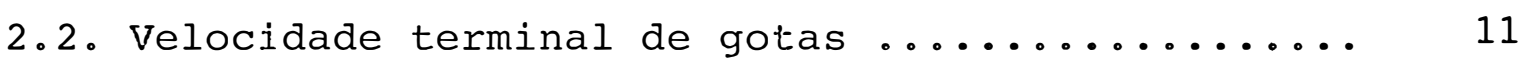

2.3. Energia cinética e momentum ............... 14

2.3.1. Relação entre a energia cinética, o momen tum e a erosão dos solos.............. 14

2.3.2. Obtenção da energia cinética do momentum da chuva .......................... 18

2.4. Refletividade do radar meteorológico ......... 23

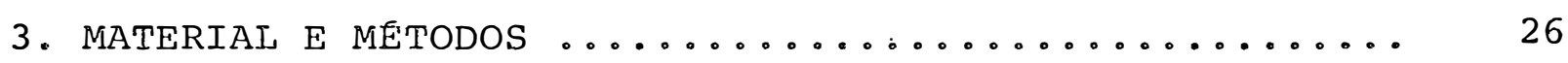

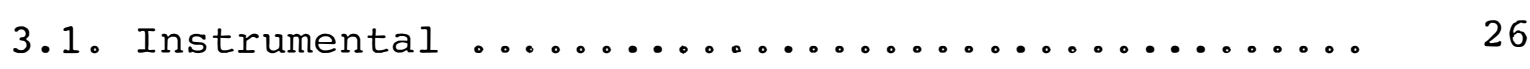

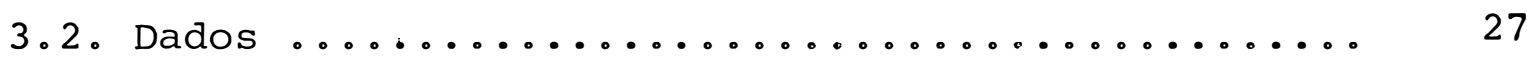

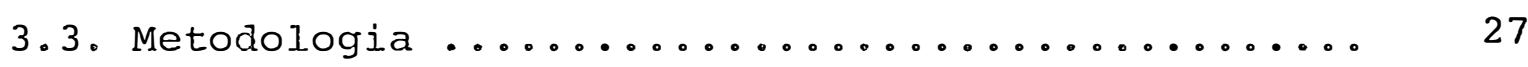

3.3.1. Classes de diâmetro e velocidade terminal

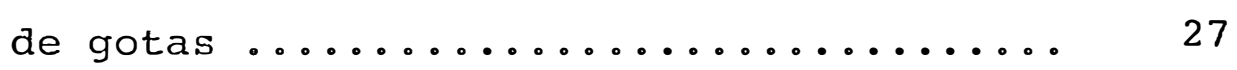

3.3.2. Cálculo do número de gotas por volume de ar e do número de gotas por volume de ar e por intervalo de classe ...................... 30

3.3.3. Obtenção do espectro de gotas .......... 31

3.3.4. Cálculo do diâmetro mediano ........... 32

3.3.5. Cálculo da concentração de energia cinética, da concentração de momentum e da concentração de volume de precipitação ............ 
3.3.6. Cálculo do fluxo de energia cinética, do fluxo de momentum e a taxa de precipita-

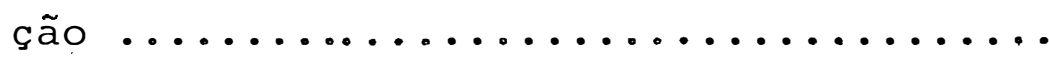

3.3.7. Cấlculo da energia cinética por unidade de áréa e de altura pluviométrica, por momentum por área e por altura pluviomé trica e da refletividade do radar.

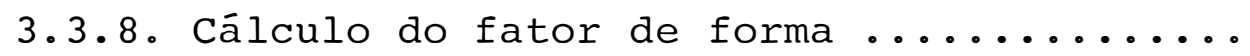

3.3.9. As relações analíticas ............... 38

3.3.10. As relações experimentais ............. 41

3.4. Programa para cálculo em microcomputador ...... 43

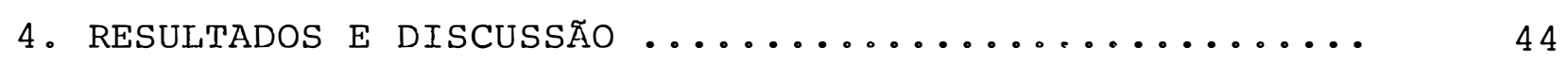

4.1. Caracterização das chuvas estudadas ........... 44

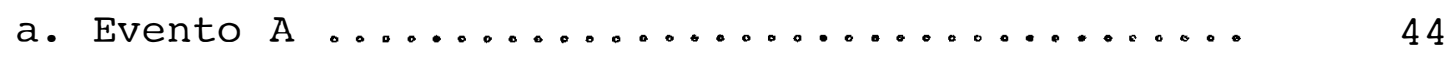

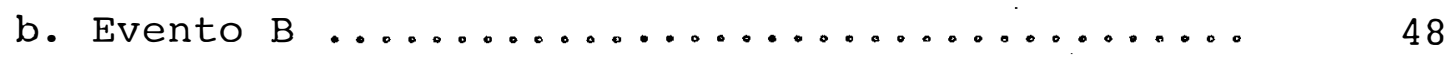

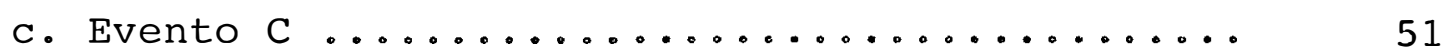

4.2. Espectros característicos e fator de forma .... 60

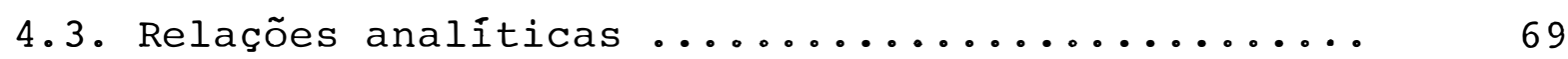

4.4. Relações experimentais ................... 69

a. Relação entre diâmetro mediano e taxa de pre-

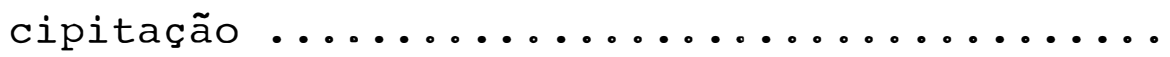

b. Relação entre energia cinética, momentum e ta

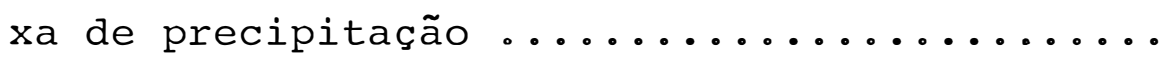

c. Relação entre fluxo de energia cinética, fluxo de momentum e taxa de precipitação .......

d. Relação entre energia cinética e diâmetro me-

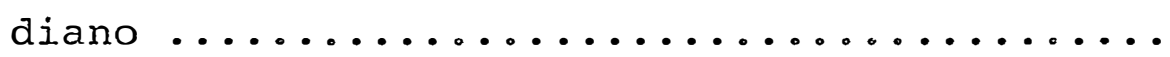

e. Relação entre refletividade do radar e taxa de precipitação ................... 90

f. Relação entre energia cinética, momentum e re

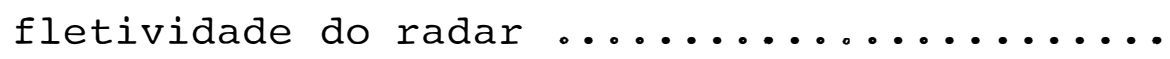

g. Relação entre fluxo de energia cinética, fluxo de momentum e refletividade do radar .... 
-viii.

4.5. Aplicações do radar meteorológico no estudo da

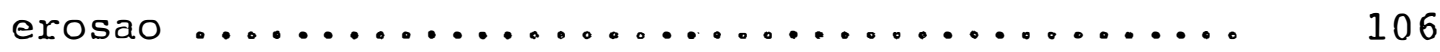

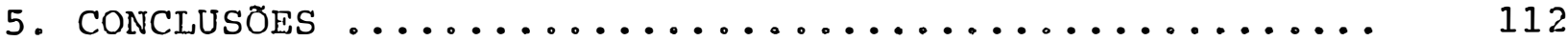

6. SUgestões PARA FUtuROS TRABAlHos ............... 115

7. REFERENCIAS BIBLIOGRAFICAS ............... 117

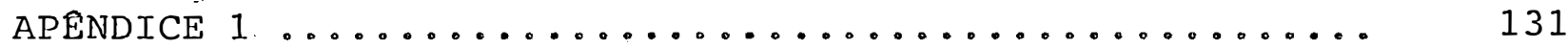

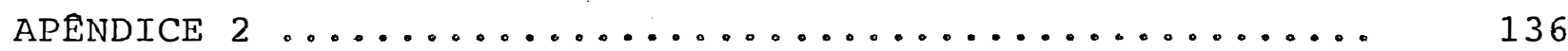




\section{LISTA DE SIMBOLOS:}

A

CEC

CMO

CV

D

Dj

DME

$\mathrm{D}(\sigma)$

D (Z)

$\triangle \mathrm{Dj}$

$\Delta \mathrm{t}$

e

FEC

FMO

$\Gamma$

$\mathrm{K}_{1}, \mathrm{~K}_{2}, \mathrm{~K}_{3}$ fatores de correção de ünidades

Lj

$\Lambda$

m

$m(D)$

ārea do disdrōmetro $\left(\mathrm{m}^{2}\right)$

concentração de volume $\left(\mathrm{mm}^{3} \cdot \mathrm{m}^{-3}\right)$

diâmetro da gota (mm)

diâmetro médio da classe j (mm)

amplitude da classe j (mm) viomécirica $\left(\mathrm{J} \cdot \mathrm{m}^{-2} \cdot \mathrm{mm}^{-1}\right)$

fluxo de momentum $\left(\mathrm{N} \cdot \mathrm{m}^{-2}\right)$

função gama $\left(\mathrm{kg} \cdot \mathrm{m} \cdot \bar{s}^{-} \cdot \mathrm{m}^{-2} \cdot \mathrm{mm}^{-1}\right)$

massa da gota de diâmetro D concentração de energia cinética ( J.m $\left.\mathrm{m}^{-3}\right)$

concentração de momentum (kg.m.s. ${ }^{-1} \mathrm{~m}^{-3}$ )

diâmetro mediano com base na massa de precipitação (mm)

diâmetro de máxima contribuição para o (mm)

diâmetro de máxima contribuição para z (mm)

tempo de integração do espectro (min)

energia cinética por unidade de ärea e de altura plu-

fluxo de energia cinética $\left(\mathrm{J} \cdot \mathrm{m}^{-2} \cdot \mathrm{s}^{-1}\right)$

leitura disdrométrica da classe j

coeficiente da exponencial $\left(\mathrm{mm}^{-1}\right)$

momentum por unidade de área e de altura pluviométrica 
$n$ (D) $j$ número de gotas por unidade de volume e de intervalo de classe $\left(\mathrm{m}^{-3} \cdot \mathrm{mm}^{-1}\right)$

No nümero de gotas com diâmetro zero $\left(\mathrm{m}^{-3} \cdot \mathrm{mm}^{-1}\right)$

$N(D)$ número de gotas por unidade de volume $\left(\mathrm{m}^{-3}\right)$

$\overline{\mathrm{PR}}_{\mathrm{kJ}}$ porcentagem de contribuição média da classe j para a taxa de precipitação do grupo $\mathrm{k}$

R taxa de precipitação $\left(\mathrm{mm} \cdot \mathrm{h}^{-1}\right)$

Rt taxa de precipitação que compõe o grupo $\mathrm{k}\left(\mathrm{mm} \cdot \mathrm{h}^{-1}\right)$ taxa de precipitação média do grupo $\mathrm{k}\left(\mathrm{mm}_{\circ} \mathrm{h}^{-1}\right)$ taxa de precipitação média do grupo $k$ na classe $j\left(m m \cdot h^{-1}\right.$ ) $\rho$ densidade da ägua $\left(\mathrm{kg} \cdot \mathrm{m}^{-3}\right)$

$S(\sigma Z) \quad$ fator de forma

$v$ (D) $j$ velocidade da gota da classe $j$

$V$ (D) volume da gota de diâmetro $D$

W massa de precipitação $\left(\mathrm{g} \cdot \mathrm{m}^{-3}\right)$

z refletividade do radar $\left(\mathrm{mm}^{6} \cdot \mathrm{m}^{-3}\right)$ 


\title{
ANÁLISE DAS RELAÇÕES ENTRE
}

\section{ENERGIA, MOMENTUM, TAXA DE PRECIPITAÇÃO E REFLETIVIDADE DO RADAR: UMA APLICAÇÃOO AO ESTUDO DA EROSÃO.}

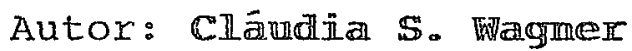

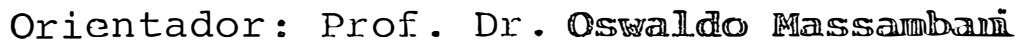

\section{RESUMO}

A energia cinética e o momentum da chuva, parâ metros proporcionais à perda de solo devido a erosão hídrica,são, via de regra, estimados a partir da taxa de precipitação, utilizando-se relações entre esses parâmetros, as quais foram estudadas no presente trabalho. A relação, conhecida como relação z-R, utilizada na meteorologia com radar para a estimativa da taxa de precipitação (R), a partir da refletividade do radar (Z), assim como relações entre à energia, o momentum e a rerfletividade, dó radar, também foram objetos deste estudo.

Os parâmetros estudados foram os referentes a três chuvas convectivas do verão de 1.985, obtidọs a partir de mais de 500 espectros de 1 minuto, medidos através de um disdrômetro instalado no IPMet/UB, no âmbito do Projeto RADASP-II, em Bauru - SP. 
Para a caracterização dos espectros de gotas de chuva, calculou-se o fator de forma definido por JOSS e GORI (1978), verificando-se que para os espectros instantāneos (1min.) das três chuvas estudadas, a exponencialidade não ocorre, mas pạ ra tempos de integração longos (400 min.), existe uma tendência dos espectros assumirem a forma exponencial inversa proposta por MARSHALL e PALMER (1948) .

Os parāmetros calculados a partir do espectro

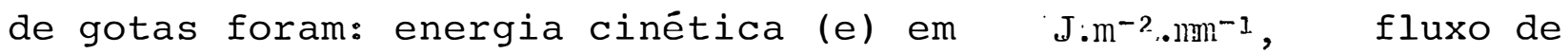
energia cinética (FEC) em J.m-2.s $\cdot \mathrm{S}^{-1}$, momentum (m) em Kg.m. $s^{-1} \cdot m^{-2} \cdot m^{-1}$, fluxo de momentum (FMO) em $N . m^{-2}$, taxa de precipitação (R) em mm.h-1, diāmetro mediano (DME) em -mm e refletividade do radar (Z) em $\mathrm{mm}^{6} \cdot \mathrm{m}^{-3}$. As relações estudadas foram: $e=e(R), F E C=F E C(R), m=m(R), F M O=F M O(R), D M E=D M E(R)$, $Z=Z(R), e=e(Z), F E C=F E C(Z), m=m(Z), F M O=F M O(Z), e=e$ (DME), às quais foram ajustadas equações de regressão experimentais e equações analiticas derivadas assumindo-se o espectro exponencial de MARSHALL e PALMER (1948). Os resultados indicaram que todas as relações experimentais obtidas são estatisticamente significativas, embora dados instantāneos sejam subestimados pelas relações $e=e(R), m=m(R)$ e $D M E=D M E(R)$ ajustadas, de for ma que as mesmas não descrevem a natureza física do processo envolvido, e que sua utilização não é recomendada para a estimativa dos parâmetros num curto espaço de tempo. Tal variabilidade foi explicada com base na inexistência de uma função unívoca entre a forma do espectro e a taxa de precipitação. 
A comparação específica entre a relação experí mental obtida entre $e=e(R)$ e a relação de WISCHMEIER e SMITH (1958), tradicionalmente utilizada para a estimativa da energia cinética da chuva, não mostrou diferença significativa.

O alto grau de correlação da relação $e=e(D M E)$

obtido, permite que a mesma seja observada na obtenção de níveis adequados de energia durante a simulação de chuva nos estudos de erosão dos solos.

As relações $e=e(z), \operatorname{FEC}=\operatorname{FEC}(z), m=m(z)$, FMO $=$ FMO $(Z)$, experimentais obtidas, permitiram que CAPPIs e PPIs fornecidos pelo radar meteorológico, fossem utilizados na estimativa da variabilidade temporal e espacial dos parâmetros associados a um sistema precipitante.

Todas as relações analiticas, entre os parâmetros estudados, derivadas assumindo-se o espectro exponencial de MARSHALL e PALMER (1948), estimaram valores inferiores aos dados experimentais. 


\title{
ANALYSIS OF THE RELATIONSHIPS BETWEEN KINETIC ENERGY, MOMENTUM, RAINFALL RATE AND RADAR REFLECTIVITY: AN APPLICATION TÓ THE SOIL EROSION STUDY.
}

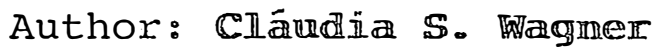 \\ Adviser: Prof. Dr. Oswallo Mlas Sambamin
}

\section{SUMMARY}

Rainfall parameters like kinetic energy and momentum are proportional to the soil erosion loss, and, generally, estimated from rainfall rate by using relationships between these parameters, which were studied in this work.

The relation known as $\mathrm{Z}-\mathrm{R}$ relation, used by radar meteorology to estimate rainfall rate ( $R$ ) from radar reflectivity ( $\mathrm{Z}$ ), and the relations between energy, momentum and radar reflectivity, were also the subject of this study.

The parameters studied refer to more than 500 one minute spectra, measured by a disdrometer installed at the IPMet/UB, in the context of RADASP-II Project, in Bauru - SP, during three convective rains, which occurred in the summer 1.985. 
The form factor defined by JOSS and GORI (1978) was calculated to characterize the raindrop-spectra. It was shown that for one minute spectra from the individual rains studied, exponenciality did not occur, while for long integration times (400 min.), there was a tendency of the spectra fitting the inverse exponencial form proposed by MARSHALL and PALMER (1948). The parameters calculated from the rain-dropspectra were: kinetic energy (e) in $\mathrm{J} \cdot \mathrm{m}^{-2} \cdot \mathrm{mm}^{-1}$, flux of kinetic energy (FEC) in $\mathrm{J} \cdot \mathrm{m}^{-2} \cdot \mathrm{s}^{-1}$, momentum (m) in $\mathrm{Kg} \cdot \mathrm{m} \cdot \mathrm{s}^{-1} \cdot \mathrm{m}^{-2} \cdot \mathrm{mm}^{-1}$, flux of, momentum (FMO) in $\mathrm{N}^{-\mathrm{m}^{-2}}$, rainfall rate $(R)$ in $\mathrm{mm} \cdot \mathrm{h}^{-1}$, median diameter (DME) in $\mathrm{mm}$, radar reflectivity $(\mathrm{Z})$ in $\mathrm{mm} 6 \mathrm{~m}^{-3}$. The relations studied were: $e=e(R), \quad F E C=F E C(R), m=m(R), F M O=F M O(R), D M E=D M E(R)$, $z=z(R), e=e(z), F E C=F E C(Z), m=m(Z), F M O=F M O(Z)$, $e=e(D M E)$, to which experimental regression equations were fitted. In addition to that, analytical equations, derived from MARSHALL and PALMER'S (1948) exponencial spectra, were also fitted to the same relations.

The results indicated that all the experimental relations obtained are statistically significant, although a instantaneous data subestimation occurred through the following fitted relations: $e=e(R), m=m(R)$ and $D M E=D M E(R)$. In fact, these relations do not describe the physical nature of the process involved, and their use is not recommended to estimate parameters in a short time period. This variability was explained 
through an inexistence of a univocal function between the spectrum form and rainfall rate.

The specific comparison of the experimental relation obtained $(e=e(R))$ and the WISCHMEIER AND SMITH (1958) relation, traditionally used to estimate kinetic energy of rain, did not show a significative difference.

The high correlation of the relation $e=e(D M E)$ obtained, makes it possible to obtain adequate energy levels during the rain simulation on soil erosion studies.

The experimental relations $e=e(z)$, $\mathrm{FEC}=\mathrm{FEC}(\mathrm{Z}), \mathrm{m}=\mathrm{m}(\mathrm{Z}), \mathrm{FMO}=\mathrm{FMO}(\mathrm{Z})$ obtained, permitted that CAPPIs and PPIs given by the meteorological radar, could be used to estimate temporal and spatial variability of parameters associated with a precipitation system.

All the analytical relations between the parameters studied, based on MARSHALL and PALMER'S (1948) exponencial spectrum, predicted smaller values than the experimental data. 


\section{INTRODUÇÃO}

Os danos causados pela erosão hídrica em solos cultivados promoveram a intensificação da pesquisa sobre os processos erosivos, levando ao desenvolvimento de modelos de previsão de perda e ao aperfeiçoamento de práticas de controle. Tais pesquisas resultaram na identificação e classificação das variáveis determinantes do processo erosivo, em cinco fatores básicos, os quais são: 1 . erodibilidade do solo; 2. erosividade da chuva, 3. topografia; 4. cobertura e manejo do solo e 5. práticas de controle de erosão.

o potencial da chuva em causar erosão foi inicialmente avaliado em termos do escoamento superficial, causado pelo excesso de precipitação, devido ao fato de se considerar a sua componente do movimento em direção do declive, como força 
principal atuante no deslocamento de particulas de solo. Porém, vários estudos têm mostrado a importância do impacto das gotas de chuva, ressaltando que a transferência da cquantidade de movimento das gotas às partículas de solo, atua como força no seu deslocamento e transporte. Desta forma, a avaliação da ação conjunta do impacto e da enxurrada mostrou que, embora o impacto não transporte quantidade significativa de solo ao longo do declive, este causa o deslocamento de partículas aumentando o material disponivel ao transporte pela enxurrada, de maneira que a ausência do impacto resulta na diminuiçăo considerável da perda de solo.

Estudos empiricos correlacionando o salpico a características relativas ao tamanho e à velocidade de gotas, de monstraram que a energia cinética e o momentum das gotas podem ser considerados parâmetros, os quais expressam a magnitude do impacto. Consequlentemente, os indices de erosividade existentes, que visam quantificar a perda de solo devido à ação da chuva,são geralmente combinações da energia cinética (ou momentum) e de pa râmetros relativos ao escoamento superficial.

A energia cinética ou o momentum são de difícil medida direta, sendo, geralmente, obtidos a partir da taxa de precipitação, utilizando-se relações empiricas, as quais foram obtidas em diversas localidades, com base nas distribuições do tamanho de gotas e velocidade terminal encontradas. Porém, existem restrições na utilização dessas relações empíricas em 
situações com espectros divergentes daqueles encontrados originalmente.

No Brasil, a relação mais comumente utilizada é aquela obtida por WISCHMEIER e SMITH (1958), a partir dos dados de distribuição do tamanho de gotas de LAWS e PARSONS (1943). Esta relação, tendo sido obtida de espectros de gotas médios,não considera a variabilidade temporal da relação e, portanto, não é recomendada para a estimativa da energia de eventos isolados específicos.

A distribuição do tamanho de gotas tem sido bastante estudada pela meteorologia com radar, devido ao interes se existenté na obtenção da relação entre a refletividade do radar e a taxa de precipitação, visando estimativa da variação tem poral e espacial desta última, via radar meteorológico. Nestes estudos utiliza-se com frequência o espectro exponencial descrito por MARSHALL e PALMER (1948), que também se ajusta bem aos es pectros de LAWS e PARSONS, na tentativa de obter relações teóricas entre estes parâmetros.

A utilização do espectro de MARSHALL e PALMER, para o cálculo da energia cinética, do momentum e da taxa de precipitação, possibilitaria a obtenção de relações teóricas aplicáveis ao estudo da erosão. Além disto, deste enfoque deduzem-se relações entre a energia cinética, o momentum e a refleti vidade do radar, estendendo o uso do radar à avaliação da distrí buição espacial e temporal da energia cinética e do momentum associados a precipitação observada. 
Mas, essencialmente, é a avaliação observacional do espectro, que permitirá o estabelecimento funcional entre essas grandezas, principalmente em nossa região tropical. Este é o objetivo principal deste trabalho, o qual está subdividido em:

- caracterização disdrométrica dos espectros de gotas observados na região de Bauru - SP, para eventos predominantemente convec tivos do verão de 1985;

- determinação de relações analíticas, derivadas do espectro de MARSHALL e PALMER, entre a energia cinética, momentum, refletí vidade do radar e taxa de precipitação;

determinação de relações experimentais entre a energia cinética, momentum e taxa de precipitação, e estudo de sua variabili dade temporal. 
.5 .

\section{REVISÃO BIBL IOGRÁFICA}

\subsection{Distribuição do tamanho de gotas}

O interesse existente na obtenção do tamanho

de gotas reside em áreas diversas, como a física de nuvens, a ra diometeorologia e a erosão de solos. Na física de nuvens o aspec to mais freqlentemente pesquisado é a relação da distribuição do tamanho de gotas (DTG) com o mecanismo de precipitação (WALDVOGEL, 1975); na radiometeorologia estuda-se a influência das gotas sobre o sinal do radar (BEST, 1950; ATLAS e PLANK, 1953;RIGBY et alii, 1954); na erosão de solos buscam-se relações entre o tamanho de gotas e a perda de solos, bem como a reprodução do ta manho de gotas adequado, durante a simulação da chuva (HUDSON, 1963) • 
A medida do tamanho de gotas è feita indiretamente utilizando-se métodos como o da farinha (BENTLEY, 1904; HUDSON, 1964), do óleo (EIGEL e MOORE, 1983) e do papel de filtro (WIESNER, 1895); ou diretamente utilizando-se instrumentos como as câmaras fotográficas (JONES, 1959), o espectrômetro fotoelétrico (MASON e RAMANADHAM, 1953; DINGLE e SCHULTE, 1962) e o disdrômetro (JOSS e WALDVOGEL, 1967).

A escolha do método depende da acuracidade e detalhamento desejados, e da disponibilidade de recursos (HUDSON, 1963). Assim, o método da farinha e do papel de filtro caracteri. zam-se pelo baixo custo e facilidades na obtenção dos materiais necessários, mas tornam o acompanhamento da variabilidade temporal da DTG praticamente impossível, devido a pouca automação dos métodos, além de exigirem um longo período de calibração inicial. Por outro lado, o método do óleo e o fotográfico, exigem equipamentos de custo um pouco mais alto, e embora sejam menos trabaIhosos, também não permitem a adequada automação, sendo que o üI timo tem a vantagem de medir também a velocidade das gotas. Com o espectrômetro e o disdrômetro, o trabalho de avaliação do diâmetro através de técnicas manuais, é substituído por processadores digitais, que codificam e analisam o sinal medido através do sensor do instrumento. Tal fato torna o monitoramento da variabi lidade temporal da DTG, durante uma chuva, possivel, sendo que um grande volume de dados pode ser obtido em curto espaço de tem po (DONNADIEU, 1983). Entretanto, a utilização destes instrumentos é limitada, devido ao seu alto custo. 
Convencionalmente, adota-se o diâmetro equivalente para descrever o tamanho de uma gota, sendo que este é definido como o diâmetro de uma esfera de volume igual ao da gota deformada. Isto porque, durante a queda em velocidade terminal, somente gotas menores que $280 \mu$ tem forma de esferas quase perfeitas. Gotas, com diâmetro equivalente entre 280 e $1.000 \mu$, se parecem com esferóides oblatos e em gotas maiores que $1.000 \mu$ a deformação se acentua, produzindo esferóides de base achatada.Um diâmetro equivalente maior que $10 \mathrm{~mm}$, mesmo em situações de fluxo laminar, torna as gotas hidrodinamicamente instáveis, promovendo sua ruptura (PRUPPACHER e KLETT, 1980).

Os métodos de medida mencionados dão çomo resultado contagens do número de gotas em classes pré- estabelecidas. Estas contagens podem então, ser utilizadas de diversas for mas, para produzir a DTG (SMITH, 1982). Porém, geralmente, suben tende-se a DTG ou o espectro de gotas, como sendo a relação entre o número de gotas $\mathrm{n}(\mathrm{D})$, por volume unitário de ar em metros cúbicos e por intervalo de classe de diâmetro em milímetros, e o diâmetro mẽdio da classe em milímetros (D) (ROGERS, 1976). Outra forma de apresentação é a distribuição cumulativa de volume, apresentada no trabalho pioneiro sobre tamanho de gotas de LAWS e PARSONS (1943), na área de erosão de solos.

Para WILLIS (1984) a DTG é o produto final de todos os processos microfísicos e dinâmicos, que ocorrem nas nuvens, e das interações que afetam a formação e crescimento da 
precipitação líquida. As gotas de chuva originam-se de mecanismos diversos, como o derretimento de neve ou granizo, cujo processo de precipitação foi descrito por Bergeron-Wegener-Findei sen, e o processo de colisão-coalescência de gotículas de água, dominante no desenvolvimento da precipitação em nuvens quentes. Essas partículas sofrem alterações em seu tamanho através da evaporação, acreção, coalescência e quebra, durante a queda (MASON E ANDREWS, 1960).

Os fatores climáticos que podem determinar a DTG, são a concentração de núcleos de condensação, a instabilida de termodinâmica, a velocidade das correntes ascendentes, a umidade relativa abaixo da base da nuvem, a altura do nível de congelamento, entre outros (CATANEO, 1969). Em decorrência, as classificações climáticas, como, por exemplo, a classificação de Koeppen, baseada em dados de temperatura e precipitação não são suficientes pará a caracterização das DTGs ocorrentes.

Um dos fatores relacionados a DTG, mais utilizados em equações empíricas que tentam descrever o espectro de gotas é a taxa de precipitação (BEST, 1950; MARSHALL e PALMER, 1948). Na equação descrita por MARSHALL e PALMER (MP) O número de gotas $\mathrm{n}(\mathrm{D})\left(\mathrm{m}^{-3} \cdot \mathrm{mm}^{-1}\right)$ decresce exponencialmente em função do diâmetro $\mathrm{D}(\mathrm{mm})$, a partir de um valor inicial de $8.000 \mathrm{~m}^{-3} . \mathrm{mm}^{-1}$ (No) para diâmetros que tendem a zero, isto é, $n(D)=\operatorname{Noexp}(-\Lambda D)$. A inclinação dessa reta, em um gráfico mono-logarítmo, é dada por $\Lambda=4,1 R^{-0,21}\left(\mathrm{~mm}^{-1}\right)$, e portanto, tem relação inversa com a 
taxa de precipitação, isto é, é mais acentuada para taxas baixas e menor para taxas maiores, de forma que o número de gotas com diâmetro maior é mais frequlente a taxas altas. Em locais, onde não se dispõem de medidas disdrométricas, utiliza-se com frequência este espectro exponencial (CATANEO, 1969). Esta equação também se ajusta bem, exceto para diâmetros pequenos, às DTGs ob tidas por LAWS e PARSONS (1943) (LP).

Entretanto, em inúmeras situações, não se verị fica o ajuste da equação de MP aos espectros medidos(STRANZ, 1971; DIEM e STRANTZ, 1971; CZERWINSKI e PFISTERER, 1972), principalmente, se as DTGs observadas são instantâneas (ANIOL et alii , 1973; JOSS e GORI, 1978). Segundo SEKHON e SRIVASTAVA (1970), a equação de MP é obtida de um grande número de DTG, agrupadas de acordo com a taxa de precipitação, resultando numa DTG média e No e $\Lambda$ em função de R. FUJIWARA (1965) também ressalta que a equação empíricà de MP baseia-se em dados coletados durante muitas chuvas, ignorando-se diferenças entre chuvas individuais. Pa ra precipitações originadas de chuvas convectivas, os desvios em relação a MP, também são consideráveis (ROGERS, 1976). WALDVOGEL (1974) mostrou que um parâmetro considerado constante pior lT $\left(N^{\prime}=8.000 \mathrm{~m}^{-3} \cdot \mathrm{mm}^{-1}\right)$, apresenta variações bruscas associadas a atividade convectiva, as quais foram chamadas de "salto do No" (Nojump).

WALDVOGEL (1975) sugere que, de uma maneira ge ral, pode-se dizer que os espectros originários em nuvens quen- 
tes são monodispersos, enquanto que os formados pelo processo de Bergeron-Wegener-Findeisen são exponenciais. Assim, JOSS e GORI (1978) propõem um parâmetro, chamado fator de forma, que indica a forma de DTG em um gráfico mono-log, tendendo a um, quando o espectro é exponencial, e a zero, quando é monodisperso, o qual será utilizado neste trabalho para a caracterização dos espectros obtidos. Na tentativa de ajustar o espectro exponencial inverso a dados medidos instantaneamente, os diâmetros podem ser normalizados em. função do diâmetro mediano e o nümero de gotas em uma classe de tamanho em função do número total de gotas (SEKHON e SRIVASTAVA, 1970). WONG e CHIDAMBARAM (1985) utilizam este espectro exponencial normalizado, para analisar a DTG de nuvens convectivas, mostrando que, através deste método, espectros de taxas de precipitação diversas podem ser comparados. ULBRICH (1983) ajusta a função gama ao espectro, obtendo uma equação que descreve a curvatura muitas vezes encontrada no espectro de MP.

Finalmente, ao invés de expressar a DTG em fun ção da taxa de precipitação, muitos trabalhos buscam um parâmetro simples, que represente o espectro, como o diâmetro mediano, definido como o diâmetro que divide o volume ou a massa de precí pitação em duas partes iguais, para correlacioná-lo com a taxa de precipitação e observar a. sua variação em função do tipo de chuva (LAWS e PARSONS, 1943; BLANCHARD, 1953; HUDSON, 1963; CAIMI e MENZIES, 1978). 


\subsection{Velocidade terminal de gotas}

Durante a queda, as gotas de chuva atingem um estado de equilíbrio, no qual a força de atrito do ar, que se opõe ao movimento, se iguala à força gravitacional, que acelera a gota na direção descendente (PRUPPACHER e KLETT, 1980). A força de atrito exercida pelo ar, sobre uma esfera rígida e não deformada, é derivada da lei de viscosidade de Newton, e pode ser expressa como (ROGERS, 1976):

$$
\left|\vec{F}_{r}\right|=6 \pi r v n(\operatorname{ReC} / 24)
$$

onde $F_{r}$ é a força de atrito, $r$ é o raio da esfera, $v$ é a velocidade da esfera, $n$ é a viscosidade dinâmica do ar, Re é o número de Reynolds e C é o coeficiente de arrastamento. Em condições de fluxo não turbulento, isto é, quando o raio da esfera é $<40 \mu$, o número de Reynolds é $<1$, e o termo (ReC/24) é aproximadamente 1 , de modo que a equação (1) se torna igual a equação dada pela lei de Stokes (ROGERS, 1976):

$$
\left|\overrightarrow{F_{r}}\right|=6 \text { Irvn }
$$

A força gravitacional é igual ao próprio peso de uma esfera ou gota, isto é:

$$
\left|\vec{F}_{G}\right|=m g=\left(4 \pi r^{3} / 3\right) g \Delta \rho
$$


onde $F_{G}$ é a força gravitacional, $\Delta \rho$ é a diferença entre a densidade da esfera ou gota e a densidade do ar e g é a aceleração da gravidade. Portanto, no estado de equilíbrio, as forças expressas por (1) e (3) se igualam, obtendo-se a velocidade de queda:

$$
V_{T}=(2 / 9) r z(\Delta \rho / n)(\operatorname{ReC} / 24)
$$

que è a equação da velocidade terminal $\left(V_{T}\right)$ ou velocidade máxima, que uma esfera de raio $r$ atinge durarte a ciueda en fluxo laminar.Fazen do-se novamente $(\operatorname{ReC} / 24)$ aproximadamente 1 , tem-se a equação de Stokes para a velocidade terminal de esferas (ROGERS, 1976):

$$
V_{T}=(2 / 9) r z(\Delta \rho / \eta)
$$

onde $V_{T}$ é proporcional ao quadrado do raio da gota. Porém, ocorrendo o crescimento das gotas, a hipótese de esferas rígidas e perfeitas não é mais satisfeita, devido à deformação que sofrem resultando na alteração do regime do fluxo de laminar para turbu lento, o que pode ser evidenciado através do aumento do número de Reynolds (PRUPPACHER e KLETT, 1980). Quando se traça a curva do coeficiente de arrastamento em função do número de Reynolds para esferas e gotas, pode-se observar que a partir de Re de aproximadamente 1.000 , o coeficiente de arrastamento para gotas não é mais somente função de Re, mas também de outros fatores as sociados a deformação da gota, diferindo bastante da curva traça 
da para esferas (FOOTE e DUTOIT, 1969). Assim, GUNN e KINZER (1949) desaconselham o uso das equações derivadas da lei de Stokes para o cálculo da velocidade terminal de gotas (VTG) maiores. Segundo ROGERS (1976), experimentos indicam que para nümeros de Reynolds altos o coeficiente de arrastamento se torna independente e tem valor aproximadamente 0,45, resultan do em uma relação válida para o intervalo de raio de 0,6 a 2mm;

$$
V_{T}=k_{1} r^{0,5}
$$

onde $k_{1}$ é igual a $\left(2.200\left(\rho_{0} / \rho\right)\right.$ ) mo, m $^{-1}, \rho$ é a densidade do $\operatorname{ar} e \rho_{o}$ é a densidade de referência do ar a $1.013 \mathrm{mb}$ e $20^{\circ} \mathrm{C}$. Para raios entre $40 \mu$ e $0,6 \mathrm{~mm}$ a relação empírica seria:

$$
V_{T}=k_{2} r
$$

onde $k_{2}$ é igual a $8.000 s^{-1}$

Entretanto, como ROGERS (1976) ressalta, estas equações, embora sejam aproximações úteis, estão sujeitas a certos erros decorrentes da deformação que as gotas sofrem. O proce dimento habitual, nos estudos que requerem o conhecimento da velocidade terminal das gotas próximo a superfície, é a utilização dos dados experimentais de GUNN e KINZER (1949). Este trabalho diferencia-se dos seus predecessores pela utilização de métodos 
eletrônicos para a avaliação da VTG, e pela cuidadosa medida das massas das gotas em estudo, levando a resultados discrepantes em relação aos existentes na época, com exceção dos dados de LAWS (1941), bastante utilizados nas pesquisas do proceșso de erosão, que foram aproximadamente confirmados. GUNN e KINZER (1949) medi ram a $V_{T}$ de gotas com diâmetro crescentes entre 0,1 e 5,8mm, obtendo valores de velocidade na faixa de 0,27 e $9,17 \mathrm{~m} . \mathrm{s}^{-1}$, res pectivamente.

Estudos posteriores se detiveram com a determi nação da VTG (BEARD e PRUPPACHER, 1969), porēm, preocupados com a acuracidade das medidas de gotas micrométricas, e com a influência da variação de densidade e viscosidade do ar, uma vez que os dados de GUNN e KINZER (1949) são para condições de 1.013 mb e $20^{\circ} \mathrm{C}$. FOOTE e DUTOIT (1969) ajustaram polinômios de 30 e 5o graus aos dados de GUNN e KINZER (1949), que podem substituir o trabalho de interpolações das tabelas originais, e que foram utilizados neste trabalho.

\subsection{Energia Cinética e Romentum}

2.3.1. Relação entre a energia cinética, o momentum e a erosão dos solos

O entendimento do processo de erosão hídrica teve um grande avanço com os estudos realizados por LAWS (1940) ELLISON (1944, 1947), EKERN (1950) e outros, que identificaram as 
gotas de chuva e o escoamento superficial como agentes erosivos causadores do processo, e analisaram os subprocessos de deslocamento e transporte de particulas causados pelos agentes.

A importância relativa de um ou outro agente sofre variações de acordo com a situação e com as características de solo. De um modo geral, aceita-se que durante - estágio de erosão laminar, ou aquela erosão que ocorre na superfície do solo localizada entre os sulcos, o impacto das gotas desloca grande quantidade de partículas, além de aumentar a turbulência e, portanto, a capacidade de deslocamento do escoamento superficial (MEYER e MONKE, 1965; MEYER et alii, 1975). De forma que, uma redução de $90 \%$ na energia das gotas incidentes sobre a super fície de um solo, mantendo-se a taxa de aplicação de água constante, pode reduzir a perda de solo em até 90\% (YOUNG e WIERSMA, 1973). Porém, a habilidade do impacto das gotas de tránsportar partículas de solo é limitada, quando comparada às distâncias pẹ corridas pelo escoamento superficial, no sentido do declive. Entretanto, grande parte do solo transportado pelo escoamento superficial, principalmente quando este se concentra em sulcos de dimensões reduzidas, consiste em partículas originárias das áreas entre sulcos, que atingem o mesmo através do transporte pelo impacto das gotas (MUTCHLER e YOUNG, 1975). Quando os sulcos se tornam profundos e largos, formando ravinas e vocorocas, a impor tância relativa do impacto decresce, sendo que o escoamento superficial se torna o agente erosivo principal. A grandeza do im- 
pacto é determinada por características relativas às gotas de chuva e ao solo. A influência do tamanho e velocidade de queda de gotas, sobre a quantidade de solo deslocada e transportada pe lo impacto, foi analisada por vārios autores, os quais obtiveram resultados como:

$$
\begin{aligned}
& \text {. } S \propto V 4,3 D I, 1 R 0,65 \text { (ELLISCN, 1944) } \\
& \begin{array}{l}
\text { - } S \propto E \\
\text { (EKERN, 1950) }
\end{array}
\end{aligned}
$$$$
\text { - S } \alpha \text { V1,4 (BISAL, 1960) }
$$$$
\text { - S \& M (ROSE, 1960) }
$$$$
\text { - } S \propto E^{a} \quad(F R E E, 1960)
$$

- $\mathrm{S} \propto$ a (WILLIAMS, 1969)

- $S \propto E^{a} R^{b} \quad$ (BUBENZER e JONES, 1971)

- $S \propto V^{1,25 D 5,25}$ (VAN ASCH e EPEMA, 1983)

onde $\mathrm{S}$ é a quantidade de solo perdida por salpico, V, D, E, M sao, respectivamente, a velocidade de impacto, o diâmetro, a ener gia cinética e o momentum das gotas, $R$ é a taxa de precipitação, 
a e b são coeficientes dependentes do tipo de solo estudado. Alguns destes resultados, embora tenham sido obtidos, em sua maioria, em experimentos com áreas superficiais de solo reduzidas,ti veram grande importância na descrição e quantificação da ação da chuva como agente erosivo.

Assim, a maior parte dos indices de erosividade, testados e em uso, combinam a energia ou o momentum,com algum parâmetro que expresse o poder erosivo do escoamento superficial (FOSTER et alii, 1982). WISCHMEIER e SMITH (1978) propõe o EI30, produto da energia cinética total da chuva pela sua intensidade máxima em 30 minutos, resultante de correlações de 10.000 dados (parcelas-ano) com as características da chuva, como precipita ção total, intensidade máxima de 15 e 30 minutos e energia cinética total. Em outros trabalhos, de abrangência mais local, indi ces como o momentum total do período da chuva com intensidade maior que $2,1 \mathrm{~mm} \cdot \mathrm{h}^{-1}$ (ELWELL e STOCKING, 1973), a energia cinética total do período da chuva com intensidade superior a $25 \mathrm{~mm} \cdot \mathrm{h}^{-1}$ (HUDSON, 1971) e a energia da precipitação excedente(KINNELI 1983), foram mais adequados para expressar a erosividade da chuva.

Estes indices de erosividade são empíricos e baseiam-se parcialmente na suposição de que o salpico está corre lacionado com o momentum ou com a energia cinética das gotas de chuva, não existindo até o presente momento um índice de erosivi dade com validade universal (VAN ASCH e EPEMA, 1983). 


\subsubsection{Obtenção da energia cinética e do momentum chuva}

A energia cinética e o momentum da chuva podem ser calculados diretamente, a partir da DTG, medida através dos diferentes métodos citados, e da VTG, geralmente deduzida de GUNN e KINGER (1949) ou mesmo a de LAWS (1941), conforme apresen tado por EIGEL e MOORE (1983). Como a medida da DTG, pelos métodos usualmente adotados é trabalhosa e demorada (KINNELL, 1973 ; HUDSON, 1981), o procedimento mais corriqueiro é a estimativa através de relações empíricas, que correlacionam a energia (ou o momentum) a parâmetros que também são definidos pela DTG e VTG, como a taxa de precipitação e precipitação total (PARK et alii, 1983). Inúmeros autores obtiveram essas relações a partir de diferentes DTGs medidas, sujeitas, portanto, a intensas variações como abordado no item 2.1., e cuja utilização deve ser, restrita às condições originais (ROGERS et alii, 1967; STOCKING, 1978; KINNELL, 1973) .

Conforme KINNELL (1981), a energia pode ser expressa em termos de quantidade por tempo e por área (Eat) e em termos de quantidade por área e por altura pluviométrica (Eah), sendo que as duas formas se relacionam por: Eah $=c E a t / R$, onde $R$ é a taxa de precipitação (mm.h-1) e c um fator de correção de unidades.

Como os registros meteorológicos geralmente contém os dados em termos de quantidade de precipitação medida 
(P), calcula-se a energia total de uma chuva através do produto Eah x P, durante um período de taxa de precipitação constante, e a forma Eah é a mais utilizada. Logicamente, o momentum também pode ser expresso nas dimensões acima citadas.

Desta forma, as equações que representam o melhor ajuste estatístico entre a energia ou o momentum (expressos como Eat, Eah ou Mat, Mah) e a taxa de precipitação(R), apresentam formas gerais como:

a. $E a h=a+b \log R$

b. $E a h=a-b / R$

c. $E a h=a+b R-C R^{2}+d R^{3}$

d. $\operatorname{Eah}=a+b \exp (-c R)-\operatorname{dexp}(-e R)$

e. Eat $=\mathrm{aC}_{\mathrm{TE}} \mathrm{R}^{\mathrm{b}}$

f. $M a h=a-b / R$

g. $\log M a t=a \log R-b$

h. Mat $=a R+b$

i. Mat $=\mathrm{aC}_{\mathrm{TM}} \mathrm{R}^{\mathrm{b}}$
(WISCHMEIER E SMITH, 1958; ZAN CHI e TORRI, 1980; ROTH alii, 1985)

(HUDSON， 1965)

(CARTER et alii, 1974)

(MCGREGOR e MUTCHLER, 1976)

(PARK et alii, 1983)

(HUDSON, 1965)

(WILLIAMS, 1969)

(KINNELL， 1973)

(PARK et alii, 1983) 
A equação (a) foi primeiramente utilizada por WISCHMEIER e SMITH (1958), que calcularam a energia cinética a partir dos dados de LAWS e PARSONS (1943), num total de 7 pares de dados e encontraram os coeficientes: $a=11,9, b=8,73$ e $r^{2}=0,63$,

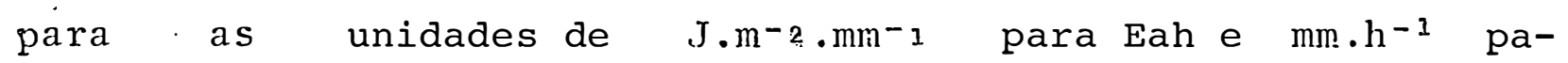
ra R.

ZANCHI e TORRI (1980), através da medida da DTG com o método da farinha, obtiveram os coeficientes: a $=9,8$, $\mathrm{b}=11,2$ e $\mathrm{r}^{2}=0,906$ (Equação $(\mathrm{a})$ ), para a região central da Itália, não citando o número de amostras realizadas e verificando que a inclusão da temperatura do ar na equação produzia coefí cientes de correlação maiores. No norte do Estado do Paraná,ROTH et alii (1985), utilizaram o método do óleo, descrito por EIGEJ e MOORE (1983), na amostragem de duas chuvas (uma convectiva e outra frontal), encontrando $\mathrm{a}=13,1, \mathrm{~b}=9,07$ e $\mathrm{r}^{2}=0,66$ (Equa ção (a)), médios para as duas chuvas, num total de 23 amostras. HUDSON (1965) sugeriu a equação (b), que apresenta $\mathrm{a}=29,9, \mathrm{~b}=128$ e $\mathrm{r}^{2}=0,61$, válida para taxas de precipitação maiores que $4,3 \mathrm{~mm} \cdot \mathrm{h}^{-1}$, e resulta em energia (Eah) em J. $m^{-2} \cdot m m^{-1}$.

Com o objetivo de verificar a validade da equa ção de WISCHMEIER e SMITH (1958), CARTER et alii (1974) ajustaram um polinômio de 30 grau (Equação(c)) às DTG medidas com o método da farinha, no estado de Louisiana (EUA), com coeficientes de $\mathrm{a}=429,2, \mathrm{~b}=534, \mathrm{c}=122,5$ e $\mathrm{d}=7,8$, para unidades de 
tonf $\cdot$ pës $\cdot a^{-1} e^{-1} \cdot \operatorname{pol}^{-1}(E a h)$ e pol $\cdot h^{-1}(R)$, que indica $O$ decréscimo da energia para taxas de precipitação maiores que 60 $\mathrm{mm} \cdot \mathrm{h}^{-1}$.

MCGREGOR e MUTCHLER (1976) repetiram este estu彑 do para as condições do norte do Estado do Mississippi (EUA) e obtiveram a equação (d) com os coeficientes: $a=27,3, b=21,7$, $c=0,05, d=41,5, e=0,07$ e $r^{2}=0,65$, com base em 315 amostras, realizadas durante o período de 6 anos. A equação (e) foi derivada por PARK et alii (1983), a partir de uma expressão lognormal ajustada a DTG medida por LAWS e PARSONS (1943), ROGERS et alii (1967), CARTER et alii (1974) e outros. Os coeficientes da equação (e) encontrados foram: $a=211.070$ e b $=1,16$, para unidades de J.ha-1.h-1 (Eat) e mm.h-1 (R), e o fator $\mathrm{C}_{\mathrm{TE}}$ corrige a energia simulada a $20^{\circ} \mathrm{C}$ para a temperatura ambiente.

O momentum expresso em termos de Mah ou Mat,já foi relacionado à taxa de precipitação através das equações (f), (g), (h) ou (i). Na equação (f) os coeficientes a e b são iguais a 75,3 e 155,2, respectivamente, e a mesma apresenta validade pa. ra taxas de precipitação maiores que $2,1 \mathrm{~mm} \cdot \mathrm{h}^{-1}$ e unidades de Kg.m.s $\mathrm{s}^{-1} \cdot \mathrm{m}^{-2} \cdot \mathrm{mm}^{-1}$ para Mah (ELWELL e STOCKING, 1976).

A equação ( $g$ ) foi derivada por WILLIAMS (1969) com base na DTG publicada por LAWS e PARSONS (1943), BEST (1950) e HUDSON (1963), e têm constantes iguais a: $\mathrm{a}=0,712$ e b $=-1,46$, para unidades de dinas. $\mathrm{cm}^{-2} \cdot \mathrm{h}^{-1}$ (Mat) e mm.h-1 (R).KINNELL (1973), utilizou a DTG medida por MUELLER (1962) em Miami (EUA), 
e obteve os coeficientes $\mathrm{a}=0,021$ e $\mathrm{b}=-0,062$ para Mat em dinas. $\mathrm{Cm}^{-2} \cdot \mathrm{s}^{-1}$ e $\mathrm{R}$ em mm.h-1 (Equação $(\mathrm{h})$ ). Nota-se que as unidades de Mat nas equações ( $g$ ) e (h), deveriam ser dinas. $\mathrm{Cm}^{-2}$ para momentum expresso em termos de quantidade por área e por tempo, que equivaleria a $\mathrm{g} \cdot \mathrm{cm} \cdot \mathrm{s}^{-1} \cdot \mathrm{s}^{-1} \cdot \mathrm{cm}^{-2}$ (massa $\mathrm{x}$ velocidade $\mathrm{xtempo-1}$ $\mathrm{x}$ área-1).

PARK et alii (1983) obtiveram a equação (i) ba seados na mesma DTG utilizada para a obtenção da equação (e), sen do os coeficientes iguais $a: a=64.230$ e b $=1,09$, com Mat expresso em $\mathrm{kg} \cdot \mathrm{m}_{\cdot} \mathrm{s}^{-1} \cdot \mathrm{ha}^{-1}$ e $\mathrm{R}$ em mm.h-1, com $\mathrm{C}_{\mathrm{TM}}$ igual a um fator: de correção para temperatura.

No Brasil, devido a inexistência de estudo detalhado sobre a DTG, a equação mais utilizada tem sido a obtida por WISCHMEIER e SMITH (1958) (BERTONI e PASTANA, 1964; FREIRE e CASTRO FILHO, 1977; CASTRO FILHO et alii, 1982; PEREIRA, 1983) • Recentemente, LEPRUN (1983) utilizou o método da farinha, para a medida do tamanho de gotas ocorrentes na região do sertão e da mata nordestinas. Como anteriormente citado, ROTH et alii (1985), no Norte do Paraná, derivaram uma relação para a energia cinética. Ambos trabalhos ressaltam o baixo número de amostragens realizadas, apontando para a necessidade de mais estudos. LOMBARDI (1977) enumera o estudo da DTG como fundamental e LAL (1984) indica o mesmo como prioridade de pesquisa nos trópicos, devido à constatação de que a taxa de precipitação ocorrente é superior a encontrada nas regiões onde originalmente a maior parte das rela ções foram obtidas. 


\subsection{Refletividade do Radar}

As gotas de chuva distribuídas em um volume de ar, devido a suas dimensões reduzidas em relação ao comprimento de onda dos pulsos emitidos pelo sistema transmissor do radar,em geral retro-espalham a energia incidente sobre elas conforme a lei de Rayleigh, resultando no fato de que a secção de espalha mento é proporcional à sexta potência do diâmetro das gotas.

Desse modo, essa potência eletromagnética do eco de retorno é proporcional a sexta potência do diâmetro, parâa metro denominado refletividade do radar $(z)$. Esta potência de re torno é expressa através da equação do radar, a qual é ajustada às características do transmissor e da antena do radar, e à natụ reza do alvo (ROGERS, 1976).

Como a refletividade do radar (Z), assim como a taxa de precipitação (R) são função da DTG, obtém-se frequentẹ mente a relação empírica, a qual é conhecida como relação $Z-R$, que de forma geral tem a expressão $z=a R^{b}$. Assim, estimativas da taxa de precipitação podem ser efetuadas através do uso do ra dar (PUHAKKA, 1979).

Existem inúmeros trabalhos sobre as relações Z -R, obtidas empiricamente em vários locais (FUJIWARA, 1965;CATANEO, 1969). BATTAN (1973) lista até 69 relações $Z-R$ diferentes citadas na literatura, sendo que ainda não se encontrou uma relação com validade universal (DOVIAK, 1983). O problema em se 
estimar $\mathrm{R}$ a partir de $\mathrm{Z}$ reside justamente na escolha dos valores a e b adequados, pois estes variam consideravelmente de caso para caso, mesmo durante um evento isolado, devido às significativas variações da DTG dentro do volume iluminado pelo radar, em relação àquele espectro que atinge o pluviógrafo (PUHAKKA, 197.9). Muitas vezes a relação $\mathrm{Z}=200 \mathrm{R}^{1}, \epsilon$, conhecida como relação de Marshall e Palmer, é utilizada em locais onde não se dispõe de medidas de DTG. Por isso, a acuracidade das estimativas da taxa de precipitação, através da refletividade do radar, dependem da efetiva DTG observada em relação a DTG para a qual a relação $Z-R$ foi obtida, podendo resultar em erros consi deráveis. (TWOMEY, 1953) .

Porém, o sensoriamento remoto da taxa de precí pitação, através do radar, permite a caracterização com alta resolução da estrutura espacial do sistema precipitante, conseqllen temente, de sua variabilidade temporal. Desse modo, em relação à medida pontual fornecida pelo pluviógrafo, a utilização do radar tem a vantagem de investigar áreas vastas, o que somente seria possivel com uma rede pluviográfica de densidade tão alta que tornaria seu custo proibitivo. A utjlização dos dadós pluviográficos, juntamente com as medidas espaciais do radar, consiste na combinação desejável no estudo da distribuição espacial-temporal da precipitação (DOVIAK, 1983) .

No Brasil, pesquisas associaāas ao uso do senso riamento remoto através de radares meteorológicos, tiveram ini- 
cio com a implantação do radar meteorológico da FAPESP no IPMet/ UB em Bauru - SP, no início da década de 70. Muitos trabalhos as sociados ao diagnóstico e uso dessas técnicas têm sido efetuados (CALHEIROS, 1981; MASSAMBANI et alii, 1982; ANTONIO, 1984).

o Projeto RADASP (Meteorologia com Radar em São Paulo) consiste na integração de uma rede de radares meteorológi cos,que cobre todo o Estado de são Paulo e parte dos estados vizinhos, objetivando o acompanhamento e previsão da precipitação no suporte das atividades agrícolas e hidrológicas. 


\section{MATERIAL E MÉTODOS}

\subsection{Instrumental}

A distribuição do tamanho de gotas foi obtida com um disdrômetro, instrumento que fornece leituras correspon dentes ao número de gotas incidentes sobre sua área, no espaço de tempo mínimo de um minuto, em classes de tamanho pré-fixadas. Este instrumento baseia-se no princípio da compensação automática da força produzida por uma gota que atinge a superfície de um sistema receptor rígido. O efeito de compensação faz com que o sistema rígido somente receba uma parte infima da energia de movimento na forma de energia cinética, sendo o restante perdido na forma de calor. Assim, o sistema retorna imediatamente a sua posição inicial. Os pulsos elétricos gerados pelo sistema recep- 
tor são classificados por um analisador de impulsos e a relação entre a sua amplitude (U) em Volts e o diâmetro das gotas (D) em milímetros é dado por $\mathrm{U}=0,94 \mathrm{D} 1,47$. O modelo de disdrômetro uti lizado é o RD-69 da DISTROMET LTD., desenvolvido por JOSS e WALD VOGEL (1967), instalado no Instituto de Pesquisas Meteorológicas (IPMet) da Universidade de Bauru (UB), na localidade de Bauru SP $\left(22^{\circ} 21 \cdot 30^{\prime \prime S}, 49^{\circ} 01 \cdot 36^{\prime \prime} \mathrm{W}\right.$ e altura de $624 \mathrm{~m}$ ANMM), no contexto do Projeto RADASP-II da FAPESP (Fundação de Amparo à Pesquisa do Estado de São Paulo).

$$
\text { O instrumento se encontra instalado em }
$$

local

bem exposto à chuva, com sua parte superior na altura da superfí cie do solo, sendo circundado por uma área coberta com espuma pa ra evitar o salpico.

\subsection{Dados}

Os registros disdrométricos analisados foram os referentes aos eventos dos dias 15 de janeiro e 11 e 14 de fevereiro de 1.985 , os três com características típicas de verão.

\subsection{Metodologia}

3.3.1. Classes de diâmetro e velocidade terminal 'e gotas

O número de classes de diâmetro (j), sua amplitude $(\Delta \mathrm{Dj})$ e diâmetro médio $(\mathrm{Dj})$ adotados são característicos do 
instrumento utilizado e se encontram na Tabela 1. Conforme se po de observar nesta tabela o espectro obtido pelo disdrômetro é truncado em $0,3 \mathrm{~mm}$, e todas as gotas maiores que $5 \mathrm{~mm}$ são avaliadas como pertencentes a classe 20 , portanto com diâmetro médio de $5,25 \mathrm{~mm}$. O efeito do truncamento em $0,3 \mathrm{~mm}$ pode ser desprezado devido à reduzida contribuição que as gotas menores que $0,3 \mathrm{~mm}$ têm para os parâmetros avaliados (ROGERS et alii, 1967). Porém,a classificação de todas as gotas maiores que $5 \mathrm{~mm}$ na classe 20 , po deria resultar em erros, principalmente para os parâmetros que são proporcionais a altas potências do diâmetro. Mas, como a fre quência de ocorrência de diâmetros maiores que $5 \mathrm{~mm}$ é reduzida e diâmetros maiores que $7 \mathrm{~mm}$ são instáveis, considera-se os erros despreziveis (JOSS e WALDVOGEL, 1967).

A velocidade terminal de gotas é função do diâmetro e foi calculada através da seguinte equação de FOOTE e DU . TOIT (1969), que descreve os dados experimentais de GUNN e KINZER (1949) :

$v(D) j=-0,193+4,962 D j-0,904 D^{2} j+0,056 D j^{3}$

onde $v(D) j$ é a velocidade terminal da gota em $\mathrm{m} \cdot \mathrm{s}^{-1}$ com diâmetro médio Dj em mm. 
Tabela 1 - Amplitude e diâmetro médio das classes de diâmetro de gotas analisadas pelo disdrômetro utilizado.

\begin{tabular}{|c|c|c|c|}
\hline $\begin{array}{c}\text { Número de Classe } \\
(j)\end{array}$ & $\begin{array}{c}\text { Classe de Diāmetro } \\
\text { (mm) }\end{array}$ & $\begin{array}{l}\text { Amplitude }(\Delta \mathrm{Dj}) \\
\text { (nun) }\end{array}$ & $\begin{array}{l}\text { Diâmetro Médio (Dj) } \\
\text { (mm) }\end{array}$ \\
\hline 1 & $0,3-0,4$ & 0,1 & 0,35 \\
\hline 2 & $0,4-0,5$ & 0,1 & 0,45 \\
\hline 3 & $0,5-0,6$ & 0,1 & 0,55 \\
\hline 4 & $0,6-0,7$ & 0,1 & 0,65 \\
\hline 5 & $0,7-0,8$ & 0,1 & 0,75 \\
\hline 6 & $0,8-1,0$ & 0,2 & 0,90 \\
\hline 7 & $1,0-1,2$ & 0,2 & 1,10 \\
\hline 8 & $1,2-1,4$ & 0,2 & 1,30 \\
\hline . 9 & $1,4-1,6$ & 0,2 & 1,50 \\
\hline 10 & $1,6-1,8$ & 0,2 & 1,70 \\
\hline 11 & $1,8-2,1$ & 0,3 & 1,95 \\
\hline 12 & $2,1-2,4$ & 0,3 & 2,25 \\
\hline 13 & $2,4-2,7$ & 0,3 & 2,55 \\
\hline 14 & $2,7-3,0$ & 0,3 & 2,85 \\
\hline - $\quad 15$ & $3,0-3,3$ & 0,3 & 3,15 \\
\hline 16 & $3,3-3,7$ & 0,4 & 3,50 \\
\hline 17 & $3,7-4,1$ & 0,4 & 3,90 \\
\hline 18 & $4,1-4,5$ & 0,4 & 4,30 \\
\hline 19 & $4,5-5,0$ & 0,5 & 4,75 \\
\hline-20 & $5,0-$ & 0,5 & 5,25 \\
\hline
\end{tabular}


3.3:2. Cálculo do número de gotas por volume de ar e do número de gotas por volume de ar e por intervalo de classe de diâmetro

A leitura fornecida pelo disdrômetro na classe $j(L j)$ refere-se ao número de gotas incidentes em uma área de amostragem (A), correspondente à superficie exposta do instrumen to $\left(0,005 \mathrm{~m}^{2}\right)$, após percorrer uma altura em metros igual ao produ to do intervalo de tempo de amostragem $(\Delta t)$ pela velocidade terminal, isto é, $\Delta t \cdot v(D) j$, de maneira que o número de gotas por $\mathrm{m}^{3}$ na classe $j(N(D) j)$ é:

$$
N(D) j=\frac{L j}{\Delta t \cdot v(D) j \cdot A}
$$

Os tempos de integração $(\Delta t)$ crescentes conside rados foram: $1,5,10,15,20,30$ e Tmin., onde $T$ é a duração total da chuva, expressos em segundos.

O número de gotas por $\mathrm{m}^{3}$ e por $\mathrm{mm}$ de intervalo de classe (n(D) j) foi calculado por:

$$
n(D) j=\frac{N(D) j}{\Delta D j}
$$

Optou-se por calcular o númer• de gotas nas uni dades acima descritas, isto é, em $\mathrm{m}^{-3} \mathrm{e} \mathrm{m}^{-3} \cdot \mathrm{mm}^{-1}$, devido à sua utilização corrente na meteorologia. De forma semelhante poder -

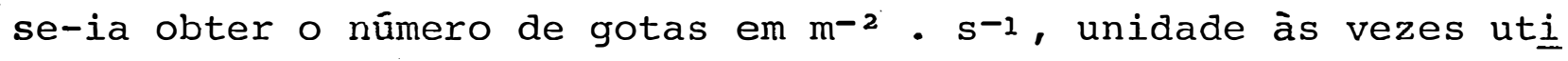
lizada nos estudos de erosão dos solos. 
3.3.3. Obtenção do espectro de gotas

O espectro de gotas consiste na relação funcional entre o número de gotas $(n(D) j)$ e o diâmetro médio da classe $j(D j)$. Tradicionalmente, MARSHALL e PALMER (1948) colocaram este espectro em papel mono-log, obtendo uma relação funcional típica, a qual tem a forma de uma distribuição exponencial inversa descrita por:

$$
\mathrm{n}(\mathrm{D})=\operatorname{Noexp}(-\Lambda \mathrm{D})
$$

onde No é o número de gotas em $\mathrm{m}^{-3}: \mathrm{mm}^{-1}$ quando $\circ \mathrm{D}$ tende a zero e $\Lambda$ é um parâmetro que é função da taxa de precipitação (R) dado por:

$$
\Lambda=\mathrm{CR}^{\mathrm{d}}
$$

Para MP as constantes assumem valores $\quad$ No $=8.000 \mathrm{~m}^{-3} \cdot \mathrm{mm}^{-1} \mathrm{e}$ $\Lambda=4,1 R^{-0}, 21$ rimm-1, onde $R$ é dado em mm. $\mathrm{h}^{-1}$.

Para obter as distribuições espectrais conforme LAWS e PARSONS (1943) (LP), agrupou-se as taxas de precipitação semelhantes, obtidas de espectros medidos durante um minuto, em k grupos com taxa de precipitação média $\left(\overline{\mathrm{R}}_{\mathrm{k}}\right)$ resultante igual a:

$$
\bar{R}_{k}=\frac{\sum_{t=1}^{n} R_{t}}{n}
$$

onde 


$$
R_{t}=3,6 \cdot 10^{-3} \cdot \frac{\pi}{6} \sum_{j=1}^{20} D_{t j}^{3} \cdot v(D) t j \cdot N(D) t j
$$

onde as taxas de precipitação têm unidades em $m m^{-h^{-1}, \mathrm{n}}$ 'é igual ao número de minutos que compõe cada grupo k. Para efeito de com paração, o agrupamento foi feito de maneira que as taxas de precipitação médias $\left(\bar{R}_{k}\right)$ resultantes fossem $1,28,24,8,50,5$ e 102,4 mm. $\mathrm{h}^{-1}$, , isto é, semelhantes às utilizadas por LP. Feito o agru pamento, calculou-se a porcentagem de contribuição média de cada classe de diâmetro j para a taxa de precipitação média do grupo $\mathrm{k}\left(\overline{\mathrm{PR}}_{\mathrm{kj}}\right)$ :

$$
\overline{\mathrm{PR}}_{\mathrm{kj}}=\frac{\overline{\mathrm{R}}_{\mathrm{kj}} \cdot 100}{\overline{\mathrm{R}}_{\mathrm{k}}}
$$

onde

$$
\bar{R}_{k j}=3,6 \cdot 10^{-3} \cdot \frac{\pi}{6} t_{t=1}^{n} \frac{D_{t j}^{3} \cdot v(D)_{t j} \cdot N(D)}{t j}
$$

Assim, traçou-se o gráfico da contribuição $\overline{\mathrm{PR}}_{\mathrm{kj}}$ em função do diâmetro médio de cada classe j, para cada gru po de taxa de precipitação, comparando o resultado com a distribuição espectral obtida por LP.

3.3.4. Cálculo do diâmetro mediano

o diâmetro mediano foi calculado com base na massa de precipitação (W') definida por: 


$$
W^{\prime}=\int_{0}^{\infty} m(D) \quad n(D) d D
$$

onde $m(D)$ é a massa da gota com diâmetro D.

Para um espectro truncado e discreto, W' pode ser aproximado por:

$$
W:=\rho \frac{I}{6} 10^{-6} \sum_{j=1}^{20} D_{j}^{3} N(D)_{j}
$$

com unidades em $\mathrm{g} \cdot \mathrm{m}^{-3}$.

O diâmetro mediano (DME') com base na massa de precipitação é,então, definido por:

$$
\mathrm{DME}^{\prime}=\frac{\int_{0}^{\infty} \mathrm{DW}(\mathrm{D}) \mathrm{dD}}{\int_{0}^{\infty} W(D) d D}
$$

e para um espectro truncado e discreto pode ser calculado por:

$$
D M E=\frac{j_{=1}^{20} D_{j}^{4} N(D) j}{j=1}
$$

resultando em unidades de milímetros para DME.

Segundo ULBRICH (1985) a utilização de DME é mais conveniente em comparação com o diâmetro mediano com base no volume de precipitação, tradicionalmente denominado D50, devi do à interpolação do espectro de gotas necessária para o cálculo deste último. 
3.3.5. Cálculo da concentração de energia cinética, da concentração de momentum e da concentração de volume de precipitação

A concentraçäo de energia cinética (CEC'), con centração de momentum ( $\left.\mathrm{CMO}^{\prime}\right)$ e concentração de volume de precipita ção ( $\left(V^{\prime}\right)$ de uma distribuição de tamanho de gotas são, respectiva mente, definidos por:

$$
\begin{aligned}
& \mathrm{CEC}^{\prime}=\frac{1}{2} \int_{0}^{\infty} \mathrm{m}(\mathrm{D}) \mathrm{v}(\mathrm{D})^{2} \mathrm{n}(\mathrm{D}) \mathrm{dD} \\
& \mathrm{OMO}^{\prime}=\int_{0}^{\infty} \mathrm{m}(\mathrm{D}) \mathrm{v}(\mathrm{D}) \mathrm{n}(\mathrm{D}) \mathrm{dD} \\
& \mathrm{CV}^{\prime}=\int_{0}^{\infty} \mathrm{v}(\mathrm{D}) \mathrm{n}(\mathrm{D}) \mathrm{dD}
\end{aligned}
$$

onde $\mathrm{V}(\mathrm{D})$ é o volume da gota com diâmetro D. Para um espectro dis erreto e truncado podem ser aproximados por:

$$
\begin{aligned}
& C E C=K_{1} \frac{\pi}{12} \rho \sum_{j=1}^{20} D_{j}^{3} V(D){ }_{j}^{2 N} N(D) j \\
& C M O=K_{1} \frac{\pi}{6} \rho_{j=1}^{20} D_{j}^{3} V(D) j_{j}^{N(D)} j \\
& C V=\frac{\pi}{6} \sum_{j=1}^{20} D_{j}^{3} N(D) j
\end{aligned}
$$

onde $K_{1}=10^{-9}$ é um fator de correção para as unidades de $D, N(D)$ e $\mathrm{v}(\mathrm{D})$ anteriormente adotadas è para a densidade da "água ( $\dot{\rho}$ ) igual a $10^{3} \mathrm{Kg} \cdot \mathrm{m}^{-3}$, de maneira que as unidades resultantes são: $\mathrm{J} \cdot \mathrm{m}^{-3}(\mathrm{CEC}), \mathrm{Kg} \cdot \mathrm{m} \cdot \mathrm{s}^{-1} \cdot \mathrm{m}^{-3} \quad(\mathrm{CMO}), \mathrm{mm}^{3} \cdot \mathrm{m}^{-3}(\mathrm{CV})$ 
3.3.6. Cálculo do fluxo de energia cinética, do fluxo de momentum e da taxa de precipitação

A função de fluxo é definida como o produto da função de concentração pela velocidade (RIGBY et alii, 1954). For tanto, o fluxo de energia cinética (FEC'), o fluxo de momentum (FMO') e a taxa de precipitação ou fluxo de volume de precipitação $\left(R^{\prime}\right)$ são, respectivamente, obtidos das expressões (21), (22)e (23), de forma que:

$$
\begin{aligned}
& \text { FEC }^{\prime}=\frac{1}{2} \int_{0}^{\infty} m(D) v(D){ }^{3} n(D) d D \\
& F^{\prime}=\int_{0}^{\infty} m(D) v(D)^{2} n(D) d D \\
& R^{\prime}=\int_{0}^{\infty} V(D) v(D) n(D) d D
\end{aligned}
$$

e para um espectro não continuo e truncado podem ser aproximados por:

$$
\begin{aligned}
& \text { FEC }=K_{1} \frac{\pi}{12} \sum_{j=1}^{20} D_{j}^{3} V(D){ }_{j}^{3 N}(D) j \\
& \text { FMO }=K_{1} \frac{\pi}{6} \sum_{j=1}^{20} D_{j}^{3} V(D){ }_{j}^{2} N(D) j \\
& R=K_{2} \frac{\pi}{6} \sum_{j=1}^{20} D_{j}^{3} V(D) j^{N(D)} j
\end{aligned}
$$

onde $k_{1}$ é $\circ$ fator de correção anteriormente citado e $k_{2}=3,6 \cdot 10^{-3}$

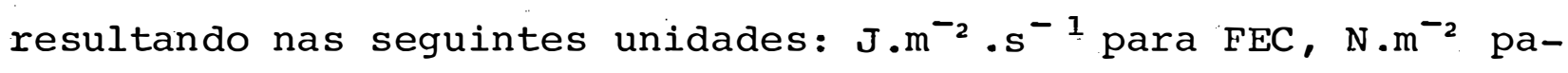
ra FMO e mm.h $\mathrm{h}^{-1}$ para $\mathrm{R}$. Assim, o que se cunvenciona como fluxo, dimensionalmente é densidade de fluxo. 
3.3.7. Cálculo da energia cinética por área e por altura pluviométrica, do momentum por área e por altura pluviométrica e da refletividade do radar

A energia cinética (e) e o momentum (m) utilizados na maior parte dos indices de erosividade existentes "são definidos, respectivamente, por (KINNELL, 1981):

$$
\begin{aligned}
& e=K_{3} \frac{F E C}{R} \\
& m=K_{3} \frac{F M O}{R}
\end{aligned}
$$

onde $\mathrm{K}_{3}=3.600$ é um fator de correção para as unidades citadas, resultando em e expresso em $\mathrm{J} \cdot \mathrm{m}^{-2} \cdot \mathrm{mm}^{-1}$ e $\mathrm{m}$ expresso em $\mathrm{kg} \cdot \mathrm{m}^{-\mathrm{s}^{-1}}$. $\mathrm{m}^{-2} \cdot \mathrm{mm}^{-1}$.

A refletividade do radar (z') é definida como:

$$
Z^{\prime}=\int_{0}^{\infty} D^{6} n(D) d D
$$

e portanto pode ser aproximada por:

$$
z=\sum_{j=1}^{20} D_{j}^{6} N(D) j
$$

resultando na unidade $\mathrm{mm}^{6} \cdot \mathrm{m}^{-3}$. 
3.3.8. Cálculo do fator de forma

O fator de forma $S(\sigma Z)$, definido por Joss e GORI (1978), foi calculado para os espectros obtidos nos tempos de integração citados no item 3.3 .2 através de:

$$
\begin{aligned}
& D(\sigma)= \frac{\sum_{j=1}^{20} D_{j}^{2} N(D) j}{\sum_{j=1}^{20} D_{j} N(D) j} \\
& D(Z)=\frac{\sum_{j=1}^{20} D_{j}^{6} N(D) j}{\sum_{j=1}^{20} D_{j}^{5} N(D) j}
\end{aligned}
$$

e

$$
S(\sigma Z)=2\left|\frac{D(Z)-D(\sigma)}{D(Z)+D(\sigma)}\right|
$$

Para um espectro truncado em 0,3 e $5 \mathrm{~mm}$ Joss e GORI (1978) especificam que os espectros de gotas são considerados exponenciais quando $\mathrm{S}(\sigma \mathrm{Z})$ apresenta valores entre 0,7 e 0,9, monodispersos quando $\mathrm{S}(\sigma \mathrm{Z})$ tende a zero, e não exponenciais quan do $\mathrm{S}(\sigma \mathrm{Z})$ é maior ou menor que os valores citados. A região do es pectro descrita pelo fator de forma se concentra entre o diâmetro de māxima contribuição para o (proporcional a $\mathrm{D}^{2}$ ), e o diâme tro de máxima contribuição para $\mathrm{z}$ (proporcional a $\mathrm{D}^{6}$ ), abrangendo, portanto, una larga faixa de diâmetros. 


\subsubsection{As relações analíticas}

Assumindo-se que a velocidade terminal das gotas é função do diâmetro através da seguinte expressão (ROGERS , $1976)$ :

$$
\mathrm{v}(\mathrm{D})=\mathrm{aD} \mathrm{D}^{\mathrm{b}}
$$

e considerando-se o espectro descrito pela expressão (11), podese reescrever a expressão (29):

$$
\begin{aligned}
& R=\frac{\pi}{6} \int_{0}^{\infty} D^{3} a D^{b} \operatorname{Noexp}(-\Lambda D) d D \\
& R=\frac{\pi}{6} a N o \int_{0}^{\infty} D^{3}+b \exp (-\Lambda D) d D
\end{aligned}
$$

cuja integração resulta em:

$$
R=\frac{\pi}{6} a \text { No } \frac{\Gamma(4+b)}{\Lambda(4+b)}
$$

relação anteriormente descrita por SEKHON e SRIVASTAVA (1970) e WALDVOGEL (1975), o que resulta na expressão (12), onde os coefi cientes c e d são iguais a:

$$
\begin{aligned}
& c=\left[\frac{\pi}{2} \frac{\pi}{6} a \operatorname{No}[(4+b)]^{[1 /(4+b)]}\right. \\
& d=-[1 /(4+b)]
\end{aligned}
$$


onde $K_{2}$ é o coeficiente de correção de unidades anteriormente cí tado. Através de raciocinio semelhante as expressões (27) e (28) passam a ser:

$$
\begin{aligned}
& \text { FEC }=\frac{\pi}{12} \rho a^{3} \text { No } \frac{\Gamma(4+3 b)}{\Lambda(4+3 b)} \\
& \text { FMO }=\frac{\pi}{6} \rho a^{2} \text { No } \frac{\Gamma(4+2 b)}{\Lambda(4+2 b)}
\end{aligned}
$$

e substituindo-se novamente pela expressão (12):

$$
\begin{aligned}
& \text { FEC }=K_{1} \frac{\pi}{12} \rho a^{3} \text { NO } \frac{\Gamma(4+3 b)}{c(4+3 b)} \cdot R^{-(4+3 b) d} \\
& \text { FMO }=K_{I} \frac{\pi}{6} \rho a^{2} \text { NO } \frac{\Gamma(4+2 b)}{c^{(4+2 b)}} \cdot R^{-(4+2 b) d}
\end{aligned}
$$

De forma que as expressões (33) e (34) podem ser escritas como:

$$
\begin{aligned}
& e=K_{1} K_{3} \frac{\pi}{12} \rho a^{3} \text { No } \frac{\Gamma(4+3 b)}{c(4+3 b)} \cdot R^{[-(4+3 b) d-1]} \\
& m=K_{1} K_{3} \frac{\pi}{6} \rho a^{2} \text { No } \frac{\Gamma(4+2 b)}{c^{(4+2 b)}} \cdot R^{[-(4+2 b) d-1]}
\end{aligned}
$$

Para a obtenção das relações $\mathrm{FEC}=\mathrm{FEC}(\mathrm{z}), \mathrm{e}=\mathrm{e}(\mathrm{z}), \mathrm{FMO}=\mathrm{FMO}(\mathrm{z})$ e $\mathrm{m}=\mathrm{m}(\mathrm{Z})$ teóricas a expressão (35) pode ser reescrita como:

$$
\begin{aligned}
& \mathbf{Z}=\operatorname{No}_{0}^{\infty} D^{6} \exp (-\Lambda D) d D \\
& z=\operatorname{No} \frac{\Gamma(7)}{\Lambda^{7}}
\end{aligned}
$$


ou

$$
\Lambda=[\operatorname{NoT}(7)]^{[1 / 7]} \cdot z^{-[1 / 7]}
$$

Substituindo $\Lambda$ (expressão (50)) nas expressões (43) e (44) obtém -se:

FEC $=K_{1} \frac{\pi}{12} \rho a^{3}$ No $\frac{\Gamma(4+3 b)}{[\operatorname{No} \Gamma(7)]}[(4+3 b) / 7] \quad z^{[(4+3 b) / 7]}$

FMO $=K_{2} \frac{\pi}{6} \rho a^{2}$ NO $\frac{\Gamma(4+2 b)}{[N O \Gamma(7))]}[(4+2 b) / 7] \cdot \mathrm{z}^{[(4+2 b) / 7]}$

Substituindo $\Lambda$ (expressão (50)) na expressão (49) por (12) tem se:

$$
\begin{aligned}
& \mathrm{z}=\mathrm{No} \frac{\Gamma(7)}{\mathrm{C}^{7}} \mathrm{R}-7 \mathrm{~d} \\
& \mathrm{z}=\mathrm{AR}^{\mathrm{B}} \quad \text { ou } \mathrm{R}=\left[\frac{1}{\mathrm{~A}}\right][1 / \mathrm{B}]_{\mathrm{Z}}^{[1 / \mathrm{B}]}
\end{aligned}
$$

Voltando às expressões (33) e (34), substituindo, respectivamente ,FEC e FMO pelas expressões (51) e (52) e dividindo ambas pela expressão (53) têm-se que:

$e=K_{1} K_{3} \frac{\pi}{12} \rho a^{3}$ No $\frac{\Gamma(4+3 b)}{[\text { No } \Gamma(7)]}[(4+3 b) / 7] \cdot A^{[1 / B]} \cdot z^{[(4+3 b) / 7]-[1 / B]}$ 
$m=K_{1} K_{3} \frac{\pi}{6} \rho a^{2}$ No $\frac{\Gamma(4+2 b)}{[N o \Gamma(7)]}[(4+2 b) / 7]^{\cdot A^{[1 / B]}} \cdot z^{[(4+2 b) / 7]-[1 / B]}$

Os fatores de correção de unidades $K_{1}$ e $K_{3}$ são os anteriormente citados, de forma que os parâmetros e, FEC, m, FMO, $\mathbf{z}$ e $\mathrm{R}$ têm unidades iguais às citadas nos itens 3.3 .6 e 3.3.7.

\subsubsection{As relações experimentais}

Conforme mencionado na revisão bibliográfica, existem algumas relações entre os parâmetros definidos nos itens anteriores, que são de interesse prático, como: 1. a relação entre a energia cinética, o fluxo de energia cinética, o momentum, - fluxo de momentum, o diâmetro mediano e a taxa de precipitação, para estudos de erosão e 2. a relação entre a refletividade do radar e a taxa de precipitação, para estudos de meteorologia com radar.

- Assim, vários modelos matemáticos citados na literatura, foram testados quanto ao seu ajuste aos dados observados nos tempos de integração de 1, 10, 20 e $30 \mathrm{~min}$. , bem como aos dados de cada chuva individual, visando avaliação da variabilidade temporal dos parâmetros da regressão e do coeficiente de correlação, utilizando-se o programa estatístico para microcompu tador, STATGRAPHICS da STSC Inc.

Os modelos ajustados às respectivas relações de interesse sao: 


$$
\begin{aligned}
a \cdot e=e(R) \cdot: e & =a R^{b} \\
: & e=a+\operatorname{blog}_{10} R \\
: & e=a+b \operatorname{bexp}(-c R)-\operatorname{dexp}(-e R)
\end{aligned}
$$

b. $e=e(z) \quad: e=a z^{b}$

$c \cdot e=e(D M E) \quad: e=\exp (a+b / D M E)$

a. $\mathrm{FEC}=\mathrm{FEC}(\mathrm{R}) \quad$ : $\mathrm{FEC}=\mathrm{aR} \mathrm{R}^{\mathrm{b}}$

: $\mathrm{FEC}=\mathrm{a}+\mathrm{bR}$

e. $\operatorname{FEC}=\operatorname{FEC}(\mathrm{Z}): \operatorname{FEC}=a \mathrm{z}^{\mathrm{b}}$

$$
\mathrm{FEC}=\mathrm{a}+\mathrm{bz}
$$

f. $m=m(R) \quad$ : $m=a R^{b}$

$g \cdot m=m(z) \quad: m=a z^{b}$

h. $F M O=F M O(R): F M O=a R^{b}$

$$
\text { : } F M O=a+b R
$$

i. $F M O=F M O(Z): F M O=a z^{b}$

$$
\text { : } F M O=a+b R
$$

$j \cdot z=z(R) \quad: z=a R^{b}$ 
k. $D M E=D M E(R): D M E=a R^{b}$.

onde e, FEC, m, FMO, R, DME e $\mathrm{z}$ sao os parâmetros anteriormente definidos.

3.4. Programa para cálculo em microcomputador

A partir das leituras disdrométricas, referentes a cada minuto das chuvas amostrados, calculou-se os vários parâmetros citados no item anterior, através de um programa em linguagem Turbo-Pascal elaborado pelo Centro de Informática na Agricultura - CIAGRI da ESALQ/USP, listado no Apēndice 1. 
.44 .

\section{RESULtADOS E DISCUSSÃO}

4.1. Caracterização das chuvas estudadas

Os parâmetros calculados, utilizando-se os espectros dos três eventos medidos nos diferentes tempos de integração, estão listados nas Tabelas 2, 3 e 4 do Apêndice 2.

a. EVENTO A

A variação dos parâmetros em função do tempo, expresso em minutos contados a partir do início das chuvas, durante as amostragens de $1 \mathrm{~min}$., pode ser observada nas Figuras 1 e 2 para a chuva do dia 15 janeiro de 1.985, que teve início as $22: 28$ hs. 

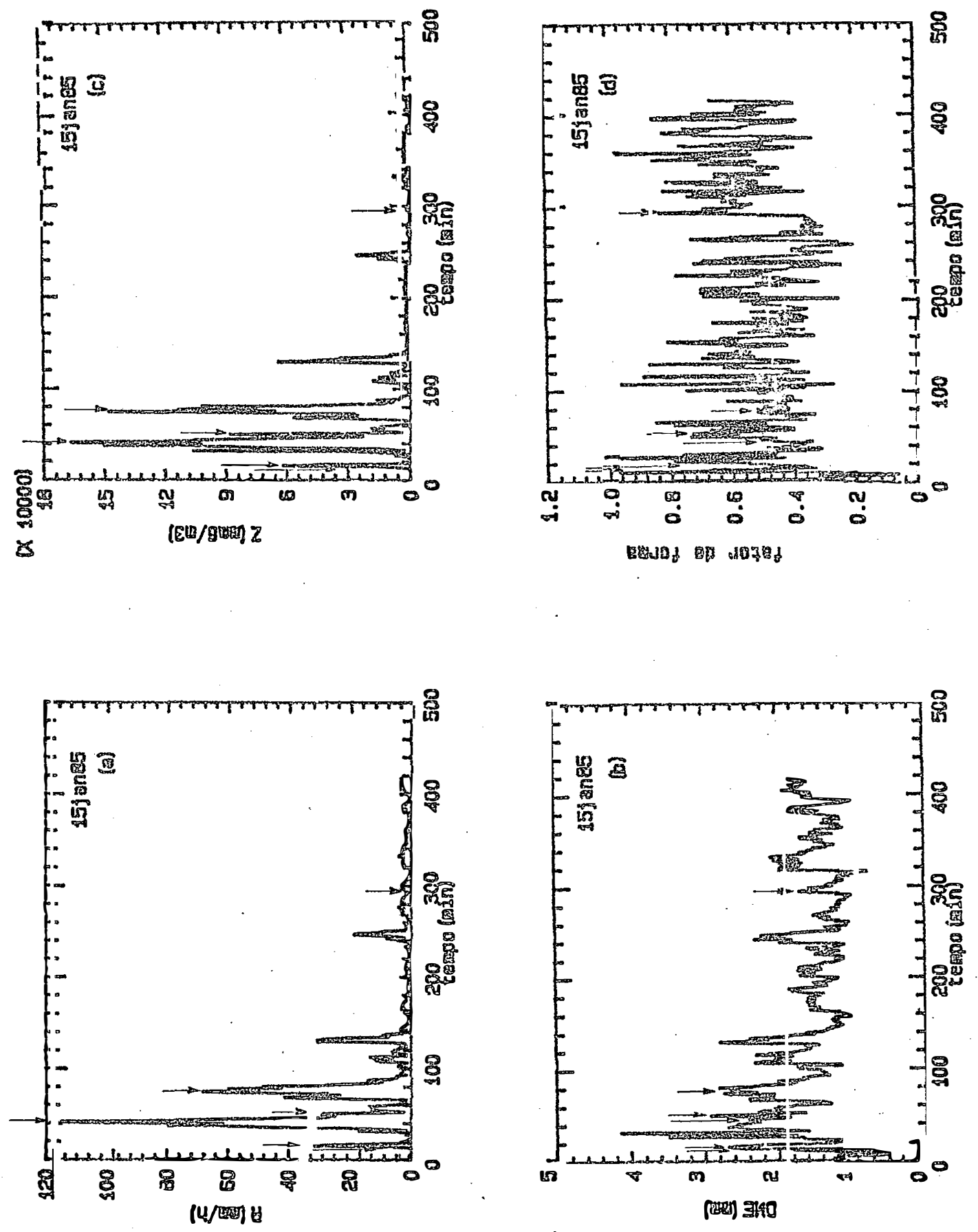

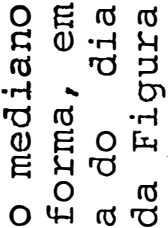

मै 4 ?

(1) ठ

究 0 尺्ञ

-r O 00 ब

-

\%

$\dot{2}^{4}$.

- $\dot{0}+\vec{r}$

- ठ म ह

बि $0 \cdot{ }^{-H}$

- NO

ब

or 4

तथ म थ थ $+\pi+0$

Q

- 4 मे

U) 0 ro $n$

010

(1) त ه

ठ

व

$x>0,-1$

ช

$++10$

(1) 0 ठ

ते प्र है

(0) प्य है

(1) प्山े

ॠ

O $ن$ 元

ic

un - 0

-

证 4

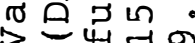

$$
p=4 \pi \sigma
$$

r

苗 

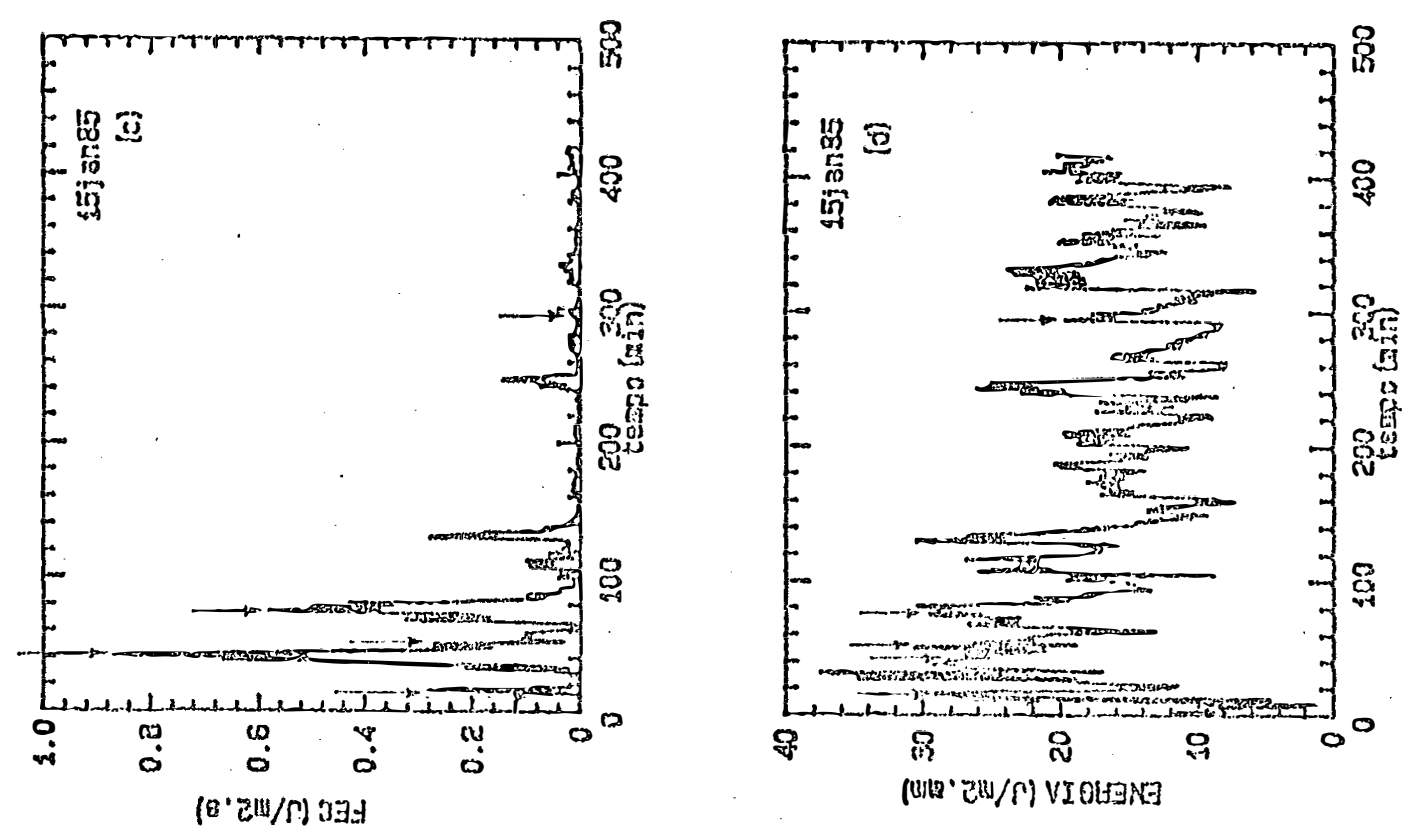

$\begin{array}{cc}0 & 0 \\ 0 & 0 \\ 2 & 0 \\ -1 & 0\end{array}$

4.

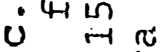

- 0 is

E 0.7 O

गु

द वे०

Q) U

E.

E.0 ? o

F 50

○्ञ

- 0 o

00

O

(स) 0) -

- $\mathrm{E} \cup$

E 0 每

is

G

E

O - is U

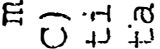

(1) II 4 \& 0

ס国
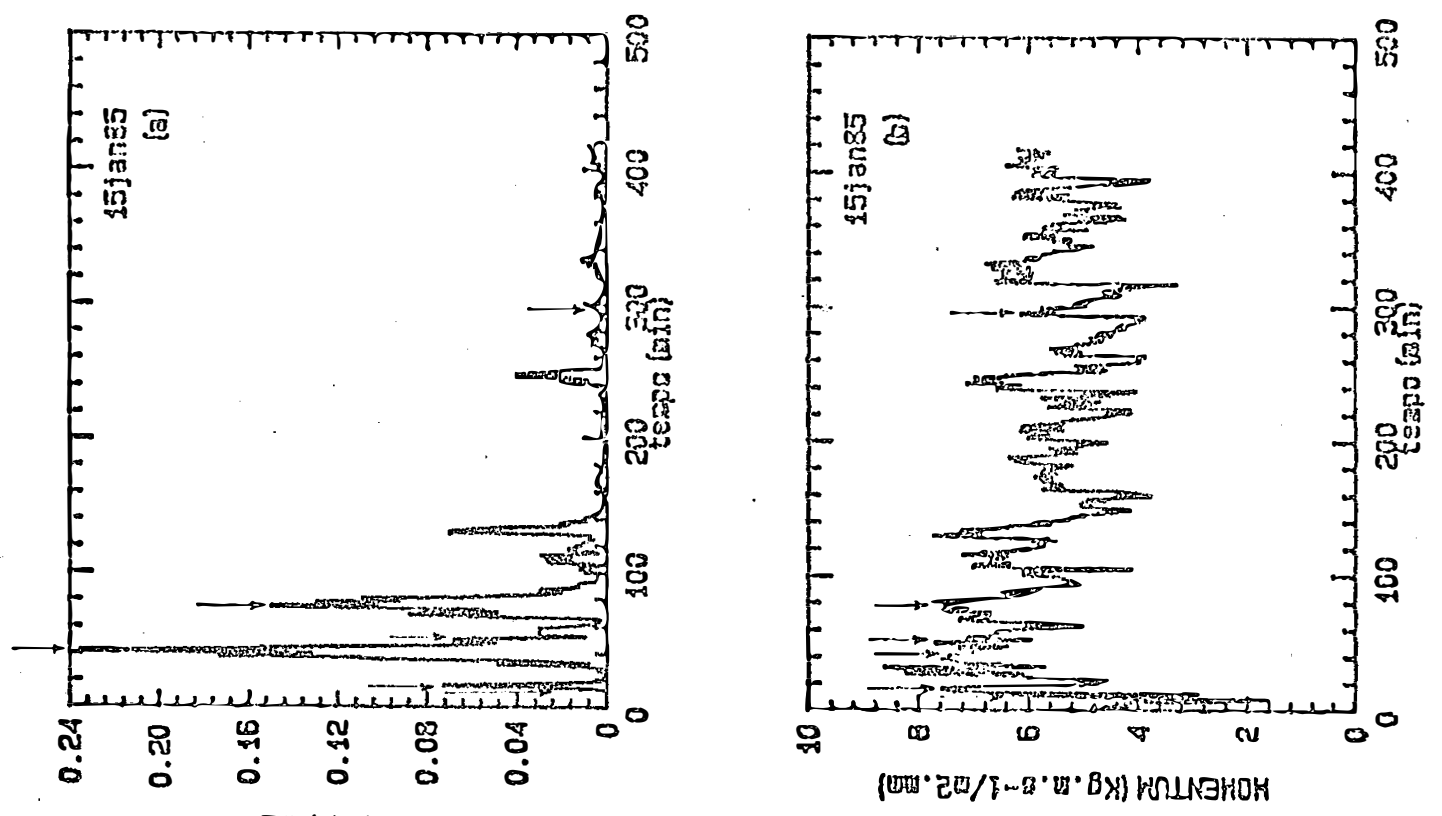

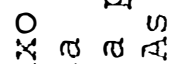

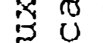

th in 0 .

$4-1+0$ in

id) ro 00

- द्व

o 0 .

0 000

or 0

in $40_{1} \mathrm{O}$

un 0 is

तथ द 0 .

- $10+0$

枈 0 O

>

(EW/N) OHA

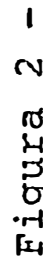


Tabela 5 - Características médias dos parâmetros para as trēs chu vas separadamente e somadas. $R$ = taxa de precipitação, $\mathrm{DME}=$ diâmetro mediano, $\mathrm{Z}=$ refletividade do radar $\mathrm{e}$ $S$ = fator de forma.

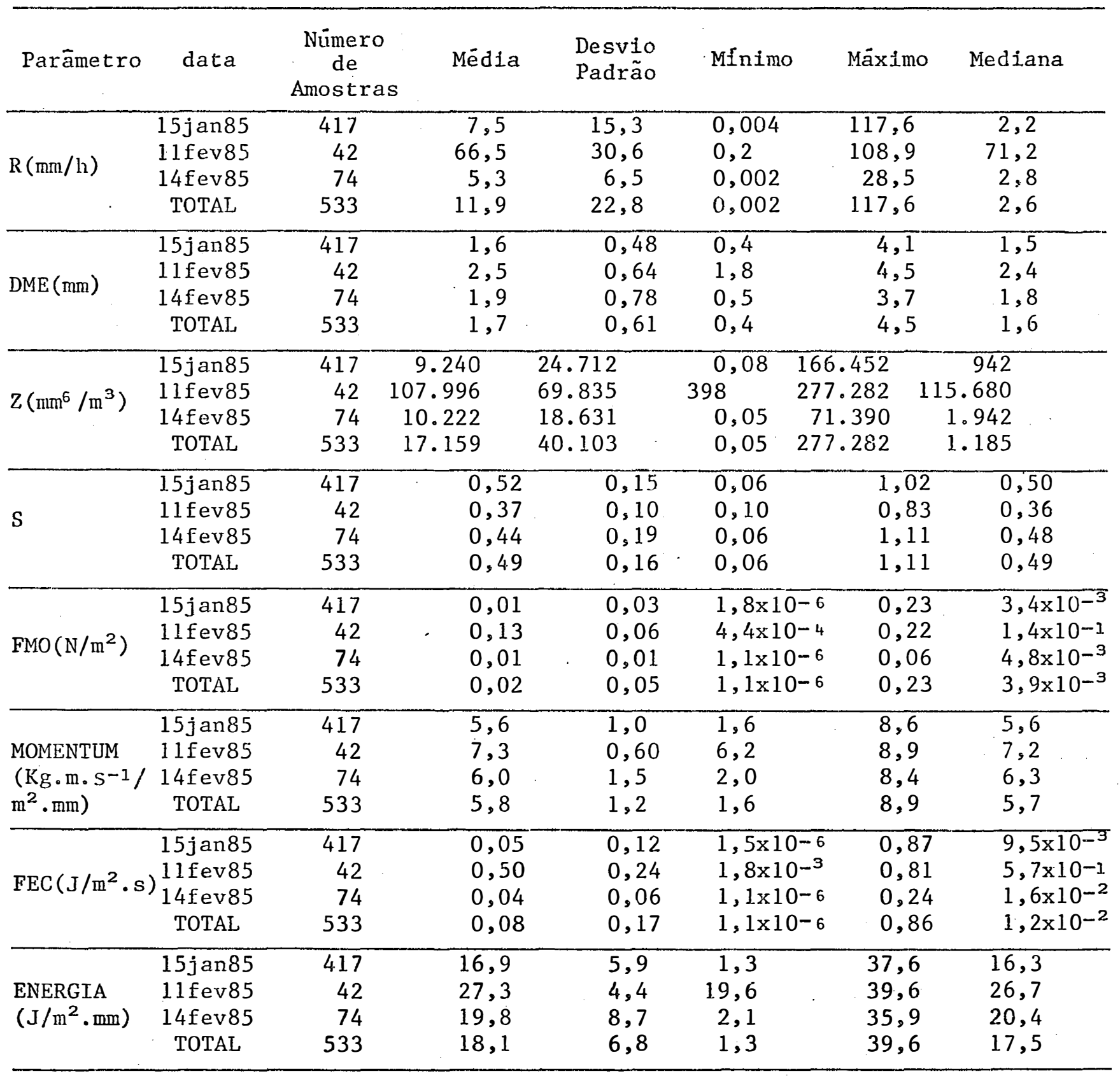


Estes dados mostram que a chuva do dia 15 de janeiro de 1.985 apresentou um tempo de 417 min., com fase inicial de taxas de precipitação intensas e picos máximos de 35,120, 72 e $34 \mathrm{~mm}^{\mathrm{h}-1}$, nos tempos 15, 40, 75 e $130 \mathrm{~min}$. , respectiva mente, e com uma fase subsequlente de taxas entre 0 e $20 \mathrm{~mm}^{\circ \mathrm{h}^{-1}}$, que se estende durante aproximadamente 4:30 horas (Figura 1a). A variação da refletividade do radar (Figura 1c), do fluxo de ener gia cinética e de momentum (Figura 2a e 2c) em função do tempo, apresenta picos máximos aproximadamente nos mesmos tempos que os da taxa de precipitação. Porém, o diāmetro mediano (Figura 1b) possue variação muito mais acentuada com uma série de picos máxí mos, de melhor conformidade com a variação da energia (Figura 2d) e do momentum (Figura 2b). O fator de forma (Figura 1d) varia em torno de seu valor médio de 0,52 (vide Tabela 5), podendo observar-se picos ocasionais próximos de 0,9, valor este definido anteriormente para espectros exponenciais inversos.

\section{b. EVENTO B}

A chuva do dia 11 de fevereiro de 1.985 (Figura 3 e 4 ), teve uma duração total menor, de $42 \mathrm{~min} .$, iniciados às 00:02 hs, e padrões de variação semelhantes para a taxa de precipitação (Figura 3a), o fluxo de momentum (Figura 4a) e de energia (Figura 4c). No caso da refletividade do radar (Figura 3c), os picos máximos iniciais não coincidem com os da taxa de 

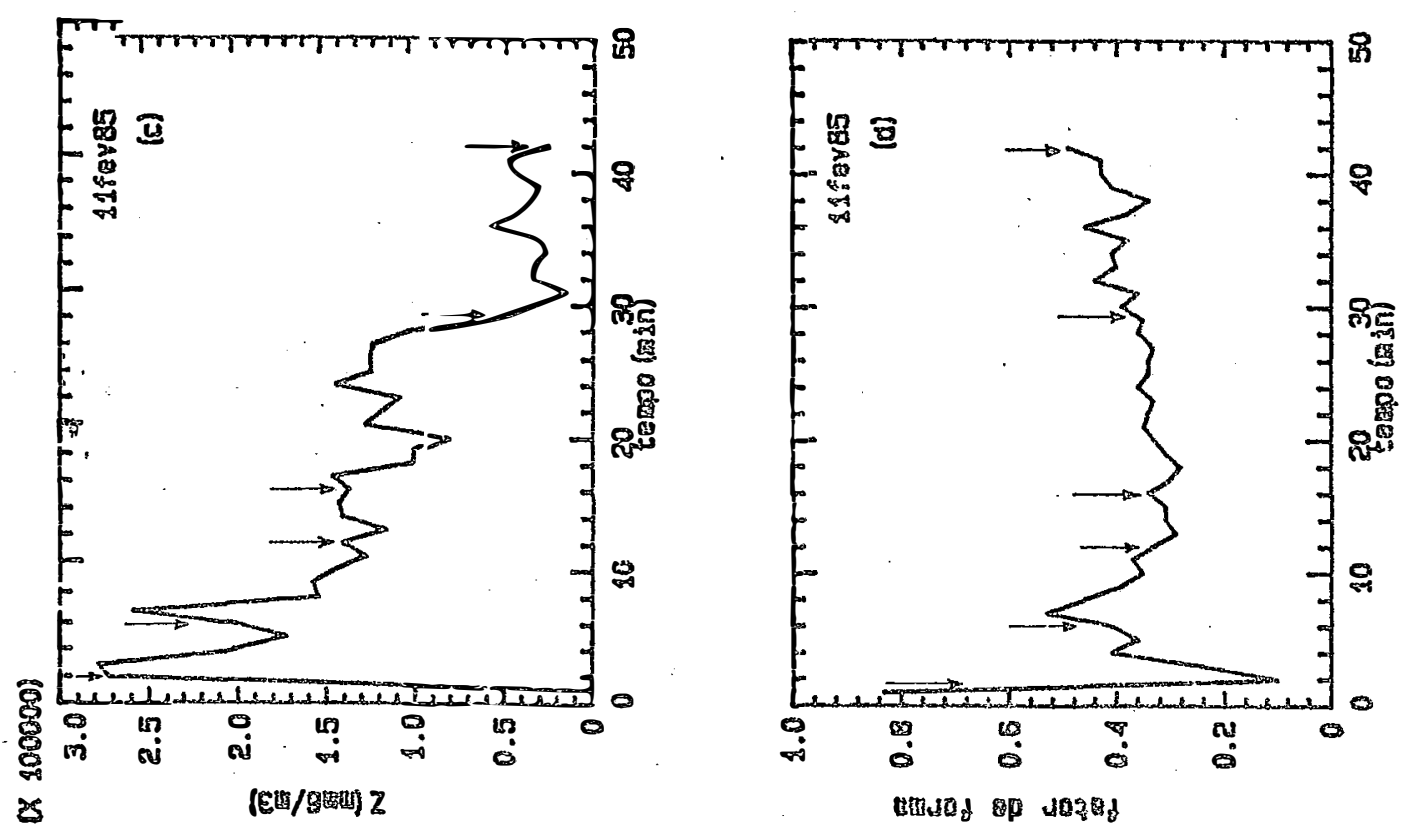

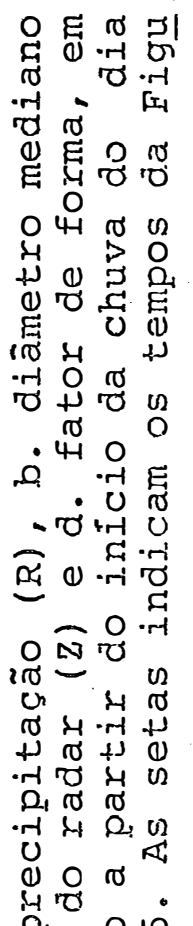

م. 0 1

(1) $\sigma$

() శా
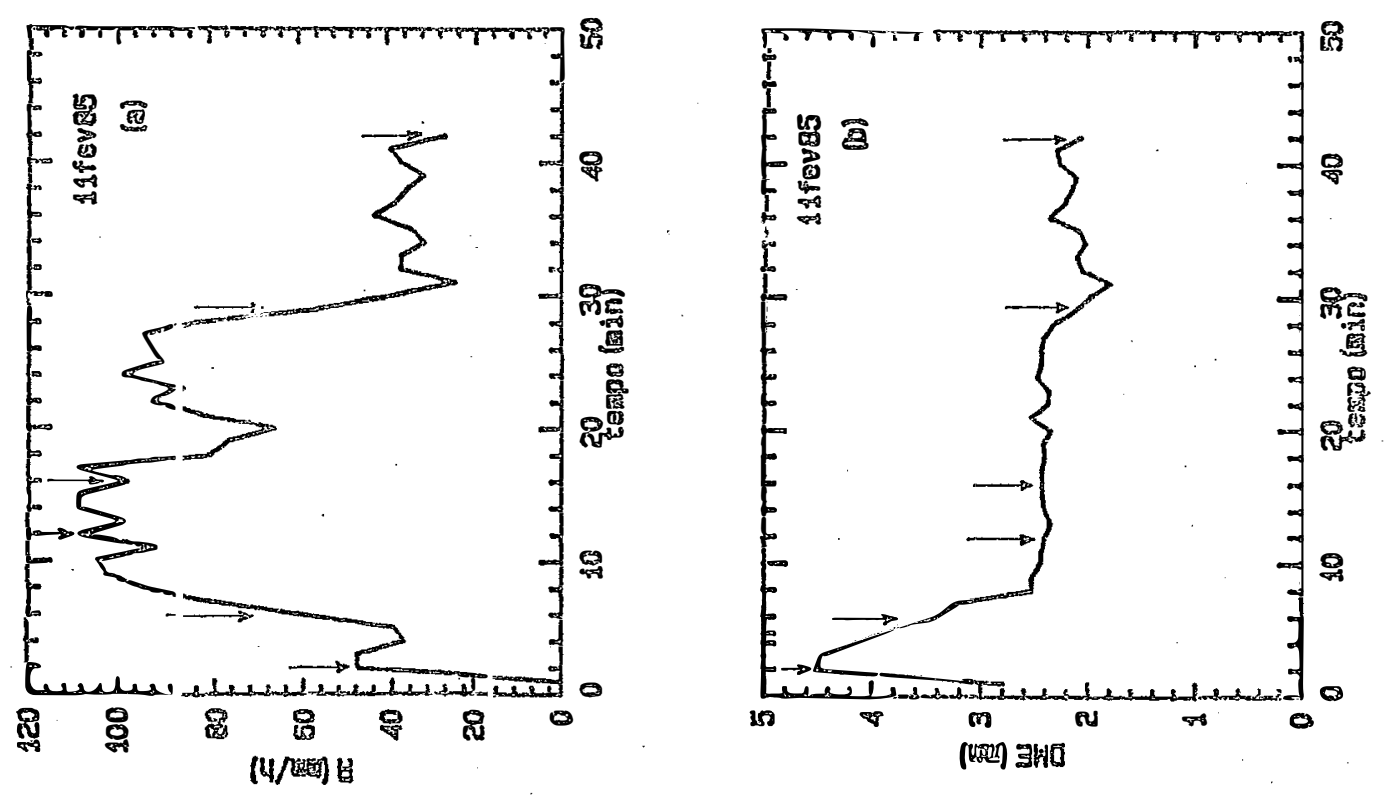

चु द्व

$\begin{array}{llll}1 & 0 & 0 & 0\end{array}$

ชี. P O

ס

० ल्- Q \&

त $4 \mathrm{E}$ ह.

(1) 010

(1) मे मे

ن 0 唄

0

on -0

r $\begin{array}{llll}0 & 0 & 0\end{array}$

-

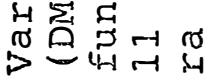

1

$m$

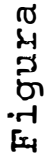



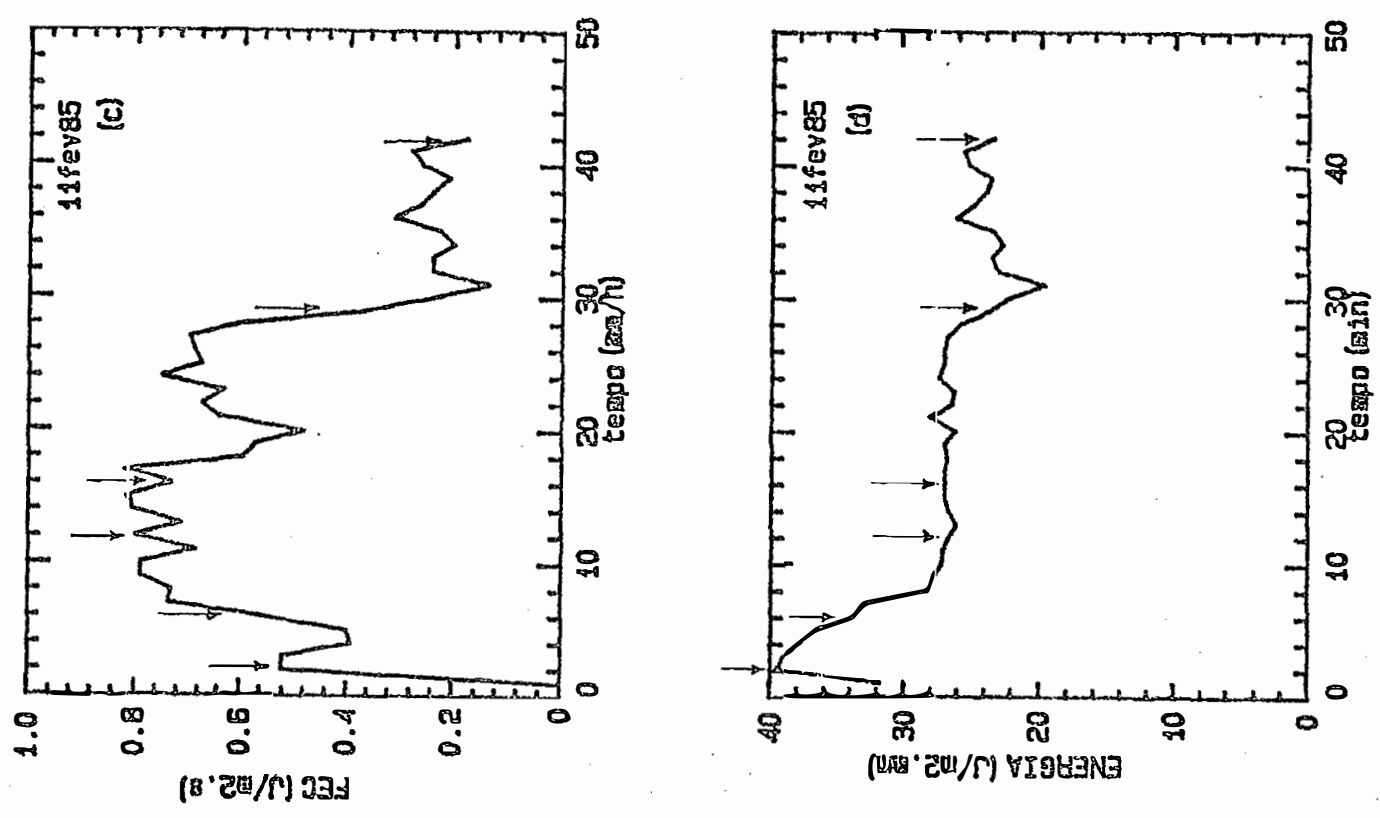

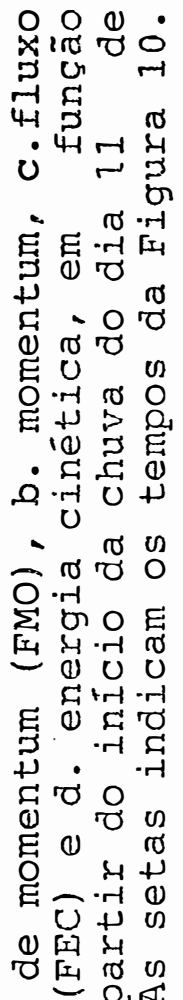
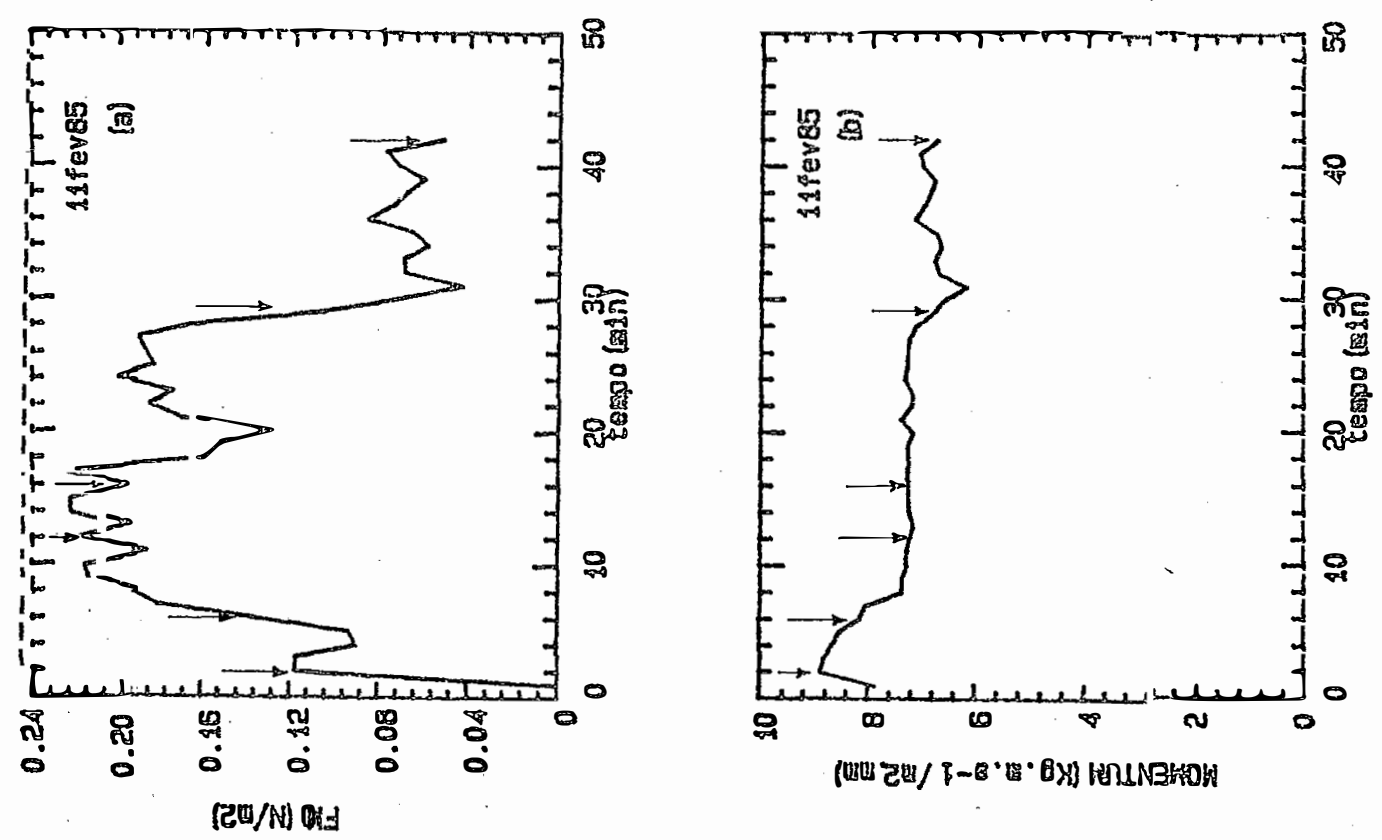

○

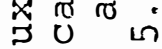
겅 00 $4+$ का क (1) $\pi$. - 5 W

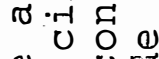
(1) U r $\begin{array}{ll}0 & 0 \\ -r & -0\end{array}$ 0 on 0 मे 100 मे $\Omega_{1} \cdot{ }_{1}$ -r $10+1$ तै 000 $>$ व

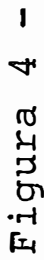


precipitação, porēm a partir de $20 \mathrm{~min}$. tornam-se semelhantes em aspecto. Novamente, as variações do diâmetro mediano (Figura 3b), do momentum (Figura 4b) e da energia (Figura 4d) são bastante análogas. Observa-se que após 5 min., o acréscimo na taxa de pre cipitação até taxas de $100 \mathrm{~mm}^{\mathrm{h}} \mathrm{h}^{-1}$, coincide com o decréscimo no diâmetro mediano até $2,4 \mathrm{~mm}$, mantendo-se neste valor durante aproximadamente $20 \mathrm{~min}$., enquanto a taxa de precipitação cai e se estabelece, durante uns $10 \mathrm{~min}$., na faixa dos $80 \mathrm{~mm} . \mathrm{h}^{-1}$, an tes de decrescer totalmente e a chuva findar. Com relação ao fator de forma esta chuva apresentou os menores valores (Figura 3d e Tabela 5).

\section{EVENTO C}

Os parâmetros da chuva do dia 14 de fevereiro de 1.985, que se iniciou às $16: 14$ hs, apresentam picos de máximo bem menores que os ocorrentes nas outras chuvas estudadas (Tabela 5). A variação dos mesmos em função do tempo é apresenta da nas Figuras 5 e 6 , e segue as formas descritas anteriormente para as outras chuvas, isto é, taxa de precipitação, refletividade do radar, fluxo de momentum e energia, variam de forma se melhante (Figura 5a, 5c, 6a e 6c), enquanto que diâmetro mediano, momentum e energia (Figura 5b, 6b e 6d), apresentam estruturas semelhantes entre si. Para o fator de forma a variação é irregu lar e sem tendência definida (Figura 5d). 

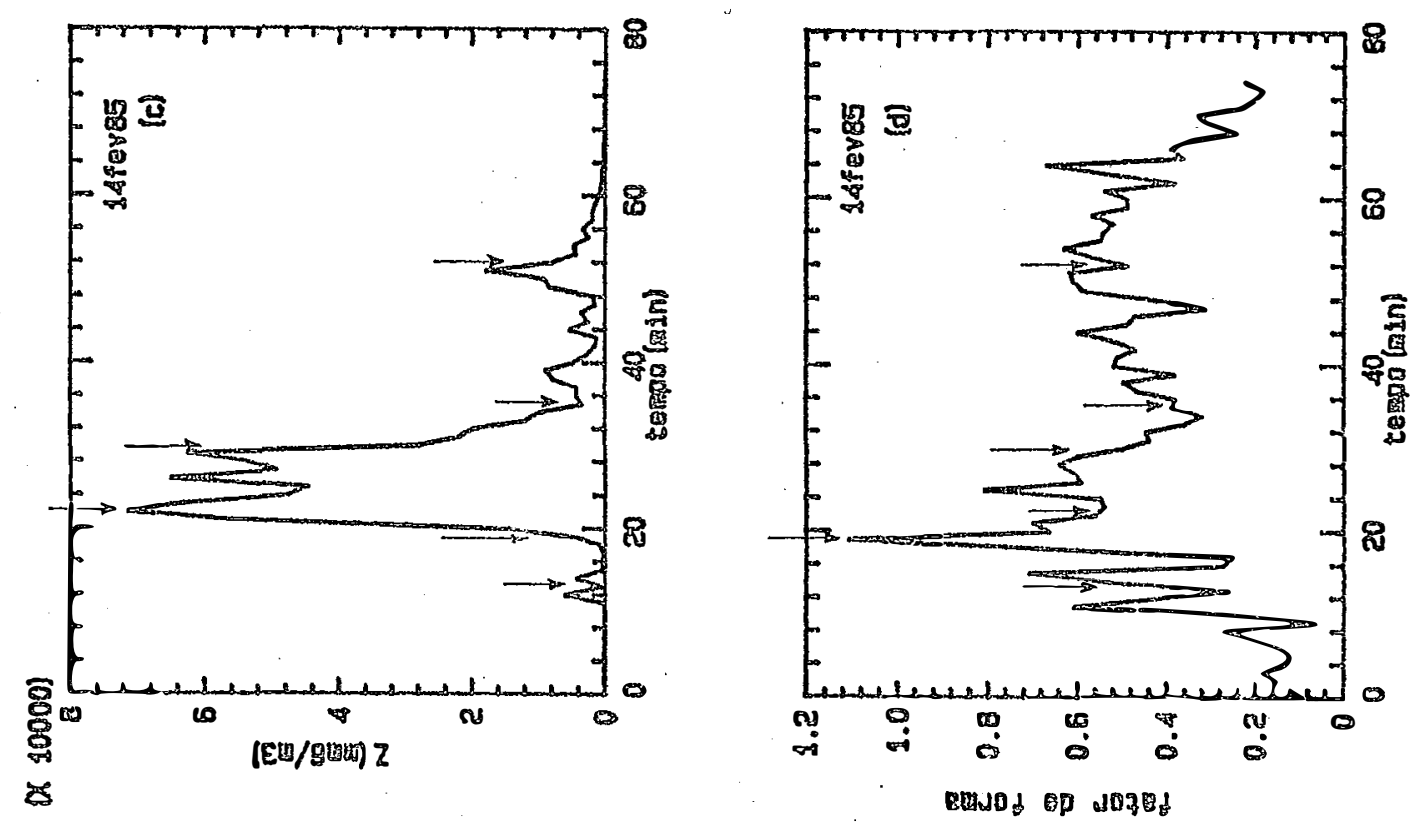

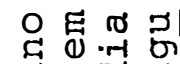

ช

नु के म

ه

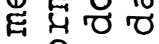

0 饮

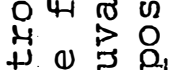

Q

范 4 ए

- $\mathrm{d} 0 \mathrm{O}$

ठ大

. 410

. .70

- त्रा

ब 0. ज्न

० ิิ

$100 \%$

\% $\mu \cdot r$.

$+\sigma+0$

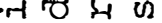

ค 100

- 400

O

¿

م.

(1) त

ه

ब

每

+

वं 4 年

ه

(1) $4+5$

ర

- 0

O 0 它

or - 0 .

苗至

ชั
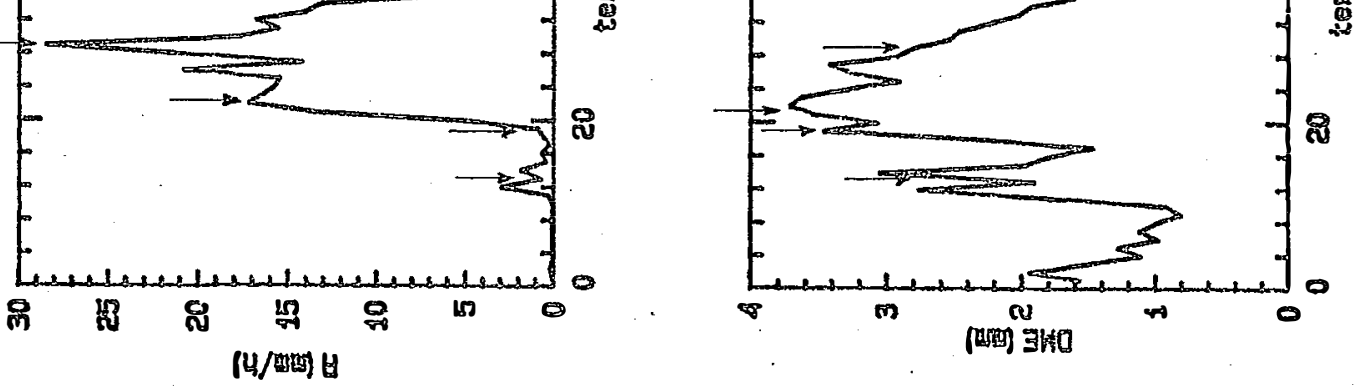

$\Rightarrow$ स्ना

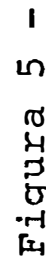



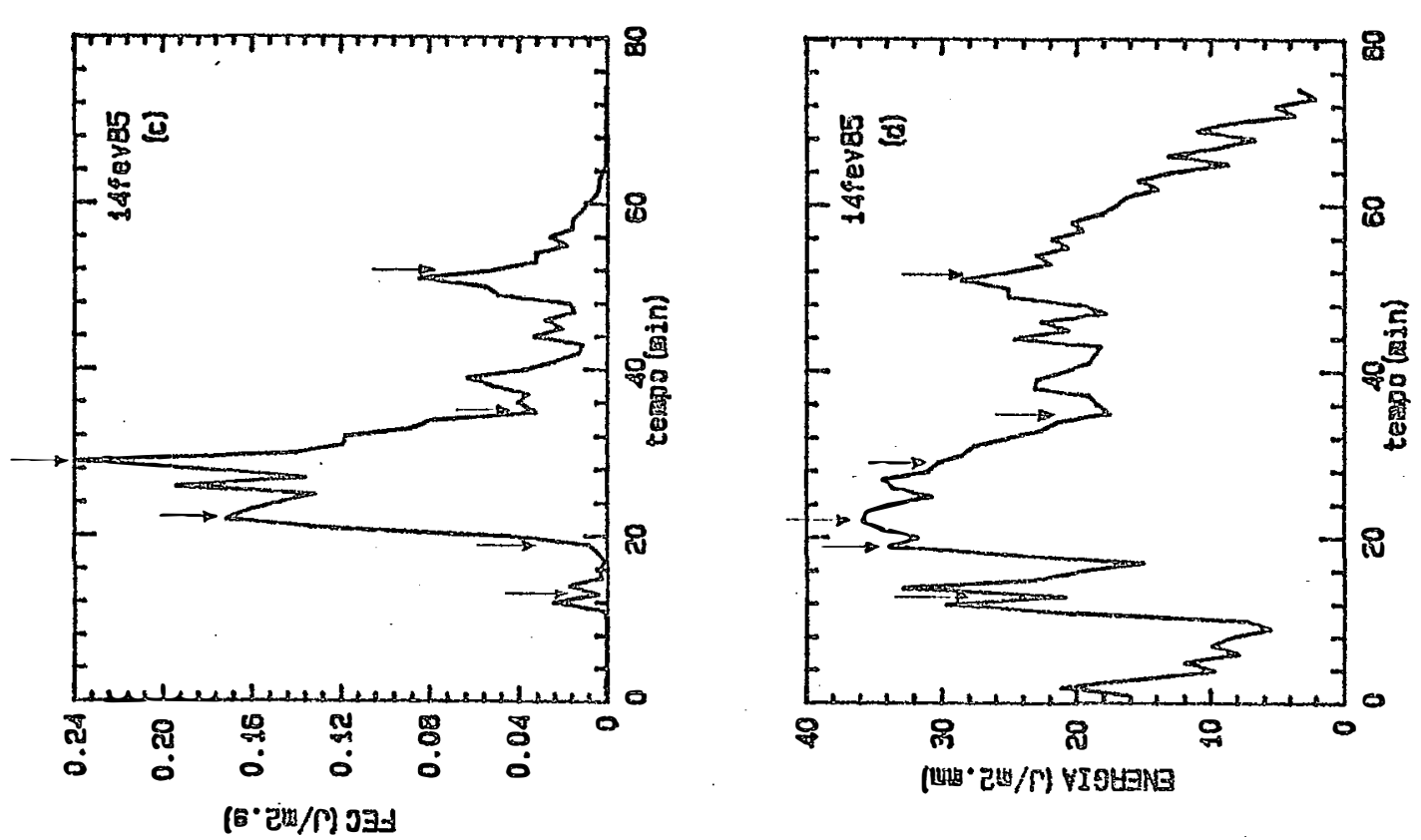

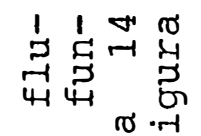

نह नु प्र

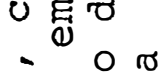

至 $-\frac{0}{\sigma}$

के

द.

ज沙 E

Оू.

先

ब

- Oٓ.

- म्न 0 잉

O Q ए)

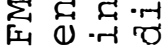

. 0 .

हृ ه

茎造

Uै

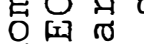

E $I_{I_{1}} \Omega_{1} \Omega_{2}$

(1) $\sigma$

ه

O.r O
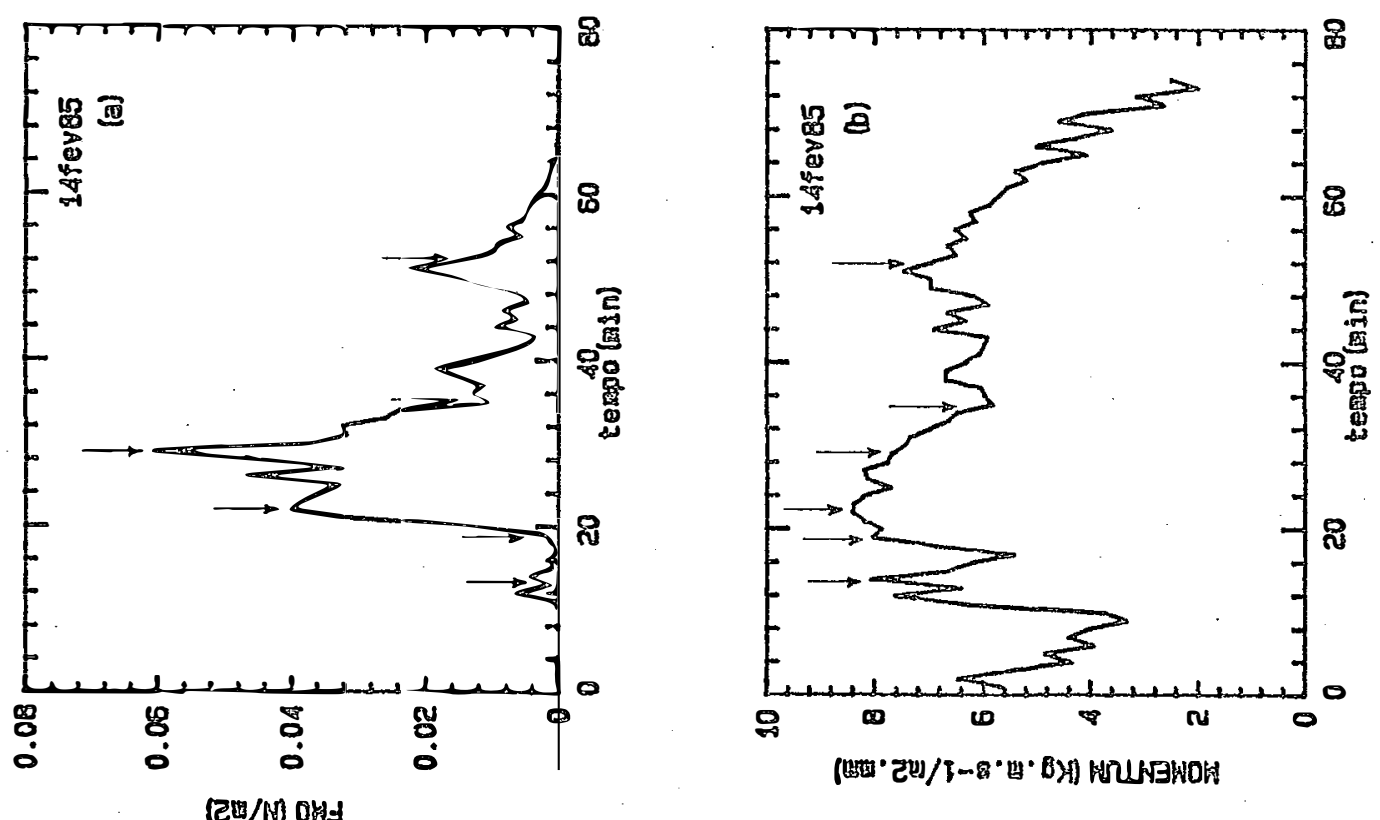

$x$ t

उ० +5 .

म्न 9 -

4.

- वे

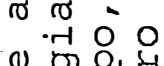

(1) का म्न

त्व

$0 \mathrm{C}+\mathrm{H}$

ता 010

$\begin{array}{llll}0 & 1 & 0 & 0 \\ 0 & 0 & 0 & 0\end{array}$

न व

崩

TER/N OHS 
As Figuras 1 a 6 estão resumidas na Tabela 5 em termos dos seus valores médios, desvio padrão, valores mínimos e máximos e mediana encontrados.

A frequência dos parâmetros, nos períodos de. 1 min. amostrados, é apresentada nas Figuras 7 e 8 , nas quais as três chuvas são comparadas entre si, e depois somadas, resultando na frequência relativa total. Os valores médios de cada classe de freqlência citada nas Figuras estão na Tabela 6.

Na Figura 7 observa-se que as taxas de preci pitação ocorrentes em aproximadamente $80 \%$ dos minutos amostrados, das chuvas dos dias 15 de janeiro de 1.985 e 14 de fevereiro de 1.985, se situam na faixa dos 0 a $12 \mathrm{~mm} . \mathrm{h}^{-1}$, havendo um decrés cimo acentuado na frequência de taxas maiores que $12 \mathrm{~mm} \cdot \mathrm{h}^{-1}$. Por outro lado, a chuva do dia 11 de fevereiro de 1.985 apresenta ca sos de ocorrência em todas as classes com taxas acima cee $24 \mathrm{~mm}_{\mathrm{i}} \mathrm{h}^{-1}$, com aproximadamente $25 \%$ dos casos na faixa de 36 a $48 \mathrm{~mm} \cdot \mathrm{h}^{-1}$, além de, por volta de $40 \%$ dos minutos amostrados, acusarem taxas no intervalo de 72 a $120 \mathrm{~mm} \cdot \mathrm{h}^{-1}$.

A frequência relativa total de todos os parâ metros estudados é definida em grande parte pela chuva do dia 15 de janeiro de 1.985, que contribui com $78 \%$ do tempo total amostrado, de forma que a distribuição da frequência total da taxa de precipitação é bastante semelhante a dessa chuva, com exceção de alguns casos nas classes maiores, que mostram a contribuição da chuva do dia 11 de fevereiro de 1.985 . 

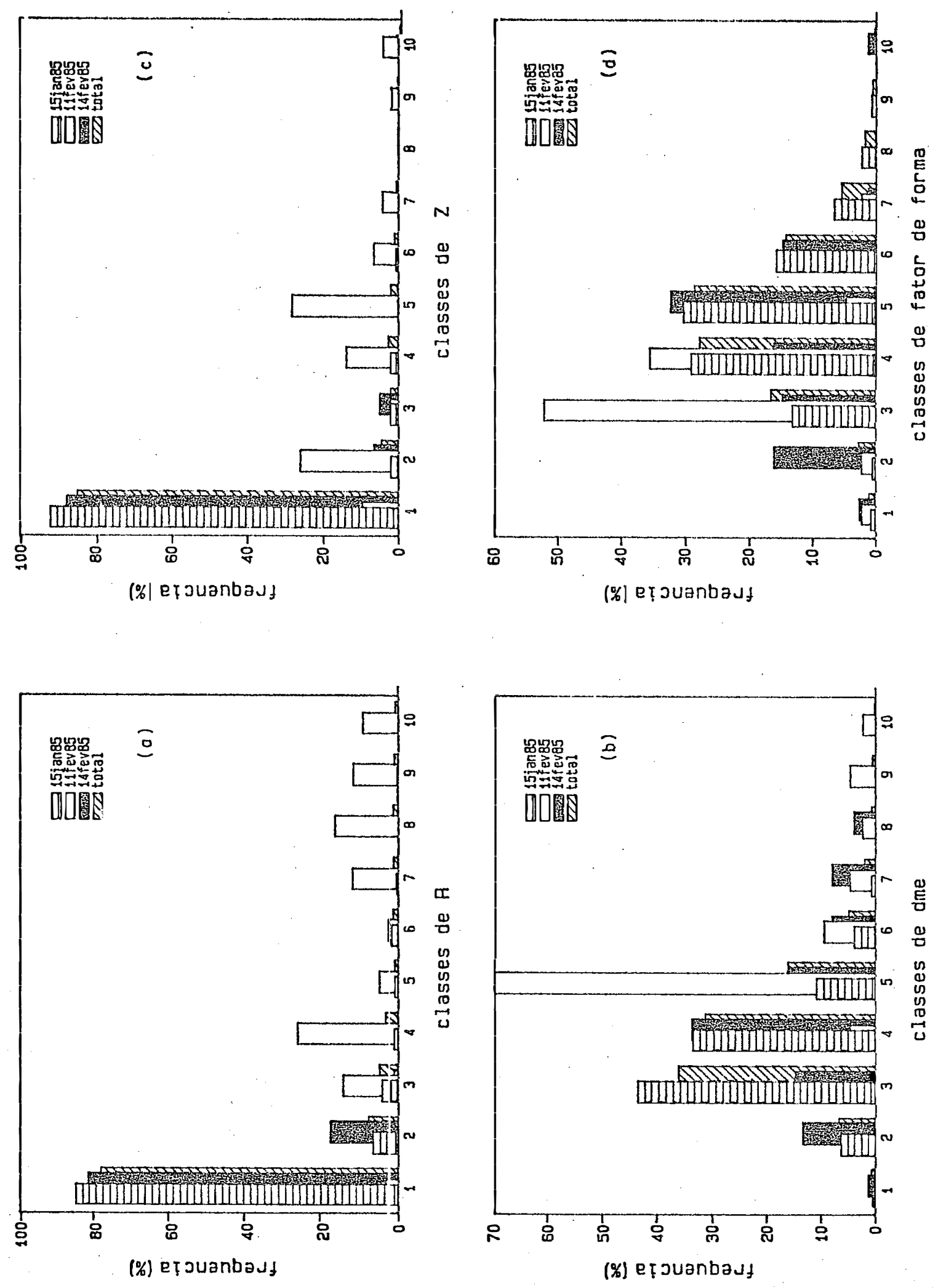

O n

\& 00

स द न

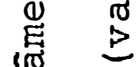

ir

ซण का थ

ह્વ

- O

Q $\psi \mathrm{H}$

- (1) U

$\overbrace{}^{\text {व }}$

$-4$

O

200 ro

थै

\%

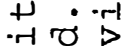

, न

न 010

U)

HN

(1) 4

ه

ठ

त्र थ.

$+0 \frac{0}{1}$

(0)

(0)

(1) $\widetilde{\sigma} 0$

"

$\sigma \stackrel{r}{>} \Omega$

-

$U+\nabla$

द (1)

(1) त मो 2

क $4+0$

Fi 0 ⿰冫

(1) म 0 N

H E

Hi 0

ه

‥-1 n

$0 \overparen{0}$ [

$200 \sum^{2}-1$

u合 0

ब 0 व

- $\mathrm{C}$ 己

म 00 ह $+\cdot$.

ज 元 豆 -

1

(\%) eт̧ ouanbadt

(\%) etrouanbadt 


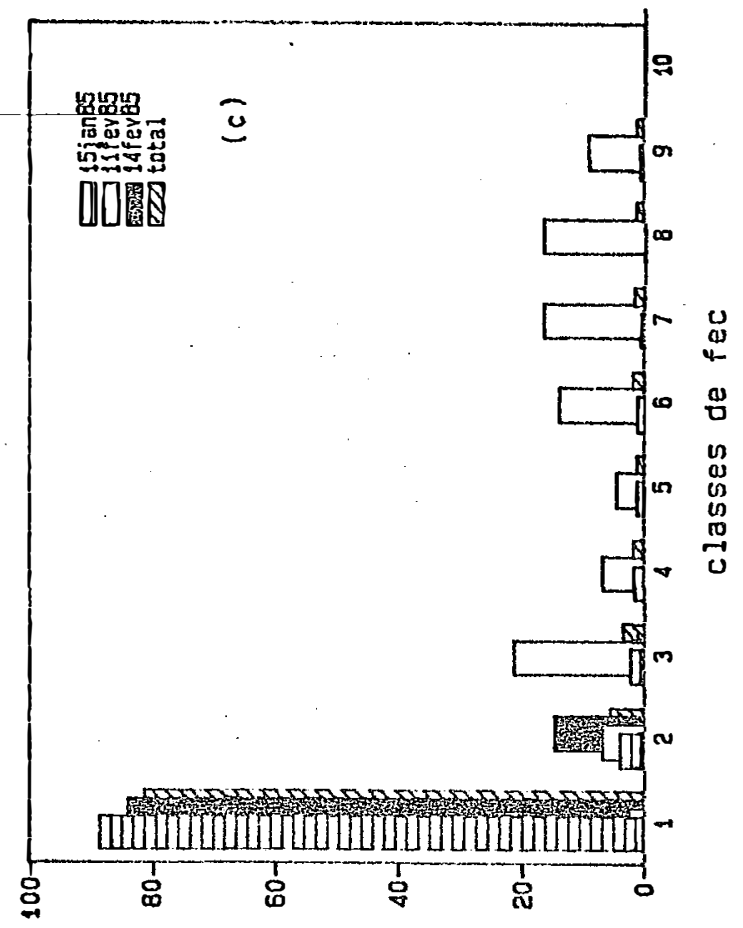

(\%) eт̧วuanbadł

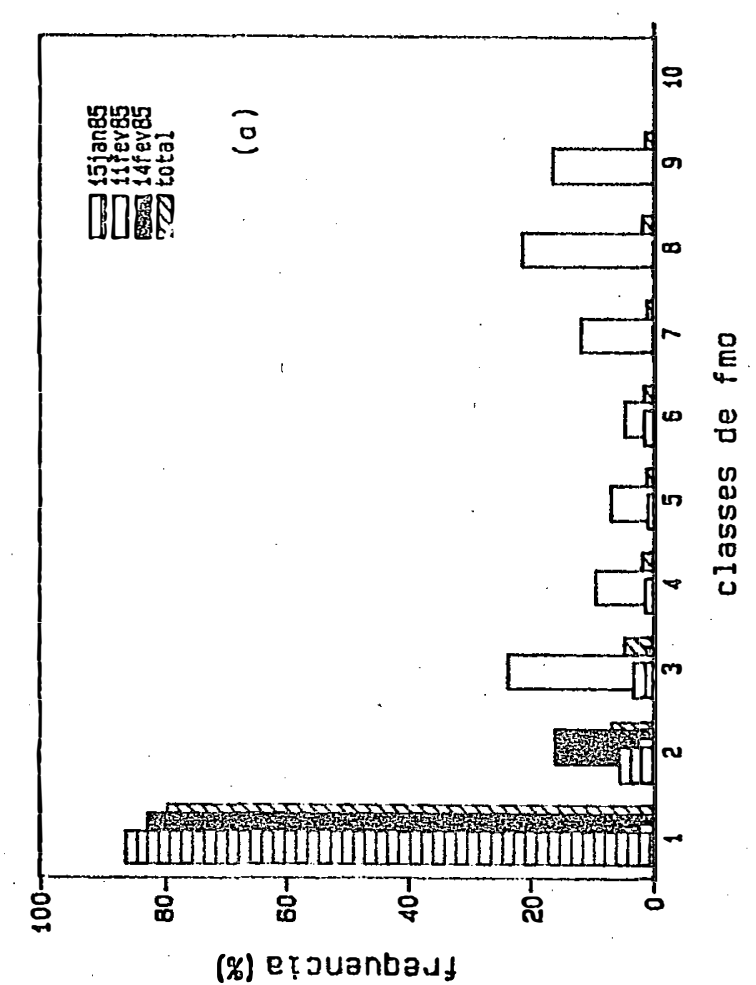

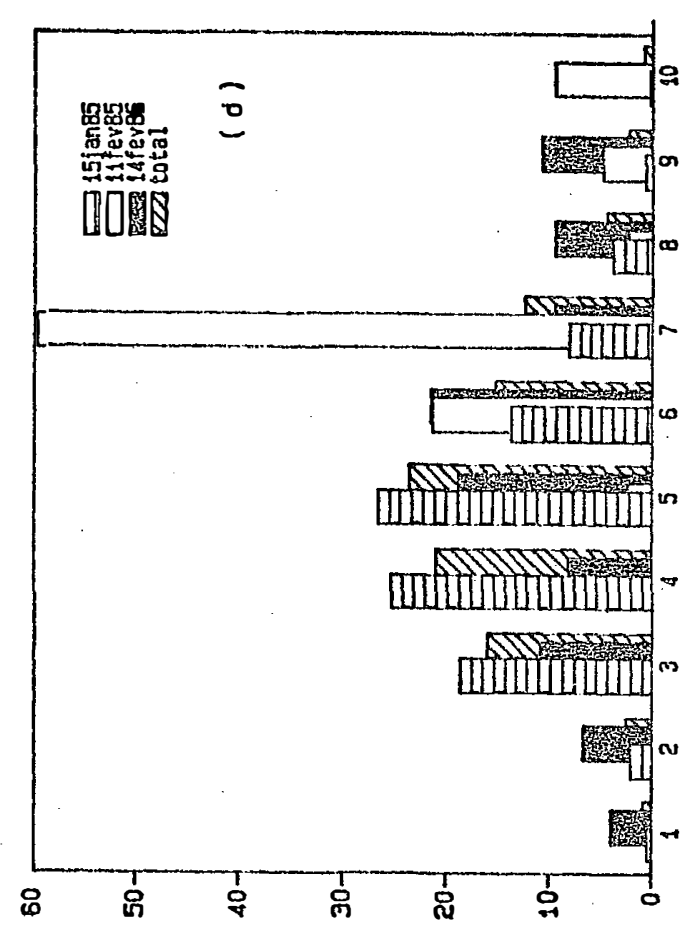

(\%) eт juanbaut

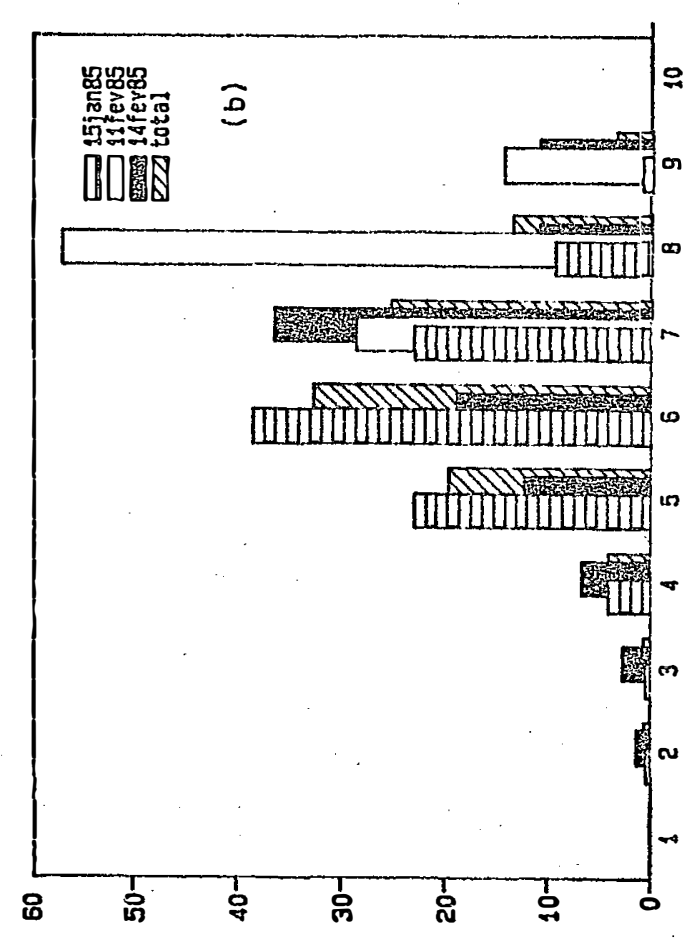

(\%) er juanbadt

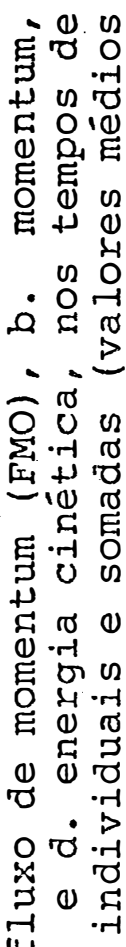

4 ऊิ

- 质

$\sigma \underline{x_{1}}$

ช

0

r.

- $1+10$

U⿺辶斤

(1)

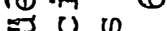

西告 0

(1)

म्न न 0

廿

(2) 4ै

ठ

(1) \&

0 सु

ति 0 os u

ur 0 व

- $E$ U

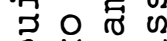

$\Omega \times \pi$

न

प्युज न्न

次. E U

में

$\infty$

先 


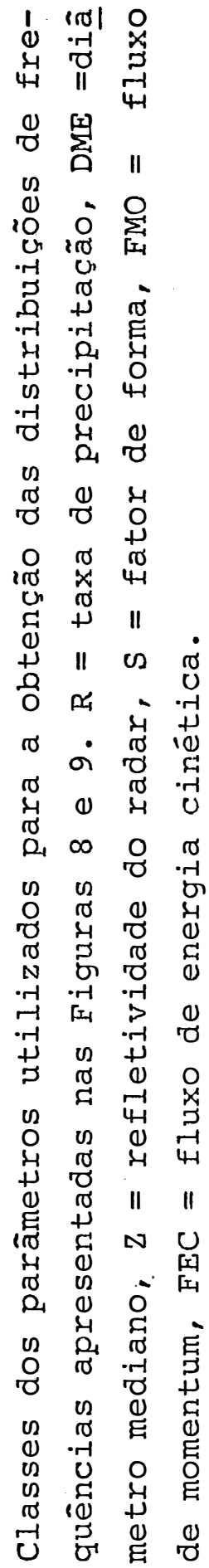

1
0
$\sigma$
0
0
0
0

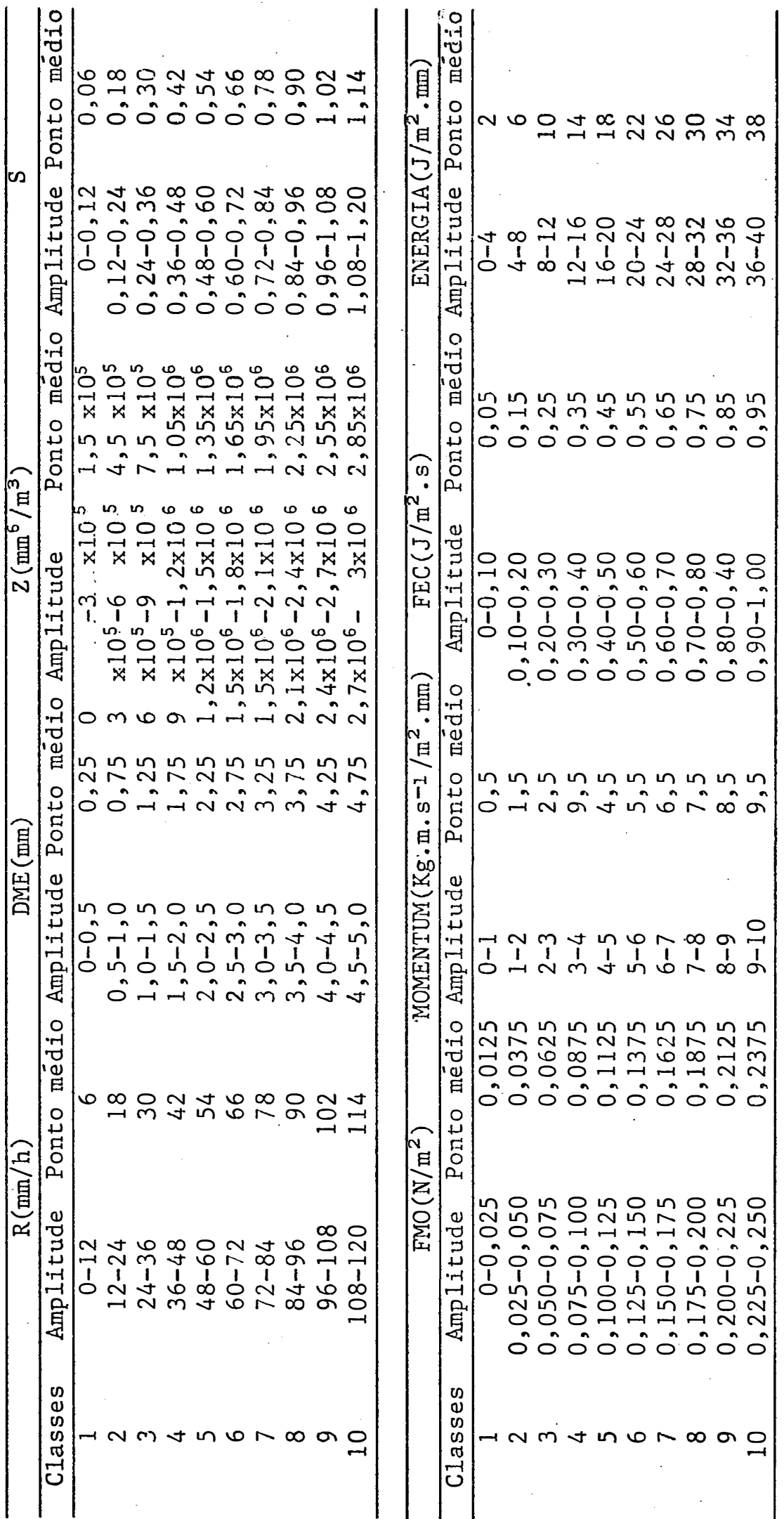


No caso da distribuição de frequência dos diâmetros medianos amostrados (Figura 7b), têm-se, novamente, que o pico máximo para a chuva do dia 11 de fevereiro de 1.985 ocorre em uma classe maior (2 a 2,5mm), quando comparado com as clas ses mais frequentes, 1 a $1,5 \mathrm{~mm}$ e 1,5 a $2 \mathrm{~mm}$, das chuvas dos dias 15 de janeiro de 1.985 e 14 de fevereiro de 1.985, respectivamen te. Além disto, os minutos com DME maior que $4 \mathrm{~mm}$, se restringem à chuva do dia 11 de fevereiro de 1.985 .

$\mathrm{Na}$ figura $7 \mathrm{C}$ são apresentadas as frequências relativas para a refletividade do radar, que têm forma semelhante a da Figura 7a. O maior número de casos estudados nas chuvas dos dias 15 de janeiro de 1.985 e 14 de fevereiro de 1.985 (93 e 85\%, respectivamente), se situa entre 1 e $30.000 \mathrm{~mm}^{6} \cdot \mathrm{m}^{-3}$ ou en tre 0 e $45 \mathrm{dBZ}\left(1 \mathrm{dBZ}=10 \log _{10} \mathrm{z}\right)$. Já para a chuva do dia 11 de fevereiro de 1.985, esta faixa se desloca para 120.000 a $150.000 \mathrm{~mm}^{6} \cdot \mathrm{m}^{-3} \quad(51 \mathrm{a} 52 \mathrm{dBZ})$ e 30.000 a $60.000 \mathrm{~mm}^{6} \cdot \mathrm{m}^{-3} \quad(45 \mathrm{a}$ $48 \mathrm{dBZ})$, em 30 e $28 \%$ dos casos, respectivamente. Novamente, a fre quância relativa total sofre grande influência da chuva do dia 15 de janeiro de 1.985.

Os fatores de forma mais frequentes (Figura 7d), assumem valores entre 0,36 e 0,60 , em $60 \%$ dos minutos, para a chuva do dia 15 de janeiro de 1.985, em 45\% dos minutos para a chuva do dia 14 de fevereiro de 1.985, e valores entre 0,24 e 0,36 em 50\% dos casos para a chuva do dia 11 de fevereiro de 1.985. Estas frequências são refletidas nas médias do fator de forma para as três chuvas (Tabela 5). 
A distribuição de frequência dos fluxos de energia cinética e de momentum, para as três chuvas individuais e para o total de tempo amostrado (Figura 8a e 8c), é semelhante à distribuição da taxa de precipitação (Figura 7a). Porém, a dis tribuição do momentum e da energia (Figuras $8 \mathrm{~b}$ e $8 \mathrm{~d}$ ) segue a for ma da distribuição do diâmetro mediano (Figura 7b), com picos má ximos de frequência total localizados nas classes maiores, 16 a $20 \mathrm{~J} \cdot \mathrm{m}^{-2} \cdot \mathrm{mm}^{-1}$ e 7 a $8 \mathrm{Kg} \cdot \mathrm{m} \cdot \mathrm{s}^{-1} \cdot \mathrm{m}^{-2} \cdot \mathrm{mm}^{-1}$, respectivamente.

O fato de alguns parâmetros apresentarem dis tribuição de frequência e variação em função do tempo semelhan tes, está diretamente ligado à dependência dos mesmos em relação ao número, diâmetro e velocidade das gotas, observados em cada classe. A taxa de precipitação, a refletividade do radar, os flu xos de energia e de momentum, são proporcionais ao produto Da.vb, onde a assume valores $3,6,3$ e 3 , e b valores $1,0,3$ e 2, respectivamente, para os parâmetros citados. Por outro lado, o diâmetro mediano, a energia e o momentum, são proporcionais a uma divisão onde tanto numerador como denominador são proporcionais ao produto Da . vb (Equação (33), (34) e (20), respectivamente), o que explica seu comportamento diferenciado em relação aos demais parâmetros. 


\subsection{Espectros caracteristicos e fator de forma}

Alguns espectros observados nas amostras de lmin., durante as três chuvas estudadas, são apresentados nas Fi guras 9,10 e 11, juntamente com o espectro exponencial (n(D) = $8.000 \exp (-\Lambda \mathrm{D})$, para o qual calculou-se $\quad \Lambda=4,1 . \mathrm{R}^{-0,21 \mathrm{~m}^{-1}, \quad \text { a }}$ partir da taxa de precipitação observada.

Os expectros medidos nos minutos 14,15 e 42 min. da chuva do dia 15 de janeiro de 1.985 (Figura 9), têm fator de forma de $0,33,0,36$ e 0,35 , respectivamente, evidenciando o seu baixo grau de exponencialidade. Nota-se, também, que para as taxas de 3,6 e $23,9 \mathrm{~mm}_{\mathrm{h}} \mathrm{h}^{-1}(14$ e $15 \mathrm{~min}$.$) , o número de gotas$ maiores que aproximadamente $3 \mathrm{~mm}$ é mais alto que o estimado pelo espectro exponenciãl, ocorrendo o inverso para a taxa de $117,6 \mathrm{~mm} \cdot \mathrm{h}^{-1}$ (4.2 $\mathrm{min})$. Alēm disto, nos três casos o número de gotas pequenas é sempre superestimado pelo espectro de MARSHALL e PALMER (1948) (MP)。

Para os tempos de 49, 75 e $294 \mathrm{~min}$. (Figura

9) os fatores de forma correspondentes são maiores, isto é, 0,74, 0,52 e 0,83, respectivamente, ocorrendo ainda, variações em torno do espectro exponencial.

Na Figura 10, estão alguns espectros caracte rísticos da chuva do dia 11 de fevereiro de 1.985, que apresenta o menor fator de forma médio (Tabela 5). Assim, o espectro do tempo 2 min., por exemplo, tem fator de forma 0,1 , praticamente 
.61.
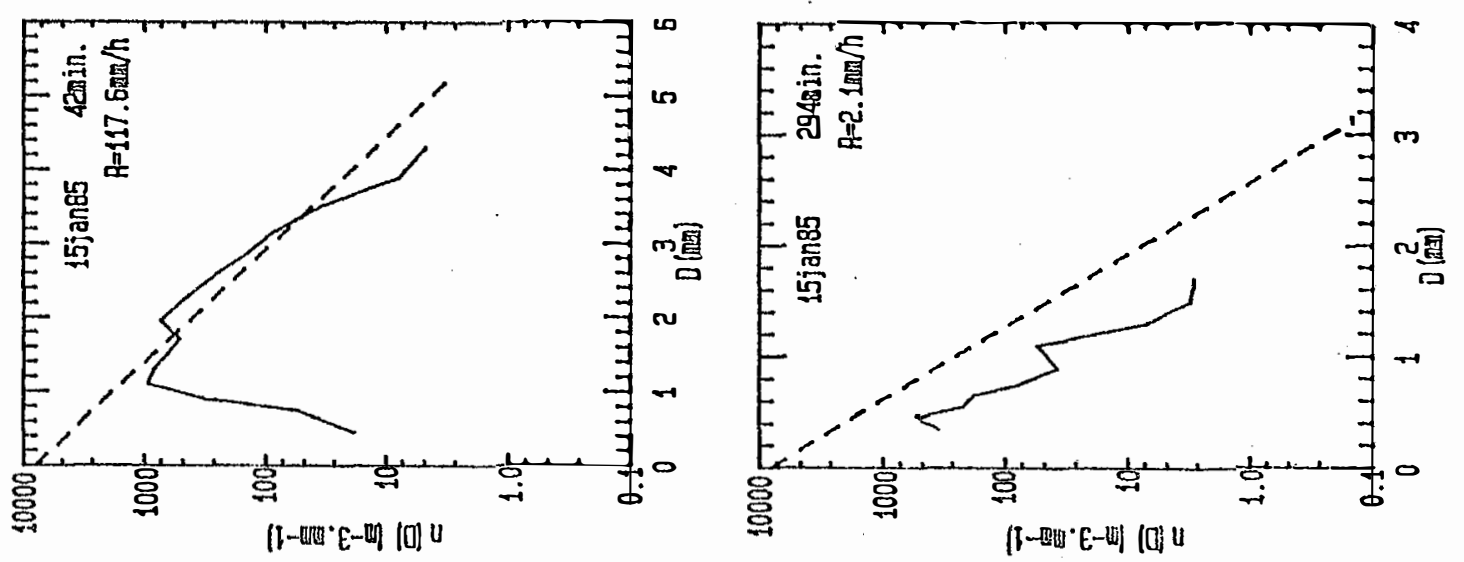

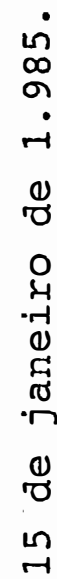
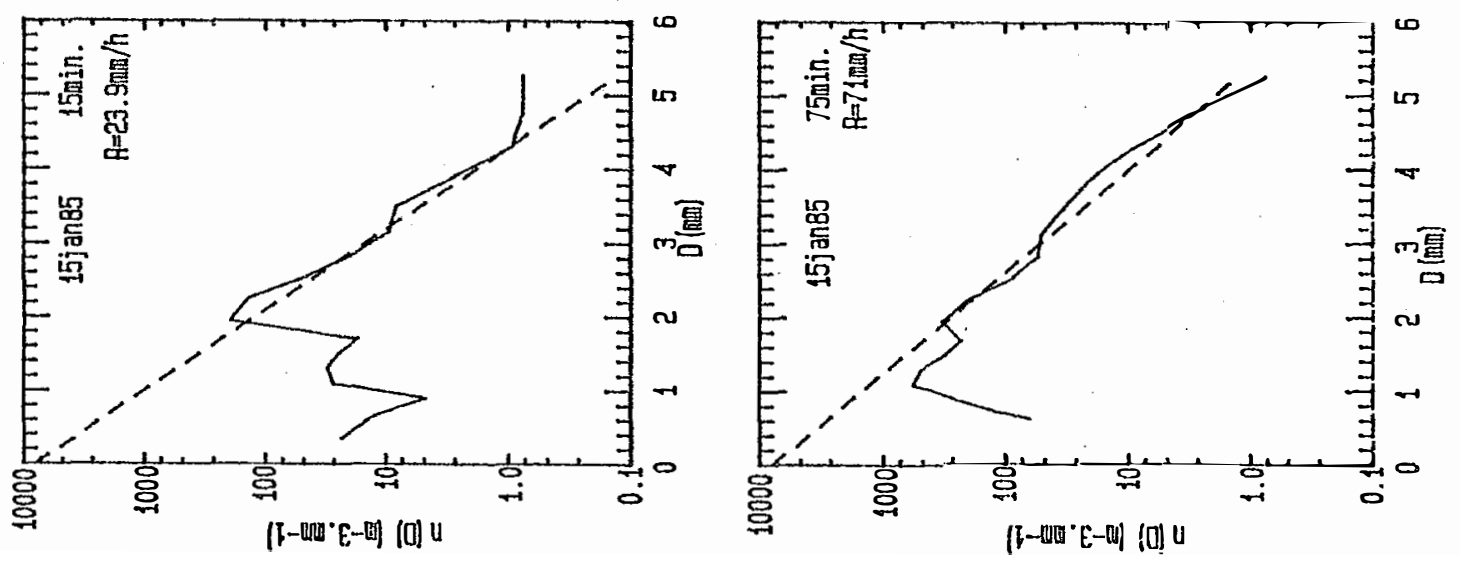

r

잉

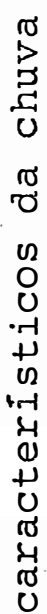
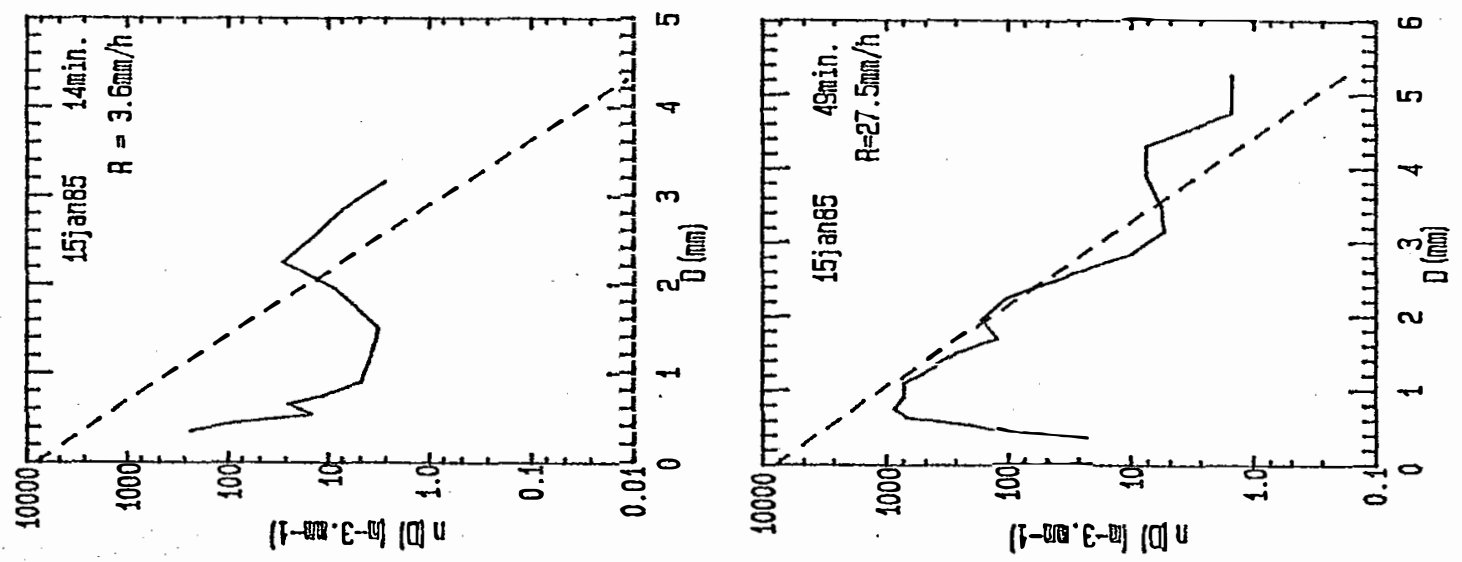

0
0
0
4
4
0
0
0
0
0
01
1
0
0
0
0
4
5
0
-1
4 

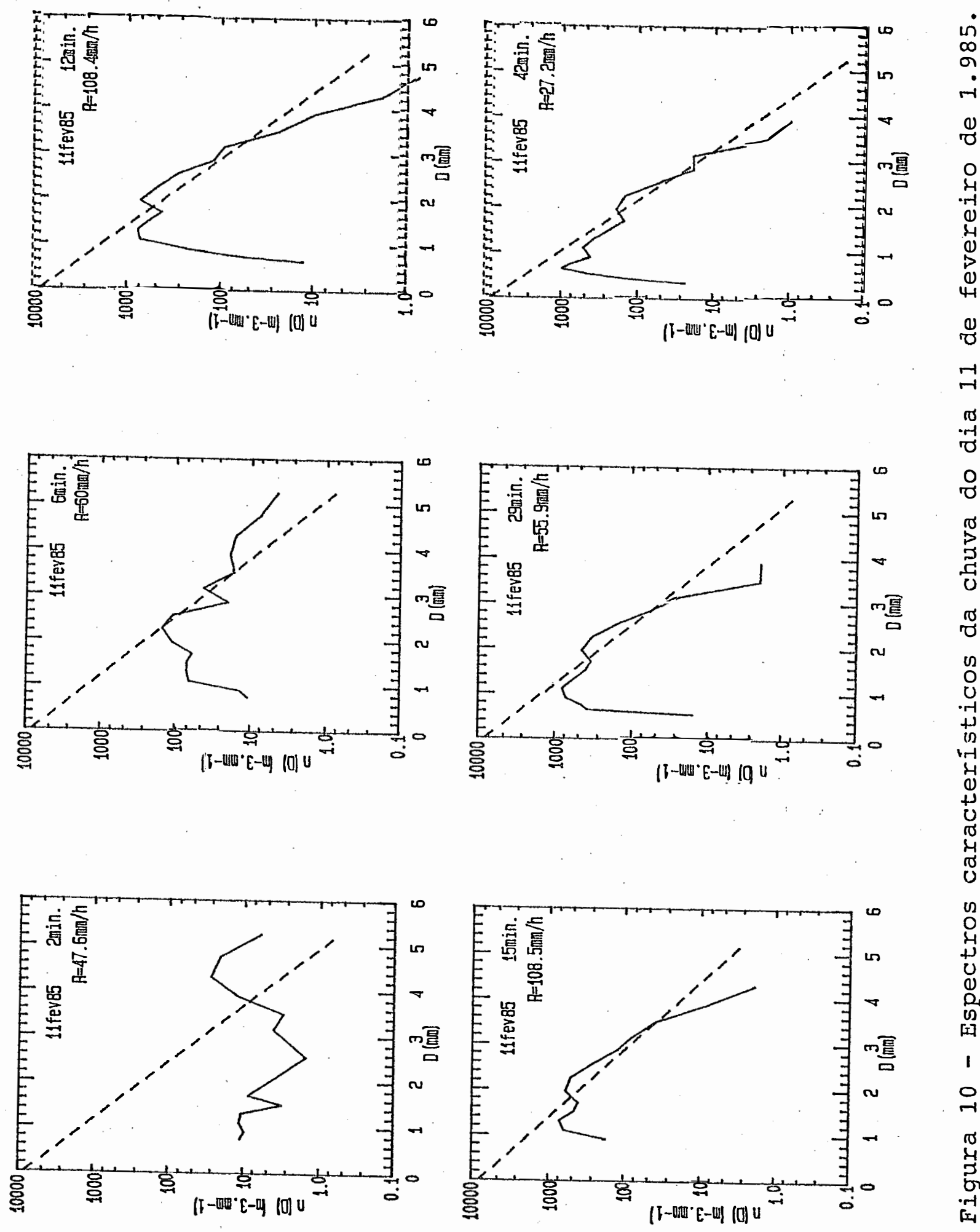

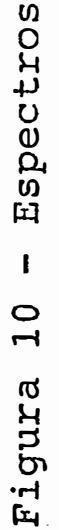



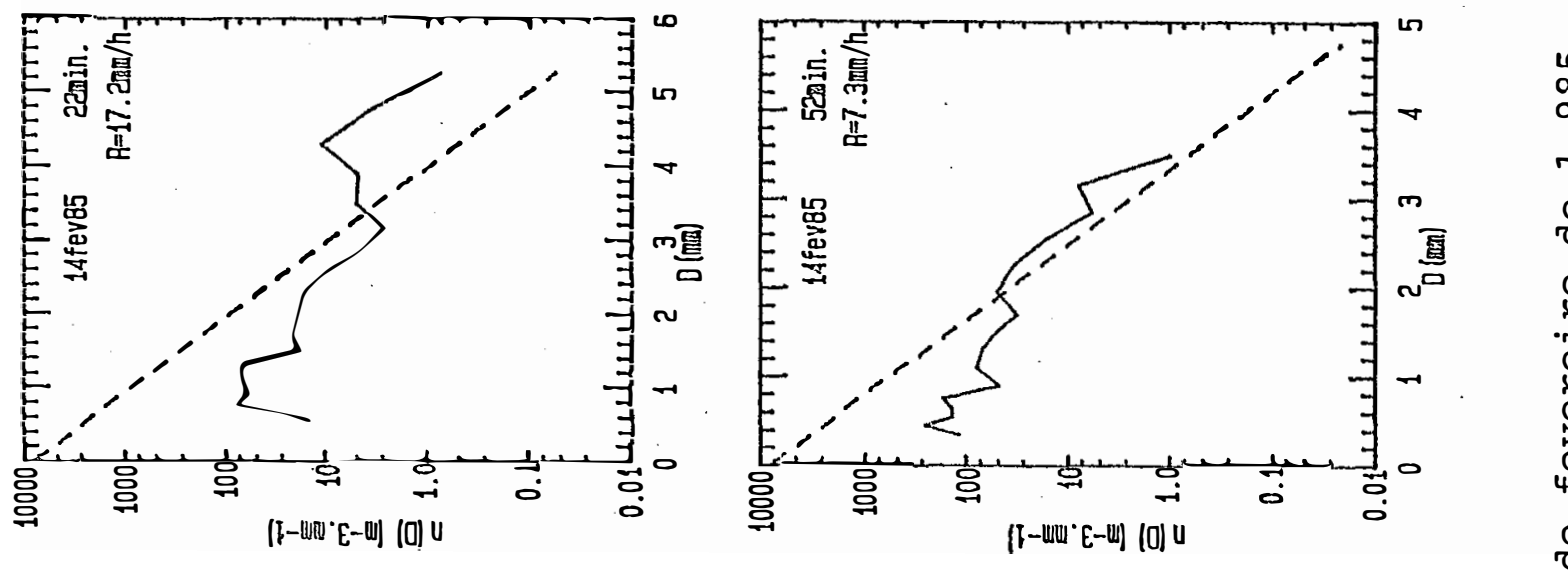

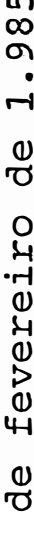
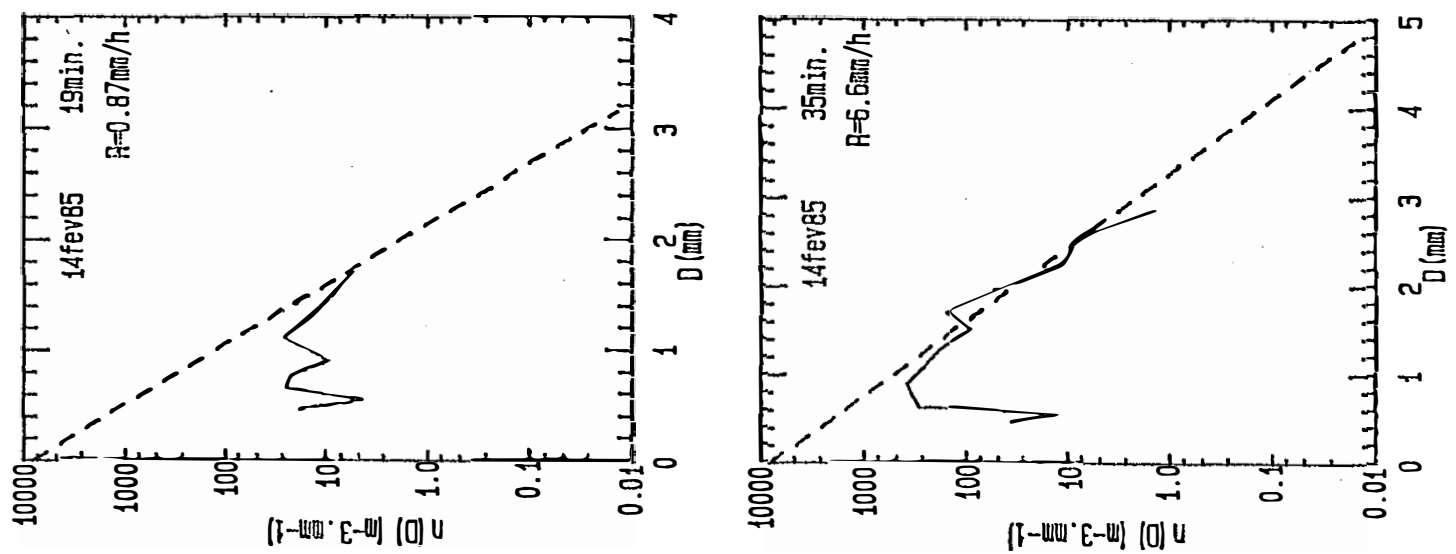

.

음

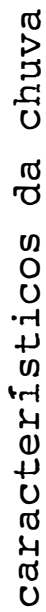
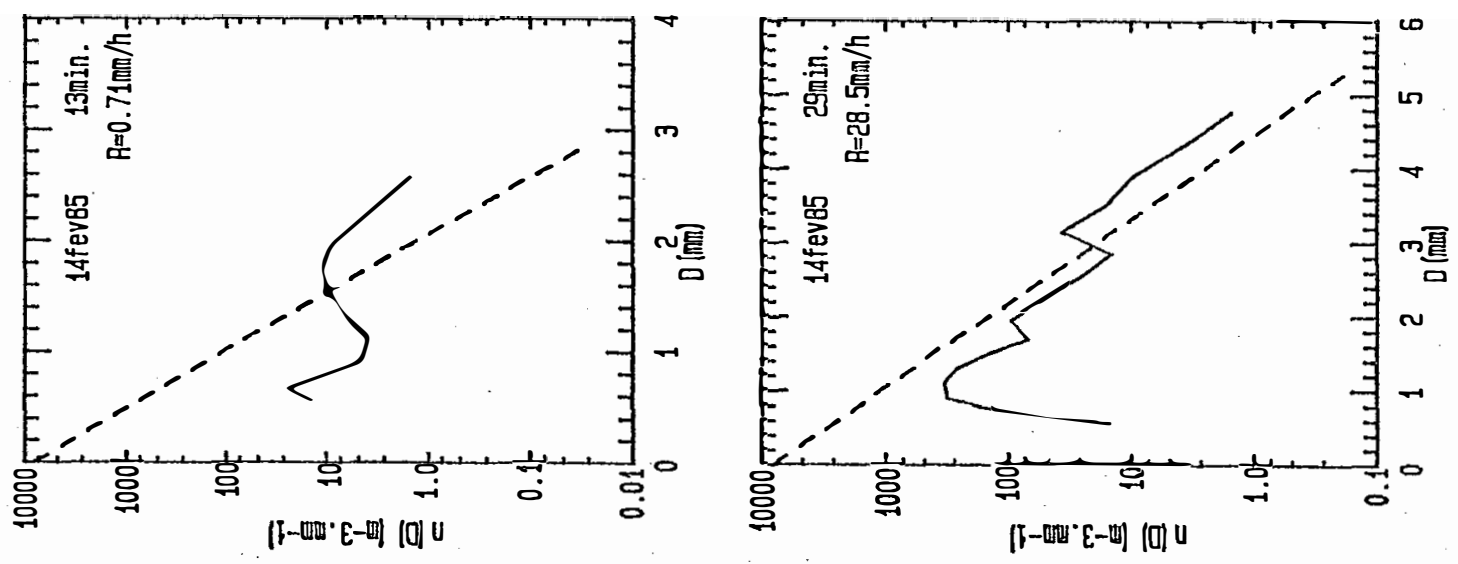

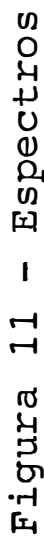


o valor assumido por espectros monodispersos. Por outro lado, os espectros de taxas próximas a $100 \mathrm{~mm} \cdot \mathrm{h}^{-1}$, novamente têm número de gotas grandes muito menores que as previstas pelo espectro de MP.

No caso da chuva do dia 14 de fevereiro de 1.985 (Figura 11), têm-se que em praticamente todos os espectros o número de gotas maiores que 2 a $3 \mathrm{~mm}$ excede o valor estimado pe la equação exponencial inversa. O fator de forma dos espectros é mínimo aos $13 \mathrm{~min}$, , e máximo aos $19 \mathrm{~min}$, , isto é, 0,26 e 1,11, respectivamente.

Observa-se que em todos os exemplos citados, apesar de não existir uma forma definida, que possa ser descrita adequadamente através de uma equação matemática, há uma tendên cia à forma de função gama. Essa função foi ajustada por ULBRICH e ATLAS (1984) à DTG, descrevendo a forma côncava ou convexa que o espectro muitas vezes assume. DINGLE e HARDY (1962) explicam a forma convexa, mais frequente em chuvas convectivas, pelo efeito combinado de quebra de gotas grandes, induzida por turbulência,e de evaporação de gotas pequenas, provocando o pico máximo característico na faixa de gotas médias. Entretanto, pode-se compro var o que o fator de forma traduz numericamente: o espectro expo nencial inverso não é adequado para descrever os espectros medidos.

Quando se aumenta o tempo de integração do espectro, o fator de forma tende a aumentar também (Figura 12), 


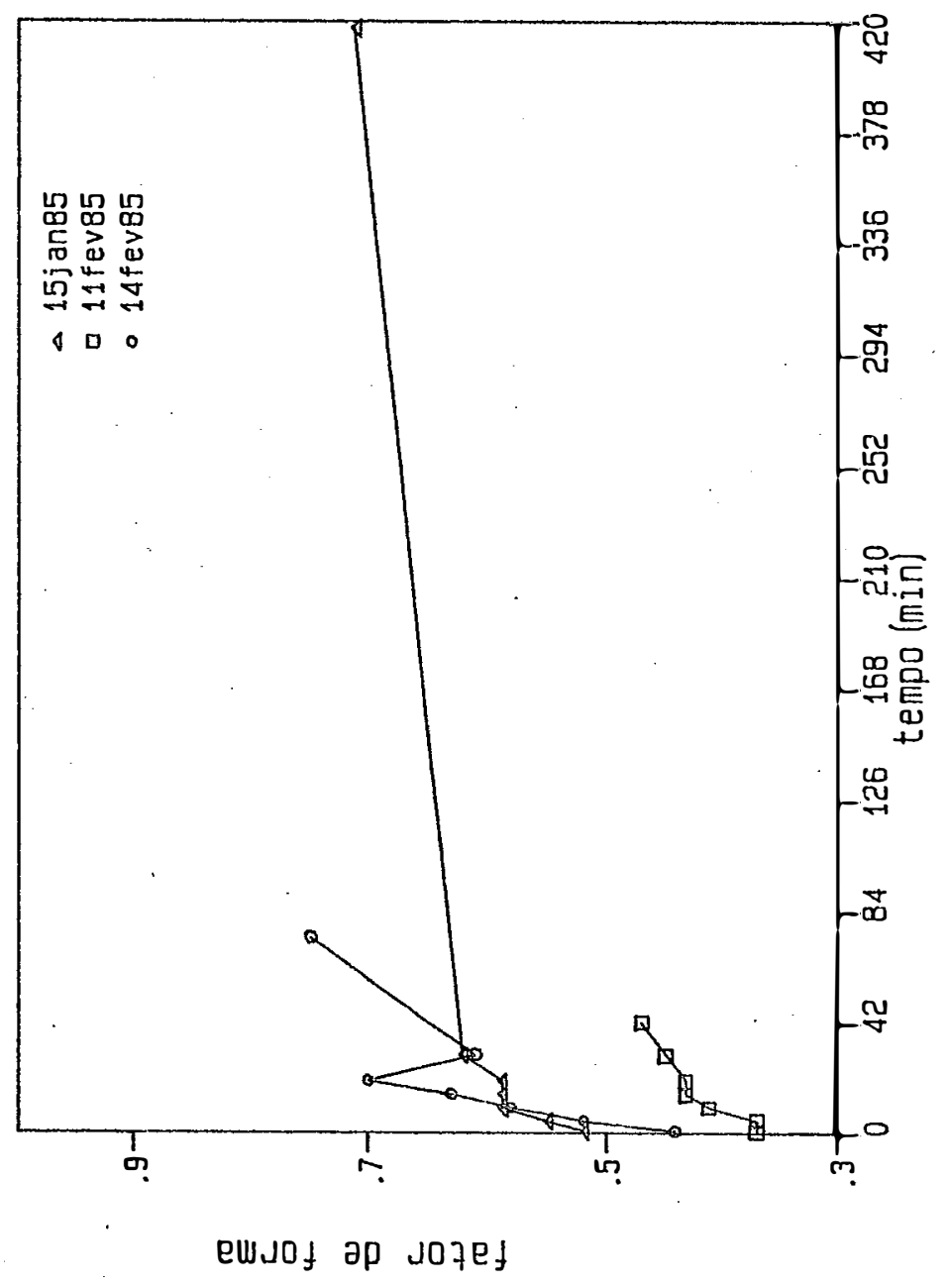

1
0
0
0
0
$y$
0

0

10

$\pi$

का

U)

.

ه

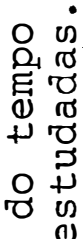

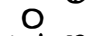

in

:

出

ह

(10

茞

0 o

(1)

व 4

मे

-

44

0 U

ठ

० थ

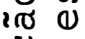

U

-1

मै

$\stackrel{0}{\circ}$

1

$\stackrel{-}{-1}$

先 
conforme constatado por JOSS e GORI (1978), embora a chuva mais longa (15 de janeiro de 1.985), não atinja o valor de 0,9, definido para o espectro exponencial, mesmo após $417 \mathrm{~min}$. Este valor $(0,9)$ foi alcançado por Joss e GORI (1978) após $500 \mathrm{~min}$. de inte gração e considerando muitos eventos.

Uma outra comparação da forma dos espectros observados foi feita conforme a estratificação proposta por LAWS e PARSONS (1943). A distribuição espectral média calculada segun do LP é apresentada na Figura 13, em comparação com os dados obtidos pelos mesmos. O número de minutos ou espectros utilizados para a obtenção da distribuição média foi de $141,13,48$ e 18 rpa ra as Figuras 13a, 13b, 13c e 13d, respectivamente. Observa - se que a distribuição medida, a partir dos espectros observados em Bauru - SP, possue maior irregularidade, apresentando até mais de um pico na distribuição. Cabe lembrar, entretanto, que a forma de distribuição de LP foi obtida através do traçado de uma curva, alisada manualmente, sobre os pontos experimentais.

Para as taxas de precipitação de até $50 \mathrm{~mm} \cdot \mathrm{h}^{-1}$ a porcentagem de contribuição das gotas maiores que aproxima damente 1,8mm é sempre maior nos dados observados em Bauru - SP, do que nos dados obtidos por LP. A porcentagem de contribuição das gotas menores que $1,8 \mathrm{~mm}$ é sempre menor nas distribuições observadas em Bauru - SP. Isto indica um maior número de gotas médias e grandes, e menor de gotas pequenas, nas chuvas convecti vas estudadas em comparação com as obtidas de LP, para taxas de precipitação menores que $50 \mathrm{~mm}^{-h^{-}}$. 


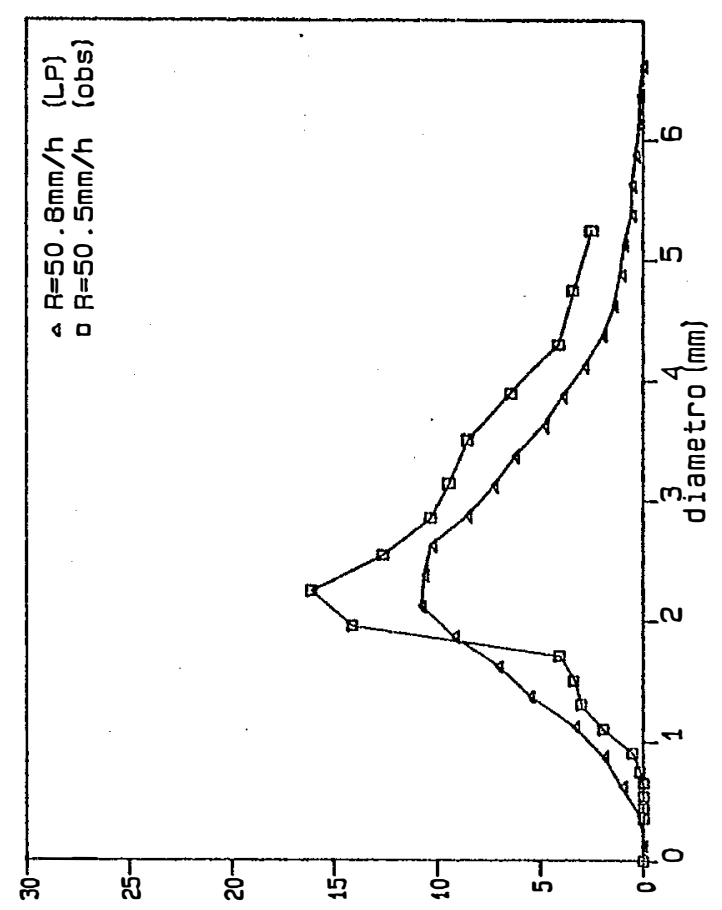

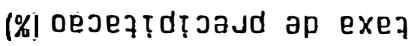

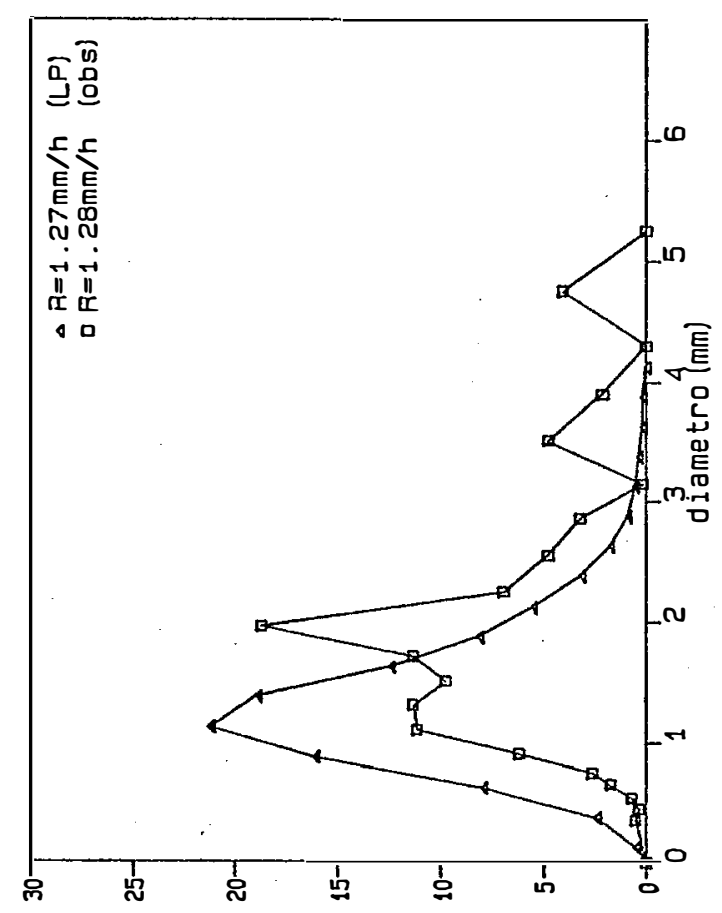

(\%) оеэеzโdтฺวлd ар ехеz

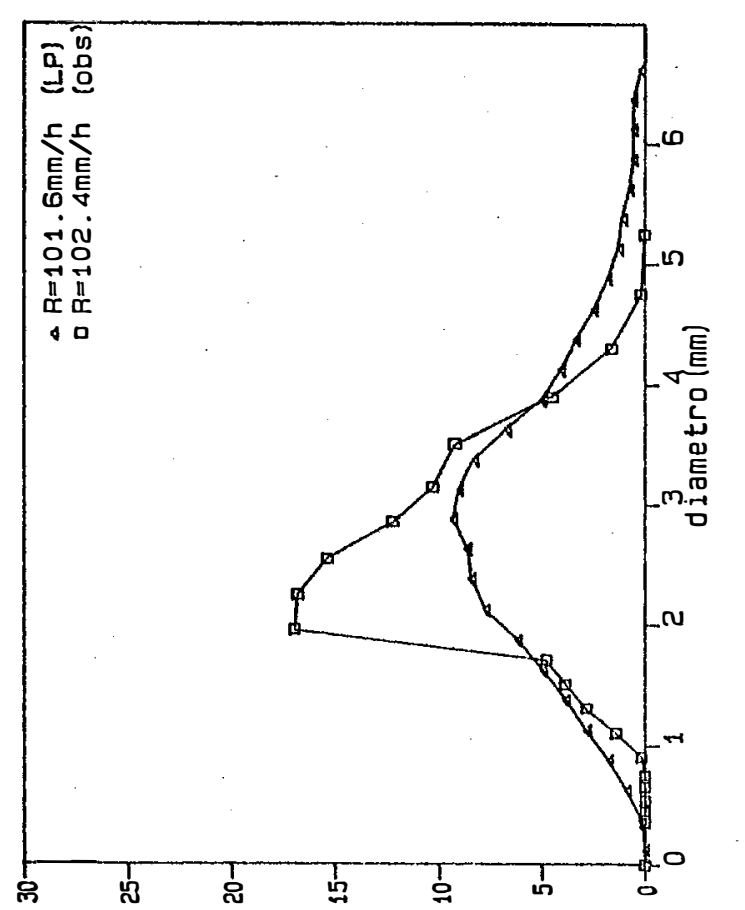

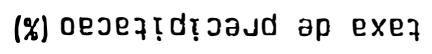

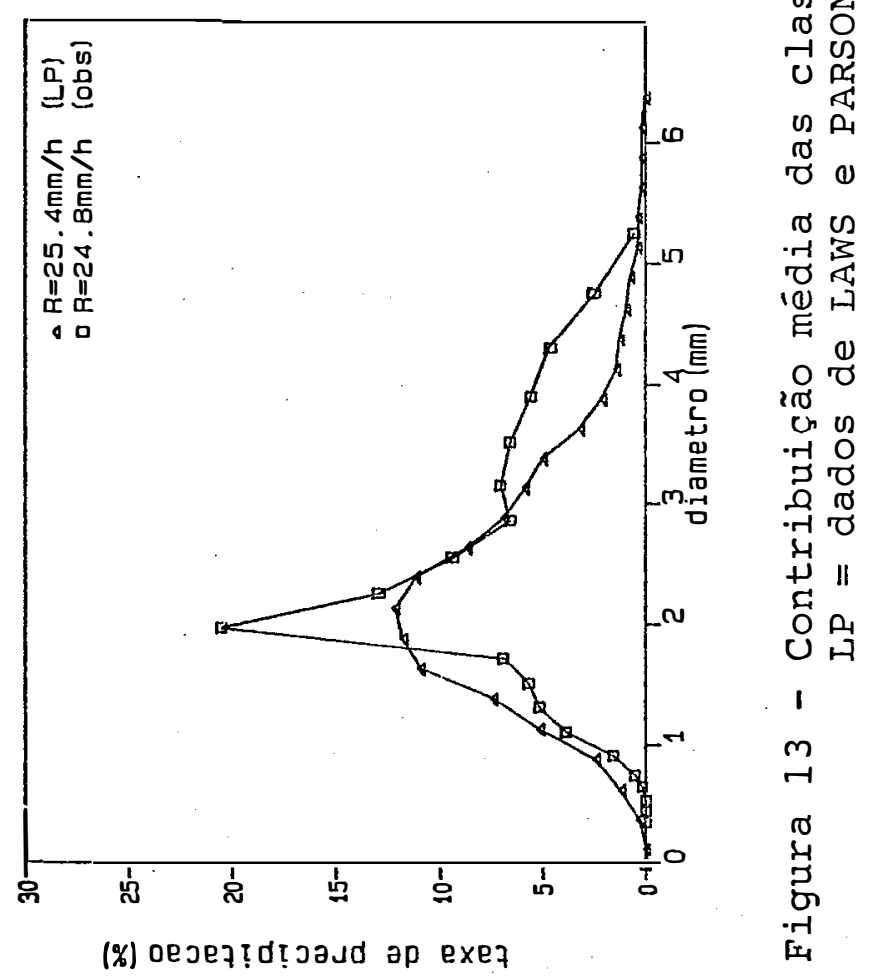


Porém, para a distribuição espectral da taxa de precipitação próxima a $100 \mathrm{~mm} \cdot \mathrm{h}^{-1}$, os resultados são um pouco diferentes, ocorrendo superestimativa do número de gotas gran des e subestimativa do número de gotas médias, pela distribuição de LP.

A natureza da distribuição espectral apresen tada por LP, indica que o aumento da taxa de precipitação é resultante do deslocamento do pico máximo de contribuição percentual para maiores diâmetros. Entretanto, observou-se que o diâme tro com máxima contribuição para a taxa de precipitação se localiza sempre ao redor dos $2 \mathrm{~mm}$, e o acréscimo da taxa de precipitação não é ocasionado pelo deslocamento do pico para diâmetros maiores, fenômeno descrito por LP, mas sim, pelo aumento do número de gotas médias e pela presença de gotas grandes.

Isto parece indicar uma significativa diferença entre os sistemas precipitantes estudados em outras latitu des (LAWS e PARSONS, 1943; MARSHALL e PALMER, 1948) e os siste mas convectivos observados na região tropical de são Paulo. 


\subsection{Relações Analiticas}

As relações anteriormente derivadas (Capítulo 3 item 3.3.9), assumindo o espectro exponencial inverso, podem ser substituídas quanto às suas constantes (Equações (41), (42) , $(45),(46),(47),(48),(51),(52),(53),(54),(55))$, resultando no que se convencionou chamar, neste trabalho, de relações analiticas entre os parâmetros.

Essas relações foram calculadas assumindo - se valores para as constantes citados na literatura, e são apresenta das na Tabela 7, onde se observa a variação entre os coeficientes calculados, conforme o valor das constantes. Estas relações serão apresentadas juntamente com àquelas deduzidas a partir dos dados observados.

\subsection{Relações Experimentais}

Os parâmetros das relações experimentais, obtị dos através da análise de regressão são apresentados nas Tabelas $(8$ a 18$)$.

A análise de variância (teste t) das regressões obtidas indicou um alto grau de significância $(P=0,005)$ de todos os coeficientes das regressões obtidas, bem como dos seus coeficientes de correlação e de determinação. 
Tabela 7 - Relações deduzidas do espectro exponencial de MARSHALL e PALMER (1948) (n(D) $=8.000$ exp $(-\Lambda D))$, após substituição das constantes No, $a$ e $b$, nas equações citadas. $\mathrm{R}=$ taxa de precipitação, $\mathrm{FEC}=$ fluxo de energia cinética, $F M O=$ fluxo de momentum, $e=$ energia cinética, $\mathrm{m}$ = momentum, $\mathrm{Z}=$ refletividade do radar (unidades: vide texto) .

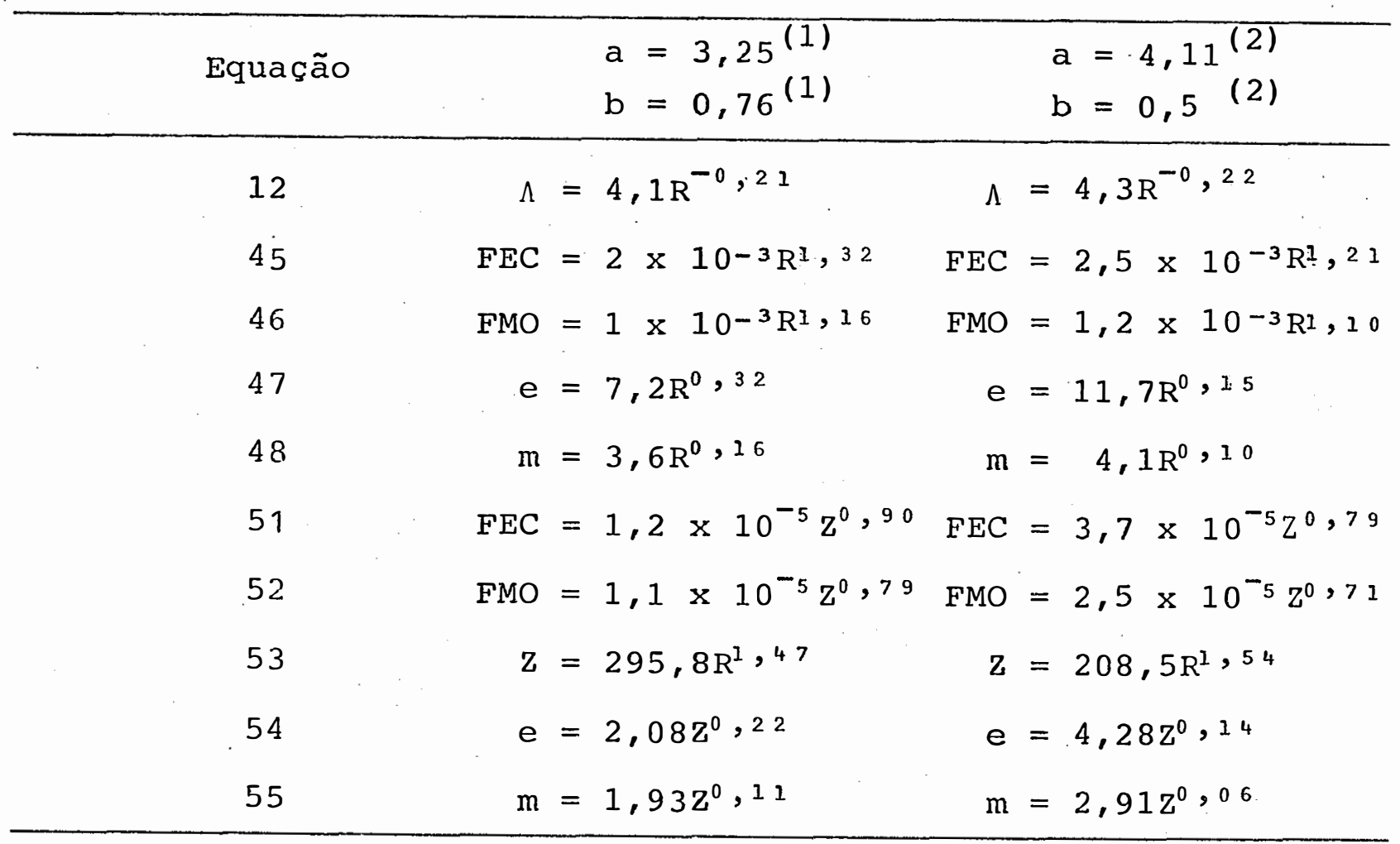

(1) WALDVOGEL

(1975)

(2) WILLIS

(1984) 
De uma maneira geral, nota-se que não existe qualquer tendência de aumento ou decréscimo no coeficiente de correlação e de determinação, conforme o tempo de integração do espectro aumenta de 1 para $30 \mathrm{~min}$., e o número de amostras é redu zido de 533 para 16. Da mesma forma, não se observa tendência definida nos parâmetros das regressões, embora a variação destes com o aumento do tempo de integração seja acentuada em alguns casos. Esta variação também ocorre quando se analisa as chuvas sepa radamente, ocorrendo casos de coeficientes de determinação altamente significativos para uma chuva, e ausência de correlação para outra (Tabela 8 a 10 ).

Para cada diagrama de.espalhamento entre os pa râmetros analisados ajustou-se modelos de regressão entre os mesmos e esses são comparados com os comumente existentes na literatura. Comparativamente, a representação gráfica dos modelos é apresentada nas Figuras 14 a 26.

a. Relação entre diâmetro mediano e taxa de precipitação

A relação entre o diâmetro mediano (DME) e a taxa de precipitação (R) (Figura 14 e Tabela 8) apresenta um al to grau de espalhamento dos dados em torno do modelo ajustado, principalmente para taxas menores que $50 \mathrm{~mm} . \mathrm{h}-1$, que se traduz em um baixo coeficiente de determinação ( $r^{2}$ máximo 0,632 para 533 


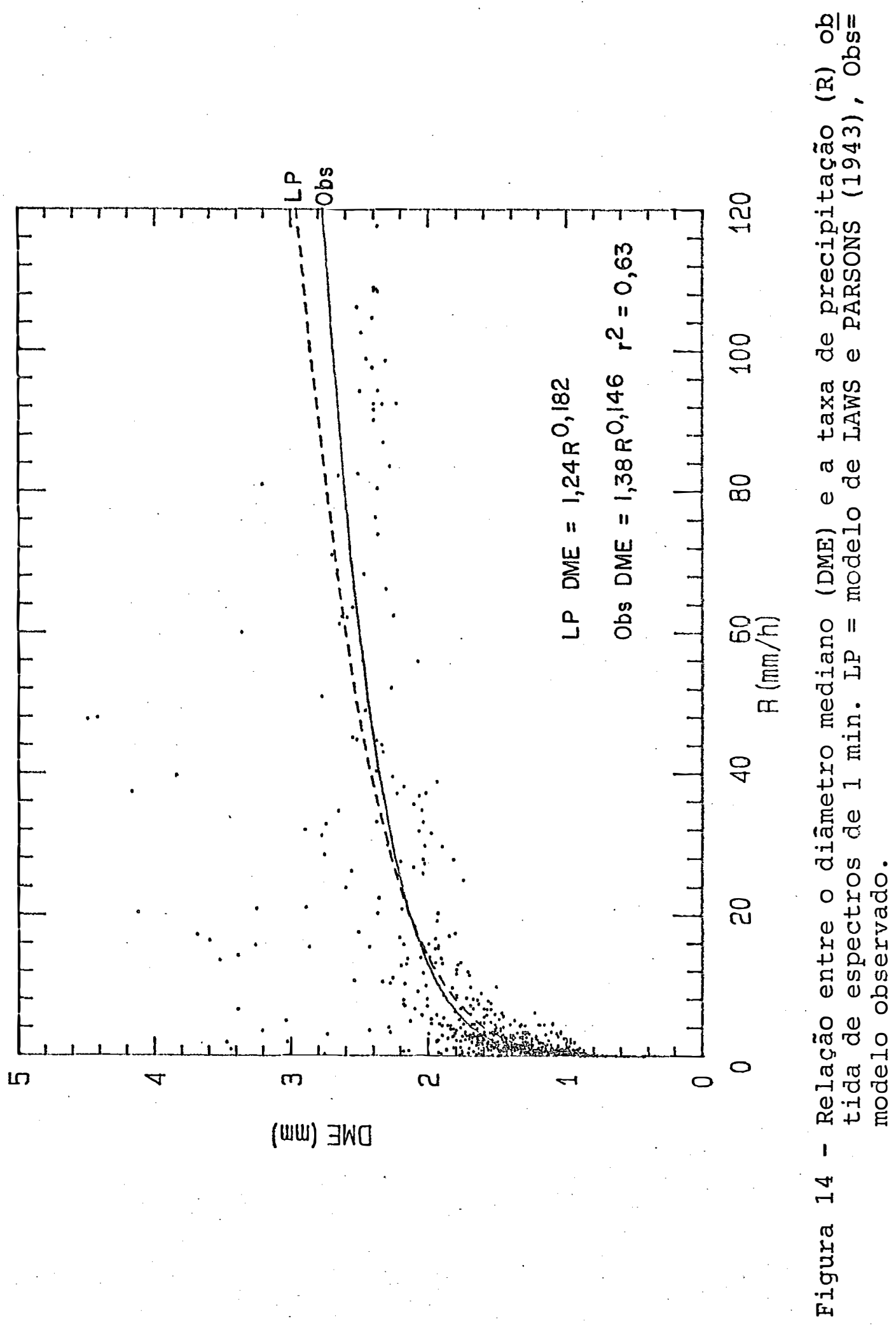




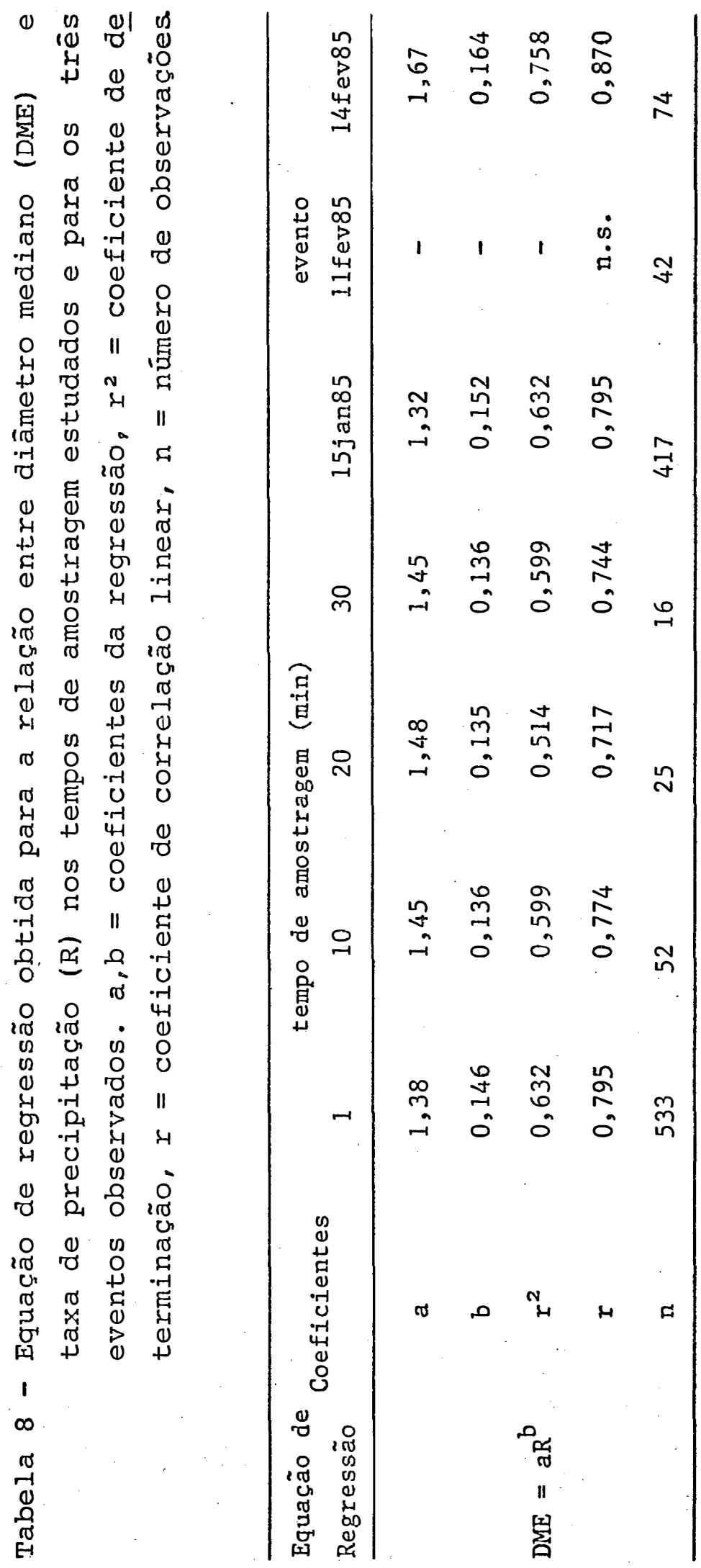


observações), embora o teste $t$ indique a significância da correla ção ao nível de 0,5\% de probabilidade, devido ao alto grau de liberdade do modelo testado (G.L. $=531$ ).

$\therefore$ Na análise individual dos três eventos,

a correlação dos dados da chuva do dia 14 de fevereiro de 1.985 apresentou o maior coeficiente $(r=0,87)$, e os dados da chuva do dia 11 de fevereiro de 1985, não apresentaram correlação. Tal fato deve-se em parte à ausência de taxas de precipitação (R) bai xas (menores que $\left.20 \mathrm{~mm} \cdot \mathrm{h}^{-1}\right)$, de forma que os pontos no gráfico DME $x$, referentes ao dia 14 de fevereiro de 1985, se localizam praticamente em torno de uma reta paralela ao eixo $\mathrm{x}$, traçada entre valores de DME iguais a 2 e $2,5 \mathrm{~mm}$.

Em comparação com a equação de LAWS e PARSONS (1943), nota-se que somente a altas taxas de precipitação (maiores que 50mm.h-1), as duas curvas se distanciam um pouco, sendo que o modelo observado indica menores diâmetros para uma mesma taxa de precipitação.

Isto também reitera as conclusões tiradas da comparação entre as distribuições percentuais de LP e dos dados observados (item 4.2). Entretanto, estatisticamente as duas equações não são significativamente diferentes $(P=0,05)$.

Essa variabilidade do DME em função de $R$ foi constatada por ROGERS et alịi (1967), que chamam a atenção pa ra o erro considerável, cometido na previsão de DME a partir de $R$ em minutos individuais de uma chuva. MCGREGOR e MUTCHLER (1976) ob 
servaram valores de DME superiores em até 1008 em relação ao valor previsto pelo modelo ajustado aos seus dados experimentais.Fa to este também observado nos casos estudados.

O decréscimo do DME para altas taxas de pre cipitação também foi observado por HUDSON (1963) e CARTER et alii (1974). O fato da relação entre DME e R, proposta por LAWS e PARSONS (1943), não resultar em decréscimo do DME para altos valores de $R$, pode ser devido à extrapolação realizada por estes autores para taxas maiores que $70 \mathrm{~mm}^{\mathrm{h}} \mathrm{h}^{-1}$. A análise de relações $\mathrm{DME}=\mathrm{a} \mathrm{R}^{\mathrm{b}}$ obtidas de dados de vários autores, mostrou que valores do coeficiente a altos $(>1)$ e b baixos $(<0.2)$, são geralmente associados a tempestades com predominância de gotas grandes (ULBRICH, $1985)$.

b. Relação entre energia cinética, momentum e taxa de precipitação

Na Figura 15, pode-se observar um espalhamento semelhante dos dados na relação entre a energia e a taxa de precipitação. Novamente, o coeficiente de determinação dos modelos é baixo, alcançando valores máximos de 0,634 , para o modelo potencial (Tabela 9), com os maiores erros encontrados na faixa de taxas menores que $50 \mathrm{~mm} \cdot \mathrm{h}^{-1}$. Embora alguns dos modelos ajustados apresentem maior coeficiente de determinação em um ou outro tempo de amostragem, não existe superioridade explícita de nenhum 


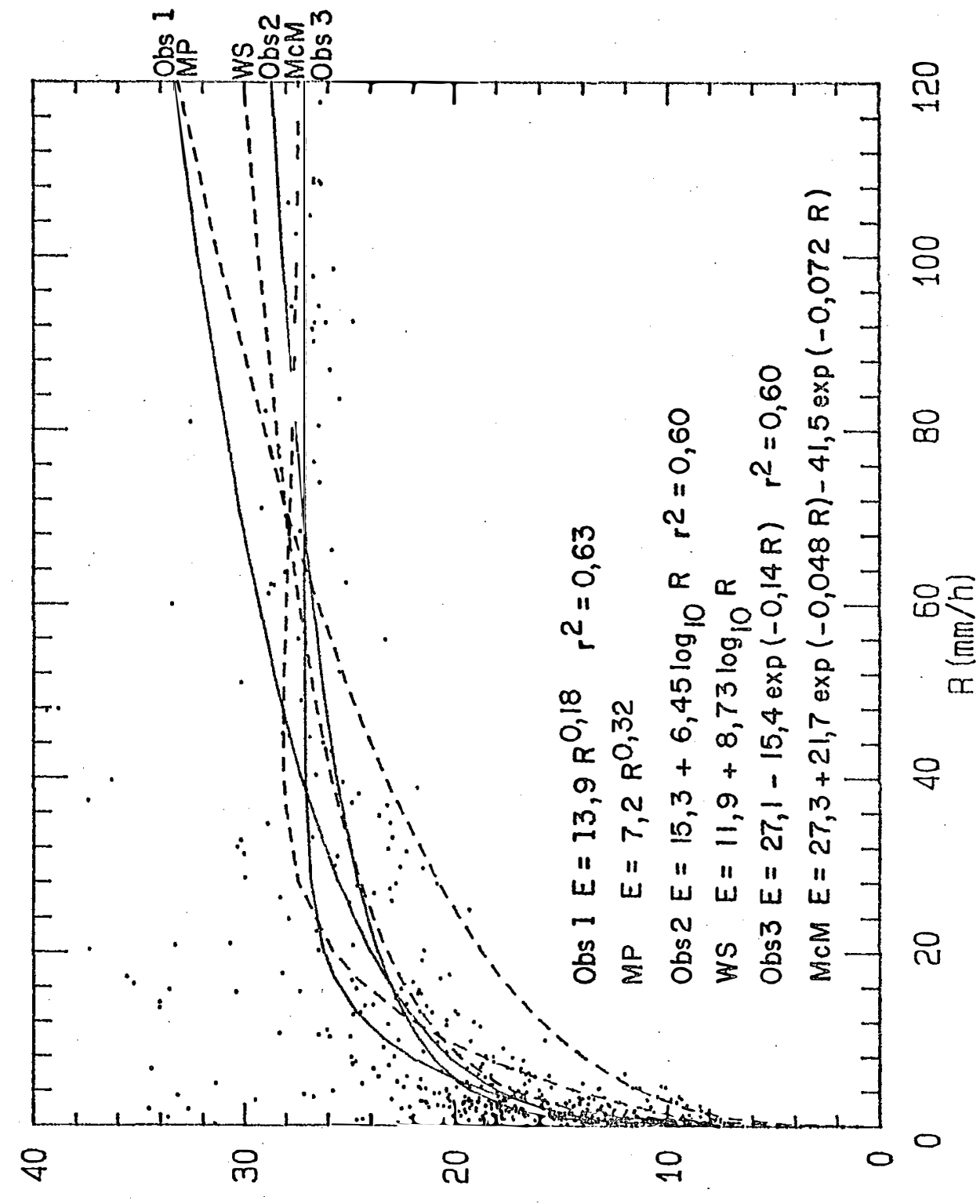

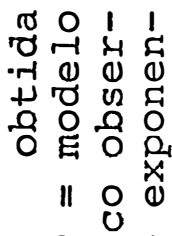

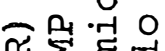

吆占望。

-tr r 0

00 म 0

i

cr $>011$ o

tै

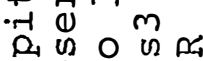

- $\mathrm{N}$ त्

บ 0 ช

म

प.

ब

(1)

r 0 U

艾

O - H

চ

$0 \infty \backsim \cup$

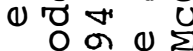

б ⿷匚न

-

(0) [x]

न त

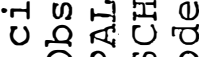

๙ $O$ D U O

- 103

Or द II

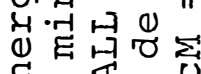

ब

๘ 000

(1) 峁

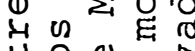

苨

व

i

u v $>$

苂

(WW'こW/N) $\forall I 9 H \exists N \exists$

1

n

कृ 


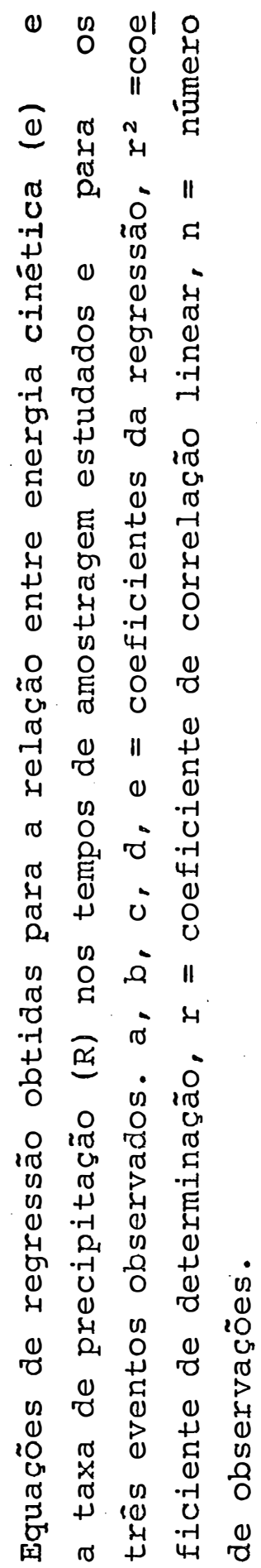

1
0
$\sigma$
-1
0
0
0
0
0

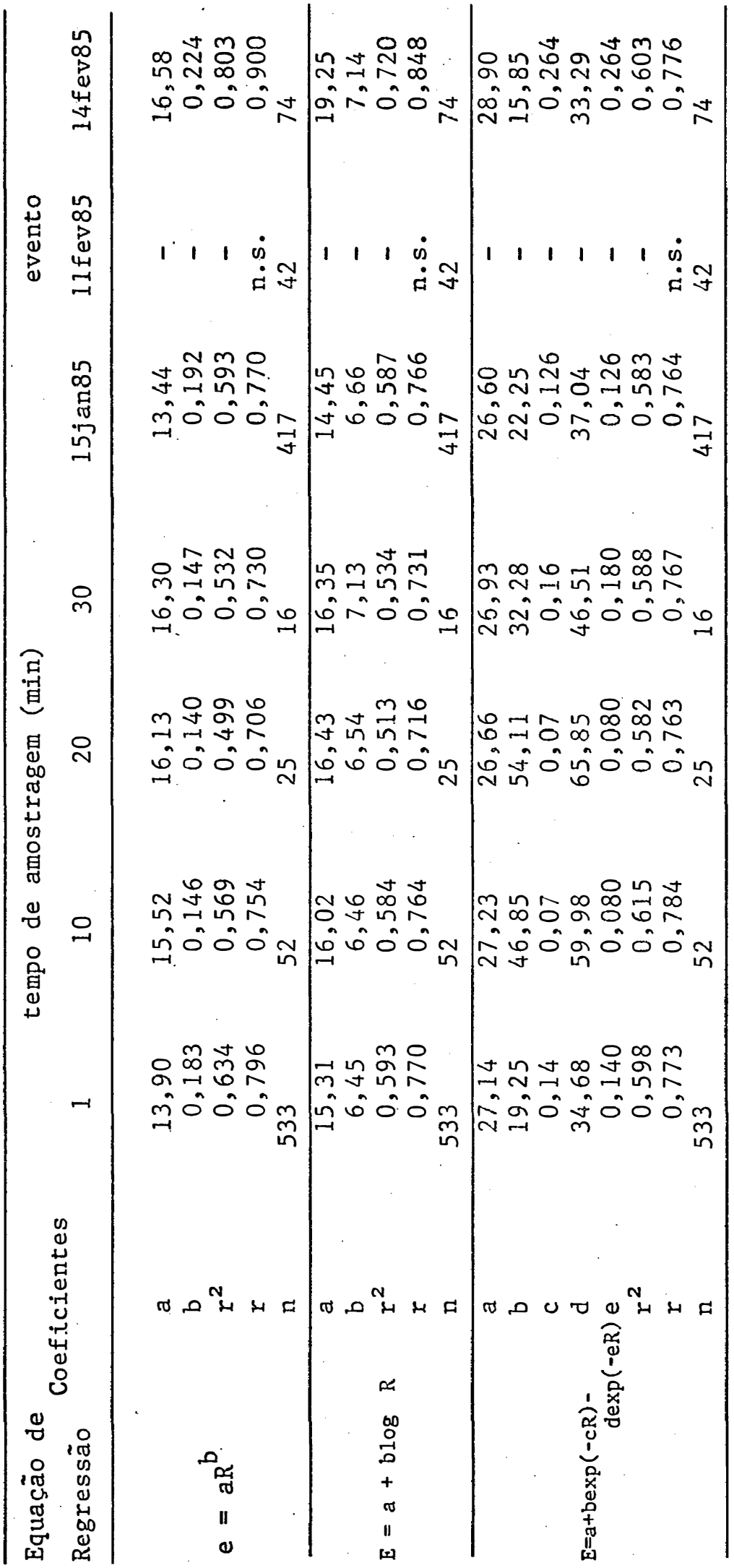


No caso do modelo potencial observa-se na Figura 15, que para altas taxas de precipitação ocorre a superestimativa da energia cinética, embora este modelo apresente o maior coeficiente de deter minação. Esta mesma tendência de superestimativa para altas taxas, também pode ser observada na equação determinada por WISCHMEIER e SMITH (1958), em relação ao modelo logarítmico ajustado.

o modelo deduzido a partir do espectro expo nencial de MP, subestima a energia para as taxas de precipitação menores que $50 \mathrm{~mm} \cdot \mathrm{h}^{-1}$. Conforme a taxa de precipitação aumenta, tem-se a aproximação da curva de MP com a potencial observada. No caso do modelo exponencial ajustado, esse difere um pouco do mode lo de MEGREGOR e MUTCHLER (1976), para taxas menores que 60mm.h-1, mas as curvas praticamente se igualam para taxas maiores (Fi gura 15).

A chuva do dia 11 de fevereiro de 1985 (Tabela 9): não apresentou correlação entre os dados observados, fato esse também explicável pela estabilização dos valores de energia para as taxas de precipitação altas, conforme foi apresentado na Figura 4d, que mostra a variação temporal destes parâmetros pa ra essa chuva. Para a chuva do dia 14 de fevereiro de 1985, encontrou-se o maior coeficiente de determinação do modelo ajustado. Os coeficientes de determinação, encontrados para as regressões ajustadas, estão de acordo com os valores citados por KINNELL (1981) $\left(r^{2}=0,50\right)$ e por MCGREGOR e MUTCHLER (1976) $\left(r^{2}=0,60\right)$, além do espalhamento dos dados experimentais, 
encontrados por esses autores, ser bastante semelhante, observan-

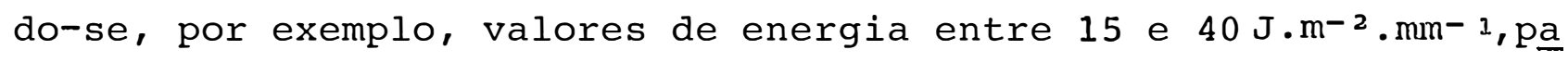
ra uma mesnra taxa de $20 \mathrm{~mm} \cdot \mathrm{h}^{-1}$.

Os dados experimentais obtidos evidenciam o mesmo tipo de comportamento, que é ilustrado pela Figura 16. Para uma taxa de $0,5 \mathrm{~mm} \cdot \mathrm{h}^{-1}$ (curva a) os valores de energia cinética

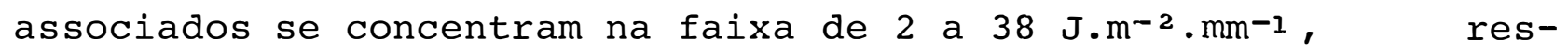
saltando o alto grau de espalhamento dos dados medidos. Por outro lado, conforme a taxa aumenta para $87 \mathrm{~mm} \cdot \mathrm{h}^{-1}$ (curva f), ocorre uma concentração em torno dos valores de 22 a $34 \mathrm{~J}_{\mathrm{m}^{-2}} \cdot \mathrm{mm}^{-1}$, 0 que em parte se deve à menor frequência de dados nessa faixa de taxa de precipitação.

A explicação para a variabilidade de valores de energia cinética, dada uma taxa de precipitação, reside no fato de que não existe uma função unívoca entre a taxa e a DTG, de maneira que espectros que produzem as mesmas taxas de precipitação possuem formatos diversos, resultando em valores de energia extremamente diferentes. Na Figura 17a e 17b têm-se alguns espectros com taxa de precipitação de 6,6 e $20,2 \mathrm{~mm} \cdot \mathrm{h}^{-1}$, respectivamente, que apresentam energia entre 17 e $37 \mathrm{~J} \cdot \mathrm{m}^{-2} \cdot \mathrm{mm}^{-1}$. Observa - se que o maior número de gotas grandes, presentes no espectro 3 da Figura 17a e nos espectros 3 e 4 da Figura 17b, provoca o aumento no valor da energia. Como a energia é proporcional a velocidade das gotas elevada a um expoente de grandeza maior do que o da taxa de precipitação, a presença de um reduzido número de gotas grandes tem efeito mais pronunciado sobre a energia. 


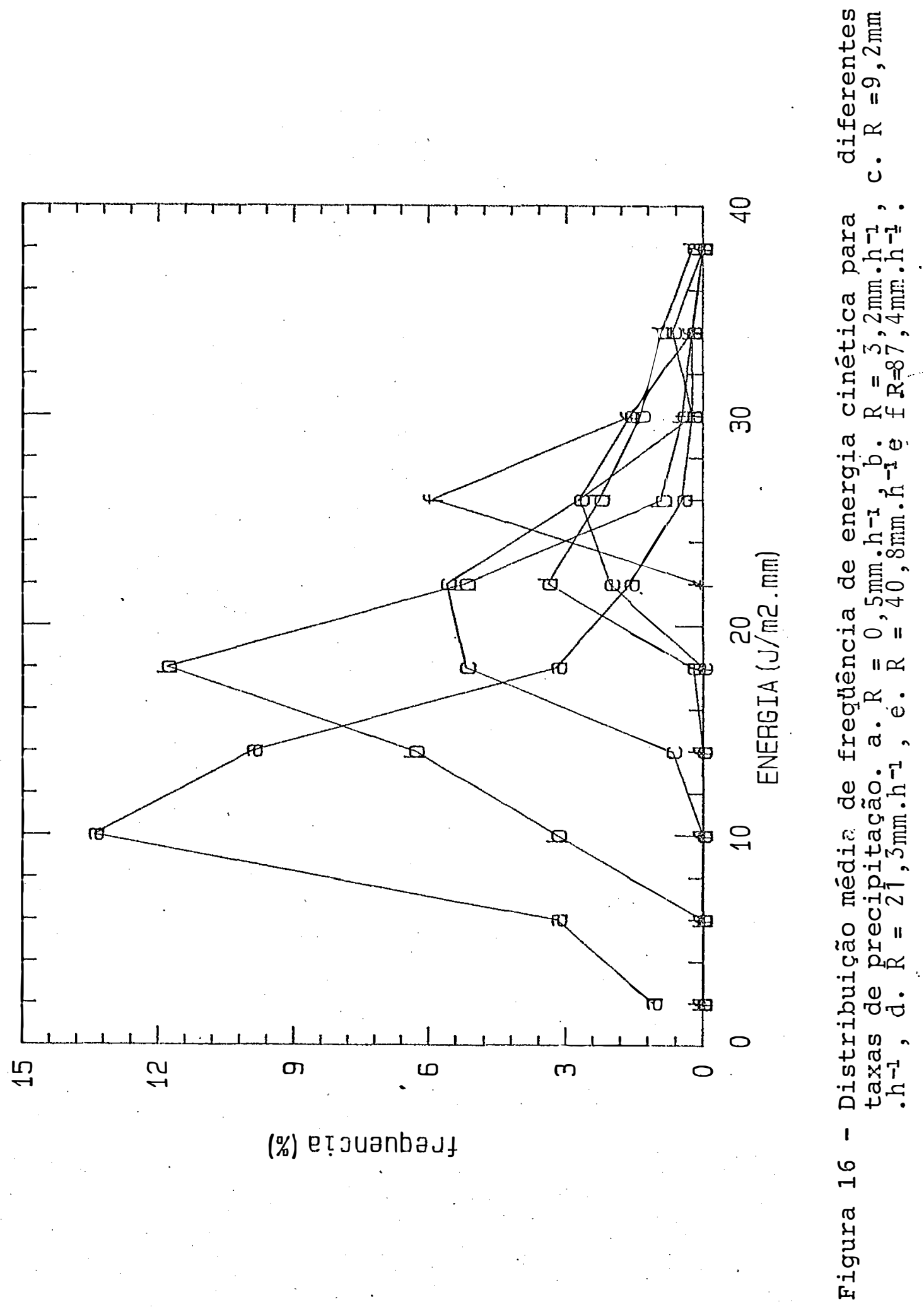




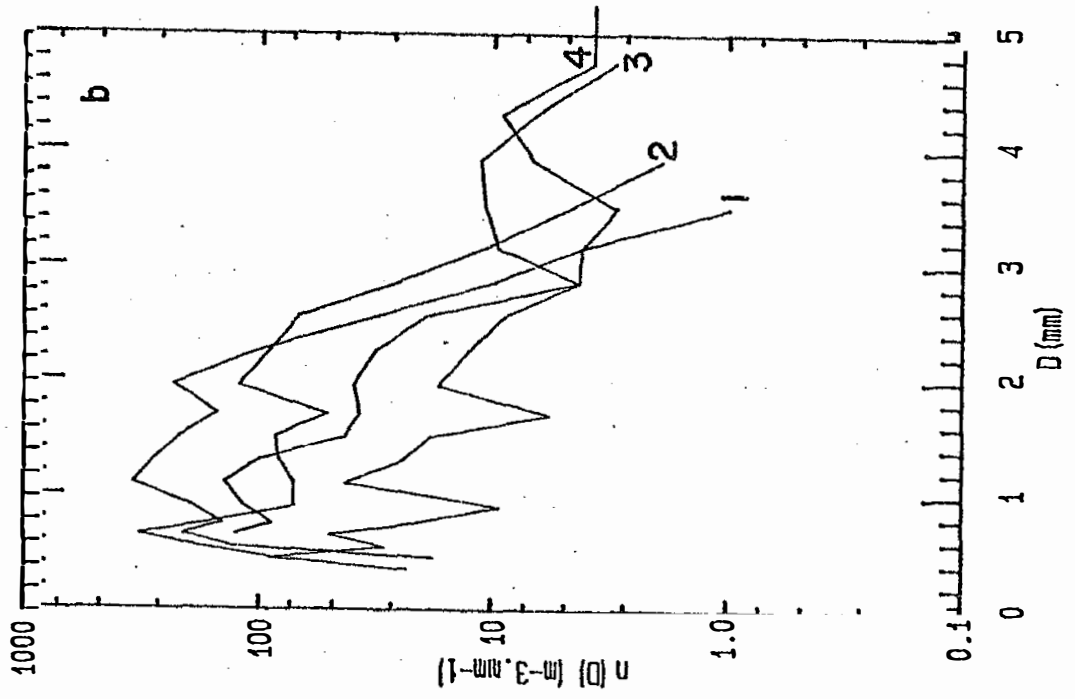

था

है EN

U E

믐

म. คり !

$\underset{G}{N} \mathfrak{i}^{-1}$

(1)

(1) II i

م

辰

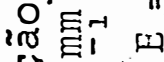

u.

क्ष

भू E ह

- 15 a

UNO

4ैم

㫕 ${ }^{-}$

ט山今

a ...m

(f)

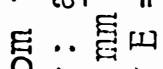

Oח

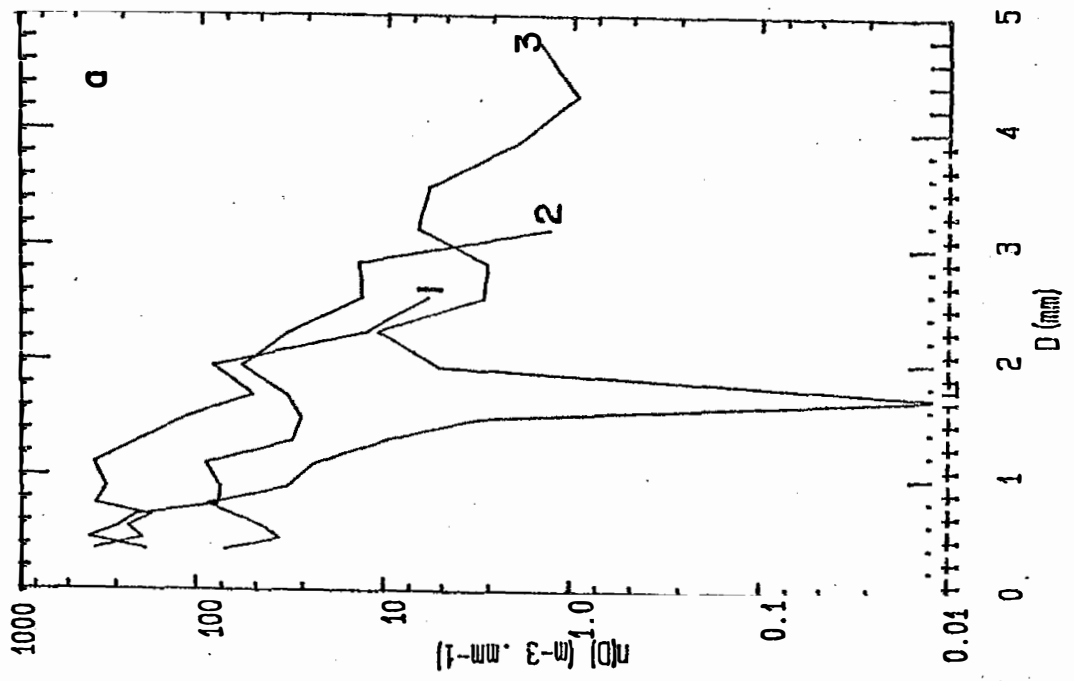

व

O हैं क्म

许忌り

U6N葛

(1) ०ैं?

लि

Uै "

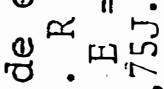

v

이

है

(j) म्तi .

प्ये

न 
Para a relação entre momentum e a taxa de precipitação (Figura 18,'rabela 10), os dados se concentram mais ao redor da curva dos mínimos quadrados, embora o coeficiente de determinação do modelo ajustado $\left(r^{2}=0,639\right)$ seja semelhante ao da relação entre energia e a taxa de precipitação. Pelos mesmos motivos abordados anteriormente para a relação energia $x$, a chu va do dia 11 de fevereiro de 1985 não apresentou correlação entre momentum e taxa de precipitação.

o modelo analitico de MP subestima os valores de momentum em todas as faixas de taxas de precipitação, mas tende a se aproximar do modelo ajustado aos dados experimentais na faixa de $R$ altos.

\section{c. Relação entre fluxo de energia cinética,fllu xo de momentum e taxa de precipitação}

A alta semelhança entre a variação dos parâa metros fluxo de energia (FEC) e fluxo de momentum (FMO), e a taxa de precipitação (R) em função do tempo, abordada no item 4.1, reflete-se na linearidade da relação entre estes parâmetros (Tabela 11 e 12), e conseqfientemente, no alto coeficiente de determinação. O modelo linear ajustado mostrou-se mais adequado para explicar os dados obtidos nos diferentes tempos de amostragem, e os da chuva do dia 15 de janeiro de 1985. Nos eventos dos dias 11 e 14 de fevereiro de 1985 o modelo potencial pro- 
.83.

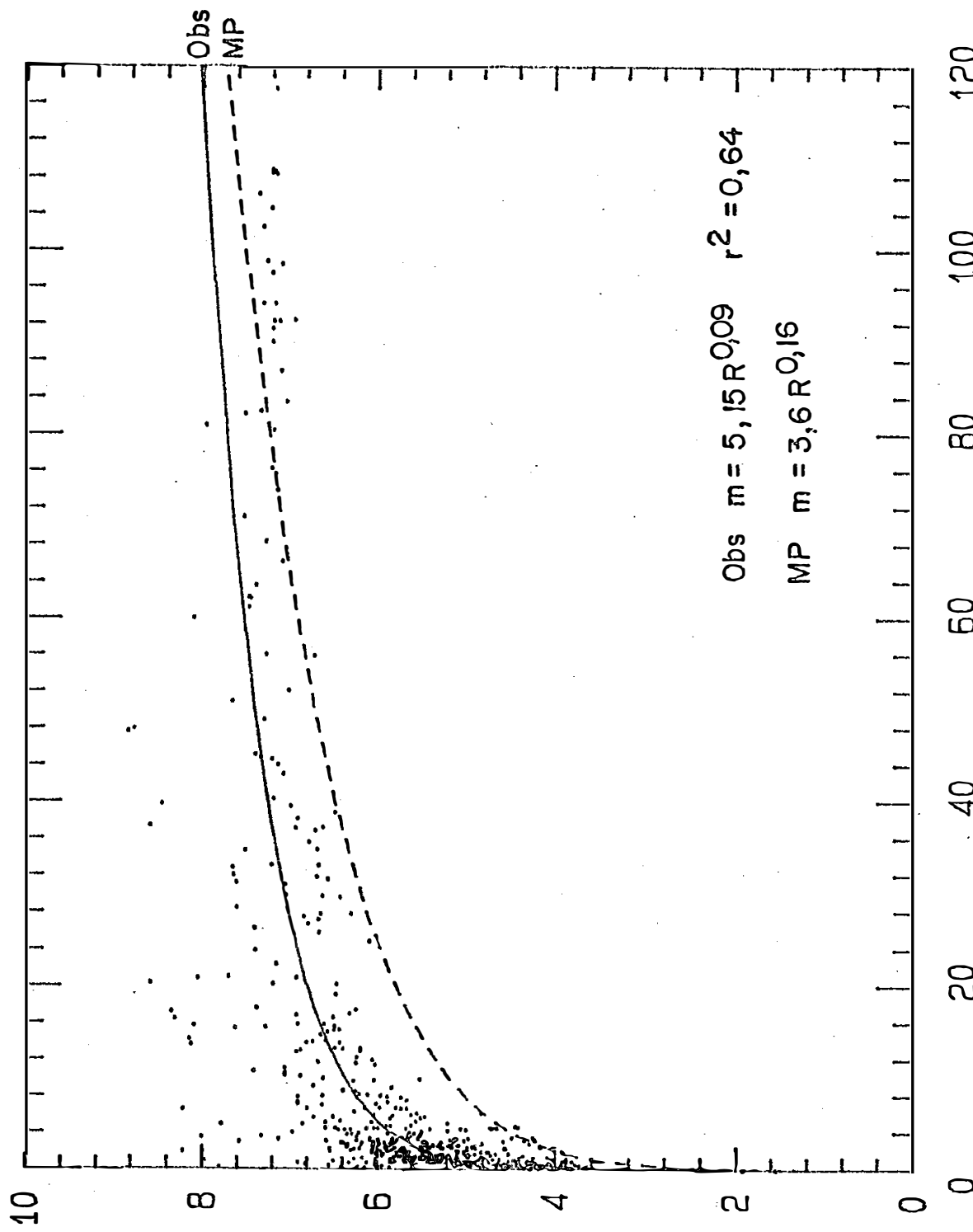

$\underset{\sim}{\sim}$

$\begin{array}{ll}0 & 0 \\ 0 & \\ 4 \\ 1 \\ 0\end{array}$

㟔这

ซृ बे

苛 0

党

이

函苟

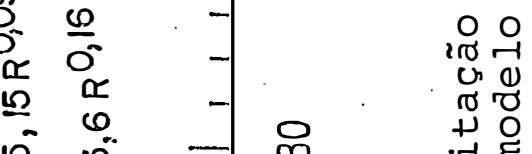

in in -

$E$ E -1 -

을

Q

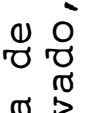

ซ

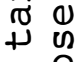

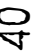

ه 0 ㅇ

톡

4 \%

을

品

요

o

豖号各

दृ. न

$0 . \dot{G}$

20 E

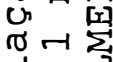

过是

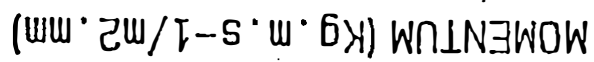

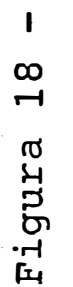




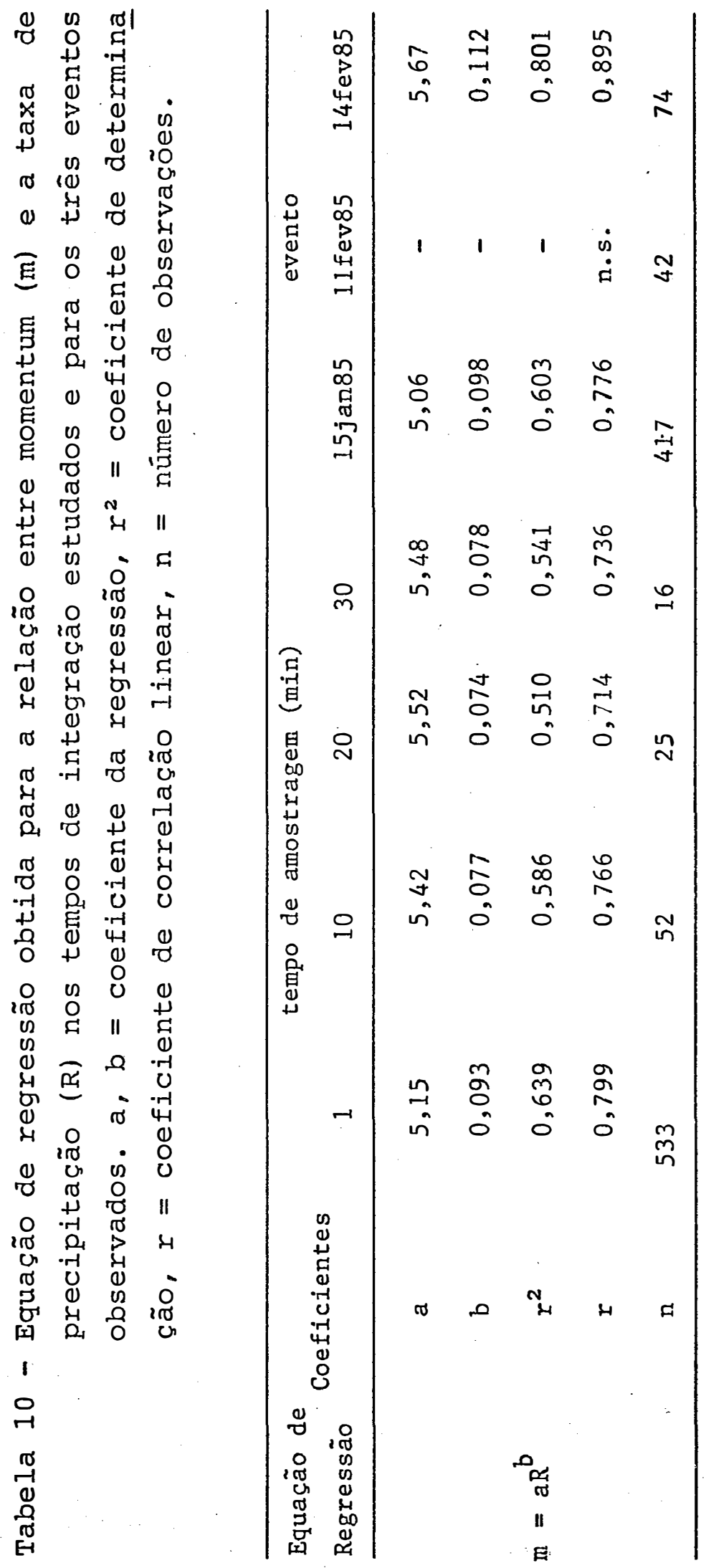




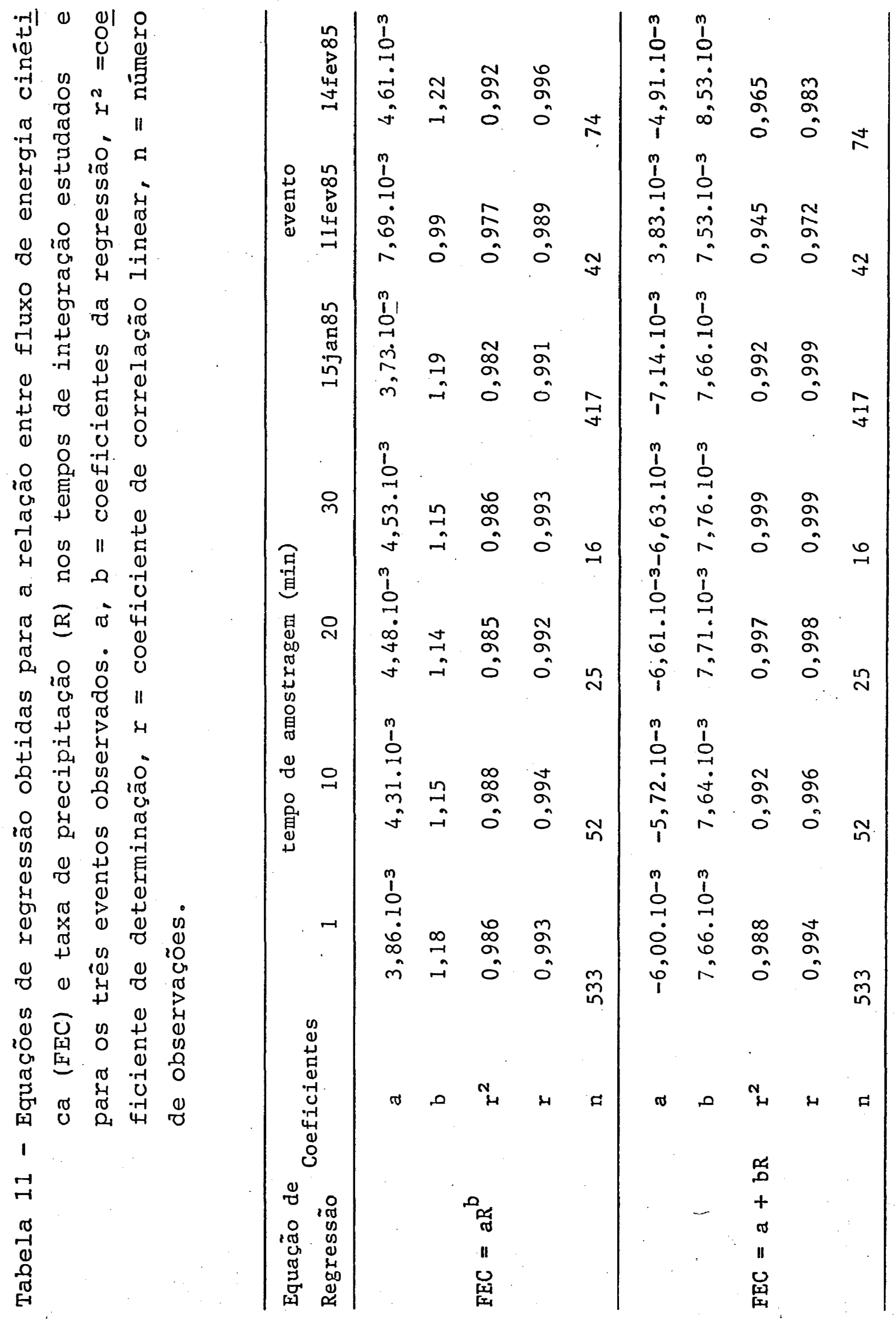




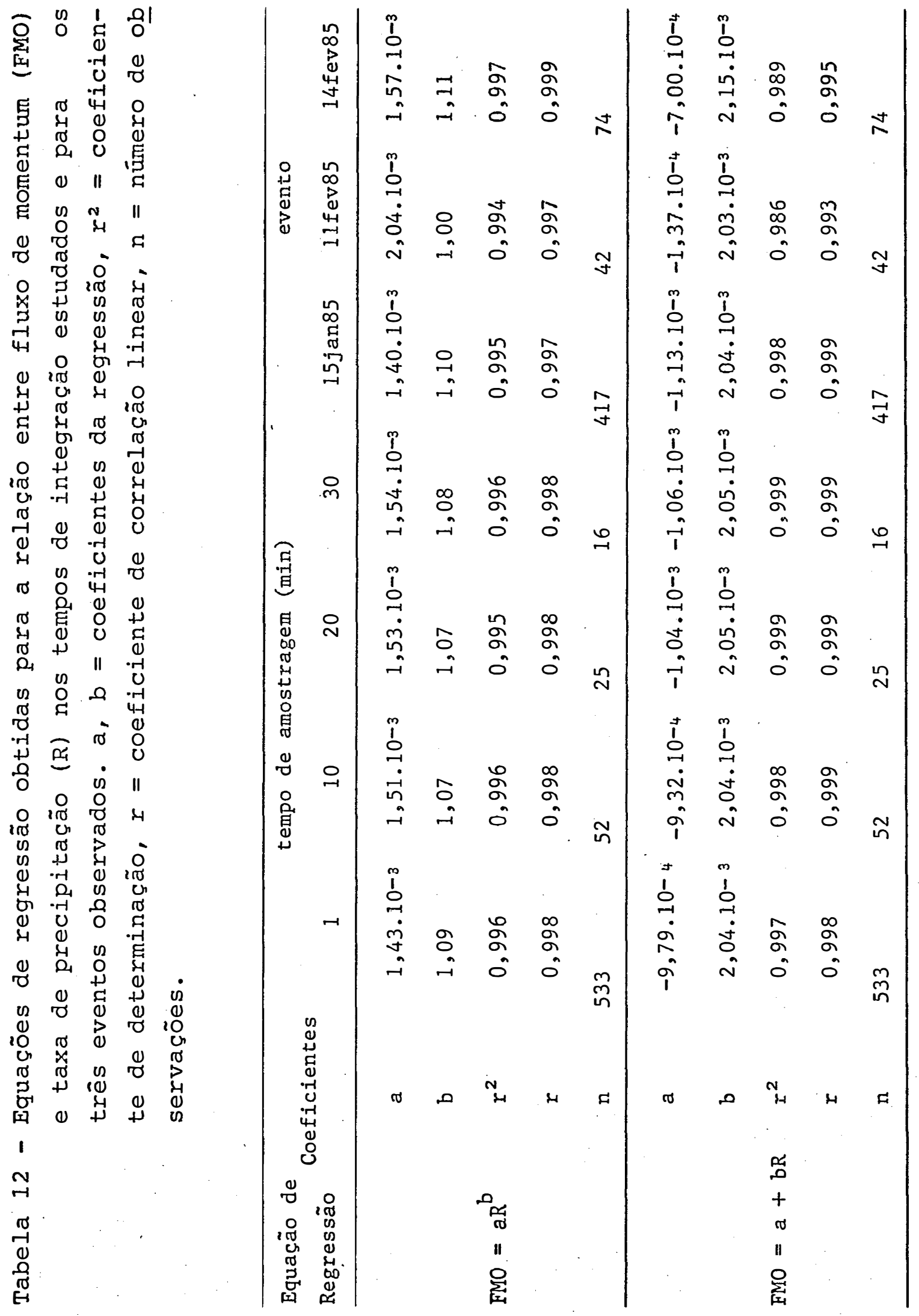


duziu um melhor ajuste. Nota-se que a taxas de precipitação maiores que $80 \mathrm{~mm} \cdot \mathrm{h}^{-1}$ o modelo potencial ajustado e o derivado de MP superestimam os valores de fluxo de energia e de momentum medidos, enquanto o modelo linear, com um coeficiente de determinação (tem po de amostragem = 1 min.) ligeiramente superior, gera erros meno res nessa faixa de $R$ (Figuras 19 e 20).

Mas, todos os modelos ajustados apresentam coeficientes de determinação maiores que 0,94, e embora alguns pontos extremos, discrepantes em relação a esses modelos, ocorram (Figuras 19 e 20), os ajustes dessas relações são mais satisfatórios, quando comparados aos ajustes das relações e $\mathrm{x} R \mathrm{e} \mathrm{m}$ x $\mathrm{R}$, abordadas no item anterior.

KINNELL (1973) notou que aproximadamente $20 \%$ dos valores de FEC medidos estavam fora do intervalo de $\pm 20 \%$ do valor estimado por um modelo ajustado. O maior grau de espalha mento da relação entre $\mathrm{FEC}$ e $\mathrm{R}$, comparativamente à relação entre FMO e R, é atribuído ao maior expoente da velocidade das gotas, utilizado para o cálculo de FEC. KINNELL (1981) ressalta o alto grau de linearidade existente na relação entre FEC e $R$, e FMO e $R_{r}$ devido à dependência desses parâmetros dos mesmos fatores como o diâmetro e a velocidade das gotas, sendo que para baixas taxas de precipitação essas relações são não lineares. 


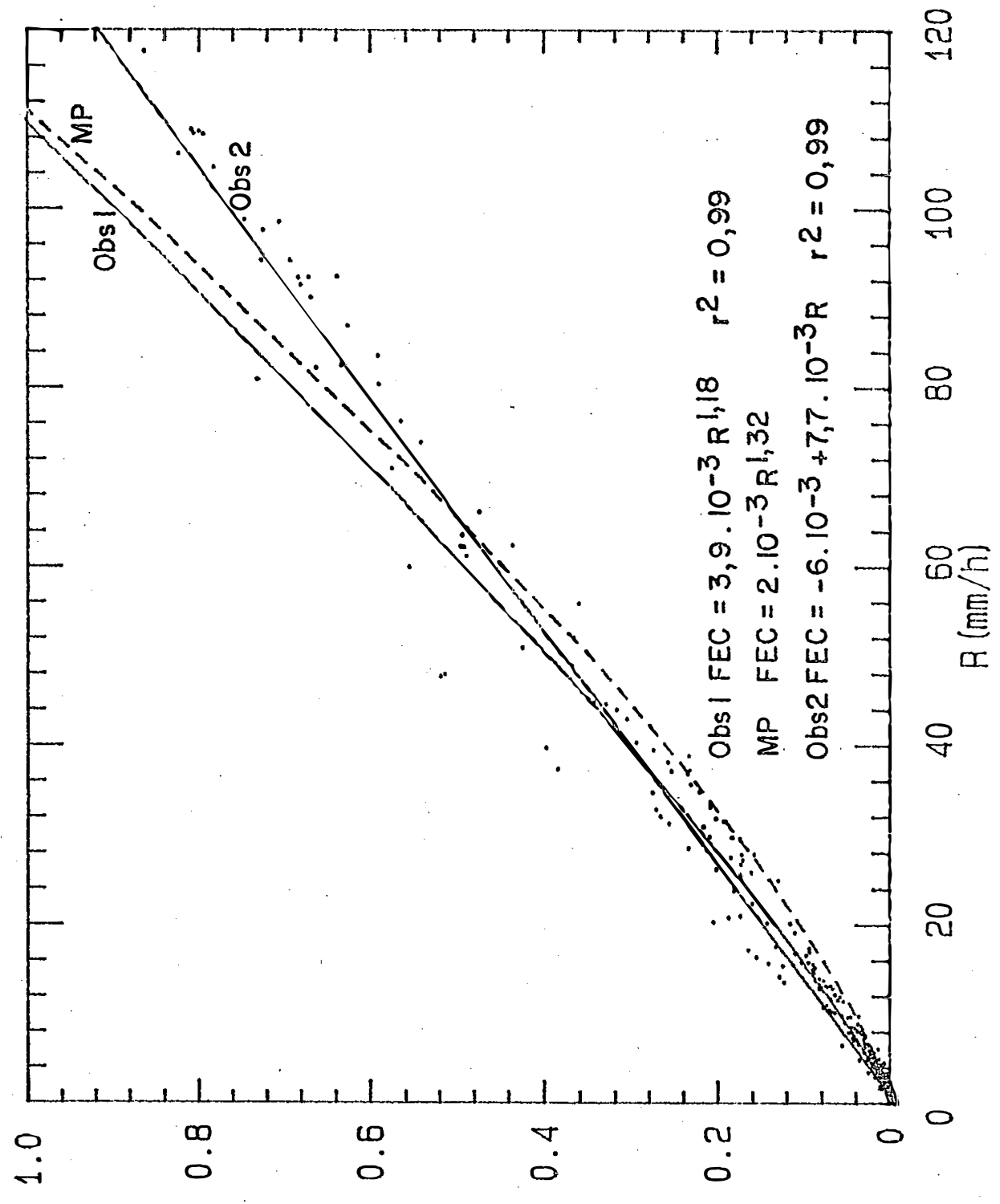

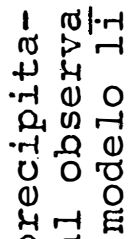

पू तु

()

ه

a) थ

गे

问

v $\underset{-1}{+\infty}=$

(1) శ్ర

(열

U

(1) 110

, त $\sum_{\text {至 }}$

ช

r-

(1)

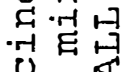

U

ro

- $\rightarrow$ (1)

का

(1)

(1) म्प त

() U

त

0 as

$x 0-1$

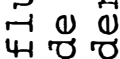

0 б 0 .

(ब) 다

$4+0$

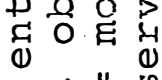

- II

유료

U $-\Sigma$

$\stackrel{\sigma}{\pi} 0-\pi$

बi

(s.

1

a

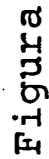




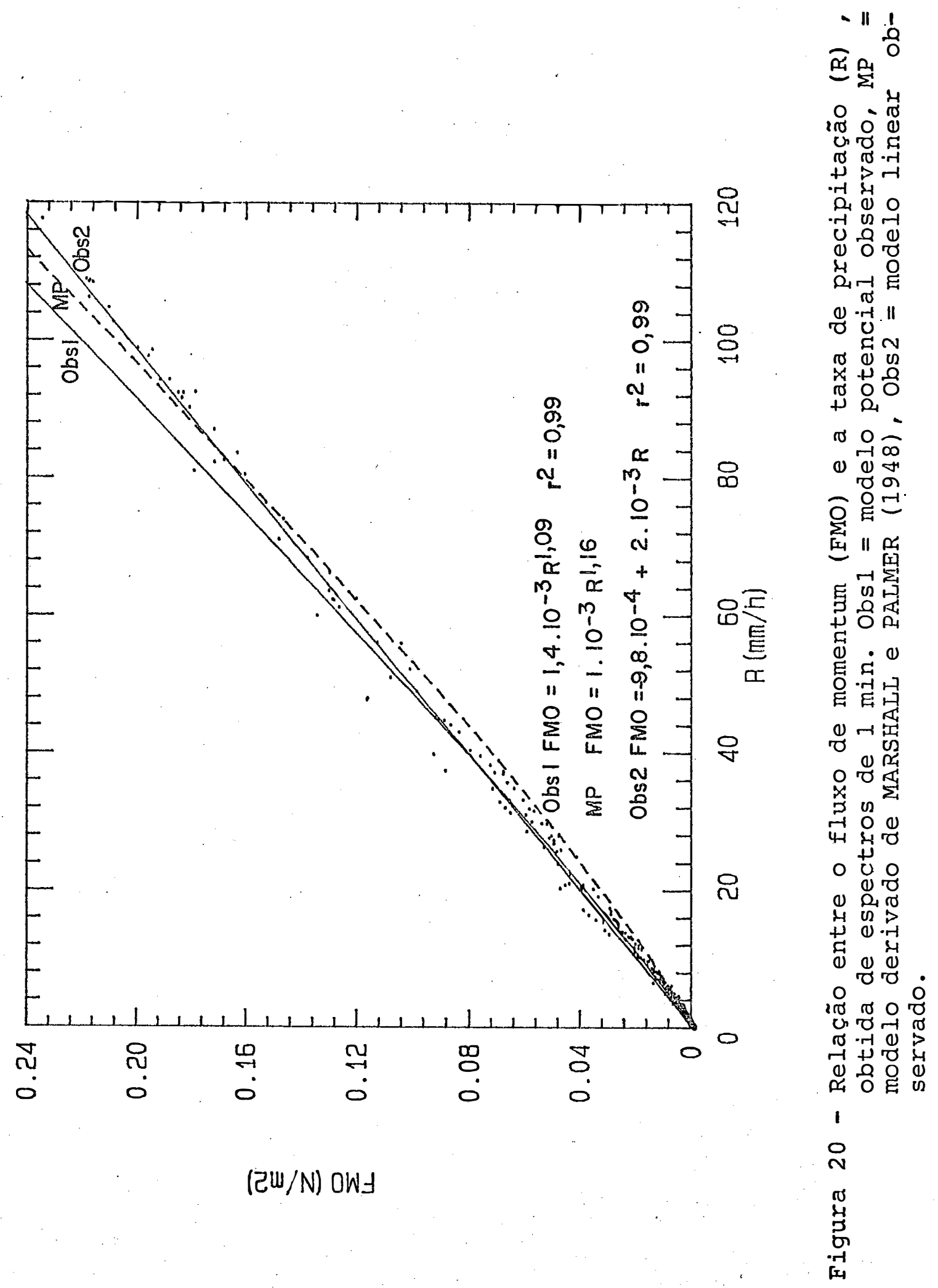



d. Relação entre energia cinética e diâmetro mediano

Na relação entre a energia e o diâmetro mediano (Figura 21 e Tabela 13), parâmetros que também apresentaram variação semelhante em função do tempo, o modelo ajustado explica 99,9\% dos dados observados, para todos os tempos de integração e chuvas estudadas.

Assim, por exemplo, o aumento da energia cí nética em função da variação do espectro, apresentado na Figura 17 é bem representado pelo deslocamento do diâmetro mediano para diâmetros maiores, uma vez que o reduzido número de gọtas maiores que $3 \mathrm{~mm}$, presentes no espectro 3 da Figura 17 a e nos espectros 3 e 4 da Figura 17b, contribuem com aproximadamente 50\% da massa de precipitação, fato evidenciado pelos diâmetros medianos de 3,42, 3,28 e 4,15, respectivamente para os espectros citados.

Portanto, o diâmetro que divide a massa ou o volume de precipitação em duas partes iguais, é o melhor indica dor da energia cinética de uma chuva.

e. Relação entre refletividade do radar e taxa de precipitação

A equação de regressão obtida para a relação Z-R é apresentada na Tabela 14 e na Figura 22, juntamente com 


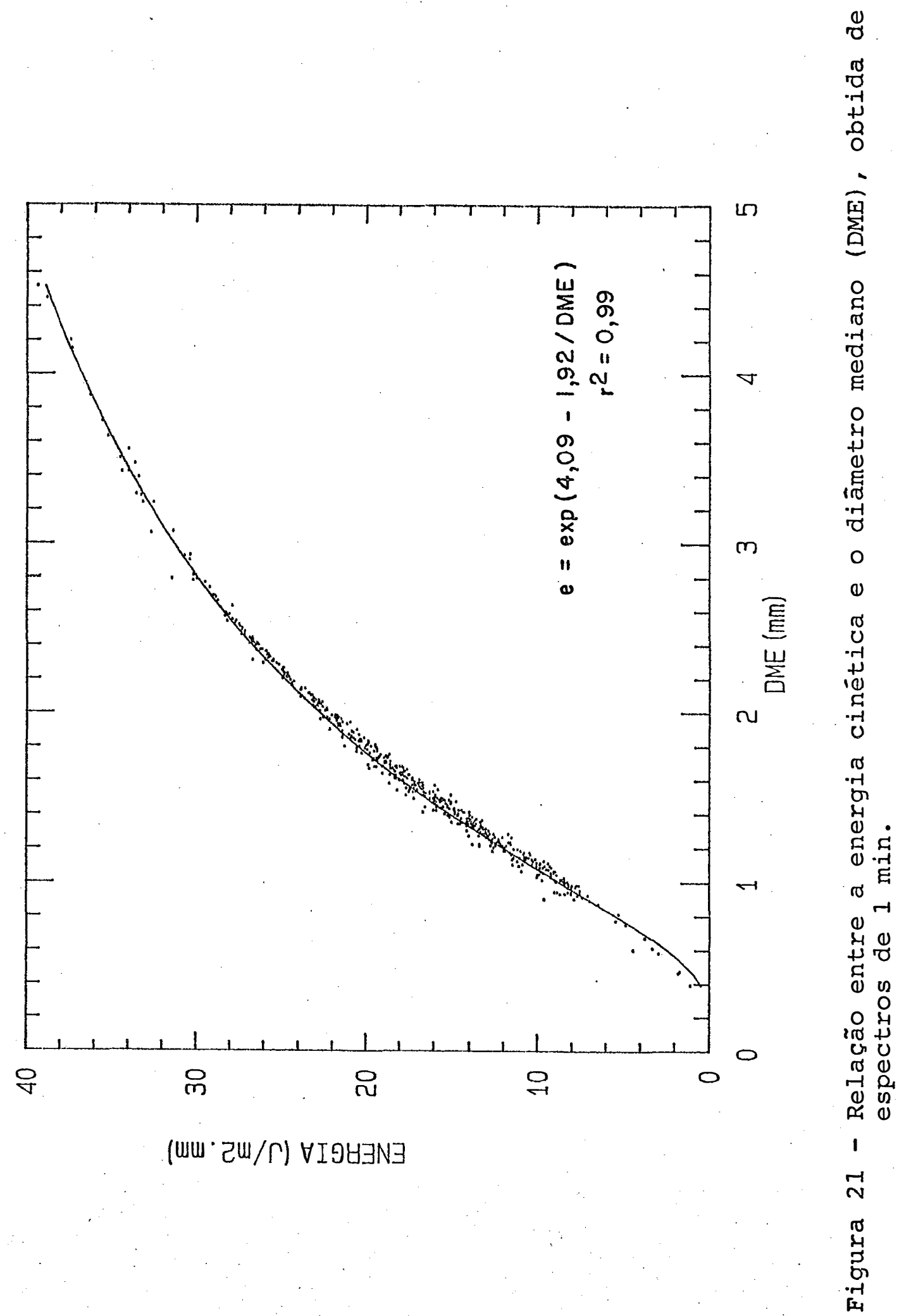




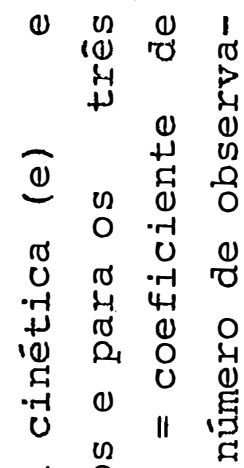

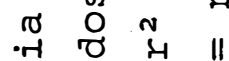

on $\pi$

मु गु

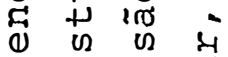

(1) थ 00

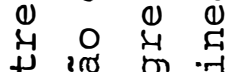

द o 0 त

(1) तु 4

- मू

1000 व

थ

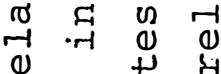

4 H

(2 व $\begin{array}{ll}0 & 0 \\ -4 & 0\end{array}$

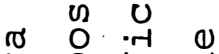

40 प

\% : 0

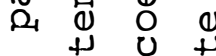

ช

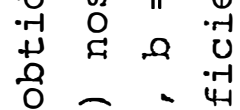

品

n 0 i

先

प

Q) न्त क्ष

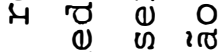

ช

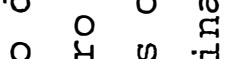

थि

u. 0 t)

శ్

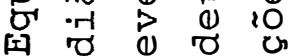

1
$m$
-1
$r$
-1
0
0
0
e

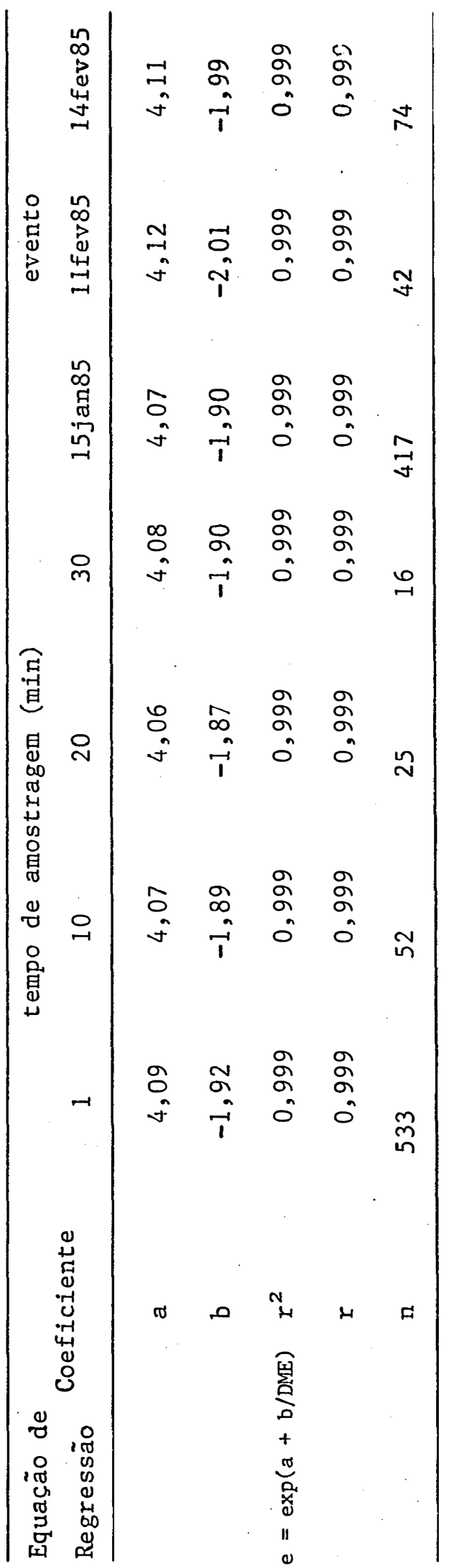




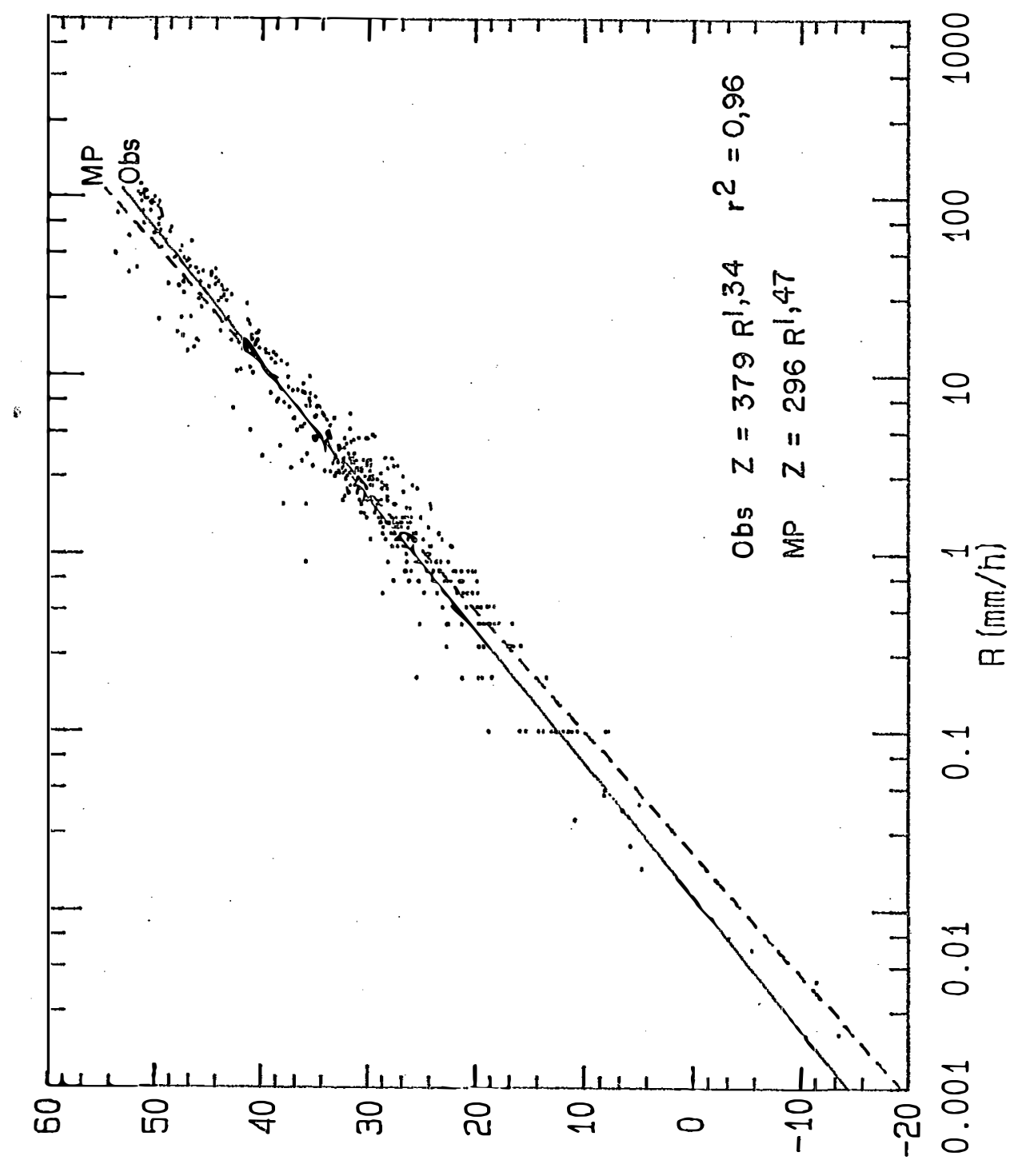

$\begin{array}{rr}\sigma & 1 \\ x & 4 \\ 0 & 0 \\ + & 0 \\ + & 0 \\ 0 & 0\end{array}$

ro 0

(1) ल्ठ

ลิ

기

ơ

검용

$\| \stackrel{4}{-4}$

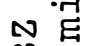

लै⿴囗十

-

- $0 \%$

तิ

म $\mathrm{O} \alpha$

贸

O 0

4 胫

잉 0

0

ه

-

-

+o 0

某 $=0$

出䍃

$4=0$

ช 0 워

(1) un 0

4 б

$++$

द्व

0 욜

2000

ur 4

न1 वृ

凹 ه

(Zघp) Z

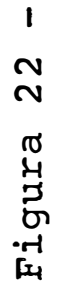




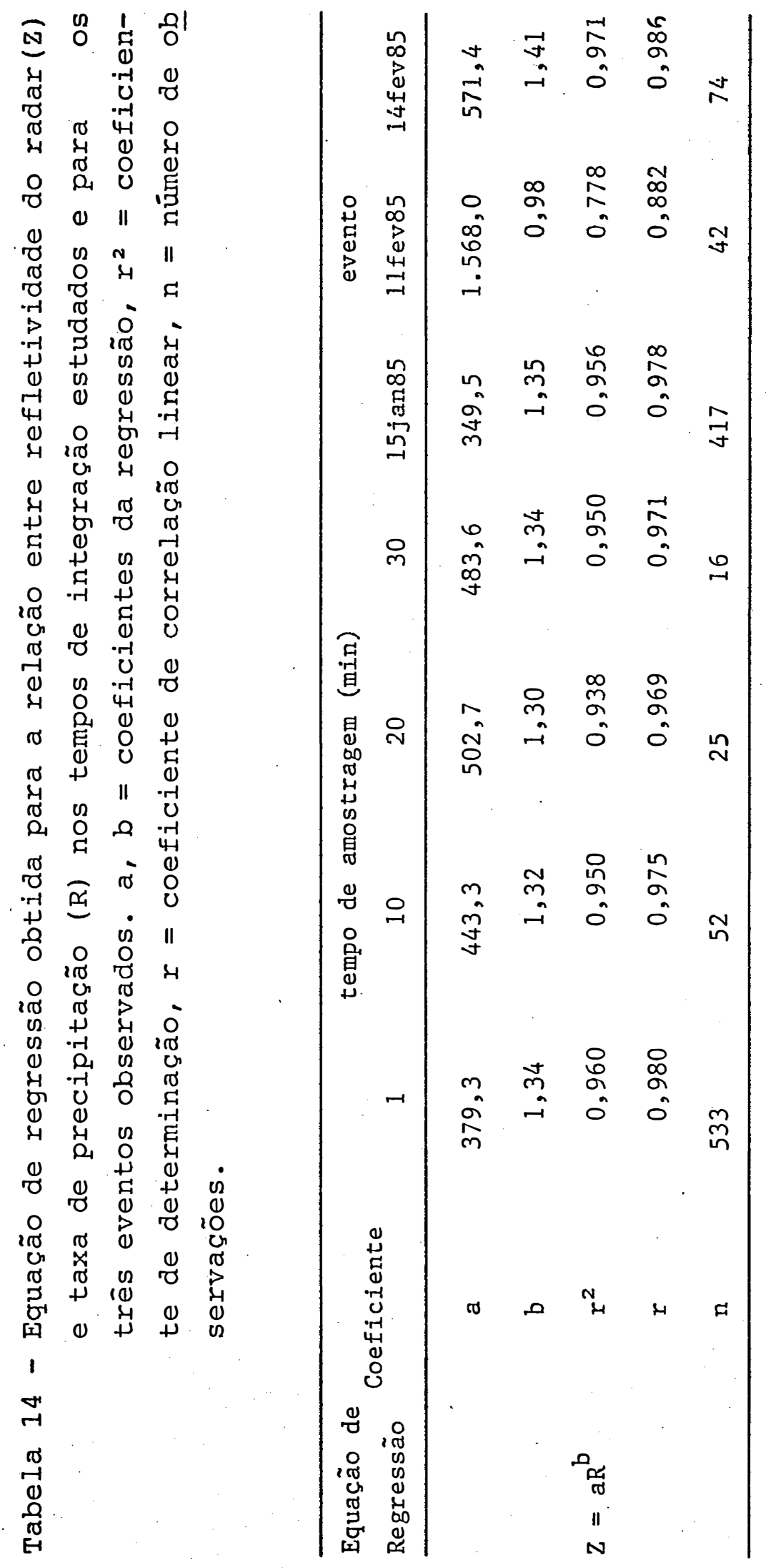


a relação derivada do espectro exponencial inverso. Essa relação analítica $\left(\mathrm{z}=296 \mathrm{R}^{\mathrm{I}, 4}\right)$ é apresentada por MARSHALL e PALMER (1948), como sendo derivada das equações $n(D)=8.000 \exp (-\Lambda D)$ e $\Lambda=4,1 R^{-0,21}$. Porém, na literatura cita-se com maior frequência a relação $z=220 \mathrm{~K}$ 1,6, a qual foi obtida experimentalmente por MARSHALL e PALMER (1948), e ë geralmente aproximada por $Z=200 R^{1}, 6$, como relação de MP.

Na faixa de 1 a $100 \mathrm{~mm} \cdot \mathrm{h}-1$ o modelo ajustado praticamente se iguala ao modelo analítico derivado do espectro exponencial. No caso da análise individual dos três eventos ocorrem diferenças entre o modelo ajustado aos dados da chuva do dia 11 de fevereiro de 1985 e o modelo analítico derivado. Novamente, embora o coeficiente de determinação seja maior que 0,94, com exceção da chuva do dia 11 de fevereiro de 1985, um espalhamento considerável ocorre em torno da reta dos mínimos quadrados.

O espalhamento dos dados Z-R em torno da re ta obtida num gráfico log-log, sujeita a estimativa da taxa de precipitação, a partir da refletividade do radar, a erros grandes, intoleráveis dependendo da finalidade da previsão (CATANEO e STOUT, 1968). WALDVOGEL (1975) sugere que essas variações sobre a linha $\mathrm{z}-\mathrm{R}$ são devidas a alterações na DTG e, que, de uma forma ge ral, pode-se dizer que espectros monodispersos resultam em expoen tes b pequenos (próximos a 1), e espectros exponenciais em expoen tes b grandes (próximos a 1,5). Valores de a grandes (próximos a 500) indicam espectros com predominância de gotas grandes e valo- 
res de a pequenos (próximos a 100), indicam espectros de gotas pe quenas.
f. Relação entre energia cinética, momentum e refletividade do radar

Quando se correlaciona a refletividade do radar com a energia cinética (Tabela 15 e Fígura 23) e com o momentum (Tabela 16 e Figura 24), o coeficiente de determinação das curvas aumenta em termos médios de 0,6 para 0,75 , em comparação com as relações destes parâmetros e a taxa de precipitação, e os valores máximos de e e m coincidem com os de $z$. No caso da relação destes parâmetros com a taxa de precipitação, isto não ocorre, e os valores máximos de energia e momentum não coincidem com os máximos da taxa de precipitação.

Observa-se que a relação derivada de MP apresenta os menores desvios para valores de refletividade do radar altos (maiores que $105 \mathrm{~mm}^{6} \cdot \mathrm{m}^{-3}$ ou $50 \mathrm{dBZ}$ ), enquanto a relação observada explica melhor as refletividades do radar menores que esses valores.

g. Relação entre fluxo de energia cinética, flü xo de momentum e refletividade do radar

Tal fato também ocorre na relação entre o fluxo de energia e o fluxo de momentum e a refletividade do radar 
.97.

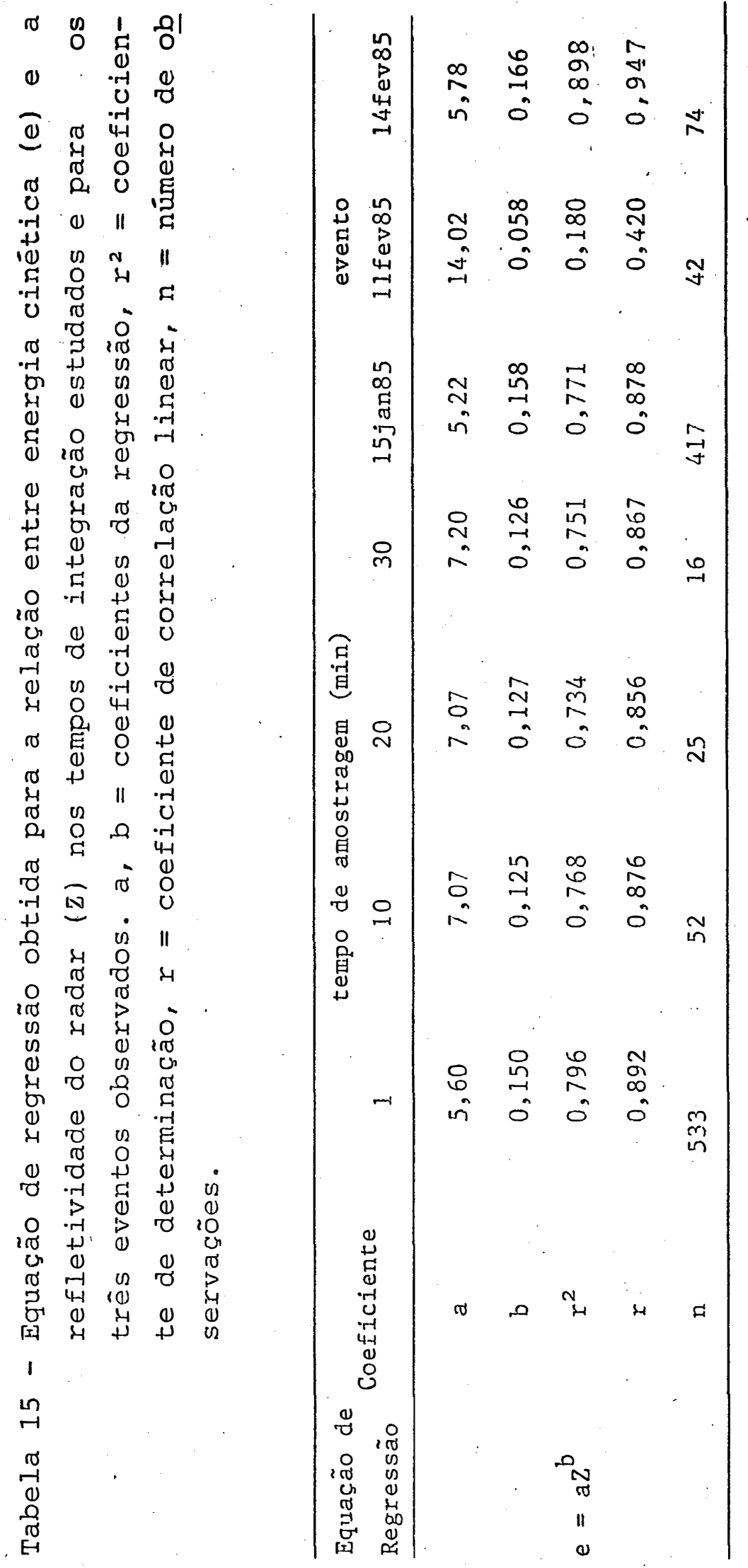




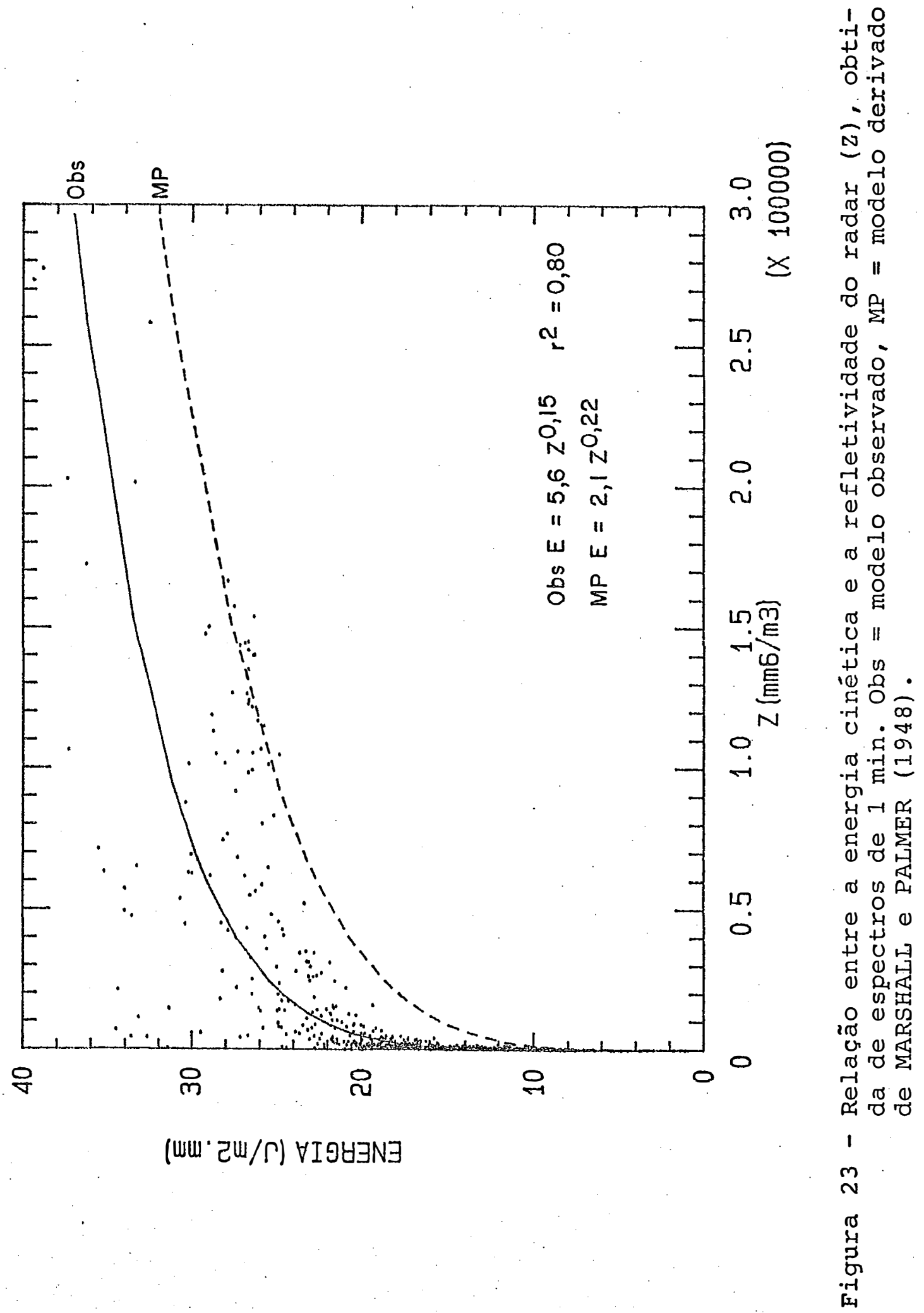




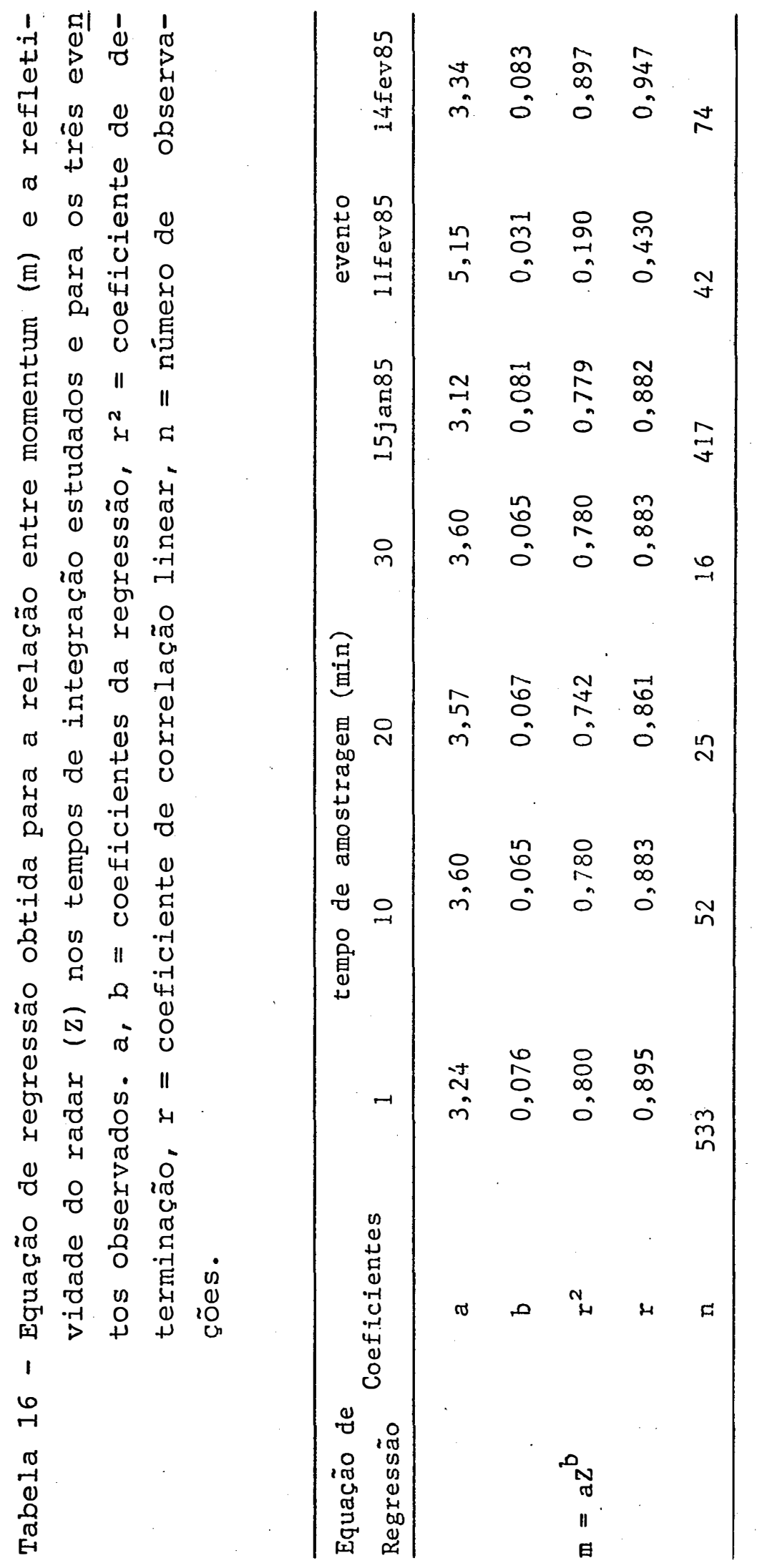




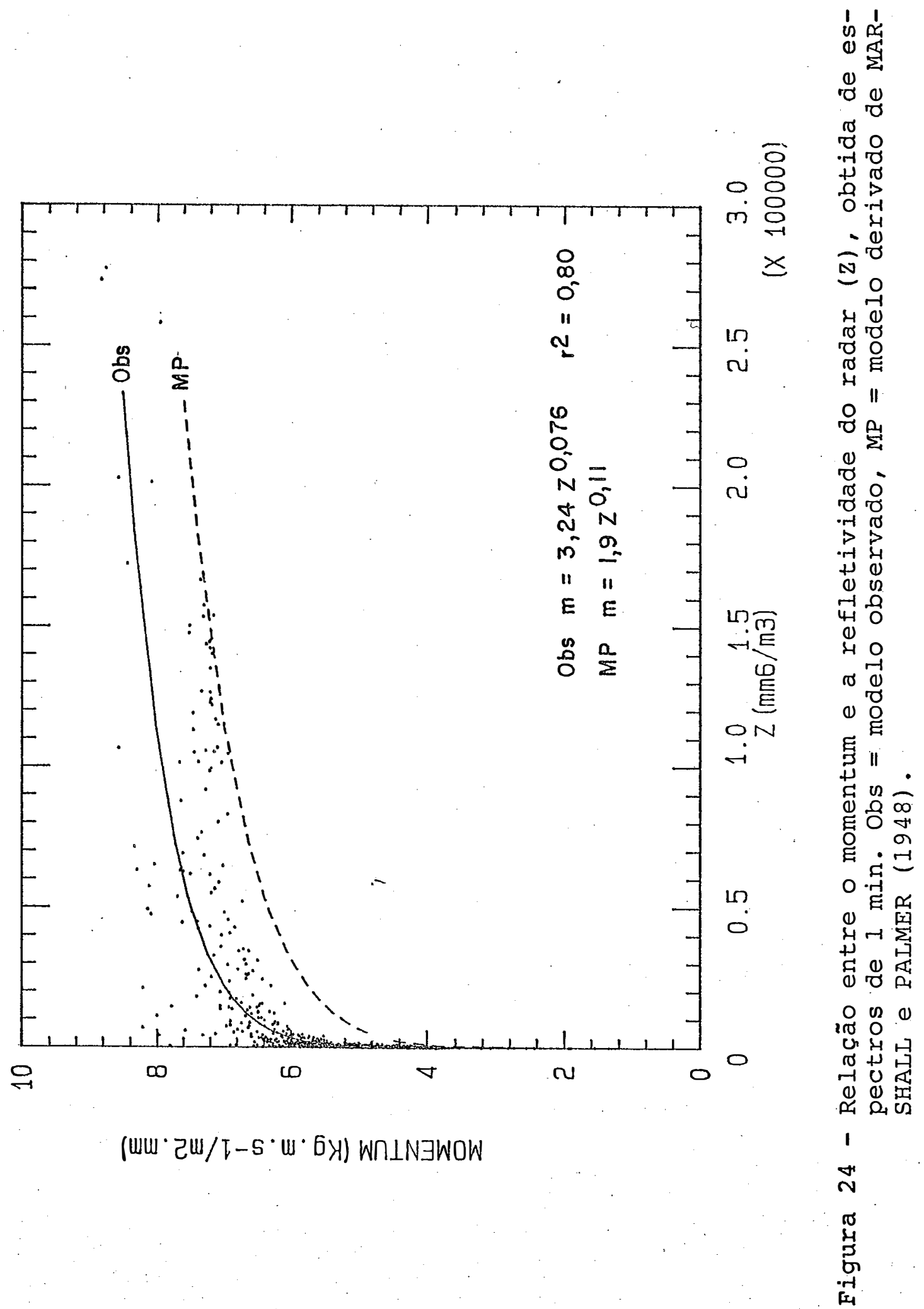


(Figuras 25 e 26 e Tabelas 17 e 18), onde os pontos de máxima refletividade (maior que $150.000 \mathrm{~mm}^{6} \cdot \mathrm{m}^{-3}$ ou $52 \mathrm{dBz}$ ) possuem valores correspondentes médios de FEC entre 0,4 e $0,7 \mathrm{~J}^{-\mathrm{m}^{-2}} \cdot \mathrm{s}^{-1}$, e FMO entre 0,08 e $0,18 \mathrm{Kg} \cdot \mathrm{m} \cdot \mathrm{s}^{-1} \cdot \mathrm{m}^{-2} \cdot \mathrm{s}^{-1}$. Os picos máximos de FEC e de FMO se concentram em valores de $\mathrm{Z}$ de aproximadamente 150.000 $\mathrm{mm}^{6} \cdot \mathrm{m}^{-3}$ ou $52 \mathrm{dBZ}$. Tanto na relação entre $\mathrm{FEC}$ e $\mathrm{Z}$, como na de FMO e Z, ocorrem pontos discrepantes referentes à chuva do dia 11 de fevereiro de 1985, que são justamente os pontos de máxima refletí vidade que não correspondem aos valores máximos dos fluxos.

Nessas relações o modelo linear tem ajuste pior que o potencial e o modelo analítico derivado de MP, estima valores de FEC e FMO inferiores aos observados, para todas as fai xas de Z (Figura 26).

o desvio da relação analítica derivada de MP comparada aos modelos ajustados aos dados experimentais é explicável. pela própria natureza do espectro, que não é exponencial. Além disso, para a obtenção das relações analíticas assumiu-se o valor de No como sendo constante e igual a $8.000 \mathrm{~m}^{-3} \cdot \mathrm{mm}^{-1}$. Isto nem sempre ocorre, pois, como abordado anteriormente, WALDVOGEL (1974), verificou que o No varia durante um evento de acordo com a atividade convectiva das células de precipitação. Ainda,os coeficientes da relação $\mathrm{v}=\mathrm{aD}^{\mathrm{b}}$ utilizados, influem bastante nos coe ficientes das equações obtidas, sendo que nem sempre são adequados para todos os tamanhos de gotas. 


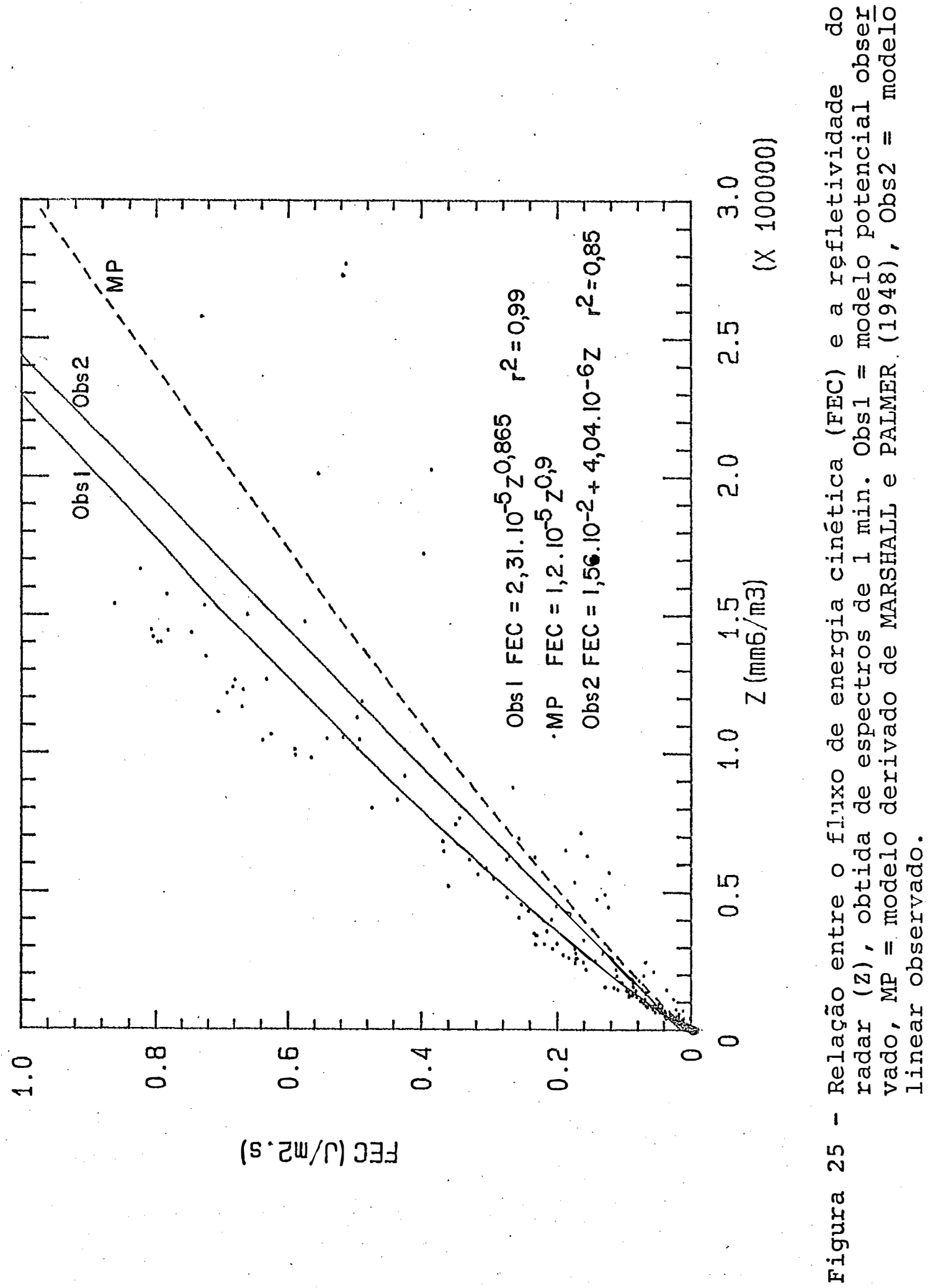




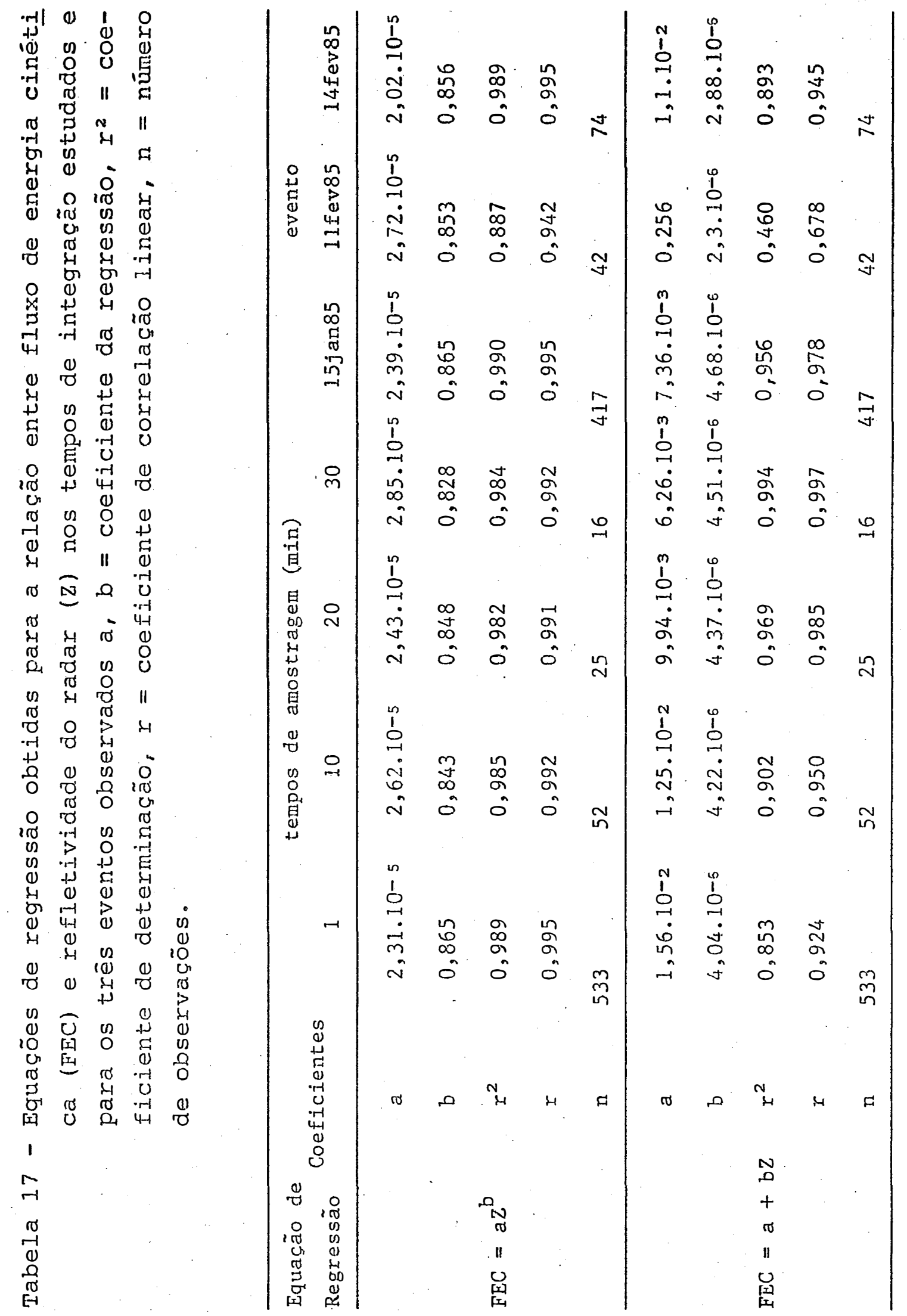




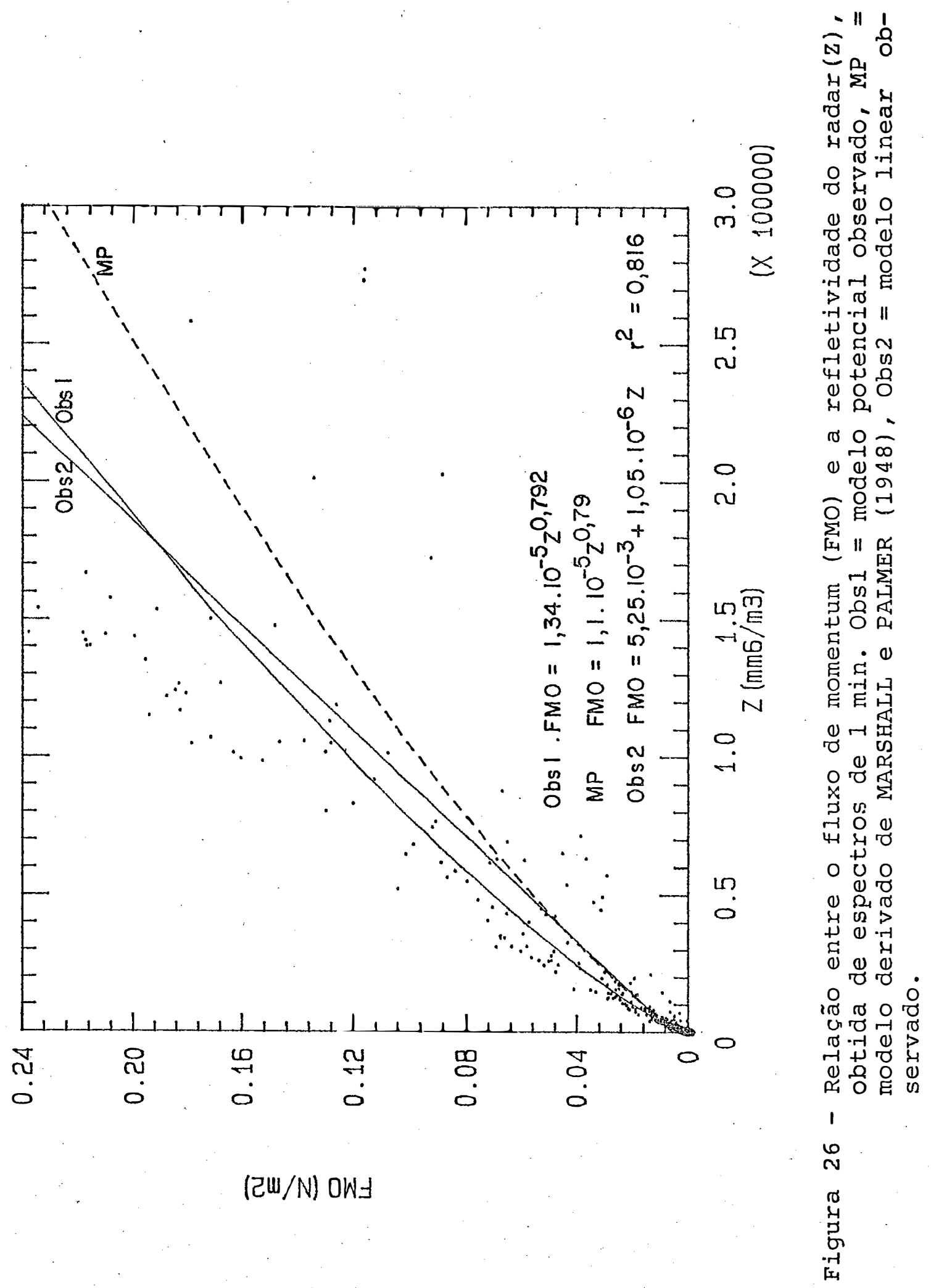


.105 .

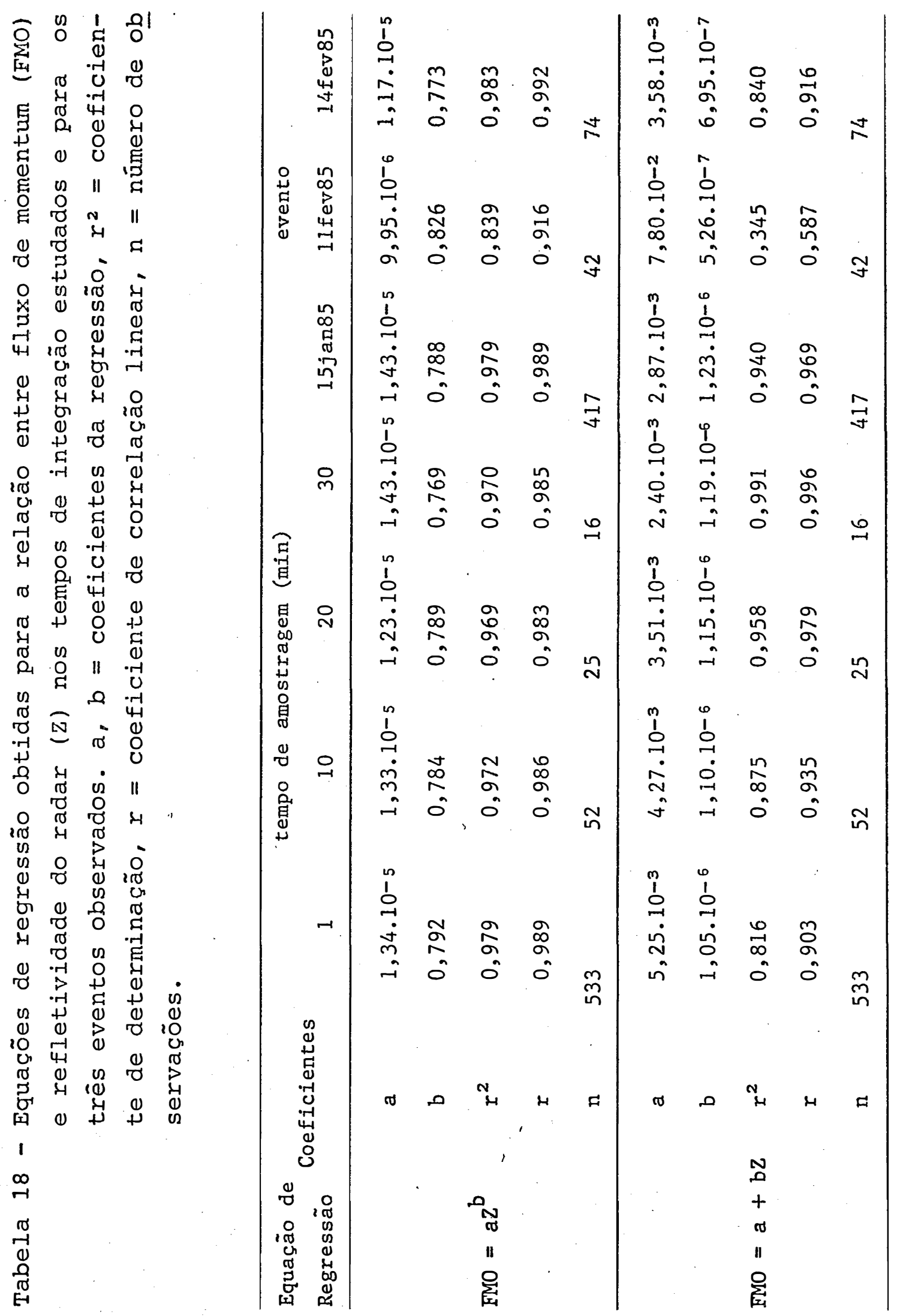


A utilização das relações analíticas deriva das, considerando-se o espectro exponencial inverso, permite que relações entre, por exemplo, energia e taxa de precipitação, sejam obtidas a partir de equações zR citadas na literatura. Exemplos dessas relações são apresentadas na Figura 27 e na Tabela 19, onde as relações ZR utilizadas são as citadas por FUJIWARA (1965). A análise dessa figura mostra que os dados observados estão dentro de uma grande faixa de relações $\mathrm{ZR}$ experimentais obtidas para vários tipos de sistemas precipitantes. Somente a curva para $z=$ 70R 1,4, foge bastante dos dados experimentais, por se tratar de uma relação obtida para espectros de gotas muito pequenas, não es tudados neste trabalho.

4.5. Aplicações do radar meteorológico ao estudo da erosão

A quantifiração do solo transportado pela ação erosiva da chuva, que incide sobre um local, depende do conhecimento da relação existente entre o parâmetro de erosividade, composto por energia ou momentum, associados à parâmetros relativos ao poder erosivo do escoamento superficial, e a quantidade de solo transportada, além de outros fatores que determinam o proces so erosivo. A partir desse conhecimento é possivel utilizar o radar para estimar a variabilidade temporal e espacial da erosão dos solos. 


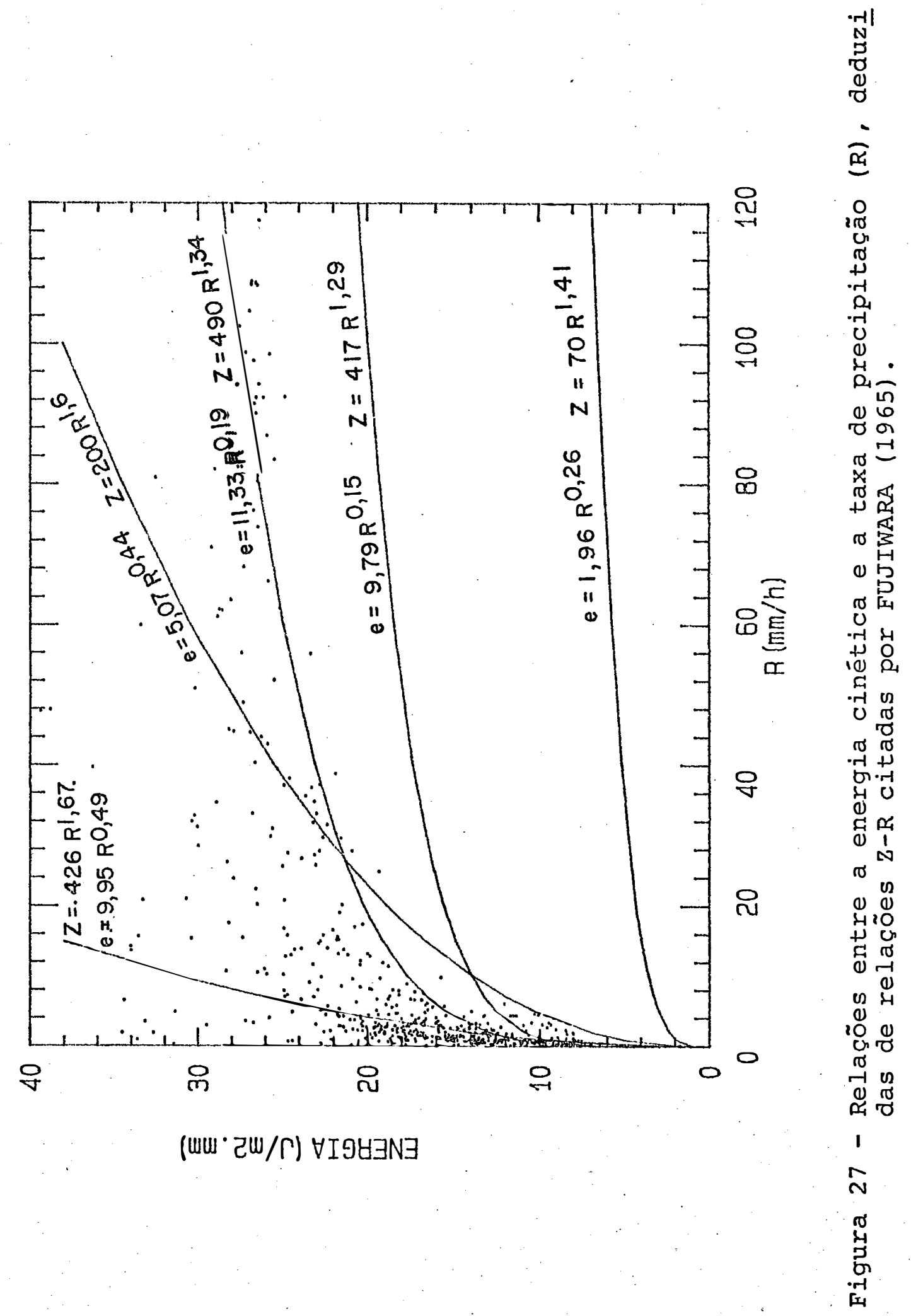


Tabela 19 - Equações analiticas entre energia cinética (e) e ta$x a$ de precipitação $(R)$ derivadas de relações $z-R$ obtidas da literatura. $\mathrm{A}, \mathrm{B}=$ coeficiente da relação $\mathrm{Z}=$ $A R^{B} ; c, d=$ coeficientes da relação $\Lambda=c R^{d} ; m, n=$ coe ficiente da relação $e=\mathrm{mR}^{\mathrm{n}} ; \mathrm{a}=3,25, \mathrm{~b}=0,76$ coeficiente da relação $v=a D^{b}$.

\begin{tabular}{rrrrrr}
\hline \multicolumn{1}{c}{$\mathrm{A}$} & $\mathrm{B}$ & $\mathrm{c}$ & \multicolumn{1}{c}{$\mathrm{d}^{(2)}$} & $\mathrm{m}^{(3)}$ & \multicolumn{1}{c}{$\mathrm{n}^{(4)}$} \\
\hline 200 & 1,60 & 4,33 & $-0,23$ & 5,07 & 0,44 \\
70 & 1,41 & 5,04 & $-0,20$ & 1,96 & 0,26 \\
490 & 1,34 & 3,81 & $-0,19$ & 11,33 & 0,19 \\
417 & 1,29 & 3,90 & $-0,18$ & 9,79 & 0,15 \\
426 & 1,67 & 3,89 & $-0,24$ & 9,95 & 0,49 \\
\hline
\end{tabular}

(1) $c=\left[\frac{\operatorname{No} \Gamma(7)}{\mathrm{A}}\right][1 / 7]$

(2) $\mathrm{d}=-\frac{\mathrm{B}}{7}$

(3) $m=K_{1} K_{3} \frac{\pi}{12} \quad a^{3}$ No $\frac{\Gamma(4+3 b)}{c(4+3 b)}$

(4) $n=-(4+3 b) d-1$ 
Com essa finalidade, as equações obtidas entre os parâmetros e, m, FEC, FMO, e a refletividade do radar (Z), per mitem que as imagens produzidas pelo radar, possam ser analisadas em termos do potencial, que as células do sistema precipitante têm, em causar erosão.

Assim, um PPI (Plan Position Indicator) (Figura 28), mapa de isolinhas de refletividade gerado pelo radar, ë convertido, através da equação $e=a z^{b}$ experimental obtida, em uma representação da energia cinética, associada a um sistema precipitante, que atinge uma área conhecida do espaço amostrado pelo radar.

Da mesma forma, O CAPPI (Constant Altitude Plan Position Indicator) (Figura 29), produzido pelo radar, permi te a avaliação da variabilidade do campo de FEC, no tempo e espaço, após conversão dos níveis de refletividade (Z) pela equação $\mathrm{FEC}=\mathrm{az}$.

Um aspecto de fundamental importância é a natụ reza espacial da distribuição do FEC e da energia durante uma tem pestade. Variações de até $0,1 \mathrm{~J} \cdot \mathrm{m}^{-2} \cdot \mathrm{s}^{-1}$ e de $7 \mathrm{~J} \cdot \mathrm{m}^{-2} \cdot \mathrm{mm}^{-1}$ são obser vadas em até 4 e $1 \mathrm{Km}$, respectivamente (Figuras 28 e 29). Como a natureza de células convectiva é caracterizada pela presença de intensos gradientes espaciais, as medidas pontuais tornam-se de pouca representatividade. 


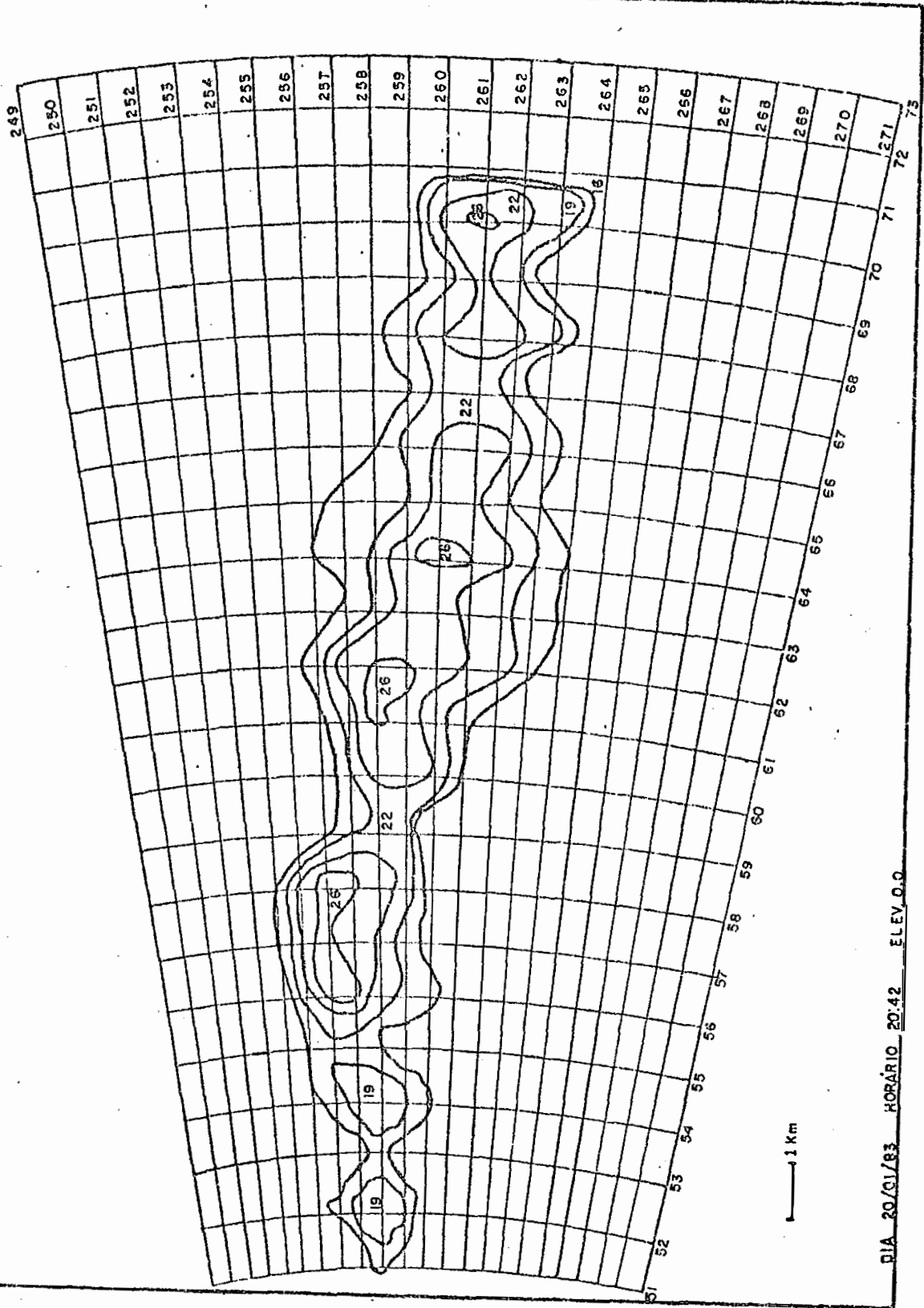

A

罗
$\vdots$
0
0

ชับ

- 1 a



ᄀis

$\overbrace{}^{-1}$

ह

No

1100

EU

i

0

(⿻) म

U

.

iaj en

स10

ن

(4)

ad 0

it 2

(1) \&

(1) +

(1) U

ه.

-

历

r-

$\cup E$

故

in

is

iิ

u

तै

- 5

का

$\rightarrow 5$

1
$\infty$
$N$
0
4
5
0
0
$-\pi$
-11 
CAPPI DE 3,5 KM - RAIO DE ALCANCE 157,5 KM 27-SET-82

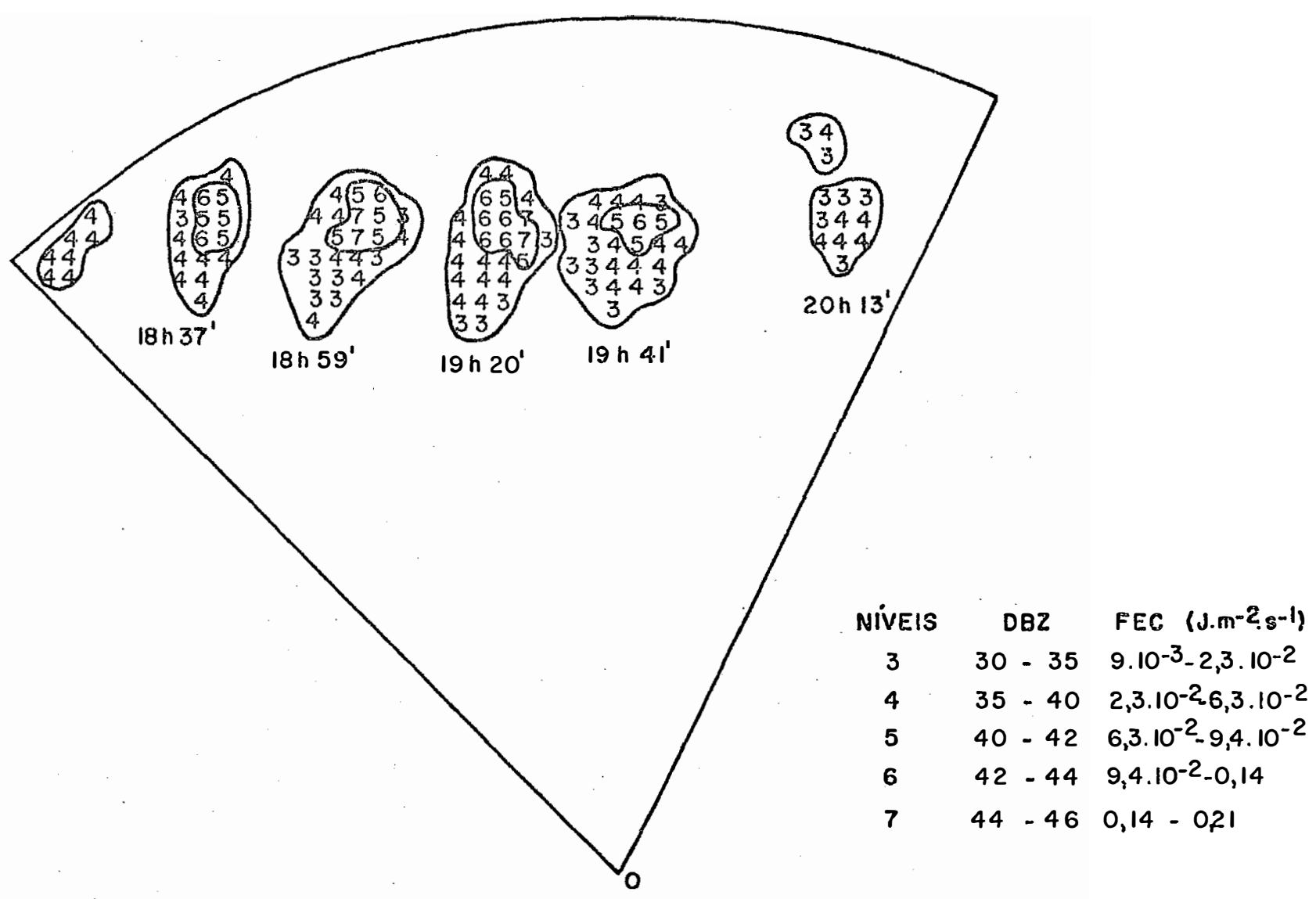

Figura 29 - Variação espacial e temporal de uma célula de precipitação. Cada número indica o nivel de refletividade do radar em dBZ e de fluxo de energia cinética (FEC) em uma área de $4 \times 4 \mathrm{Km}^{2}$. 


\section{CONCLUSÕES}

A utilização de um instrumento, como o disdrômetro, permitiu o acompanhamento e estudo da variabilidade tempo ral dos espectros de gotas ocorrentes durante chuvas convectivas, os quais são determinantes das relações entre os parâmetros de interesse. Portanto, desse estudo detalhado, destacam-se algumas conclusões principais, como:

- os espectros das chuvas convectivas estudadas caracterizam - se pela grande variabilidade ao longo dos eventos e pela não expo nencialidade, embora o fator de forma indique tendēncia à expo nencialidade, quando os mesmos são integrados durante períodos longos. 
- a acentuada variabilidade da forma dos espectros tem consequên cias sobre os valores de diâmetro mediano, energia cinética, mo mentum, fluxo de energia cinética e fluxo de momentum na sua relação com a taxa de precipitação e a refletividade do radar, de forma que as equações de regressão obtidas não descrevem a natureza física do processo.

- a equação do WISCHMEIER e SMITH (1958) para o cálculo da energia cinética da chuva não difere significativamente da equação encontrada e tal como recomendado por WISCHMEIER (1972), nao deve ser utilizada na estimativa da energia de eventos específicos.

- a energia cinética é função bem definida do diâmetro mediano da chúva, e a relação entre ambos deve ser observada na obtencão de simuladores de chuva que reproduzam os niveis de energia desejados.

os erros cometidos na estimativa do fluxo de energia cinética e do fluxo de momentum, a partir dos modelos experimentais ob tidos, são bem menores do que os cometidos na estimativa da energia cinética e do momentum, de forma que a energia e o momentum expressos como fluxo devem ser os parâmetros preferen ciais para a previsão. 
- a estimativa dos parâmetros a partir da taxa de precipitação e da refletividade do radar, utilizando-se as equações obtidas deve ser feita considerando-se que durante minutos isolados os valores reais podem ser subestimados em várias ordens de grandeza.

- as imagens geradas pelo radar meteorológico podem ser descritas em termos dos campos de fluxo de energia cinética, fluxo de momentum, energia cinética ou momentum, sendo que a sua utí lização mais específica nos estudos da erosão dos solos é possivel. 


\section{SUGESTÕES PARA FUTUROS TRABALHOS}

- Análise da melhor função analítica que descreva a natureza dos espectros de gotas em chuvas convectivas;

- Estudo da relação entre a energia cinética ou o momentum de gotas incidentes sobre amostras de solos caracteristicos das regiões brasileiras, para avaliação do salpico;

- Utilização de medidas dișdrométricas no estudo da erosão de solos em parcelas experimentais, procurando-se uma relação direta entre a energia cinética ou o momentum e a perda de solo; 
- Avaliação da relação entre a energia cinética e o diâmetro mediano e a vazão dos bicos aspersores de irrigação e de si muladores de chuva;

- Utilização dos dados de precipitação obtidos através do radar para a estimativa da perda de solo em bacias hidrográfi cas. 
.117 .

\section{REFERÊNCIAS BIBLIOGRÁFICAS}

ANIOL, R.; HARTMANNSGRUBER, R.; RIEDL, J., 1973. Erste

Ergebnisse von Messungen des Regentropfenspektrums am Hohenpeissenberg. Met. Rundschau, 26:137-141.

ANTONIO, M.A., 1984. Considerações sobre integração de medidas de chuva por radar. São Carlos, EESC/USP (Dissertação de mestrado) .

ATLAS, D.; PLANK, V.G. 1953. Drop-size history during a shower. J. Meteorology, 10:291-295. 
BATTAN, L., 1973. Radar observation of the atmosphere. Chicago and London, Univ. of Chicago Press, 324 p.

BEARD, K.V.; PRUPPACHER, H.R., 1969. A determination of the terminal velocity and drag of small waterdrops by means of a wind tunnel. J. Atmosph. Sci., 26(5):1066-1072.

BENTLEY, W.A., 1904. Studies of raindrops and raindrop phenomena. Mon. Weather. Rev., 32:450-456.

BERTONI, J.; PASTANA, F.I., 1964. Relação chuva-perdas por erosão em diferentes tipos de sol.o. Bragantia, 23:1-12.

BEST, A.C., 1950. The size distribution of raindrops. Q. J. R. Met. Society, 76:16-36.

BISAL, F., 1960. The effect of raindrop size and impact velocity on sand splash. Can. J. of Soil Science, 40:242-245.

BLANCHARD, D.C., 1953. Raindrop size-distribution in hawaiian rains. J. Meteorology, 10:457-473.

BUBENZER, G.D.; JONES JR., B.A., 1971. Drop size and impact velocity effects on the detachment of soils under simulated rainfall. Trans. ASAE, : 14:625-628. 
CAIMI, E.A.; MENZIES, Y.Q., 1978. Some aspects of raindrop size spectra in Buenos Aires. J. Rech. Atmos., 12(1):5-20.

CALHEIROS, R.V., 1982. Resolução espacial de estimativas de precipitação com radar hidrometeorológico. São Carlos, EESC/USP (Tese de Doutoramento).

CARTER, C.E.; GREER, J.D.; BRAUD, H.J.; FLOYD, J.M., 1974 . Raindrop characteristics in South Central United States. Trans. ASAE, 17(6):1033-1037.

CASTRO FILHO, C.; CATANEO, A.; BiscAiA, R.C.M.; 1982. Utilização da metodologia de Wilkinson para cálculo do potencial erosivo das chuvas em cinco localidades do Paraná. Rev. bras. ciênc. solo, 6:240-241.

CATANEO, R., 1969. A method for estimating rainfall rate-radar reflectivity relationships. J. Appl. Met., 8:815-819.

CAtaneo, A.; CAStro filho, C.; ACQUaRole, R.M., 1982. Programa para cálculo de índices de erosividade de chuvas. Rev. bras. Ci. Solo, 6:236-239. 
CATANEO, R.; STOUT, G.E., 1968. Raindrop-size distribution in humid continental climates, and associated rainfall rate-radar reflectivity relationships. J. Appl. Met., 7:901-907.

CZERWINSKI, N.; PFISTERER, W., 1972. Typen von

Regentropfenspektren von polaren bis $z u$ tropischen zonen und ihre Abhängjgkeit von Elementen des Regens. Met. Rundschau, $25(3): 88-94$.

DIEM, M.; STRANTZ, R., 1971. Typen der Regentropfenspektren II:Abhăngigkeit von der Regenintensitat. Met. Rundschau, $24(1): 23-26$.

DINGLE, A.N.; HARDY, K.R., 1962. The description of rain by means of sequential raindrop-size distributions (Plate VI): Q. J. Royal Met. Soc., 88(377):301-314.

DINGLE, A.N.; SCHULTE, H.F., 1962. A research instrument for the study of raindrop-size spectra. J. Appl. Met., 1:48-59.

DONNADIEU, G., 1983. Translation et rotation des spectres des gouttes de pluie dans des averses de nuages stratiformes et de nuages convectifs. La Houilie Blanche, 5/6:359-365. 
DOVIAK, R.J., 1983. A survey of radar rain measurement techniques. J. Clim. Appl. Met., 22:832-849.

EIGEL, J.D.; MOORE, I.D., 1983. A simplified technique for measuring raindrop size and distribution. Trans. ASAE, $26: 1079-1084$.

EKERN, P.C., 1950. Raindrop impact as the force initiating soil erosion. Soil Sci. Soc. Am. Proc., 15:7-10.

ELLISON, W.D., 1944. Studies of raindrop erosion. Agric. Eng., $25: 131-136,181-182$.

ELLISON, W.D., 1947. Soil erosion studies, Parts I-VII. Agric. Eng., 28:445-450.

ELWELL, H.A.; STOCKING, M.A., 1973. Rainfall parameters for soil loss estimation in a subtropical climate. J. agric. Engng. Res., 18:169-177.

FOOTE, G.B.; DUTOIT, P.S., 1969. Terminal velocity of raindrops aloft. J. Appl. Met., 8:249-253. 
FOSTER, G.R.; LOMBARDI, F.; MOLDENHAUER, W.C., 1982.

Evaluation of rainfall runoff erosivity factors for individual storms. Trans. ASAE, 25(1):124-129.

FREE, G.R., 1960. Erosion characteristics of rainfall. Agric. Eng., 41:447-455.

FREIRE, O.; CASTRO FILHO, C., 1977. A avaliação do potencial erosivo da chuva em Piracicaba. Rev. Agric., 52(2/3):105-111.

FUJIWARA, M., 1965. Raindrop-size distribution from individual storms. J. Atmosph. Sci。, 22:585-591.

GUNN, R.; KINZER, G.D., 1949. The terminal velocity of fall for droplets in stagnant air. J. Meteorology, 6:243-248.

HUDSON, N.W., 1963. Raindrop size distributions in high intensity storms. Rhod, J. agric. Res., 1:6-11.

HUDSON, N.W., 1964. A review of methods of measuring rainfall characteristics related to soil erosion. Research Bulletin no 1, South Rhodesia. 
HUDSON, N.W., 1965. The influence of rainfall on the mechanics of soil erosion with particular reference to kodesia. M. Sc. Thesis, South Africa, Univ. of Cape Town.

JONES, D.M.A., 1959. The shape of raindrops. J. Meteorology, $16(5): 504-510$.

JOSS, J.; GORI, E.G., 1978. Shapes of raindrop-size distributions. J. Appl. Met.. 17:1054-1061.

JOSS, J.; WALDVOGEL, A., 1967. Ein Spektrograph für Niederschlagstropfen mit automatischer Auswertung. Pure and Appl. Geophys., 68:240-246.

KINNELL, P.I.A., 1973. The problem of assessing the erosive power of rainfall from meteorological observations. Soil Sci. Soc. Am. Proc., 37:617-621.

KINNELL, P.I.A., 1981. Rainfall intensity-kinetic energy relationships for soil loss prediction. Soil Sci. Soc. Am. J., $45: 153-155$.

KINNELL, P.I.A., 1983. The effect of kinetic energy of excess rainfall on soil loss from non-vegetated plots. Austr. J. Soil Res., 21:445-453. 
LAL, R., 1984. Soil erosion from tropical arable lands and its control. Adv. Agron., 37:183-248.

LAWS, J.O., 1940. Recent studies in raindrops and erosion. Agric. Eng., $21(11): 431-433$.

LAWS, J.O., 1941. Measurements of the fall-velocity of waterdrops and rain-drops. Trans. Am. Geoph. Union, 22:709-721.

LAWS, J.O.; PARSONS, D.A., 1943. The relation of raindropsize to intensity. Trans. Am. Geoph. Union, 24:452-460.

LEPRUN, J.C., 1983. Primeira avaliação do diâmetro de gotas de chuva no Nordeste. In: Relatório do Fim do Convênio de Manejo e Conservação do Solo no Nordeste Brasileiro. ORSTROM/DRN/ SUDENE, Recife. p. 188-196.

LOMBARDI, F., 1977. Rainfall erosivity - its distribution and relationship with soil loss at Campinas, Brazil. MS Thesis, Purdue University, West Lafayette, Ind. $53 \mathrm{p}$.

MARSHALL, J.S.; PALMER, W. MCK. 1948. Shorter contributions The distribution of raindrops with size. J. Meteorology, $5: 165-166$. 
MASON, B.J.; ANDREWS, J.B., 1960. Drop-size distribution from various types of rain. Q. J. Royal Met. Soc., 86:346-353.

MASON, B.J. \& RAMANADHAM, R., 1954. Modification of the size distribution of falling rain-drops by coalescence. Q. J. Royal Met. Soc., 80:388-394.

MASSAMBANI, O.; BRIGUENTI, J.; CALHEIROS, R.V., 1983. A automação do processamento digital dos dados de precipitação obtidos por radar meteorológico em são Paulo. Congresso Nacional de Automação Industrial, 1, São Paulo - SP, Anais.

MCGREGOR, K.C.; MUTCHLER, C.K., 1976. Status of the R-factor in northern Mississippi. In: Soil Erosion: Prediction and Control. Soil Cons. Soc. Am., Ankeny, Iowa. p. 135-142.

MEYER, L.D.; MONKE, E.J., 1965. Mechanic of soil erosion by rainfall and overland flow. Trans. ASAE, 8(4):572-577.

MEYER, L.D.; FOSTER, G.R.; ROMKENS, M.J.M., 1975. Source of soil eroded by water from upland slopes. In: Present and Prospective Technology for Predicting Sediment Yields and Sources. USDA-ARS-S-40, p. 177-189. 
MUELLER, E.A., 1962. Raindrop distributions at Miami, Florida. Res. Rep. no 9B, Met. Lab., Univ. of Illinois.

MUTCHLER, C.K.; YOUNG, R.A., 1975. Soil detachment by raindrops. In: Present and Prospective Technology for Predicting Sediment Yields and Sources. USDA-ARS-S-40, p. 113-117.

PARK, S.W.; MITCHELL, J.K.; BUBENZER, G.D., 1983. Rainfall characteristics and their relation to splash erosion. Trans. ASAE。 26:795-804.

PEREIRA, H.H.G. 1983. Indices de erosividade da chuva distribuição e relação com a precipitação en Piracicaba - SP. Piracicaba, ESALQ-USP, 100 p. (Dissertação de Mestrado).

PRUPPACHER, H.R.; KLETT, J.D., 1980. Microphysics of clouds and precipitation. 2a edição. Dordrecht, D. Reidel Publ. Co. 714 p.

PUHAKKA, T., 1979. On the $\mathrm{Ze}-\mathrm{R}$ relationships in continuous and convective rain based on radar and rain gauge measurements. Report no 15, Dep. of Meteorology, University of Helsinki. 43 p. 
RIGBY, E.C.; MARSHALL, J.S.; HITSCHFELD, W., 1954. The development of the size distribution of raindrops during their fall. J. Meteorology, 11:362-372.

ROGERS, R.R., 1976. A short course in cloud physics. Oxford, Pergamon Press, 227 p.

ROGERS, J.S.; JOHNSON, L.C.; JONES, D.M.A.; JONES, B.A. 1967. Sources of error in calculating the kinetic energy of rainfall. J. of Soil and water Cons., 22:140-143.

ROSE, C.W., 1960. Soil detachment caused by rainfall. Soil Science, 89:28-35.

ROTH, C.H.; HENKLAIN, J.C.; FARIAS, G.S., 1985. Avaliação do tamanho de gotas de chuva natural e simulada para o Norte do Paraná. Rev. Bras. Ci. Solo. 9(2):171-174.

SEKHON, R.S.; SRIVASTAVA, R.G., 1970. SnOw size spectra and radar reflectivity. J. Atmosph. Sci, 27:299-307.

SMITH, P.L., 1982. On the graphical representation of raindrop size data. Atmosphere-Ocean, 20(1):4-16. 
STOCKING, M.A., 1978. The measurement, use and relevance of rainfall energy in investigations into erosion. $\mathbf{z}$. $\mathbf{f}$. Geomorph. Suppl. Bd., 29:141-150.

STRANTZ, R., 1971. Typen der Regentropfenspektren. Met. Rundschau, 24(1):19-22.

TWOMEY, S., 1953. On the measurements of precipitation intensity by radar. J. Meteorology, 10(1):66-67.

ULBRICH, C.W., 1983. Natural variations in the analytical form of the raindrop size distribution. J. Clim. Appl. Meteorology, 22:1764-1775.

ULBRICH, C.W., 1985. The effect of drop-size distribution truncation on rainfall integral parameters and empirical relations. J. Clim. Appl. Meteorology, 24:580-590.

ULBRICH; C.W.; ATLAS, D., 1984. Assessment of the contribution of differential polarization to improved rainfall measurements. Radio Sci., 19:49-57.

VAN ASCH, T.W.J.; EPEMA, G.F., 1983. The power of detachment and the erosivity of low intensity rains. Pedologie, 33:17-27. 
WALDVOGEL, A., 1974. The no-jump of raindrop spectra. J. Atmosph. Sci., 31(4):1067-1078.

WALDVOGEL, A., 1975. Tropfenspektren, Niederschlagstyp und z-R-Beziehungen. Met. Rundschau, 28:33-36.

WIESNER, J., 1895. Beitrăge zur Kenntnis des tropischen Regens. Sitz. Ber. K. Akad, Wissensch., Wien, Math. Naturswissensch. K1., 104:1397-1434.

WILIIAMS, M.A.J., 1969. Prediction of rain-splash erosion in the seasonally wet tropics. Nature, 222:763-765.

WILLIS, P.T., 1964. Functional fits to some observed drop size distributions and parametrization of rain. J. Atmosph. Sci.. $41(9): 1648-1661$.

WISCHMEIER, W.H., 1976. Use and misuse of the universal soil loss equation. J. of Soil and Water Cons., $31(1): 5-9$.

WISCHMEIER, W.H.; SMITH, D.D., 1958. Rainfall energy and its relationship to soil loss. Trans. Am. Geoph. Union, $39(2): 285-291$. 
WISCHMEIER, W.H.; SMITH, D.D., 1978. Predicting rainfall

erosion losses: a guide to conservation planning. Washington, USDA, 58 p. (Agric. Handbook 537).

WONG, R.K.W.; CHIDAMBARAM, N., 1985. Gamma size distribution and stochastic sampling errors. J. Clim. Appl. Met., $24(6): 565-579$.

YOUNG, R.A.; WIERSMA, J.L., 1973. The role of rainfall impact in soil detachment and transport. Water Res. Res., $9(6): 1629-1636$.

ZANCHI, C.; TORRI, D., 1980. Evaluation of rainfall energy in central Italy. In: Boodt, M. de; Gabriels, D. Assessment of erosion. New York, Ed. John Wiley Sons, p. 133-142. 
.131.

Apēndice 1 


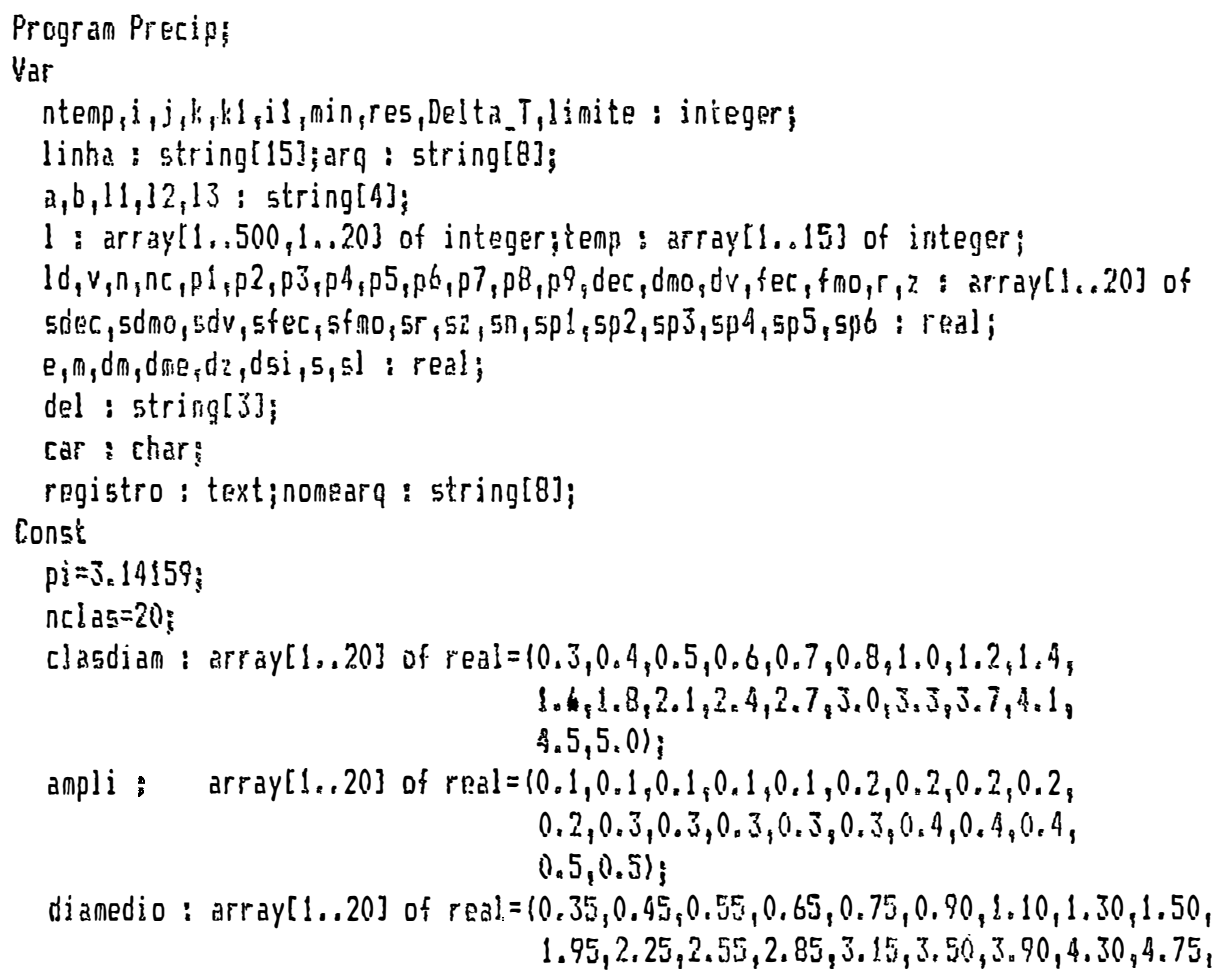

Tint : array[1..6] of intenger $=(1,5,10,15,20,30)$;

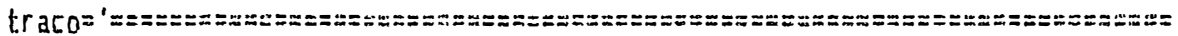

$\operatorname{cabl}=\prime$

cat $2=$

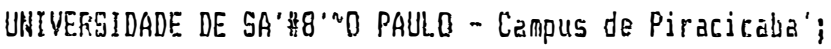

$\operatorname{cab} 3 \mathbf{I}^{\prime}$

C I A G R I - Centro de Informa'邦39'tica na Agricul tura

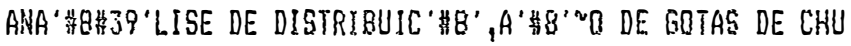

procedure spc;

Var

$k 1, k$ : integer:

beģin

$k 1:=\{; k:=0 ;\{$; writeln (length $(a), a) ;$ val $($ copy $(a, 1,4), i$, res $) ;$ writeln $(j) ;\}$

while $k<$ length $\{a\}+1$ do

begin

if $\operatorname{copy}(a, k, 1)=$ ' ' then $k=k+1 ;$

$k j:=k j+s i$

end;

$b:=\operatorname{copy}(a, f, t, 1$ length $(a)-k)$;

end: 


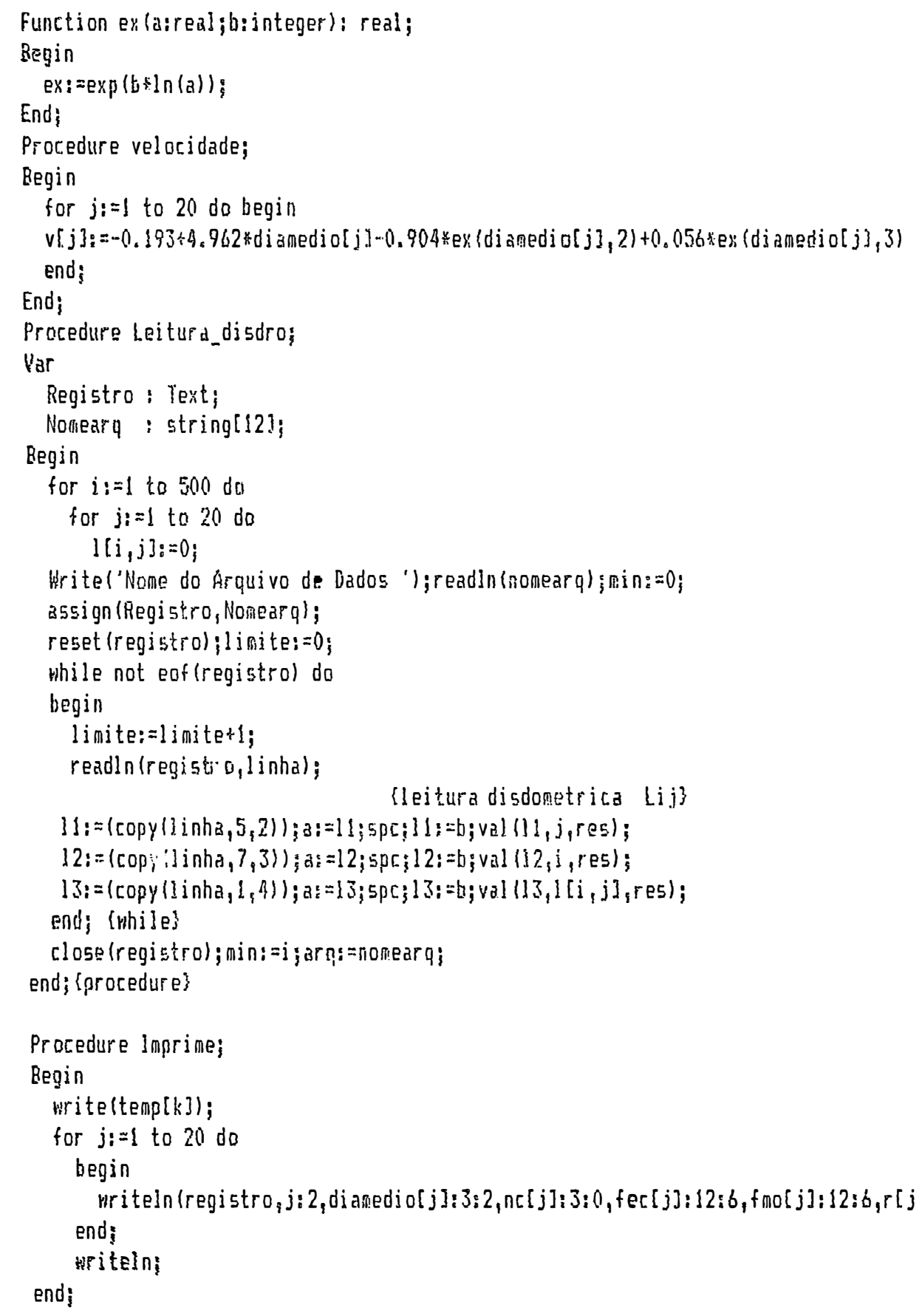


Procedure Calcula;

Regin

\{. while k limite do\} for $k:=1$ to ntemp do

begin

for $j:=1$ to 20 do

benjin

sl: $=0 ;$

$\{$ for $j:=k$ to $k+d e\}$ ta $t-1$ do $j:=t e m p[k]$;

$5]:=51+1[i, j]$; [leitupa disdrometrica media do periodo por

c.]asse\}

$\left.\operatorname{lo}[j]_{i}=5\right] ;$

$n[j]:=(] d[j] / v[j]) * 10 / 3 ;$ \{no, de gatas por volume e por $r]$ as5e $\}$

$n \in[j]:=n[j] / a m p] i[j] ;$ \{Na, de gotas por volume e por inter -

yalo de c]asse\}

\{Produtus: :

$p\lfloor[j]:=n[j] * d i$ amedio $[j] ; p][j]:=n[j] * d j$ amed $j o[j] * d j$ amedio $[j] ;$

$p 3[j]:=n[j]$ :ex $(d i$ amedio[ $[j], 3) ; p 4[j] ;=n[j] *$ ex (di amedio[j], \{) ;

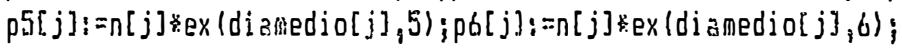

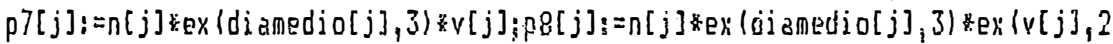

$p q[j]:=n[j]$ kex (di ânedjo[j], 3$) * \operatorname{ex}(v[j], 3)$ :

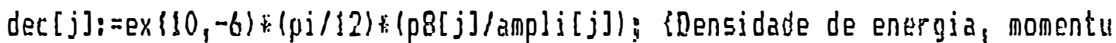
$\left.d m o[j]_{:}=e x(10,-6) *(p i / 6) *(p 7[j] / a m p] i[j]\right) ; \quad$ \{e volume de ppt por intervalo $d v[j]:=p i / 6 * p 3[j] ;$

\{de c]asse\}

fer $[j]:=\operatorname{ex}(10,-6) *(p i /] 2) *(p 9[j] / a m p] i[j]) ;\{f] u x o$ de energia, momentum $\}$

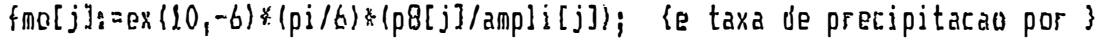
$r[j]:=3.6 * \operatorname{ex}(10,-3) *(p j / 6) *(p 7[j] /$ anp $][j j]) ; \quad$ intervalo de $c]$ asse?

\{Refletividade do radar pof interva\}o de classe:

$z[j]:=p 6[j] /$ amp $] i[j]$;

encis $\{$ for $j\}$

sdec: $=0 ;$ sdmo: $=0 ; 5 d v:=0 ; 5\}$ ec: $: 0 ; 5 f m o:=0 ; s r:=0 ; 52:=0 ; 5 n:=0 ; 5 p l:=0 ; 5 p 2:=0 ;$

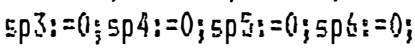

for $j i=1$ to 20 do

begin

sdec: $=5 d e c+d e c[j] * a s p] j[j]$; \{Densidade de energia, momentum e de

sdmo: $=5 d m o+d m o[j]$ ampli $[j]$; \{volume de ppt $\}$

$5 d v:=5 d v i d v[j\}$ rampli $[j] ;$

sfec: $=5\{e c+f e c[j]$ tampli[j]; \{Fluxo de energja, momentub e laxa de ppt\} sfmo: $=5 f$ motfmo[j] $\mathrm{k}$ ampli $[j]$; 


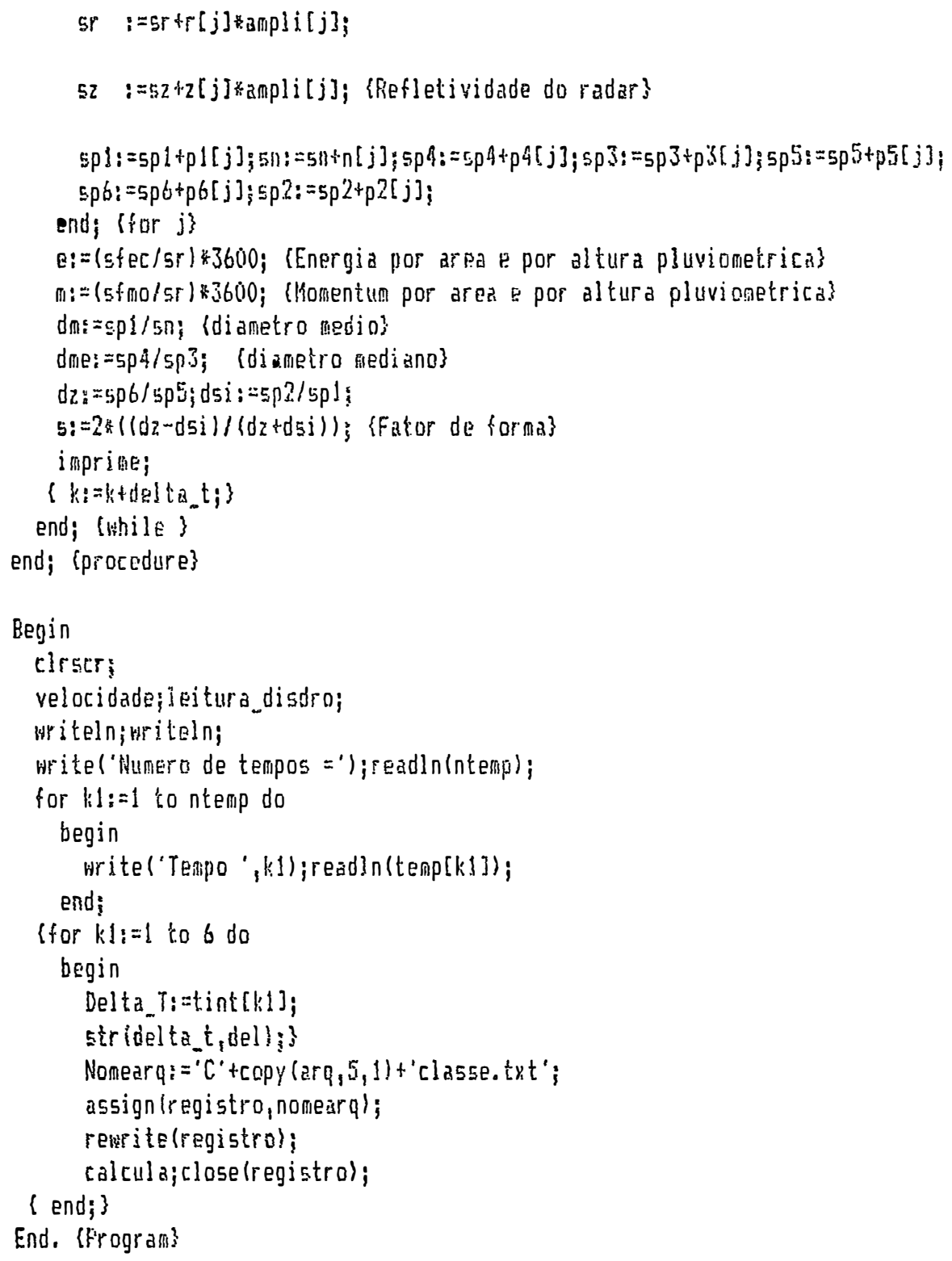

End. LFrogram? 
.136.

Apêndice 2 


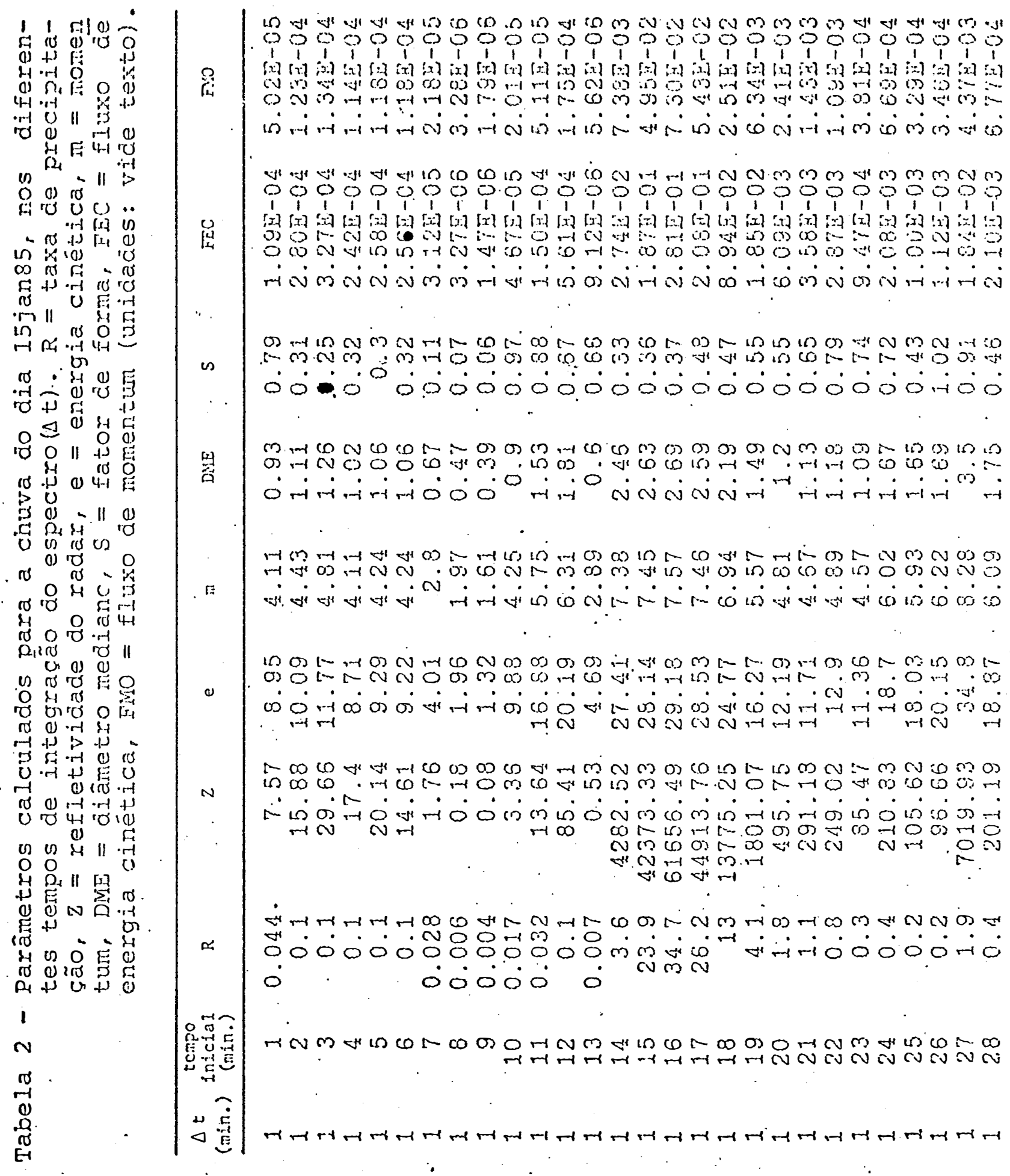




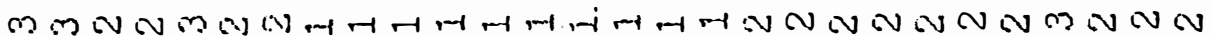

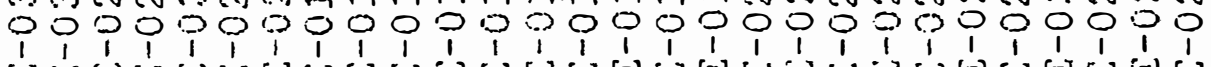

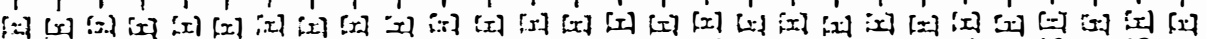
W

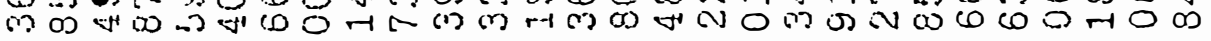

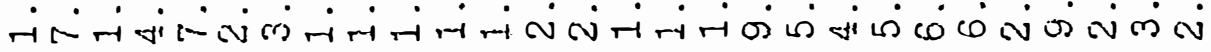

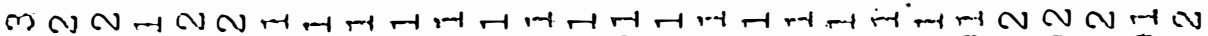

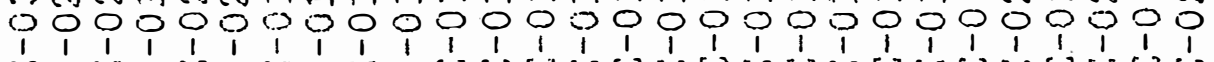

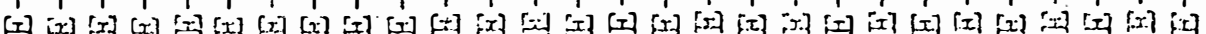

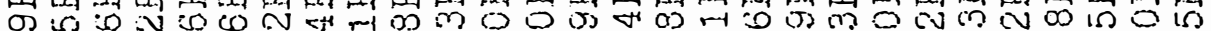

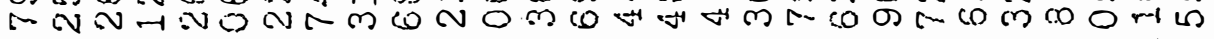

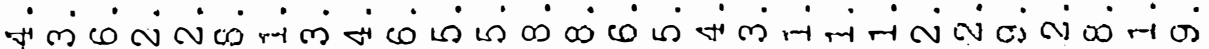

L 级.

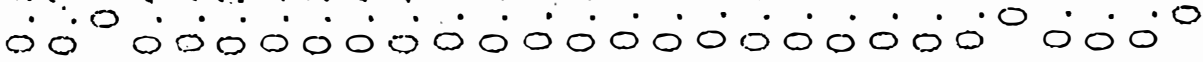

A N N ri $\mathrm{T}$ स

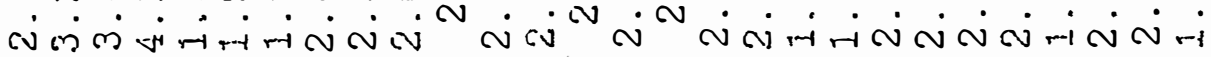

$\therefore$ - m

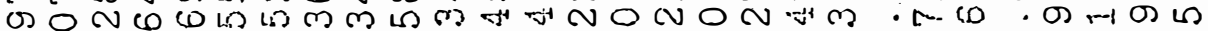

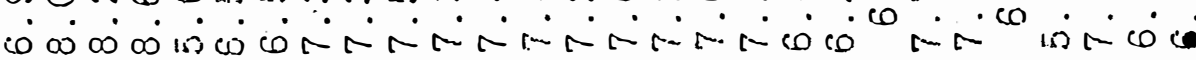

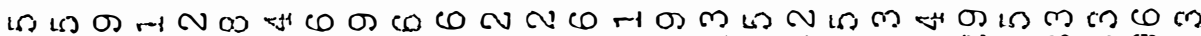

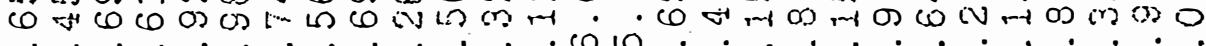
सं

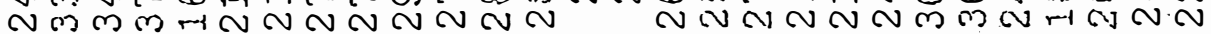

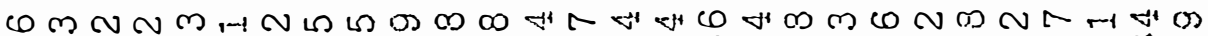

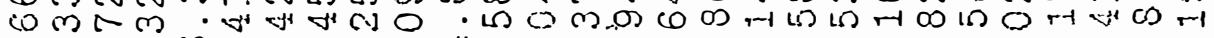

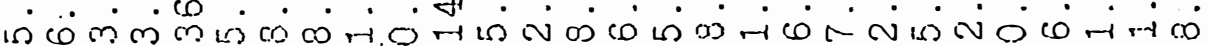

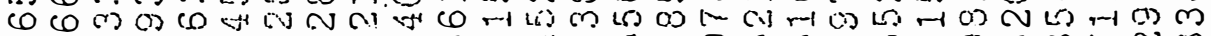
ca

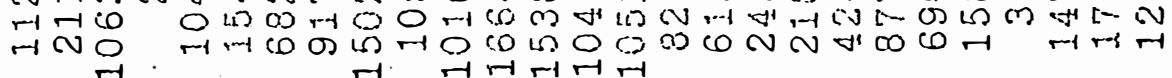
N

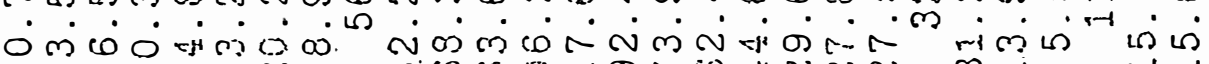
m $\mathrm{N}$ W

O) ONMM ल 


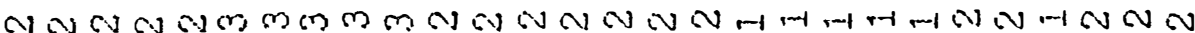

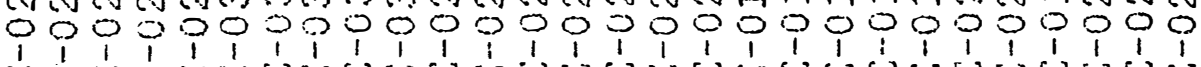

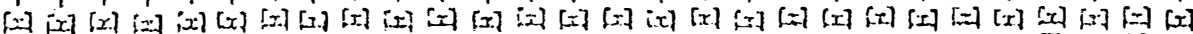

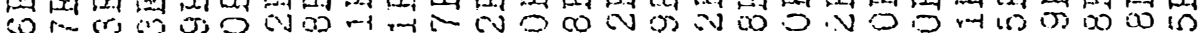

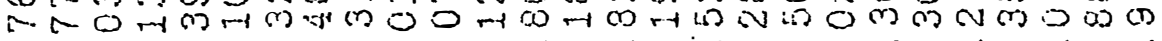
ن

N U

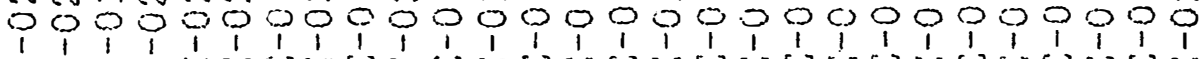
(x) [x] $x][x][x][x][\because][x] f(x)[x][x][x][x][x][x][x][x][x][x][x][x][x][x][x][x][x][f][x]$ (x)

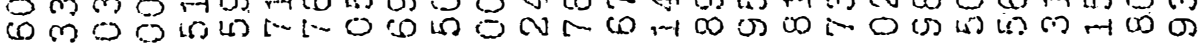

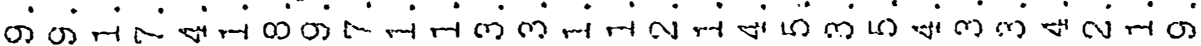

L A R

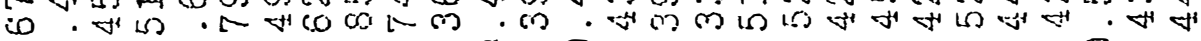

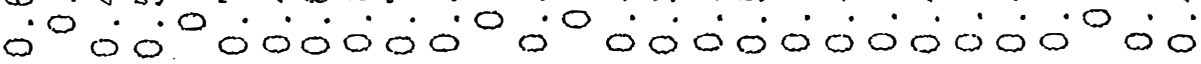

mLN" CL L

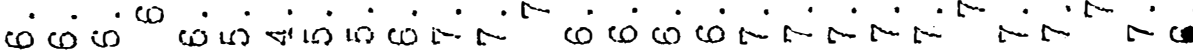

a

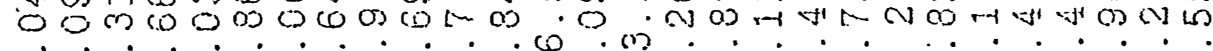

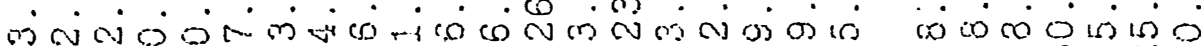

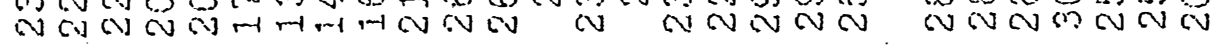

m

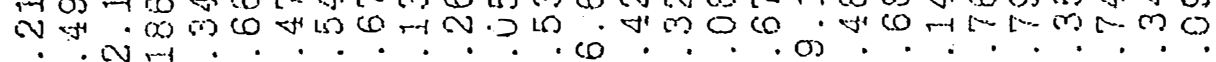
के

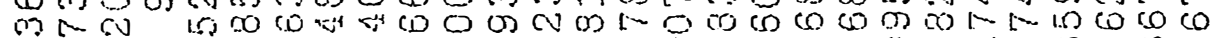
i 0 स

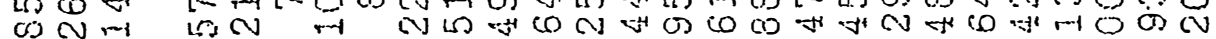

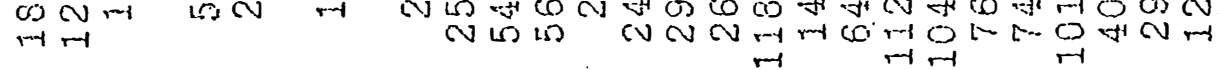

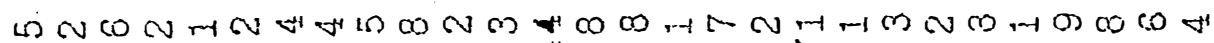
incon N" N N

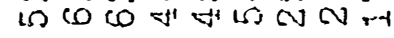

ำ

a in 


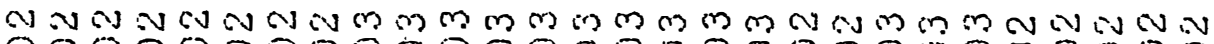
1900090000000900090000090000

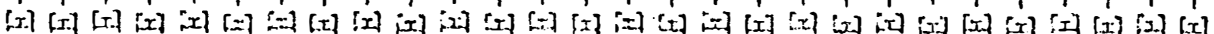

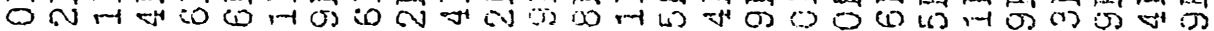
जDOK लि

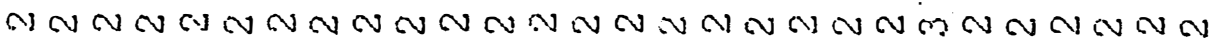
0000000000000000000000000000

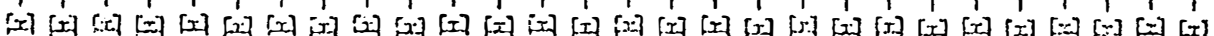

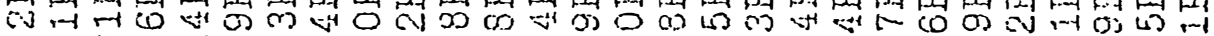
A. -

क

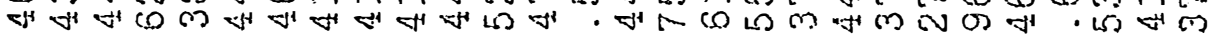

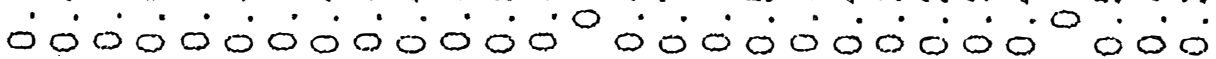

$\infty$ L I 5 O 0 .

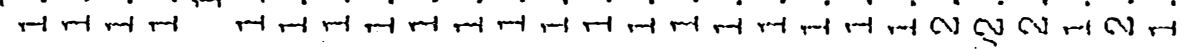

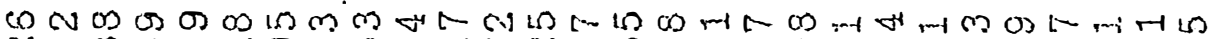
N ${ }^{\circ}$ क ف

L N

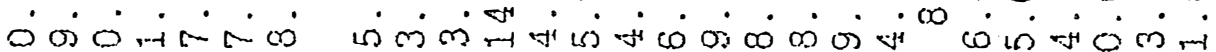
तो

का स स स

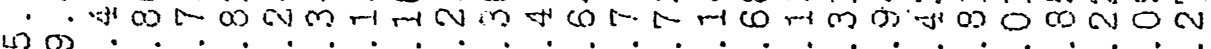

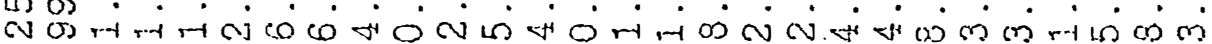

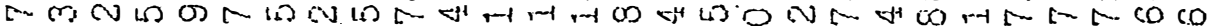

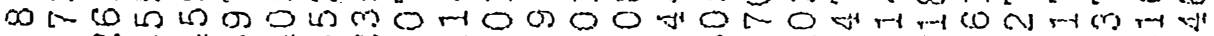

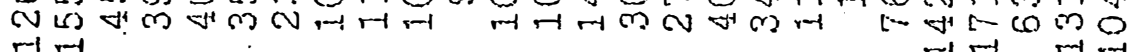

NOTNOW MLITMMNG

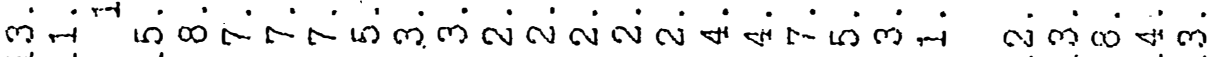
mi mi

15ं

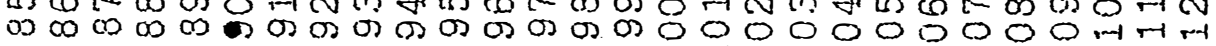

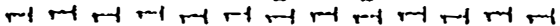




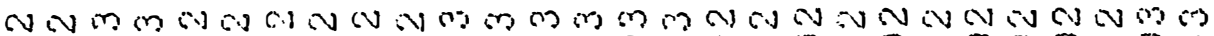

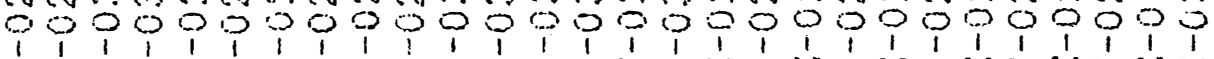

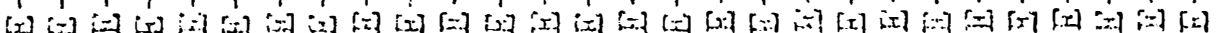
(1)

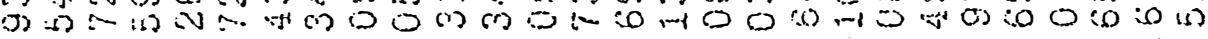
ی

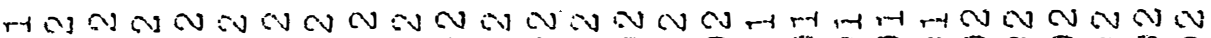

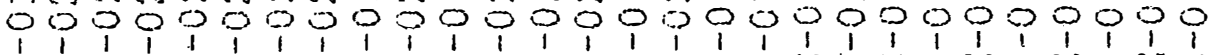

u $\quad$ (

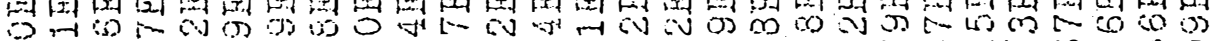
C) 8 ov

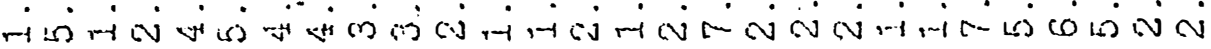

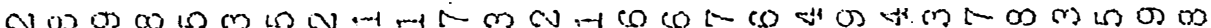

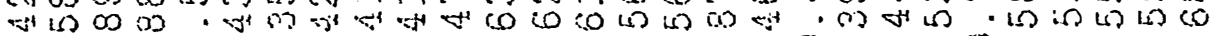

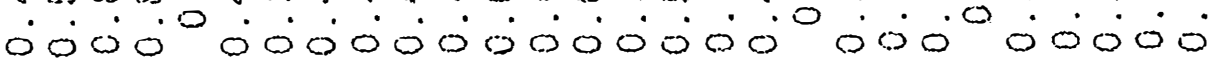

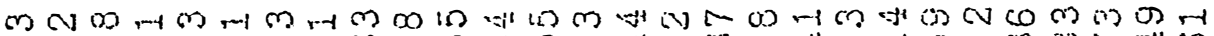

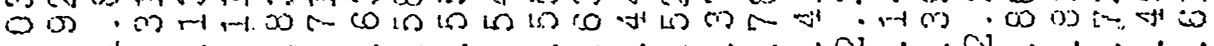

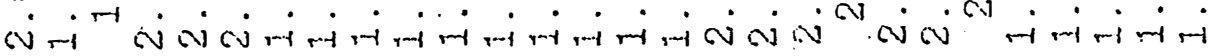

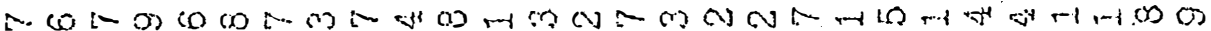

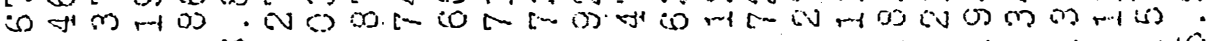

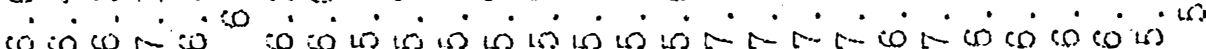

1. 0 स

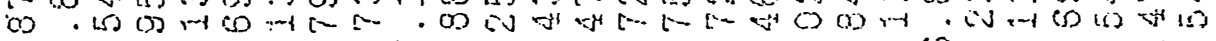
a

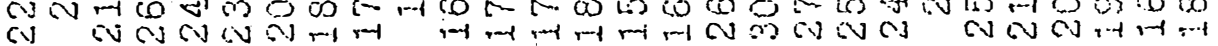

Q

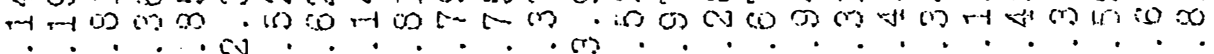
स …

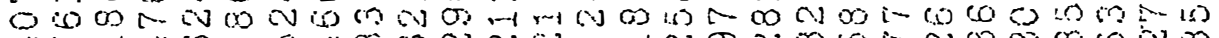

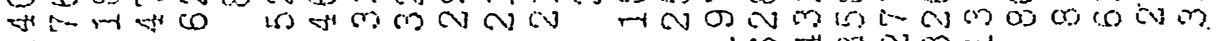
$\rightarrow 1$

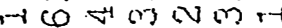

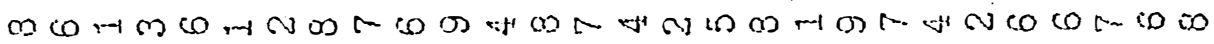

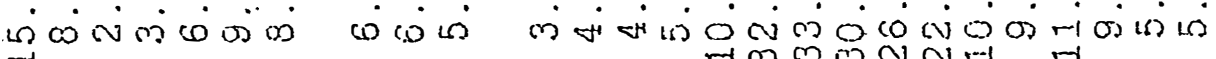
$m$

$0 \rightarrow 0$

जस

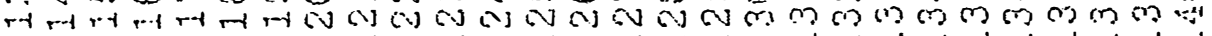

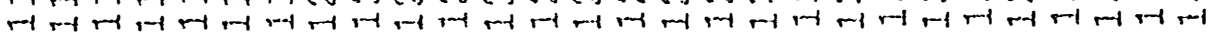




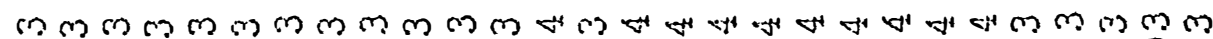

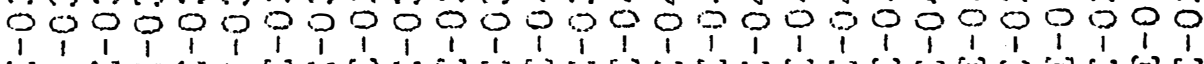

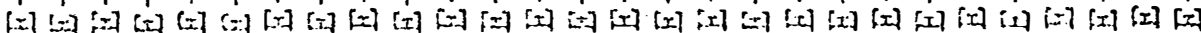
(v)

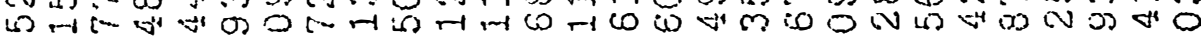

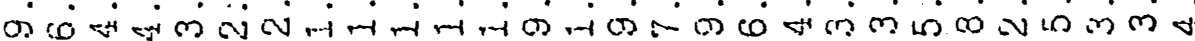

N N

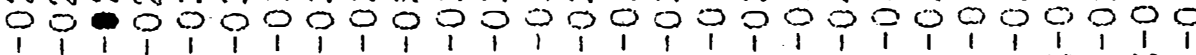

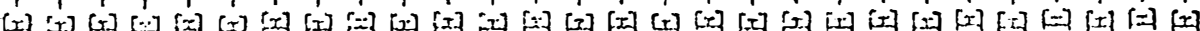
ब. CO

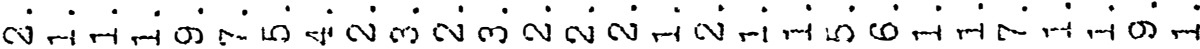

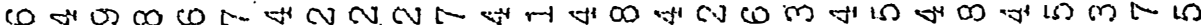
$0^{\circ}$ is th th th th a

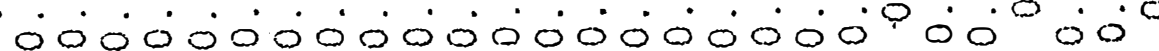

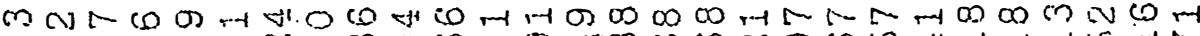

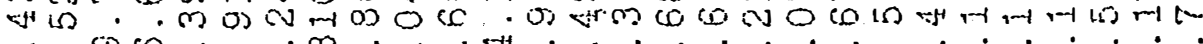

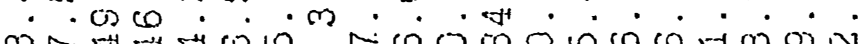
$m$ a DCN

HOMn H.

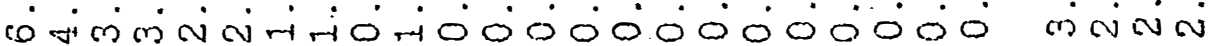

CUR NON

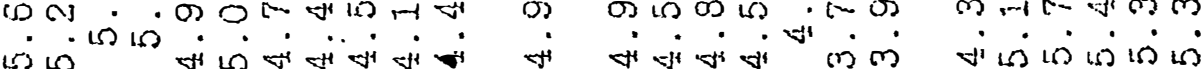

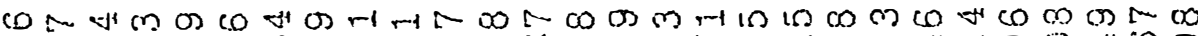
t

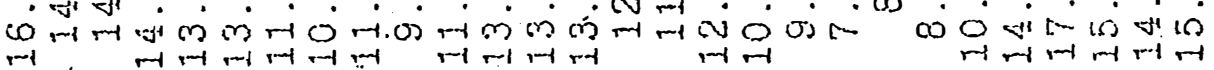

HNM G W W W

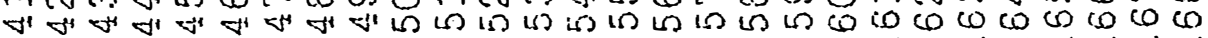

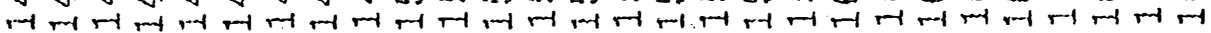
भન 


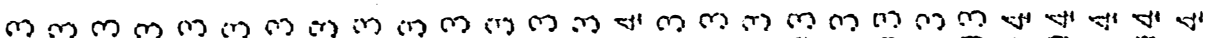
S0000000000000000000090\%0000

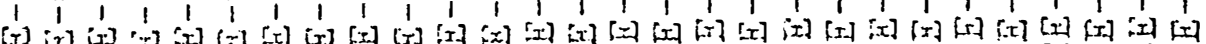

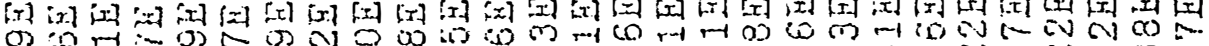

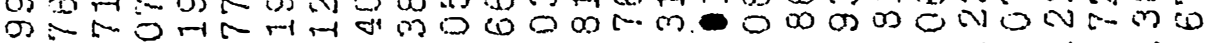
लि

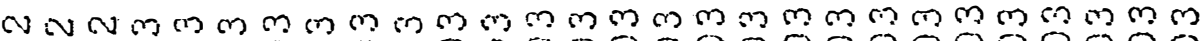
1009000000000900000000000000

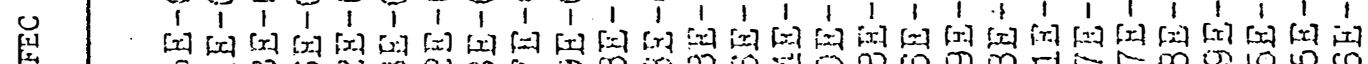

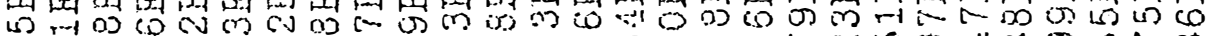

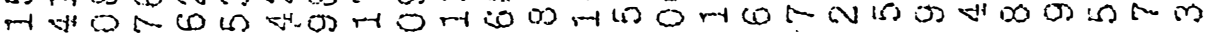
m-i

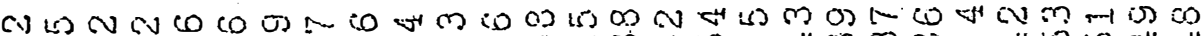
in . is - 0 ódó0.

N स

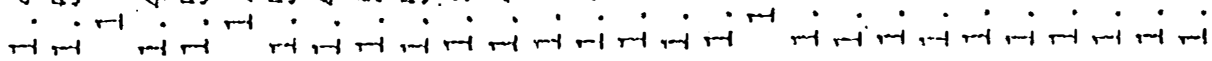

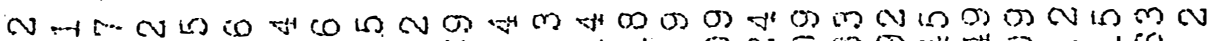

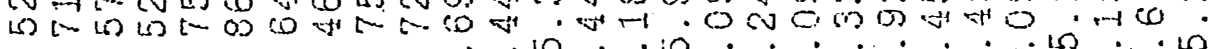
穴

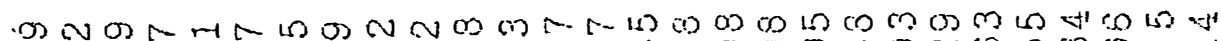

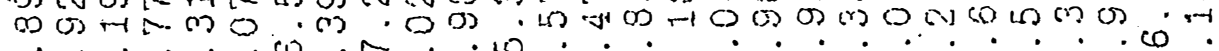

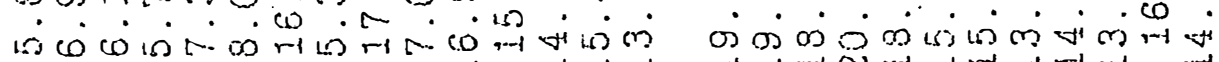

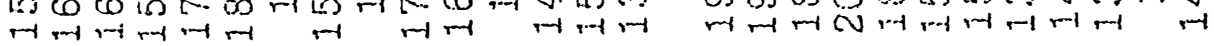

L 2 mid . O. M

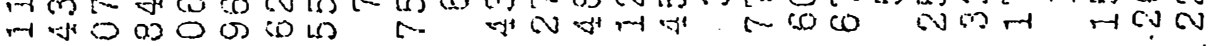
$\rightarrow-1, r$

cos)

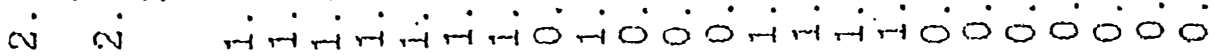

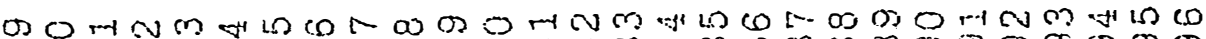

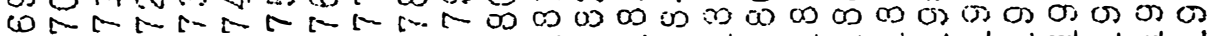


蔽

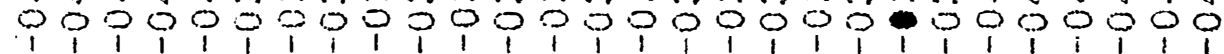

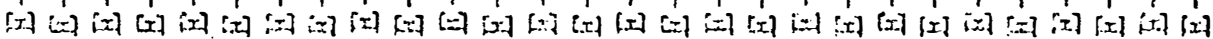

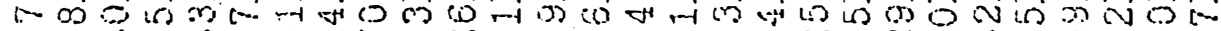

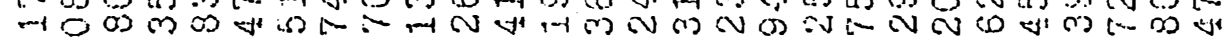
सं

mammmm nm

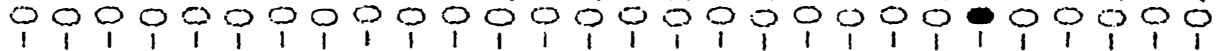

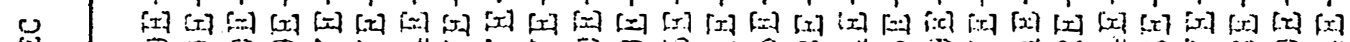

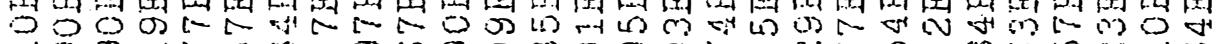

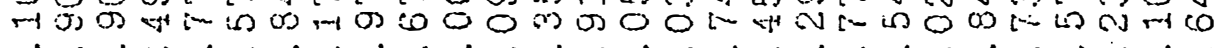

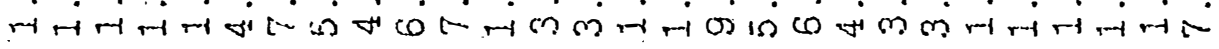

$[$ [

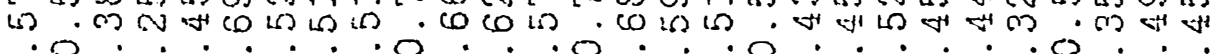

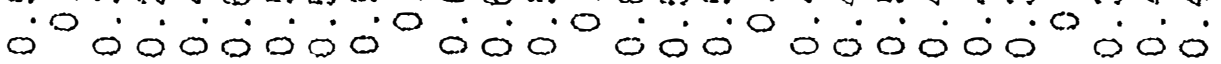

[n

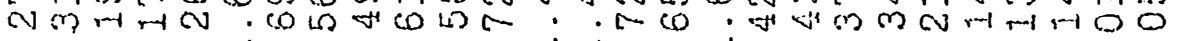

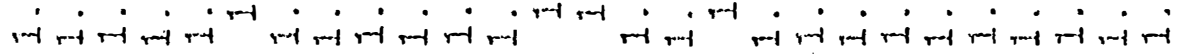

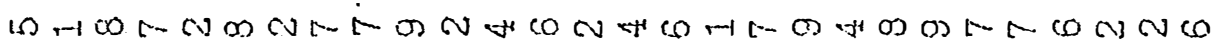

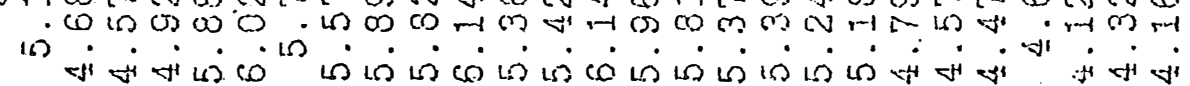
en a di

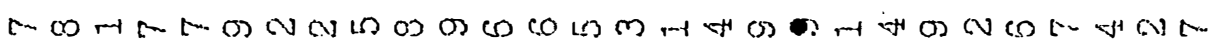
HC

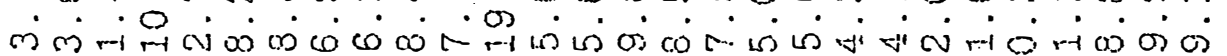

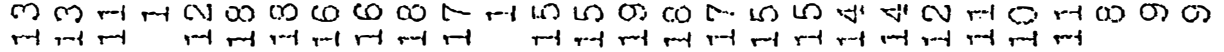

t.r.

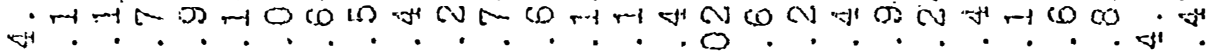
O

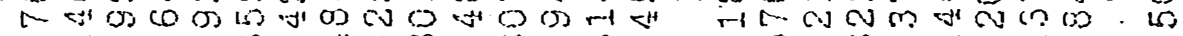
-1 -1 r w

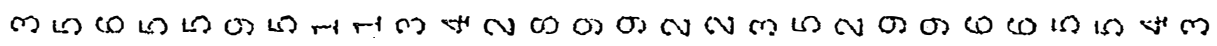

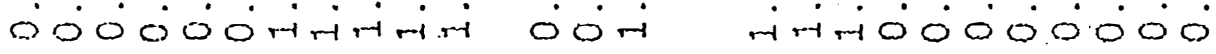

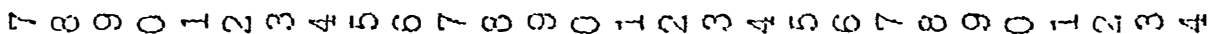

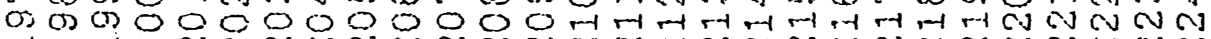
m RT 
-

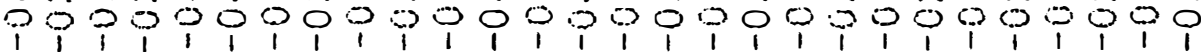

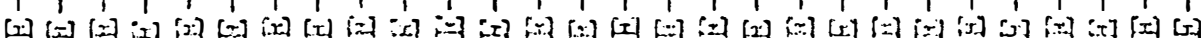

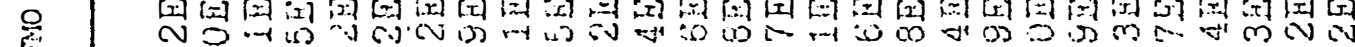
共

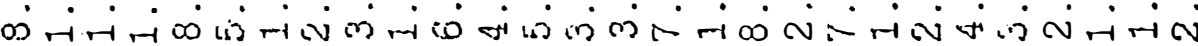

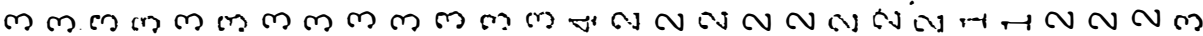

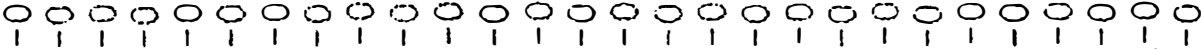

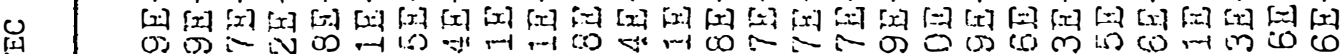

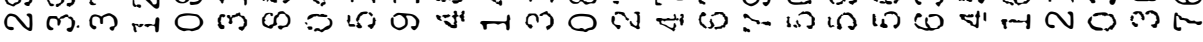

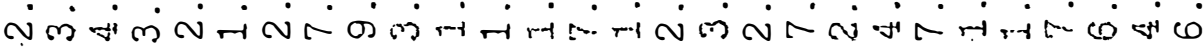

es

约

日

$m \infty \omega \pi=m \cdot \omega n$ m

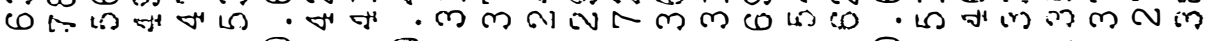

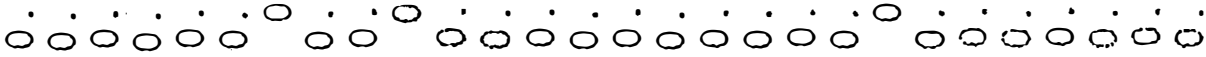

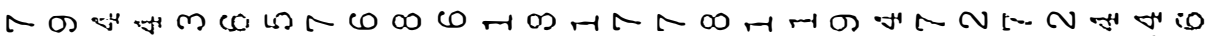
N

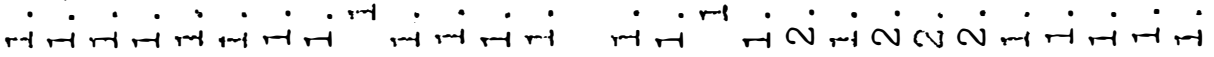

(4) [-

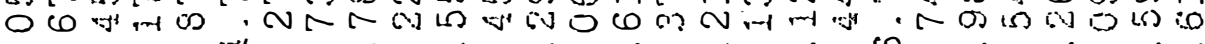
أما

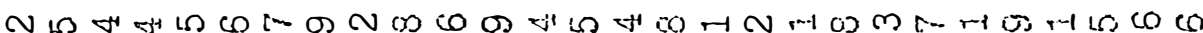

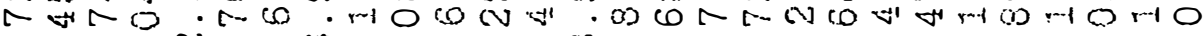

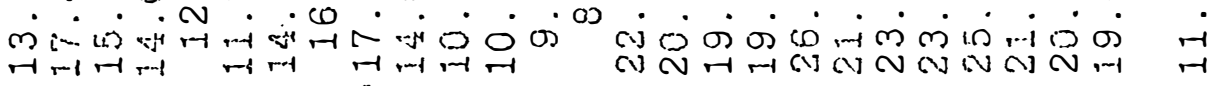

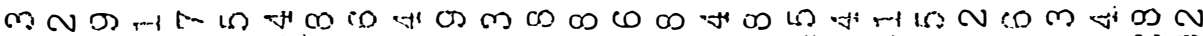
mAN लाओम Cu 0 -

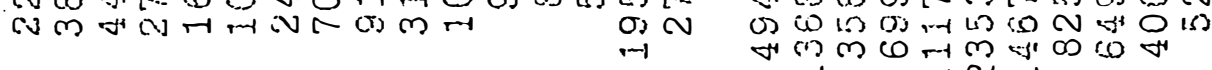
-1 H C.

cor

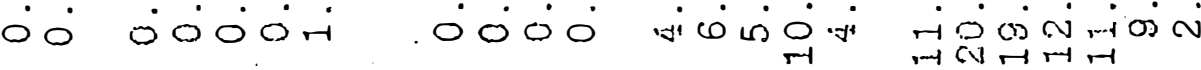

L

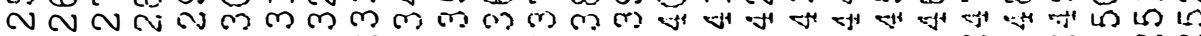

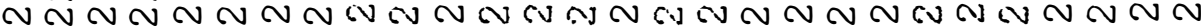

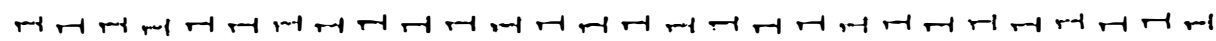




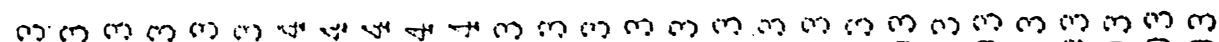

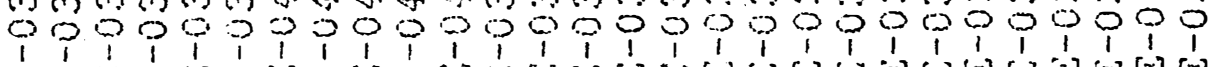

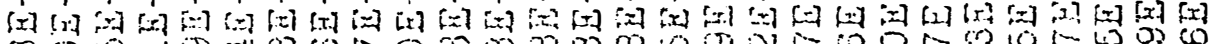

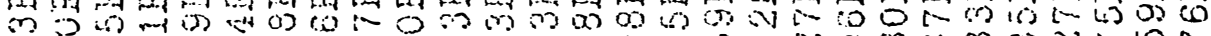

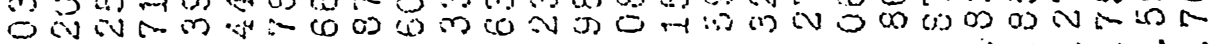

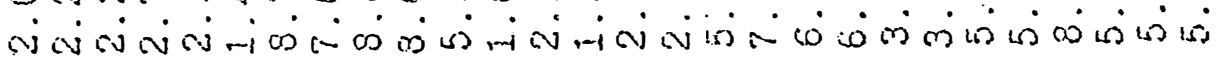

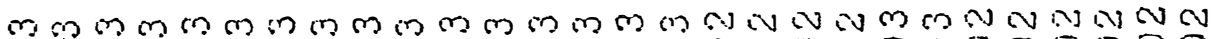

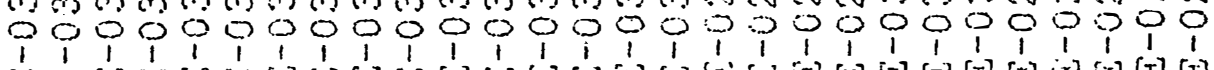

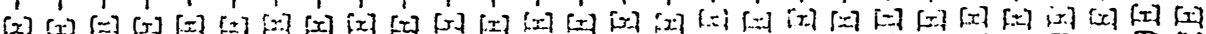

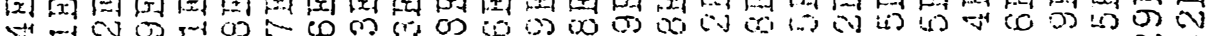
$0=0 \%$ O स

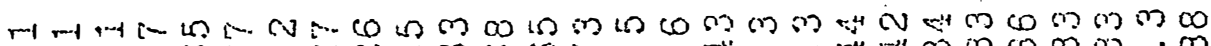
.

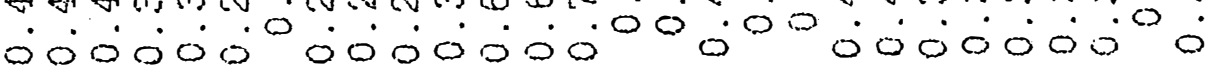

40 M 世

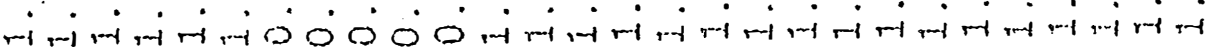

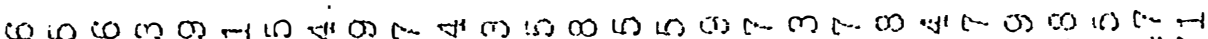

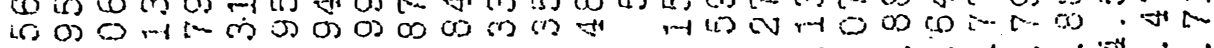
सi

[

๑

$N$

$\infty$

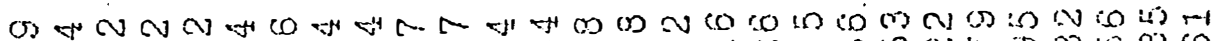

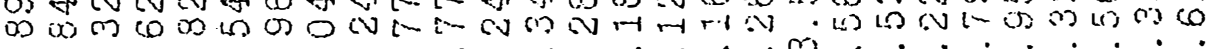
-

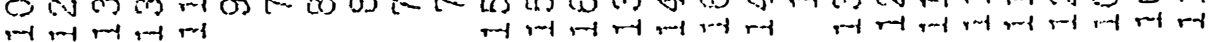

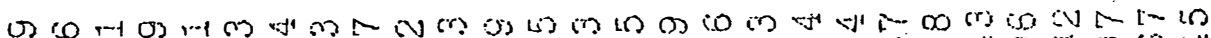

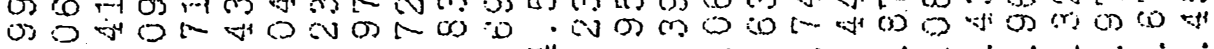
с

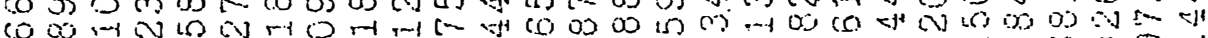

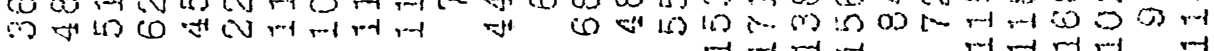

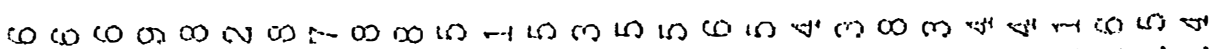

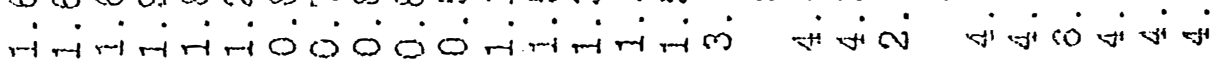

m $\mathrm{m}$ स

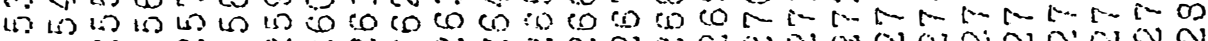

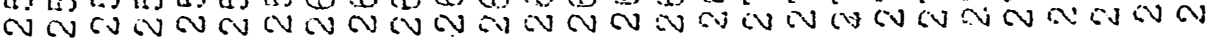

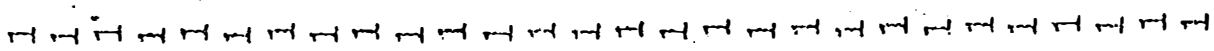




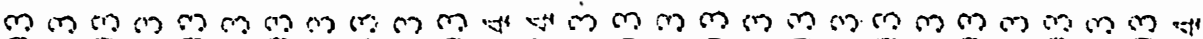
की

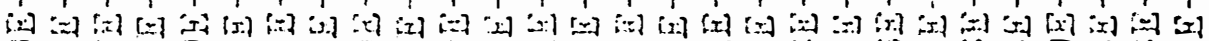

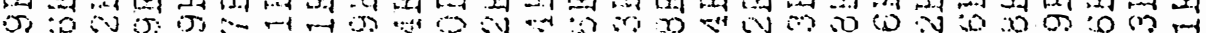

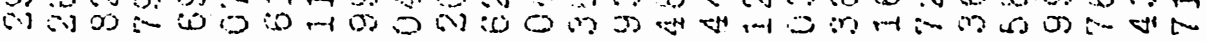
स

बm m 1090900000000000000000900000

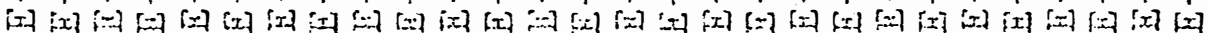

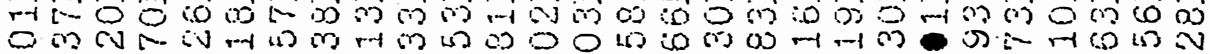
- -100 क

L N M (n

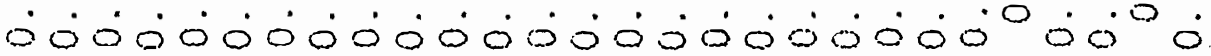

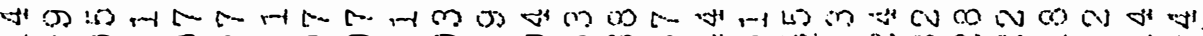

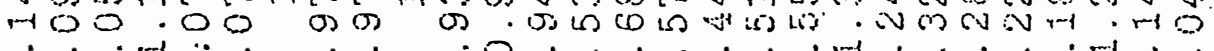

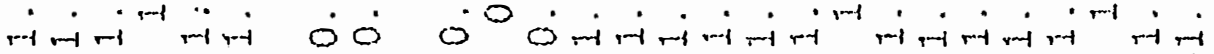

सा

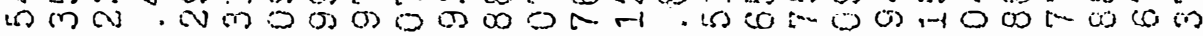

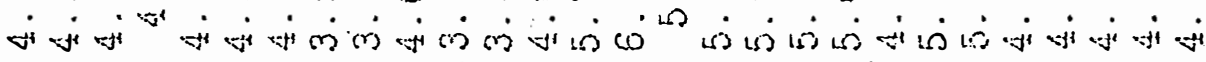
Ai

H

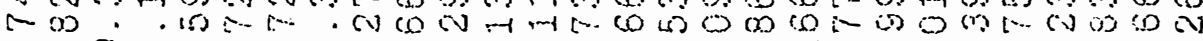

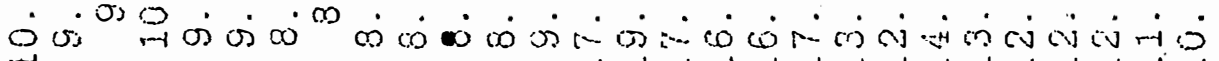

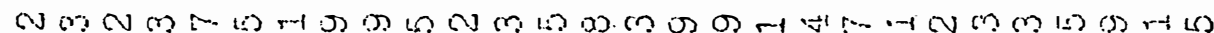

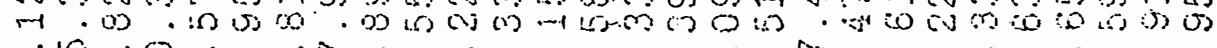
मे

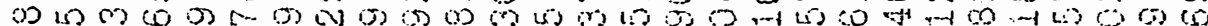
‥ 4 1

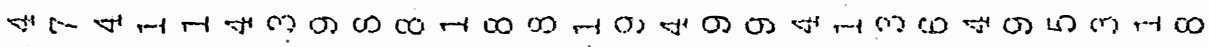

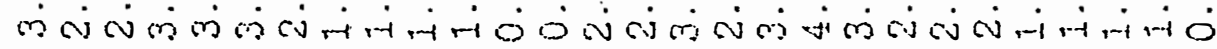

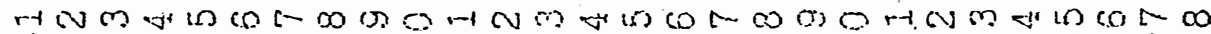
W
a 


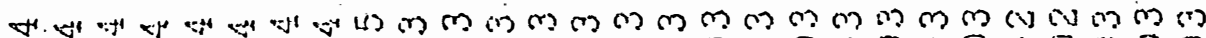

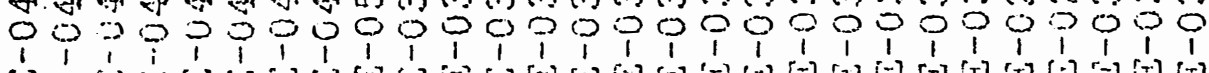

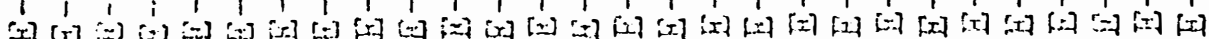

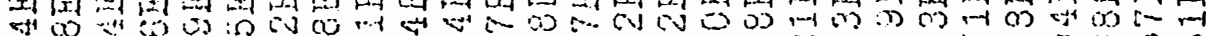

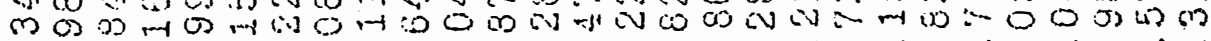
क

$n m m$ m $m$ m

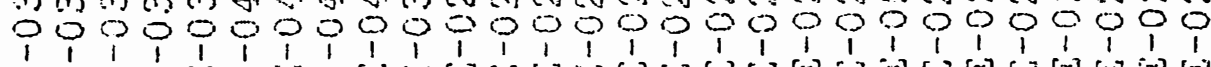
[x] a

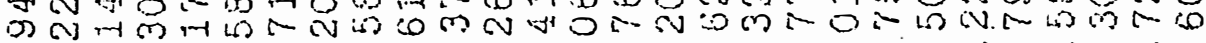

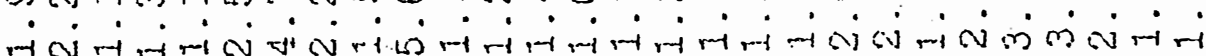

Nm

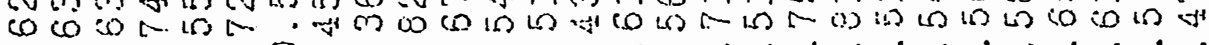

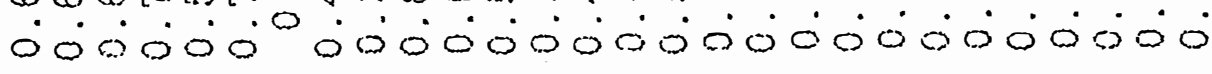

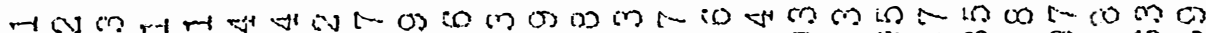

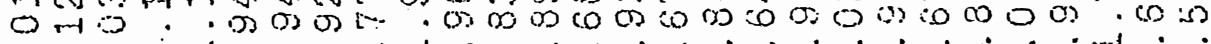

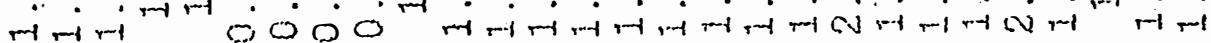

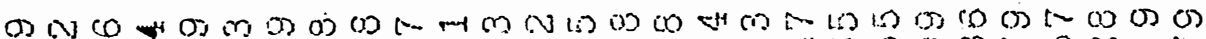

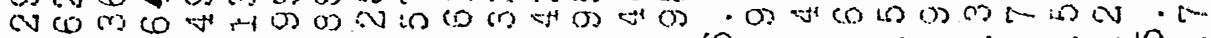

口

$\omega$

$N$

r.

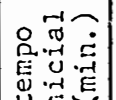

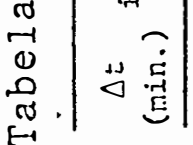

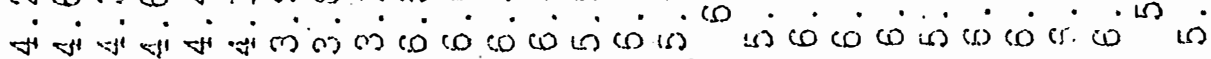

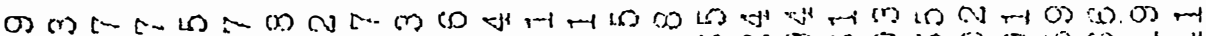

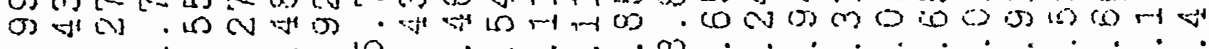

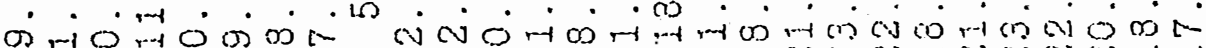

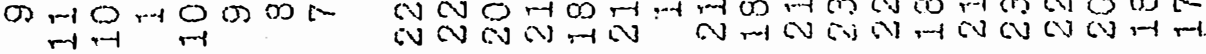

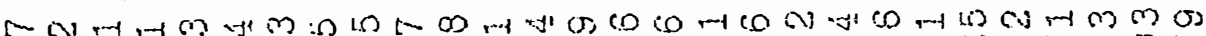
mo

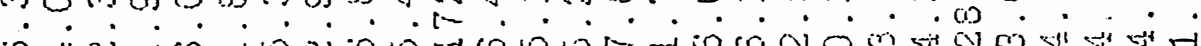

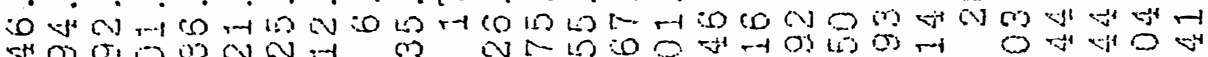

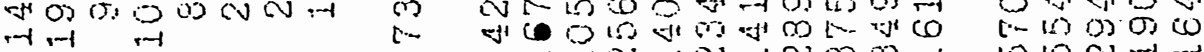

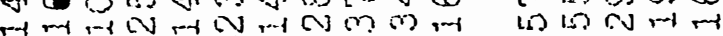

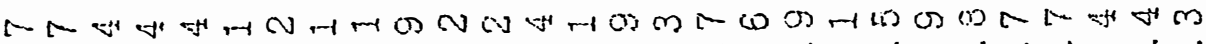

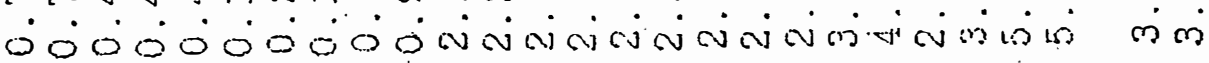

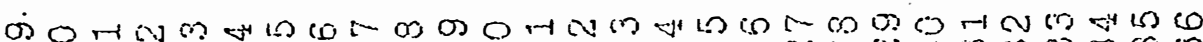
0 -

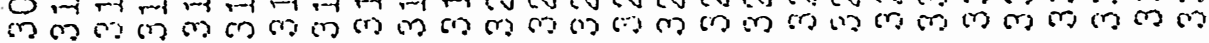


n i

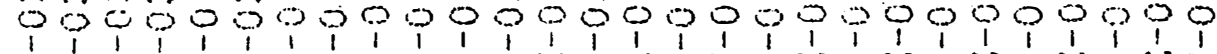

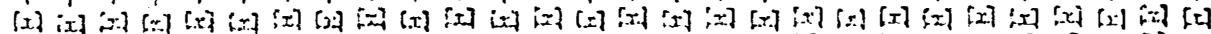

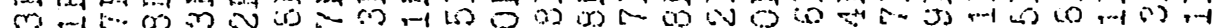

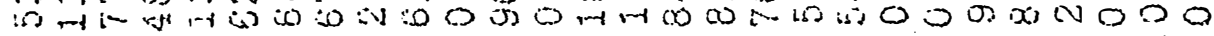
सं

a d N

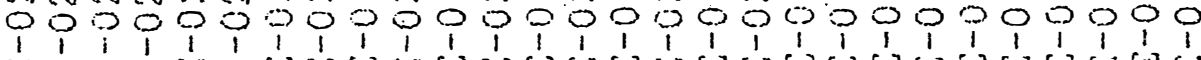

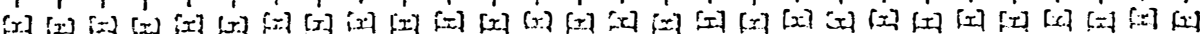

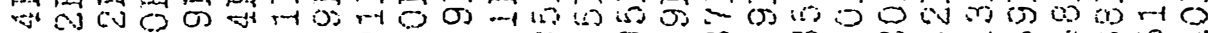

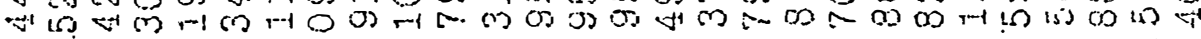

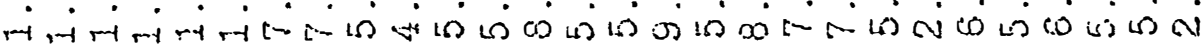

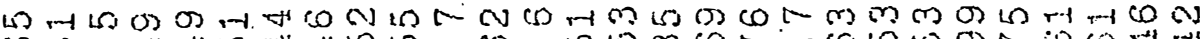

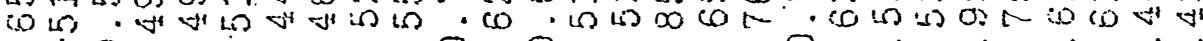

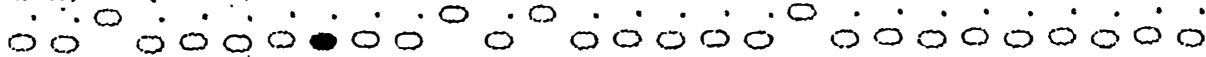

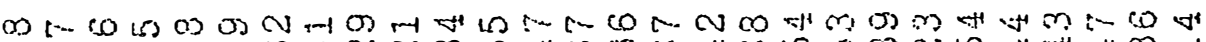
colis.

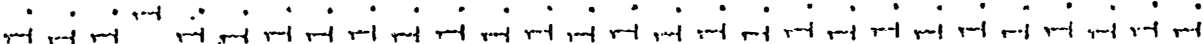

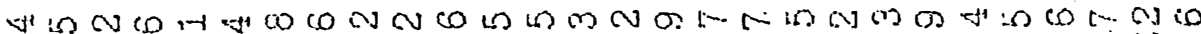

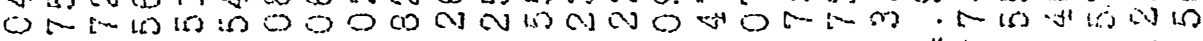
ن

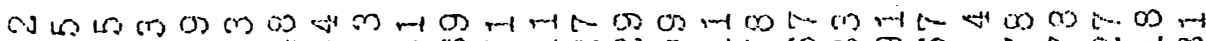

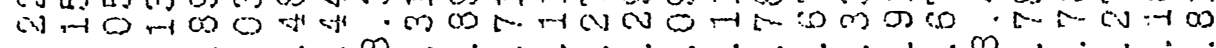

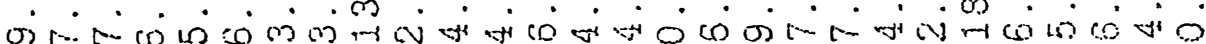

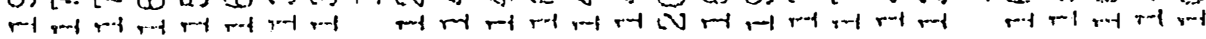

$000 \mathrm{~T}$ -

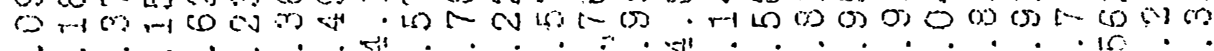
+ico in O

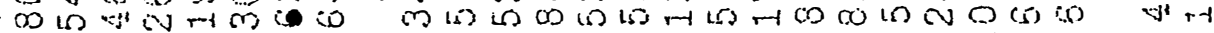
-1 $\rightarrow-1+1+1,-1$ $\rightarrow$ 거

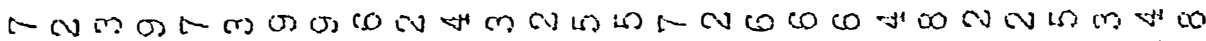

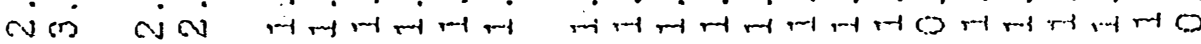

-

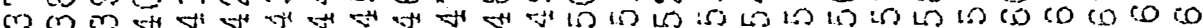

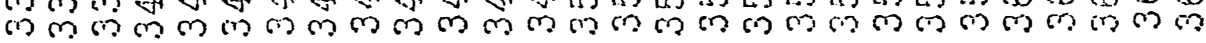




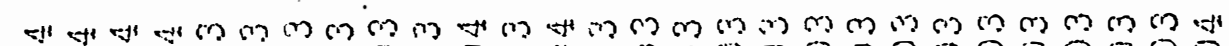

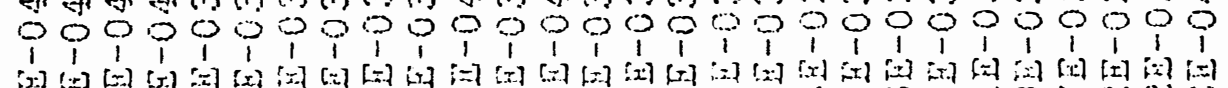
? - -0 \% को

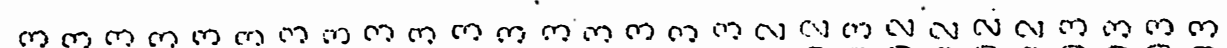

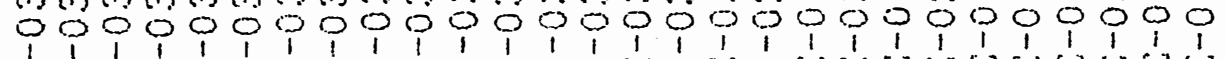

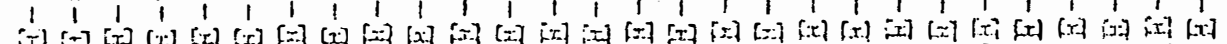

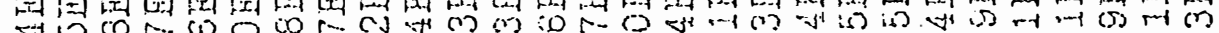

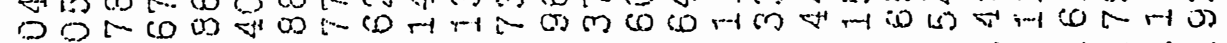

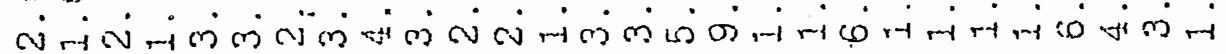

OR

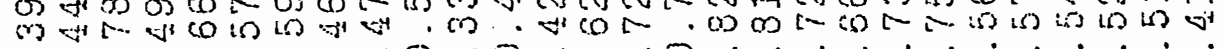

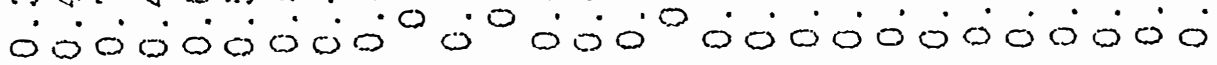

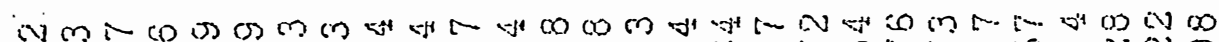

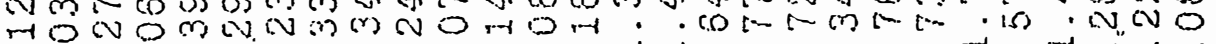

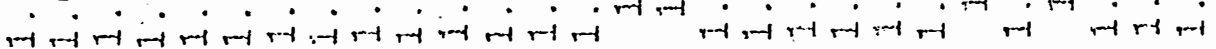

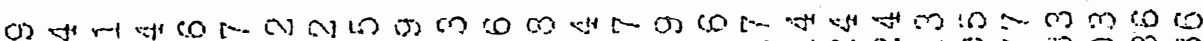
म N

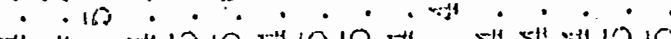

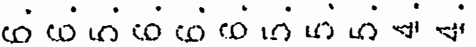

(0.

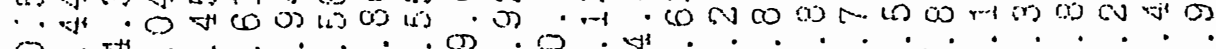

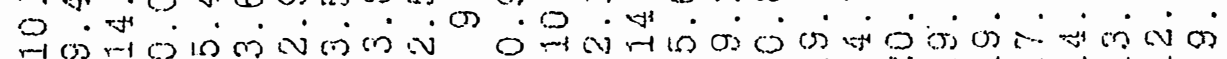

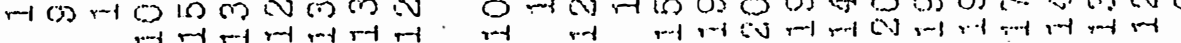

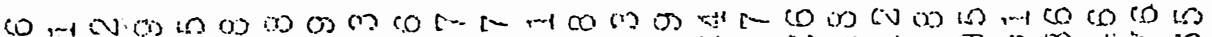

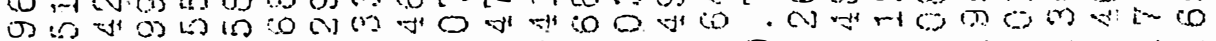
$\therefore 0$ jo in 0 or

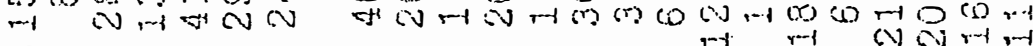

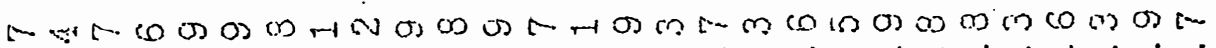

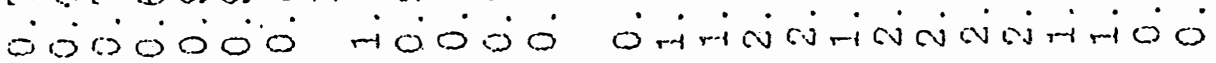

is

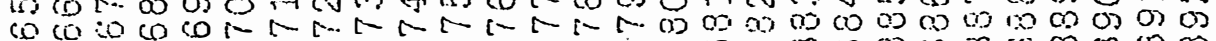
क त 


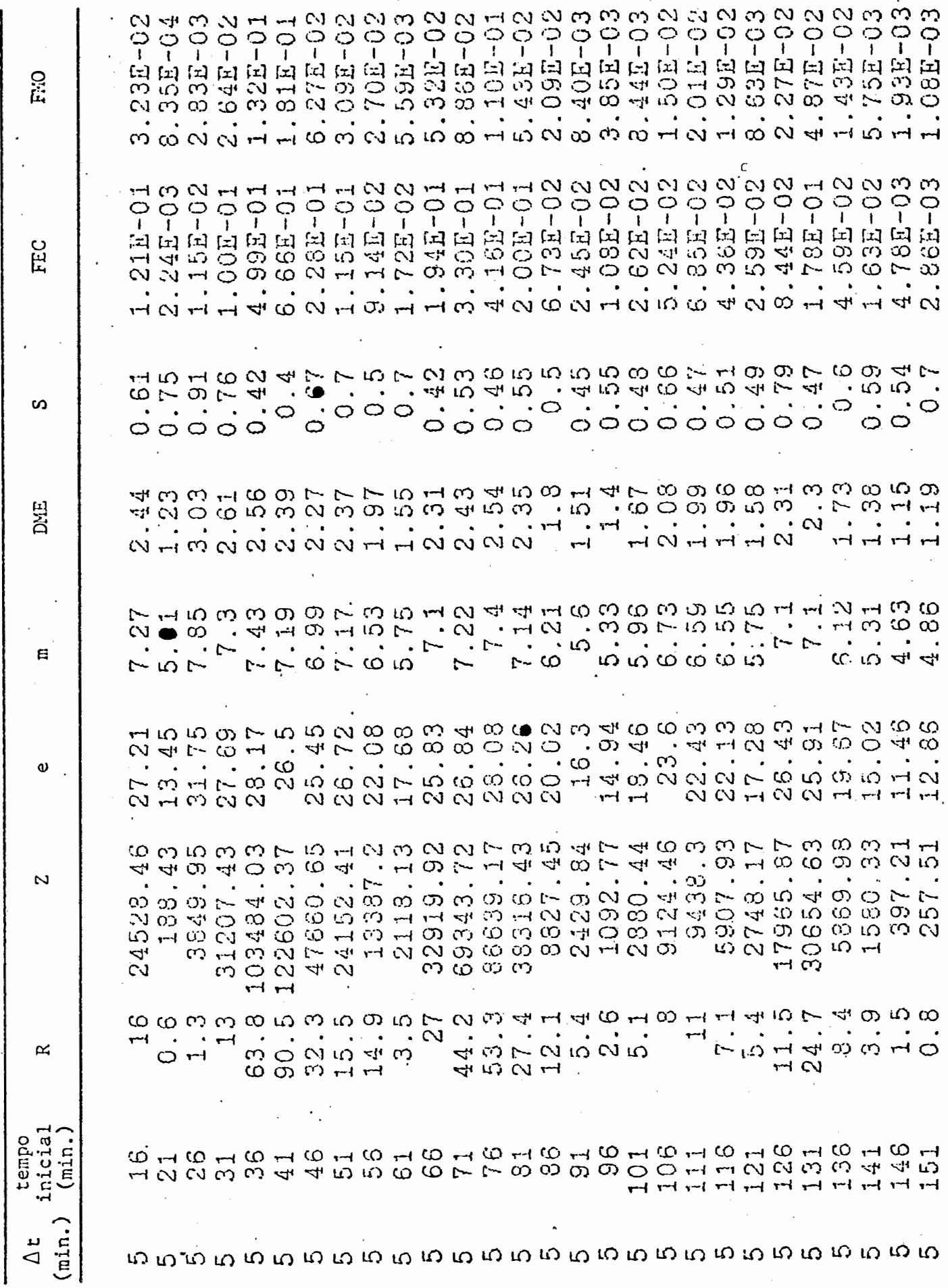




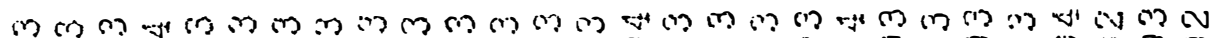
P

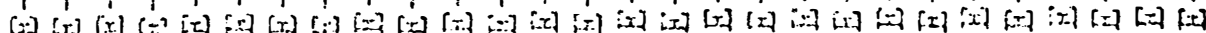
(x)

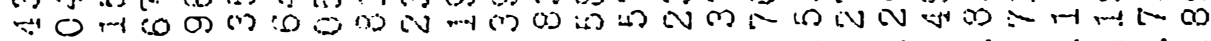

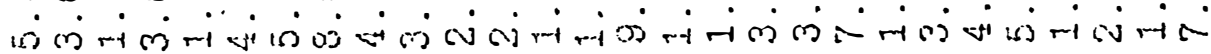

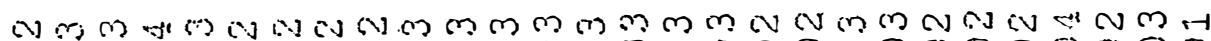

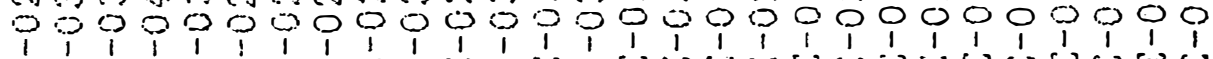

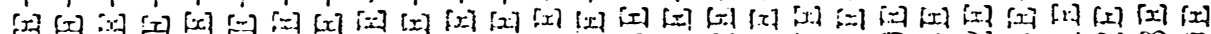

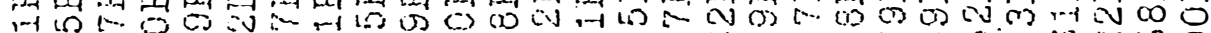

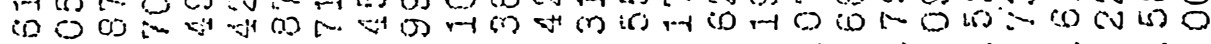

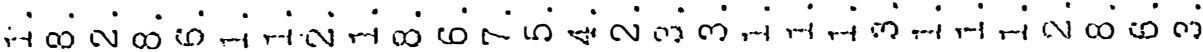

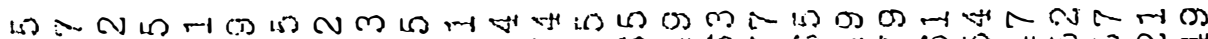

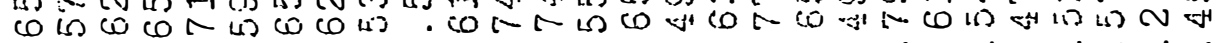
ن

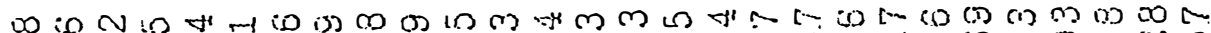

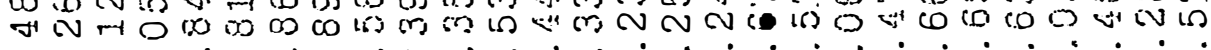

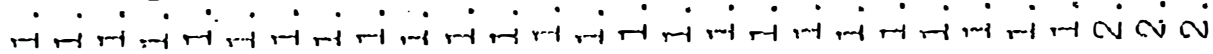

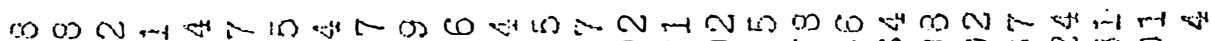

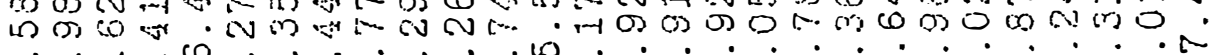
1

6ut

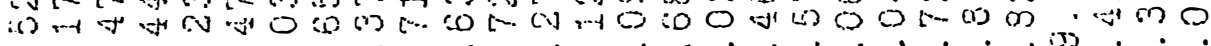

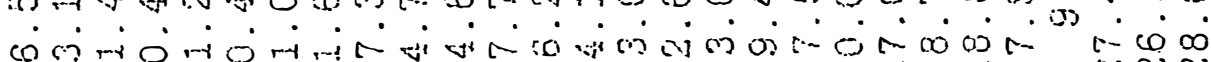

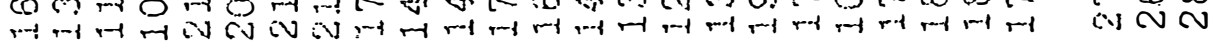

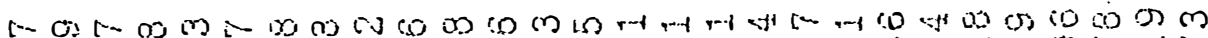

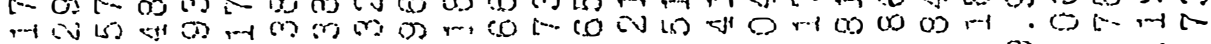
ס

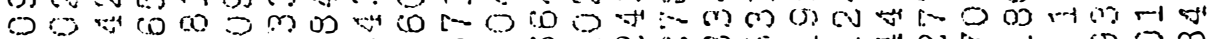

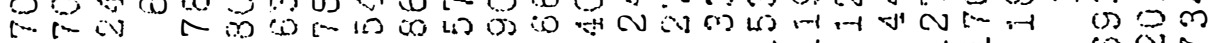
[- 1 (4)

(1) N TM

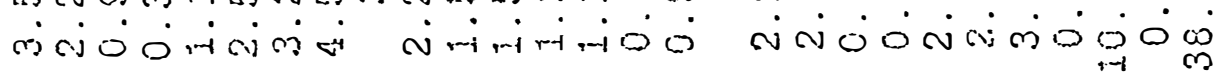

C) ,

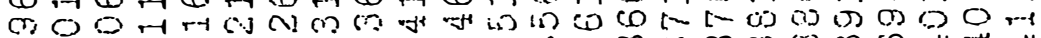
त ज

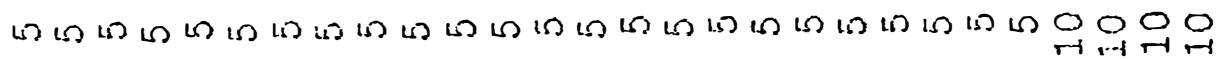




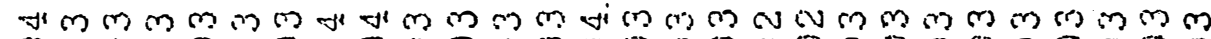
0000000000000000000000000000

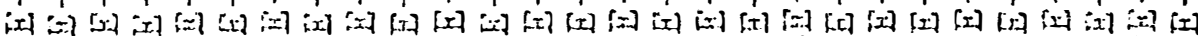

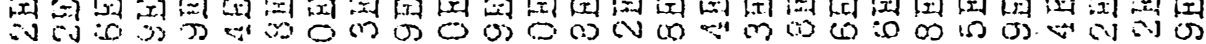
Q

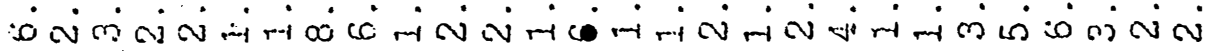

m m

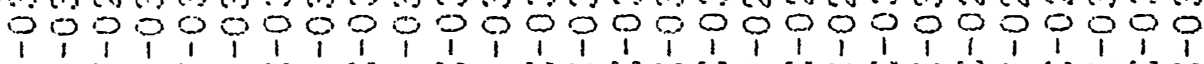

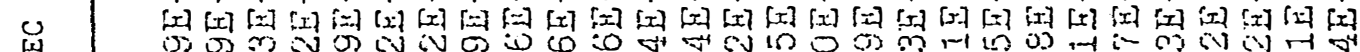

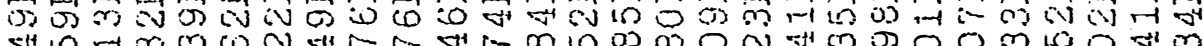

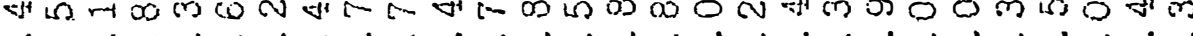

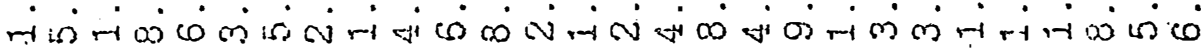

L

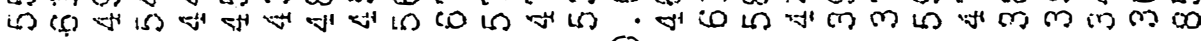

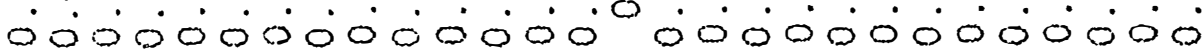

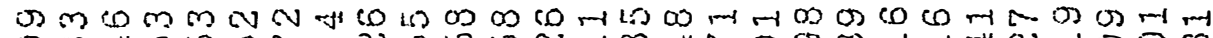
0 的 मi

DCN

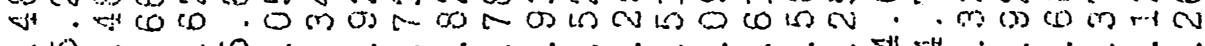

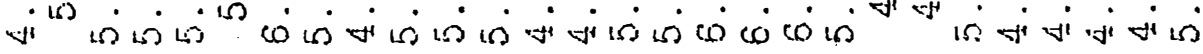

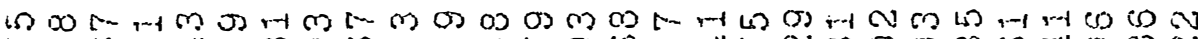

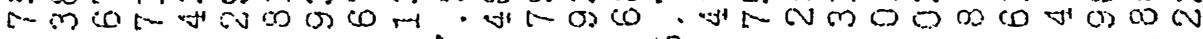

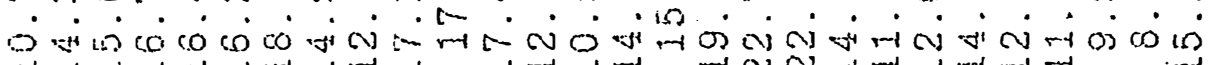

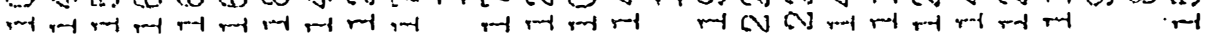

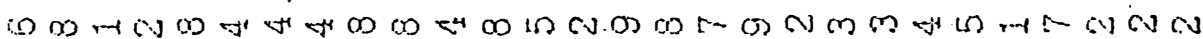

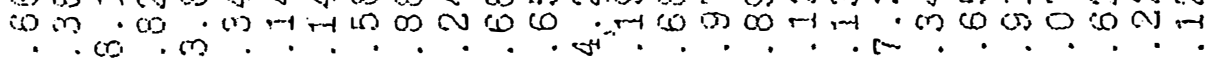

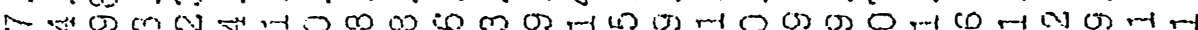

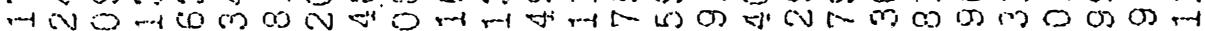

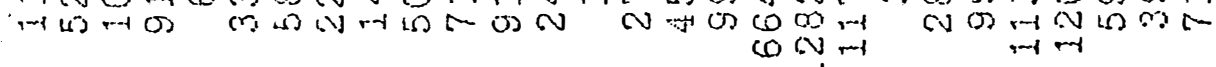

(i)

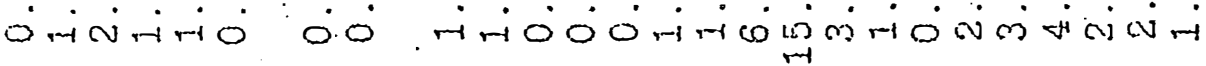

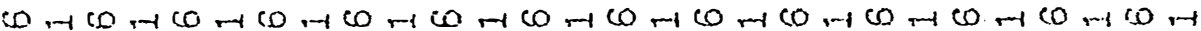

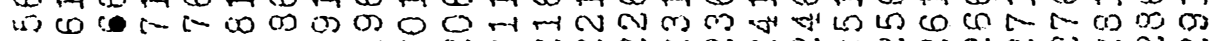
m F

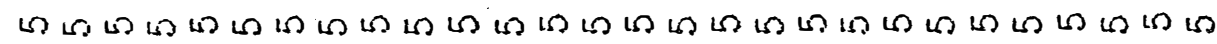




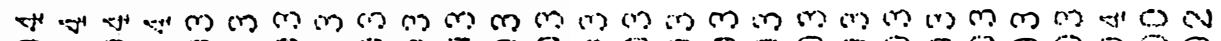

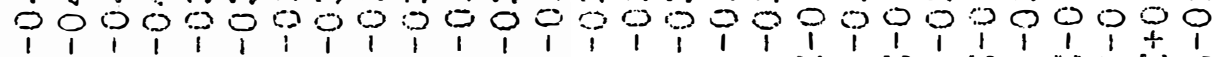

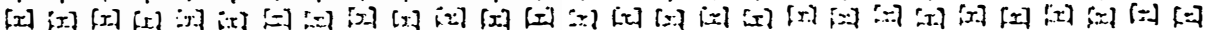

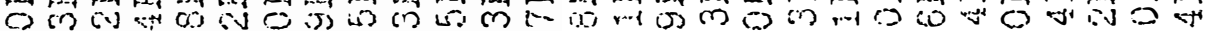

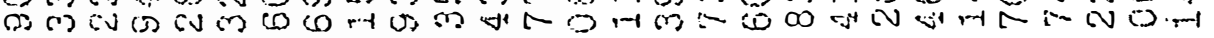

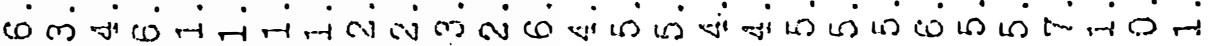

$m$ m

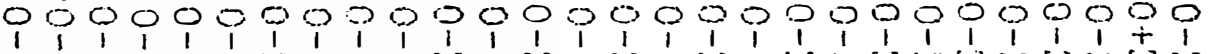

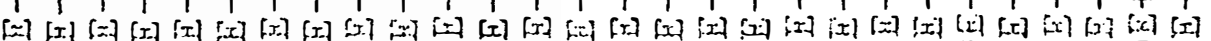

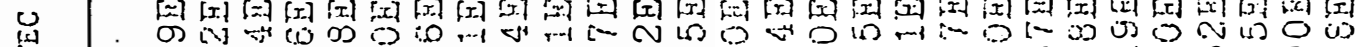

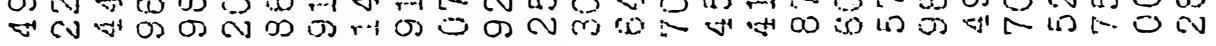
नि

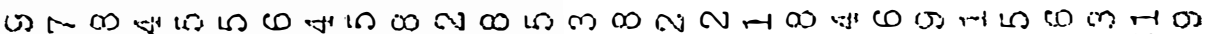

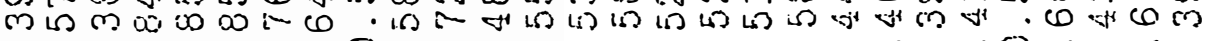
$\dot{0} \dot{0} \dot{0} \dot{0} \dot{0} \dot{0} \dot{0} \dot{0} \dot{0} \dot{0} \dot{0} \dot{0} \dot{0} \dot{0} \dot{0} 0$ O $\dot{0} \dot{0}$

Hलm

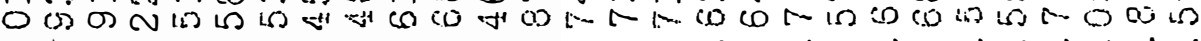

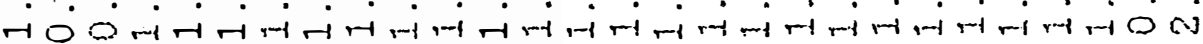

स

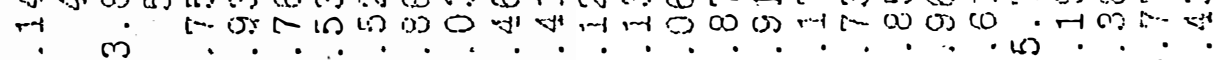
- M L

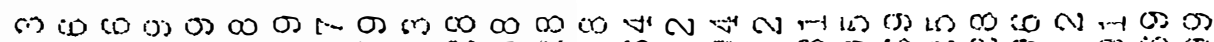

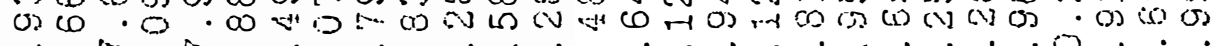

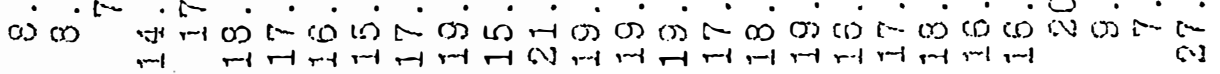

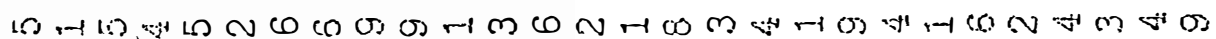

का

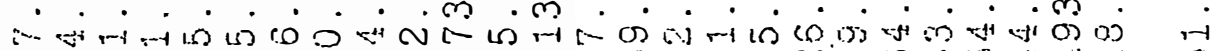
O -1 a

min

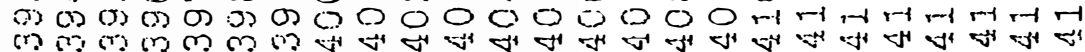

w.

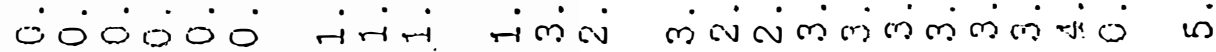




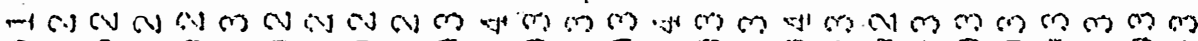

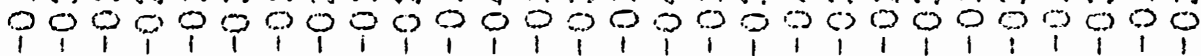

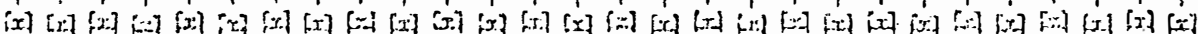

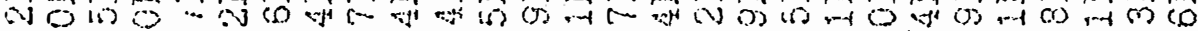

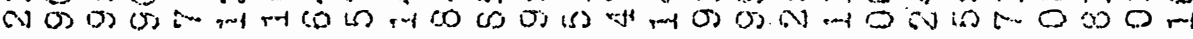

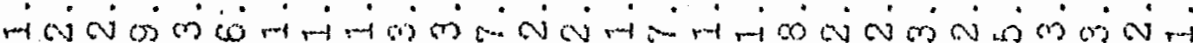

M

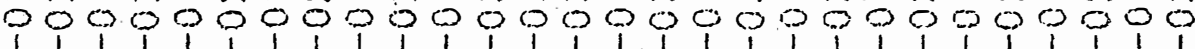

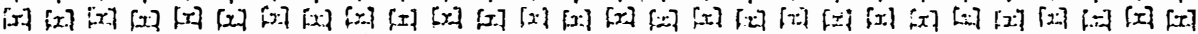

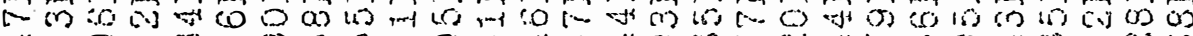

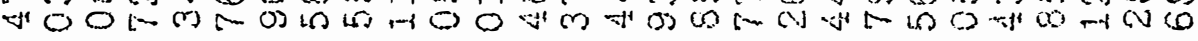
सं

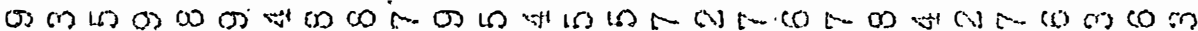

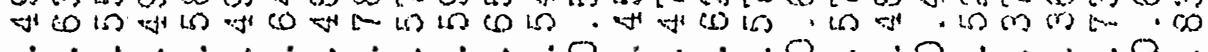

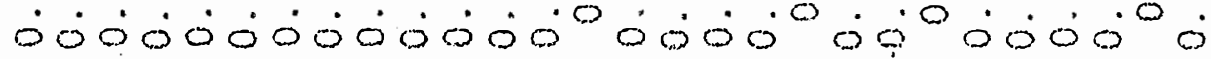

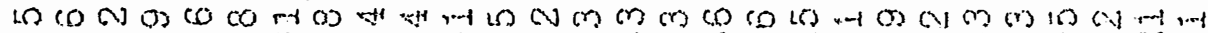

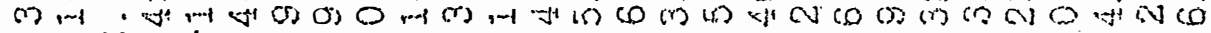

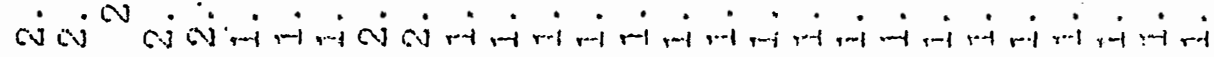

F

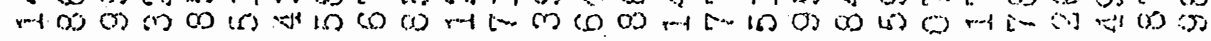
-

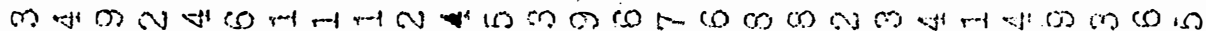
O co

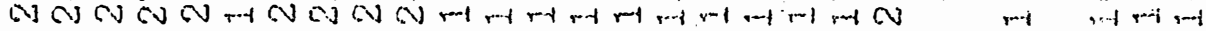

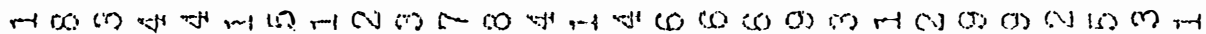
(5). $D$.

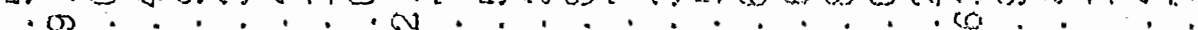
mco OS m

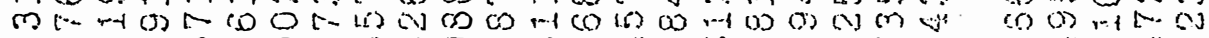

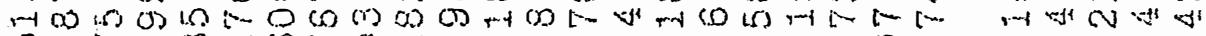

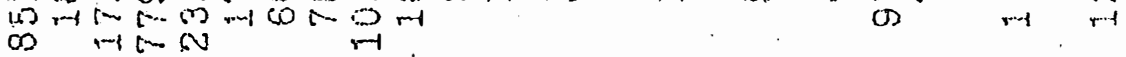

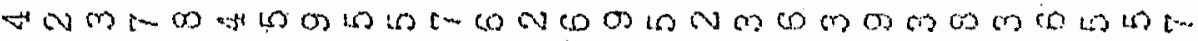

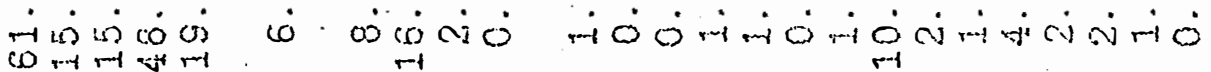

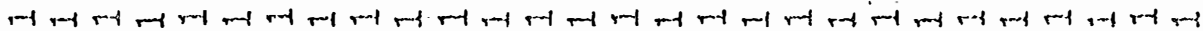

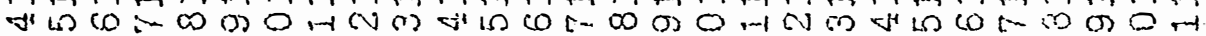

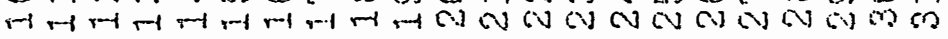


(n)

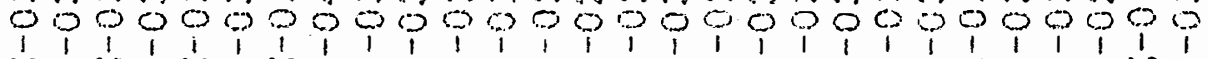

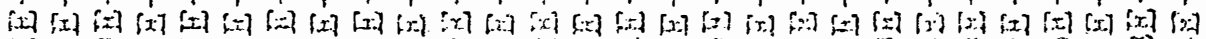

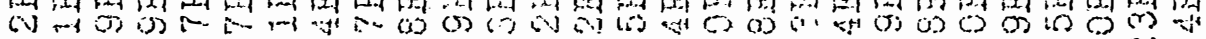

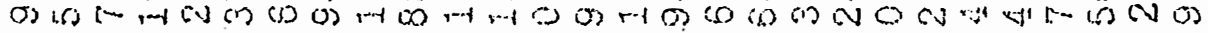
ن co 0 oj

NON

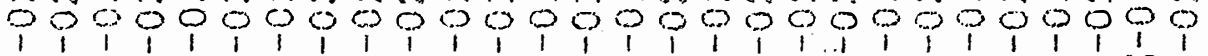

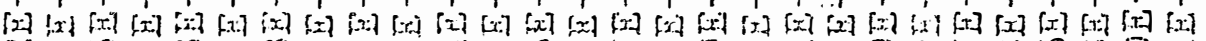

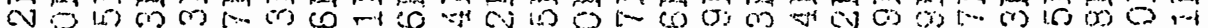

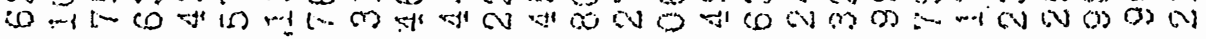

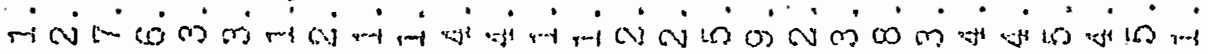

6) mis

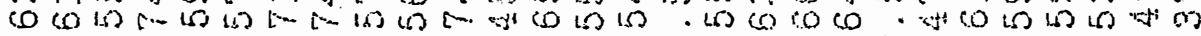
केंهं

स

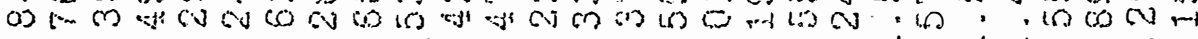

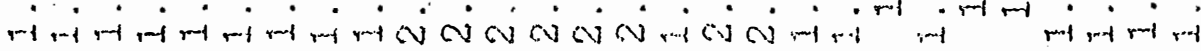

O

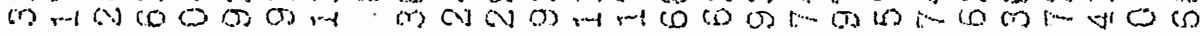

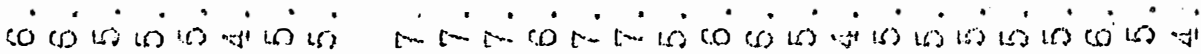

O

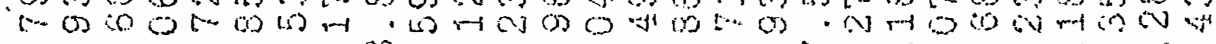
कि

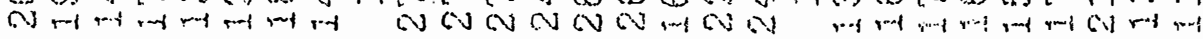

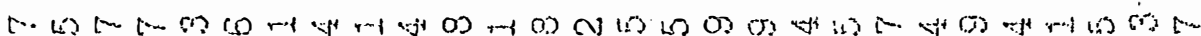
Q in

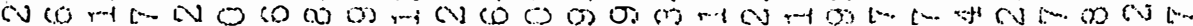

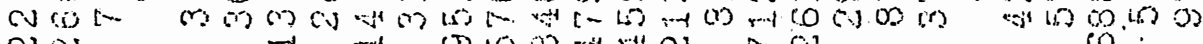
OU $Q \mathrm{~V}$

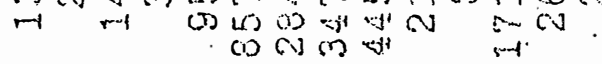

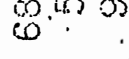

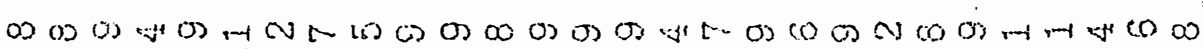

जिम

$$
\text { (1) } N \text { O n m }
$$

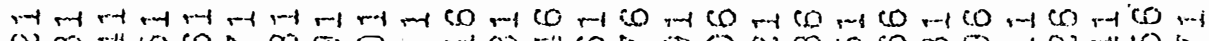

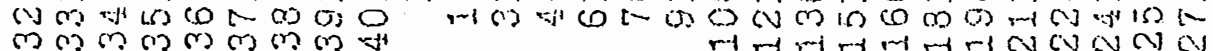


mm

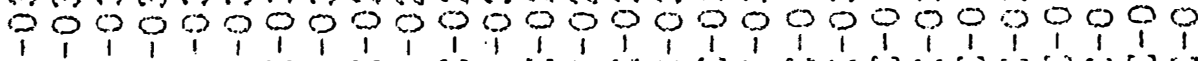
$[x][x][x][x][x][x][x][x][x][x][x][x][x][x][\because][x][-1][x][x][x][x][x][x][x][0][x][x][x]$

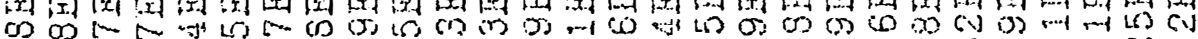

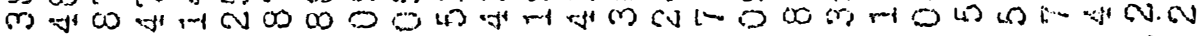
मे

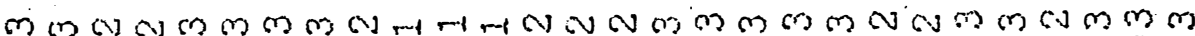

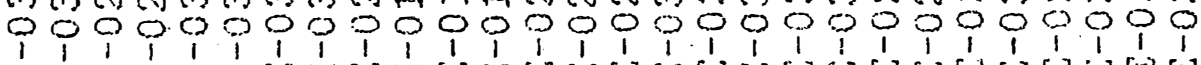
$[x][x][x][x][x]$ : $[x][x][x][x][x][-][x][x][x][x][x][x][x][x][x][x][x][x][x][x][x][x][x]$ H. W

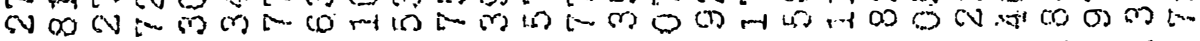

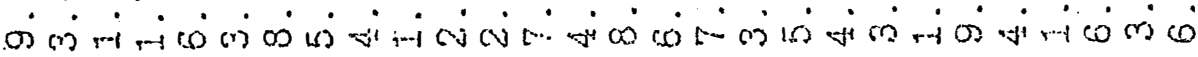

C) W

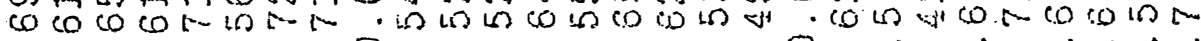

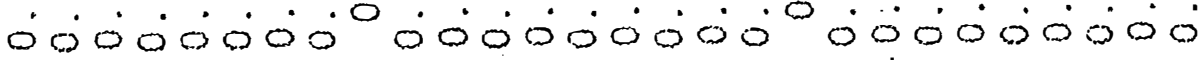

MO

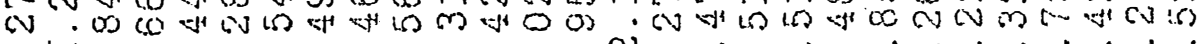

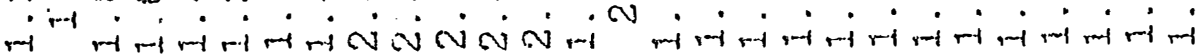

TND

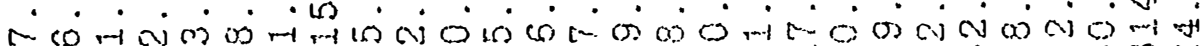
n m

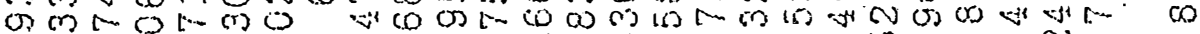

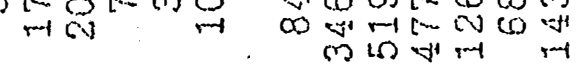
is

Non m

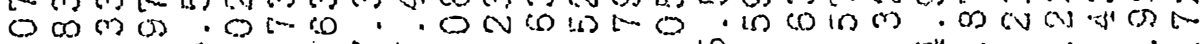

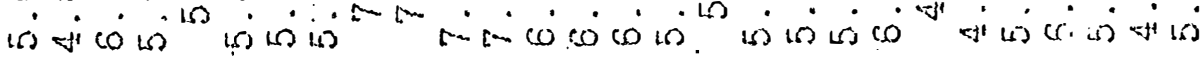

m

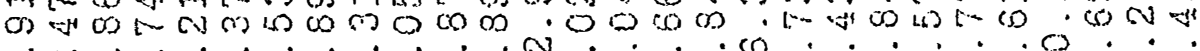

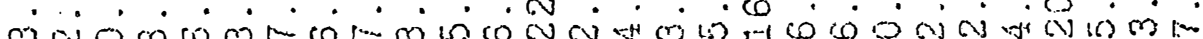

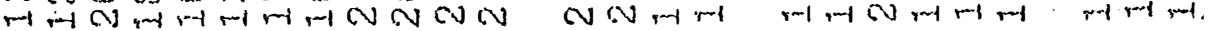

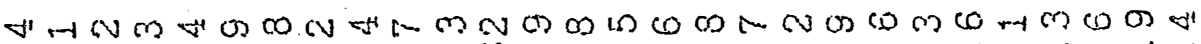
तं

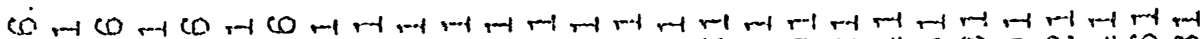

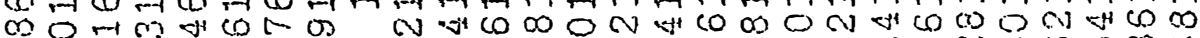
जलm 


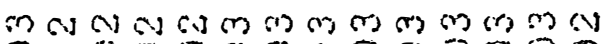
$00 \%, 9000090900$ $[x][x][x][x][-][x][x][x][x][x][x][x][x][x]$ on 6 (口) $\infty 60$ (0)

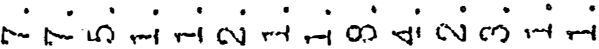

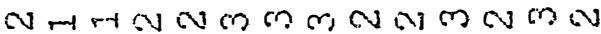
000090000000000

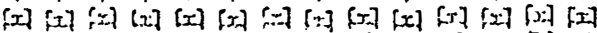
is $\mathrm{h}$ प

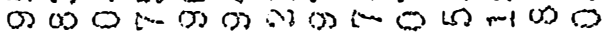
م $\dot{0}$ व

$[\cdots \infty$ is (J)

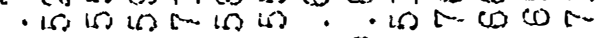
O $\dot{0}$ iिं

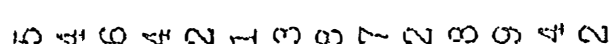

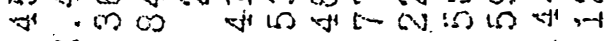

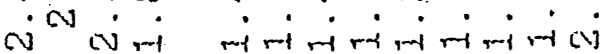

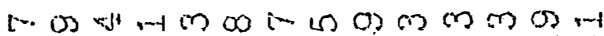

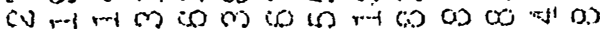

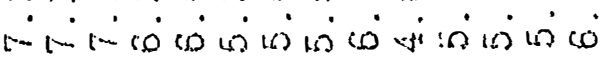

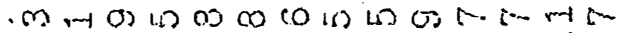

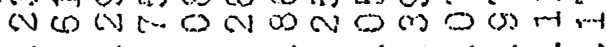
य

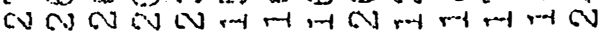

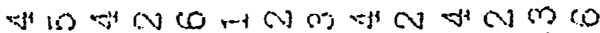
तथ,

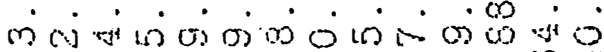

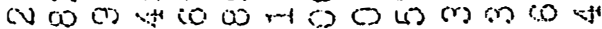

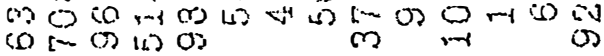
in 63

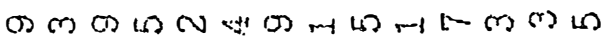

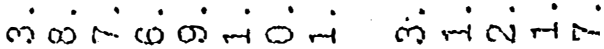
is $\mathrm{CN}$

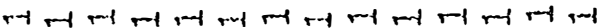

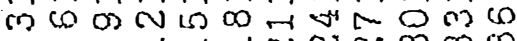
m rt r O CU O m

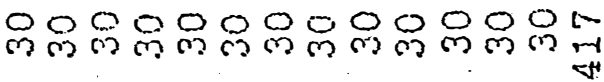




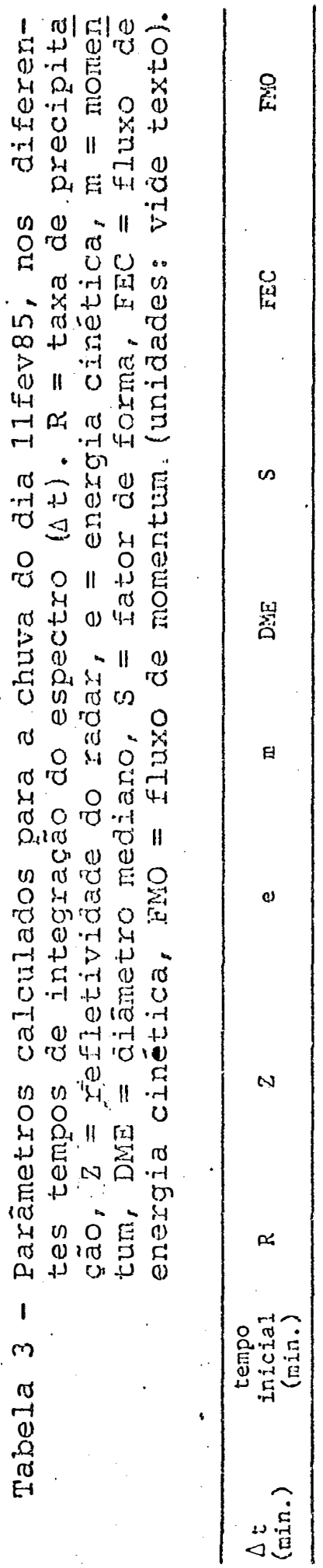

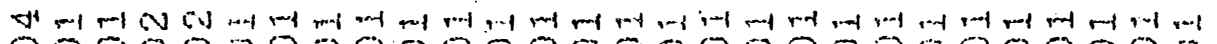

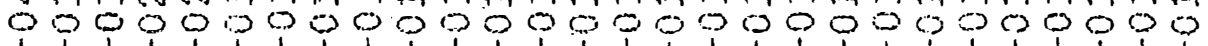

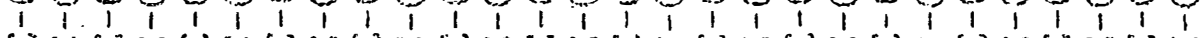

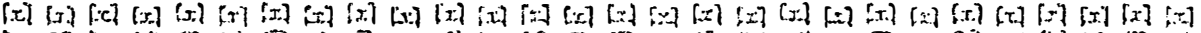
5 D...

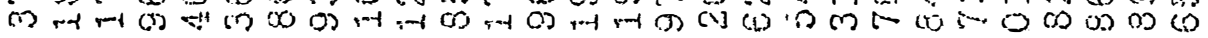

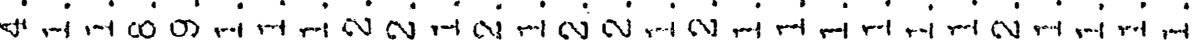

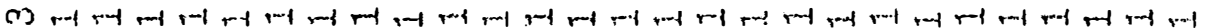

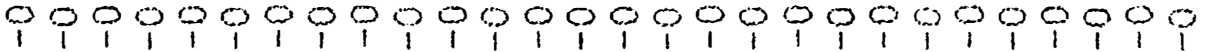

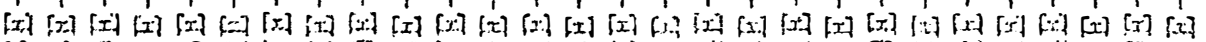

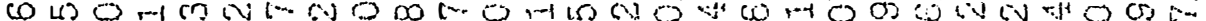

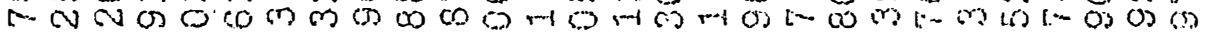

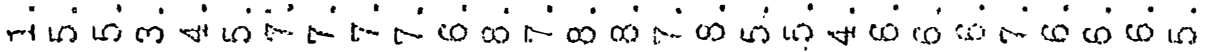

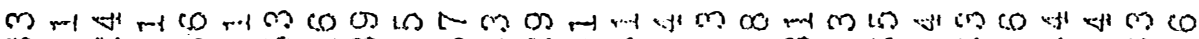

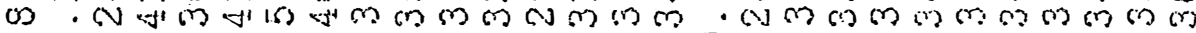
ه ن

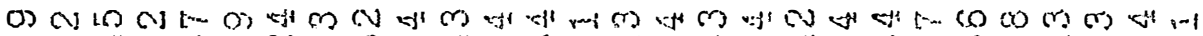

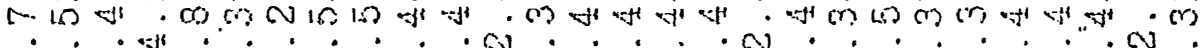

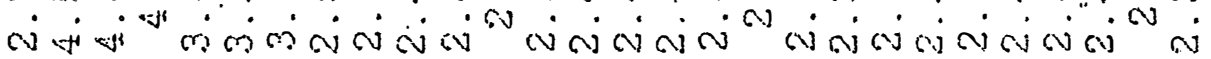

1- os m os. Co

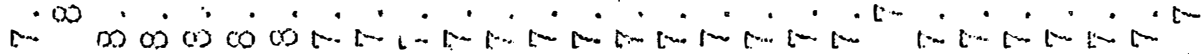

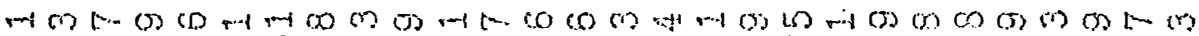

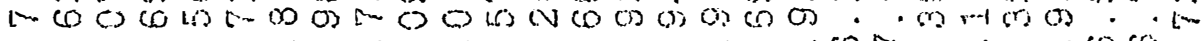

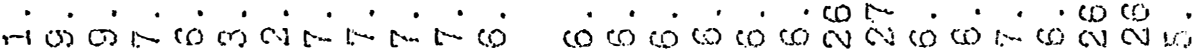

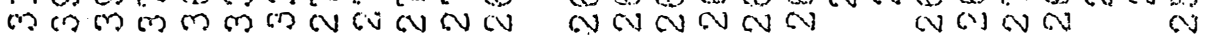

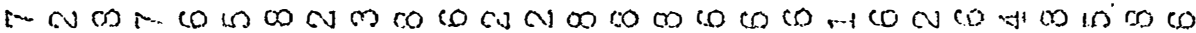

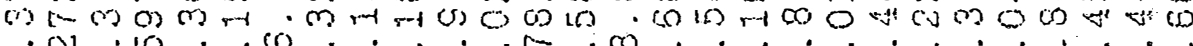
oj

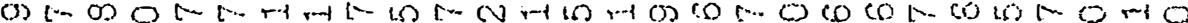

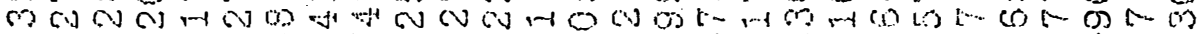
E $\quad 0$ in

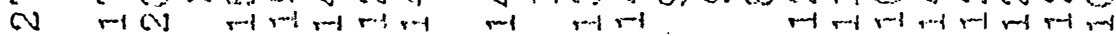

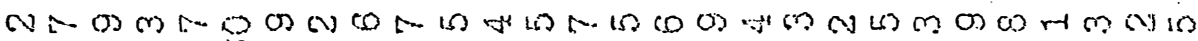

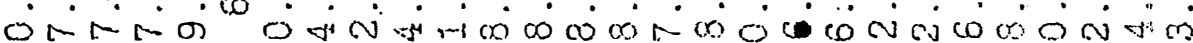

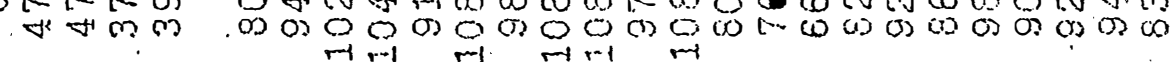

HON

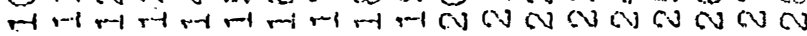

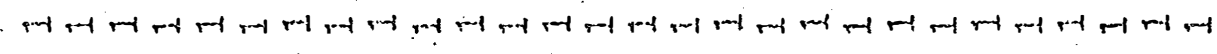




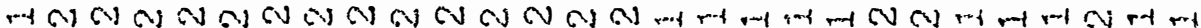

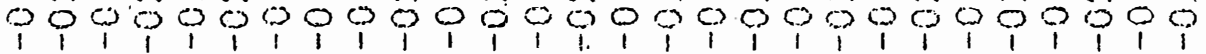
$[x][x][x][x][x][x][x][x][x][x][x][x][x][x][x][x][x][x][x][x][x][x][x][x][x][x][x][x]$

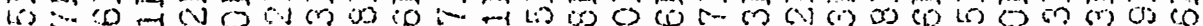

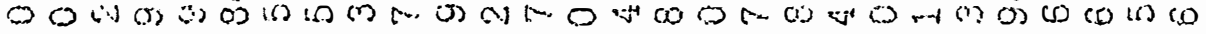
-i

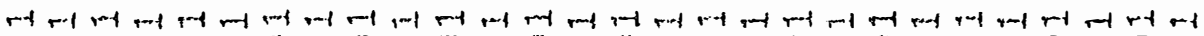

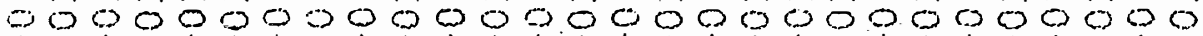
$\begin{array}{lllllllllllllllllllllllllllll}1 & 1 & 1 & 1 & 1 & 1 & 1 & 1 & 1 & 1 & 1 & 1 & 1 & 1 & 1 & 1 & 1 & 1 & 1 & 1 & 1 & 1 & 1 & 1 & 1 & 1 & 1 & 1\end{array}$ $[\because[x][x][x][x][x][x][x][x][x][x][x][x][x][x][x][x][x][x][\because[f][x][\because][x][x][x][x][x]$

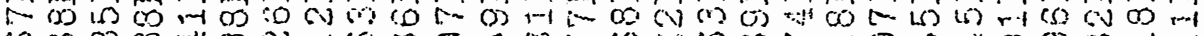
क

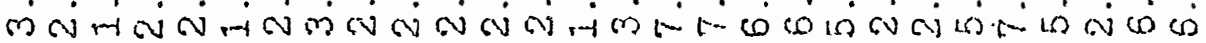

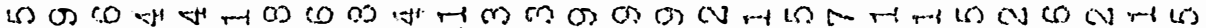

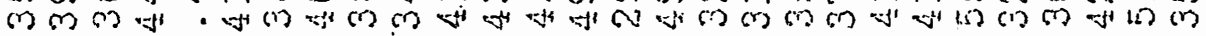

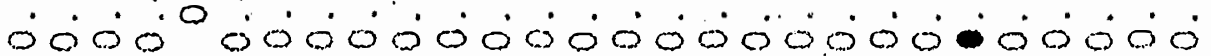

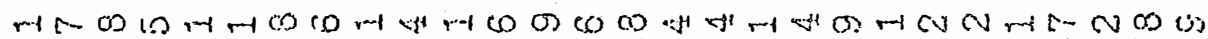

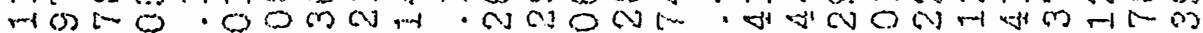
ब.

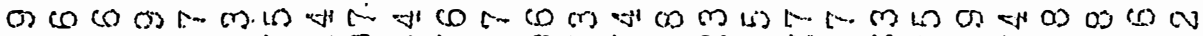

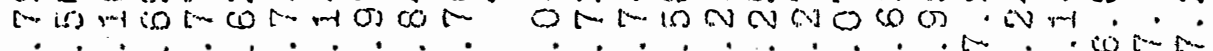

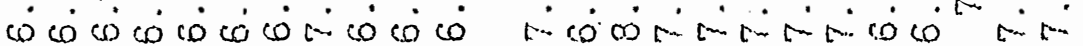

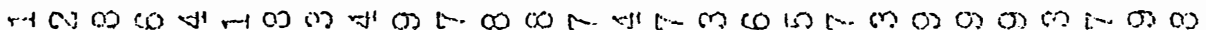

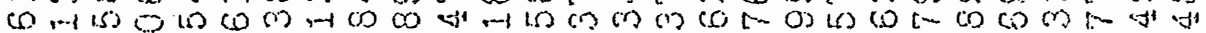

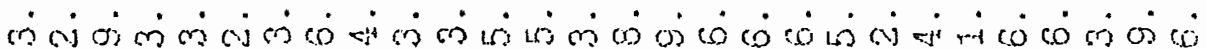
W

M

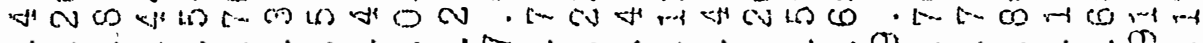
$\therefore$ min

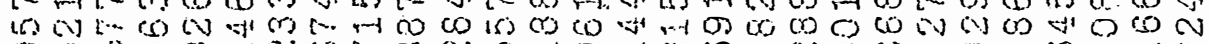

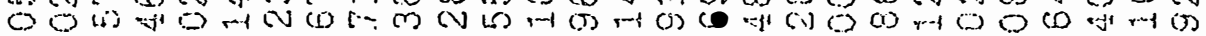

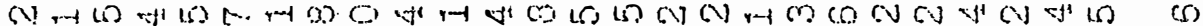
if $\mathrm{a}$ -

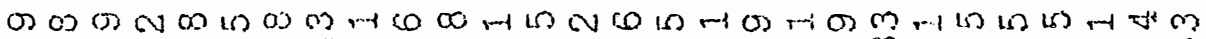

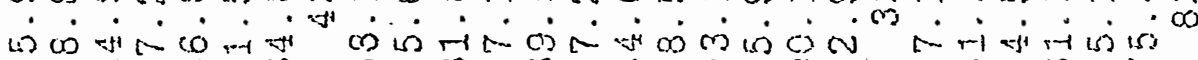
L

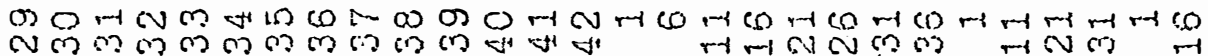

$m$ 
.161 。

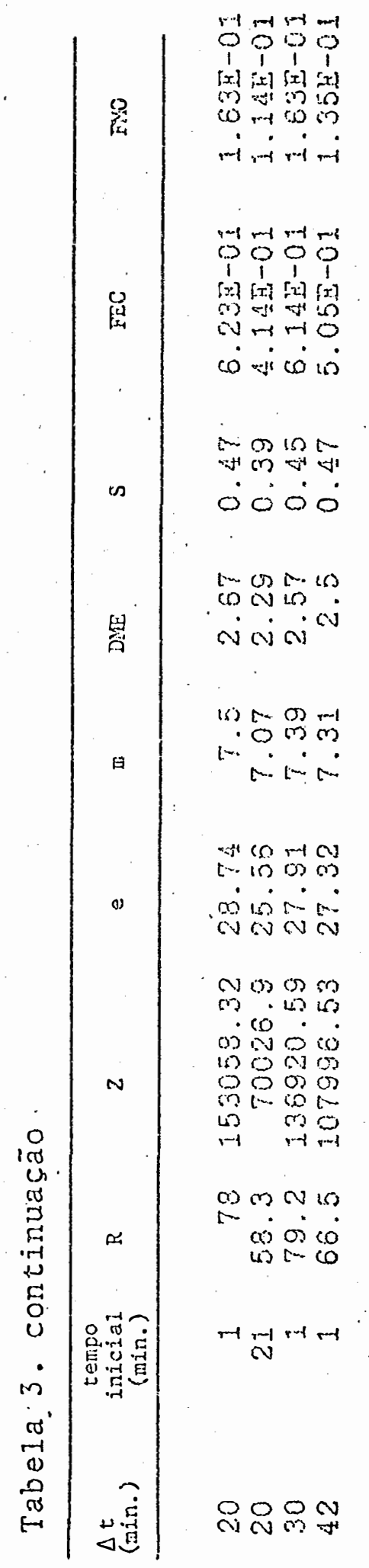




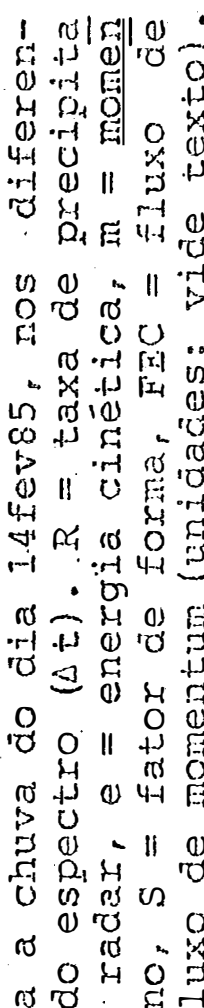

sf 0 O

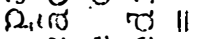

U (1) (a)

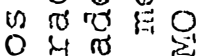

$\begin{array}{lll}0 & 4 & \\ 0 & 0 & 0\end{array}$

ro 010 .

लो 5 is

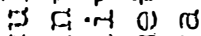

$U \cdot r+5$ E

$\rightarrow$ (1)

$\begin{array}{llll}0 & 0 \\ 0 & 0 & 0 & 0\end{array}$

()

थ थ $\mathrm{H} \|$.

मे $\mathrm{O}_{4} \|$ [I

+ E

(1) 0) 0 尺

हा -

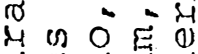

గ๐ 010 क

D + 4 (1)

1

$\infty$
$\sigma$
$\sigma-1$
0
0
0
0
0
"

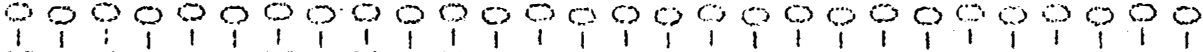
$[x][x][x][x][x][x][x][x][x][x][x][x][\because[[x][x][x][x][x][x][a][x][x][x][x][2][x][x][x]$

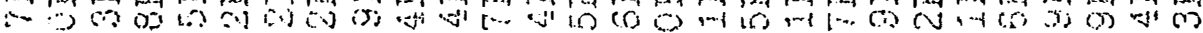

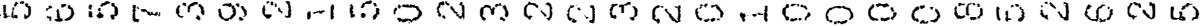
- मे को

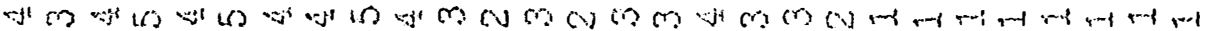

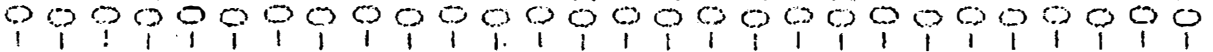

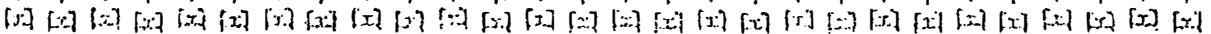
O D

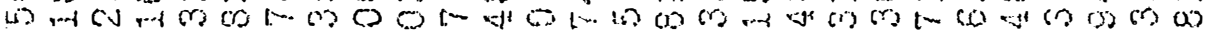
-

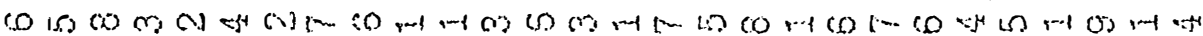

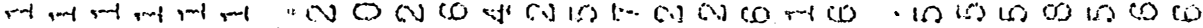
क

In a r a

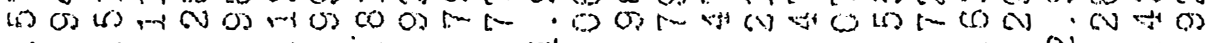
- मे

-3.

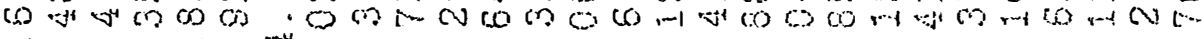
ज

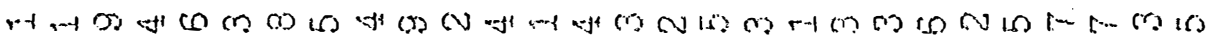

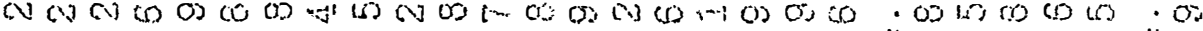

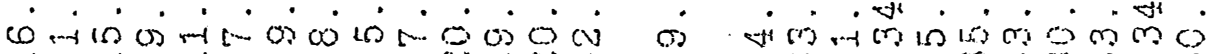
TCl

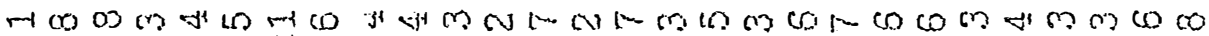
H

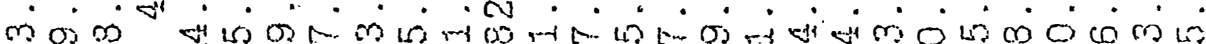

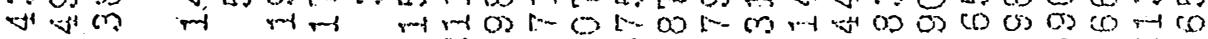

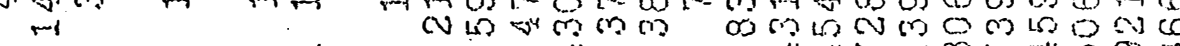

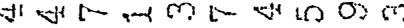

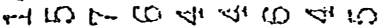

Mcordm

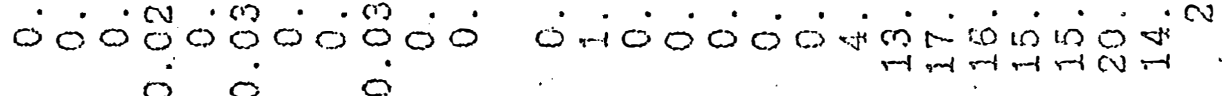

Hom

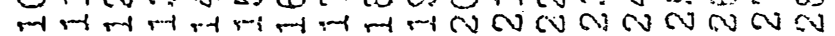

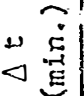




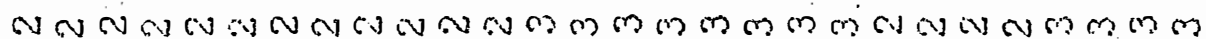
$00090000000000900000 \% 9000090$

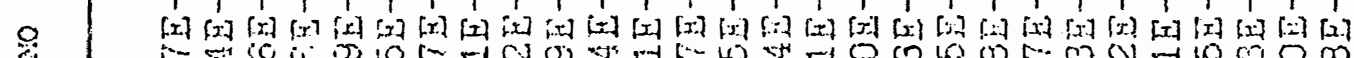

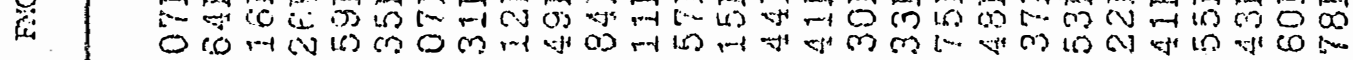
ம்

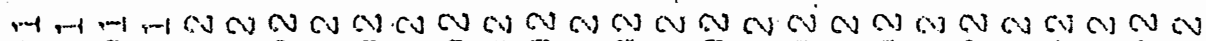
0000000000000000000000000009

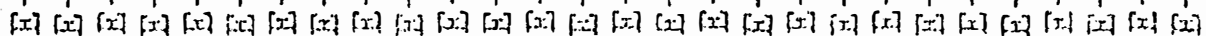

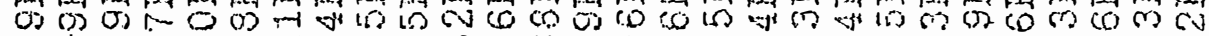

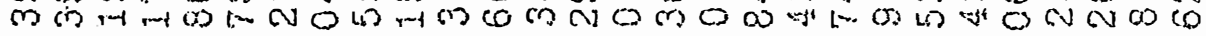
N ,

0 is H R . . . 然

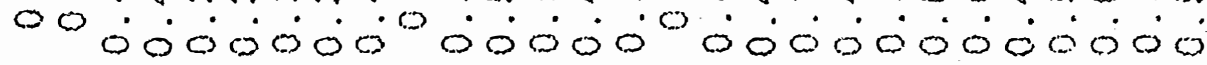

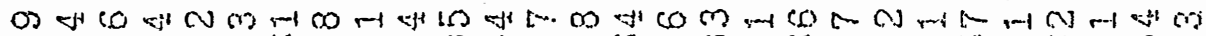

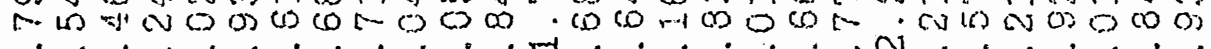

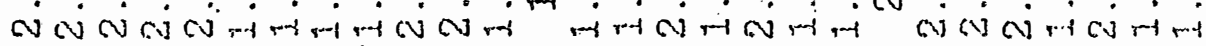

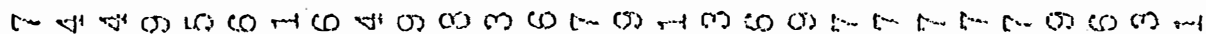

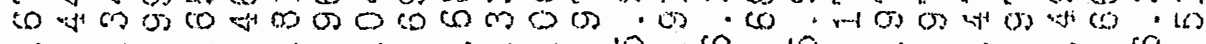

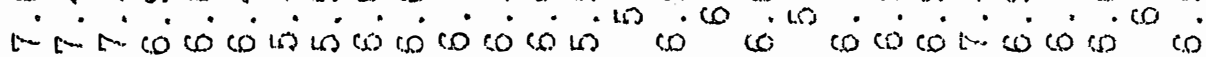

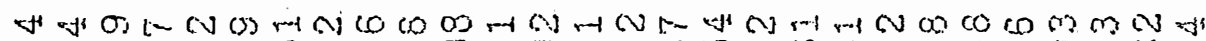

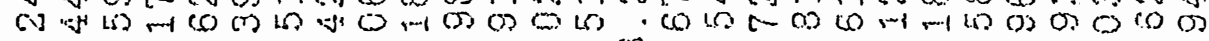
ठ वर्ति

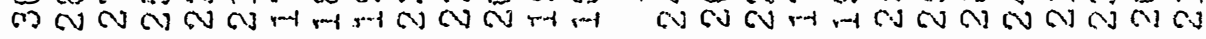

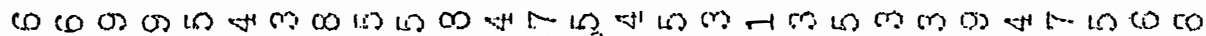
m.

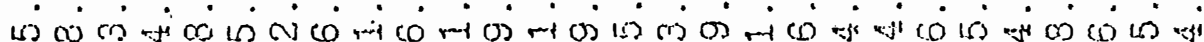

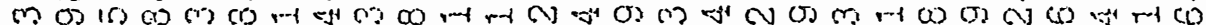

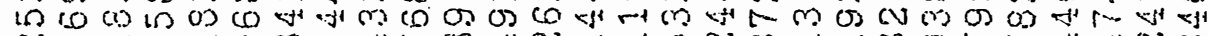

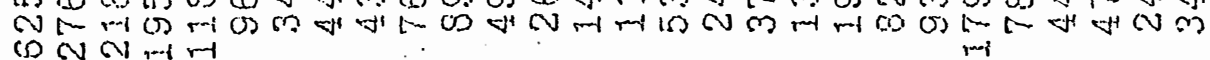

L

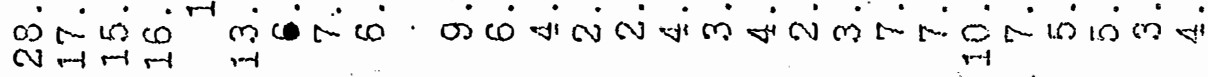

ODOHOM W बn m 


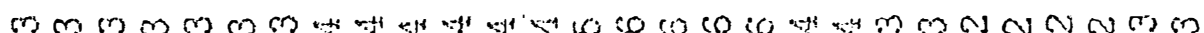

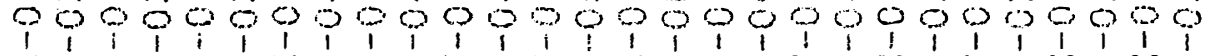

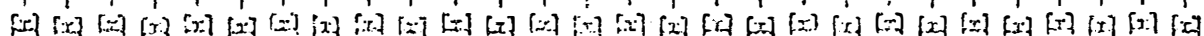

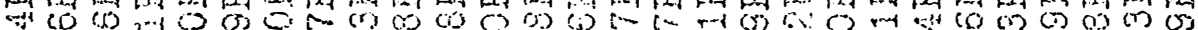

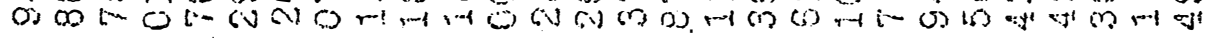
सं वर

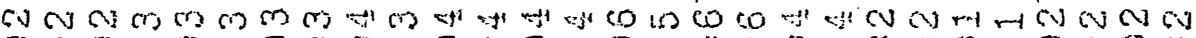
$00090000000000000000000 \% 90 \% ?$

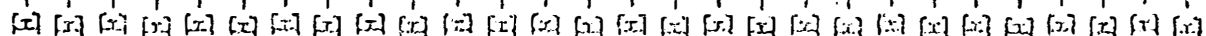

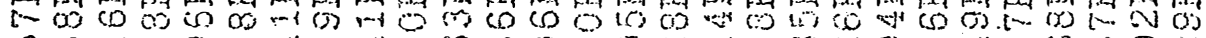

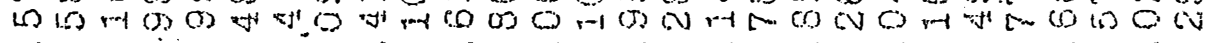

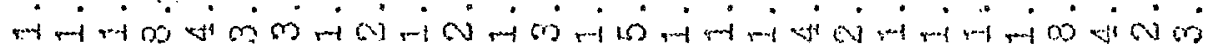

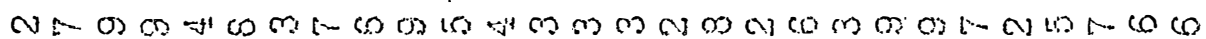

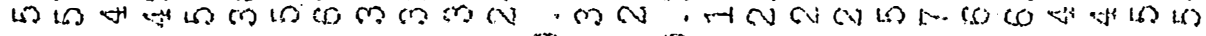

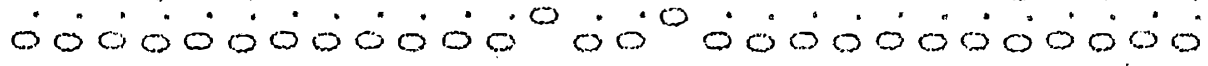

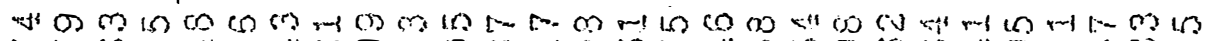
H.

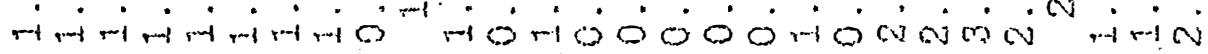

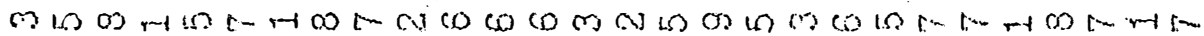

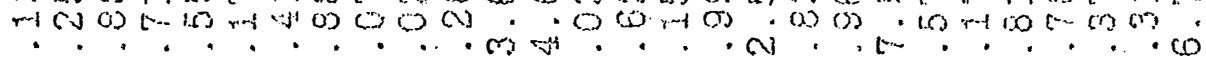

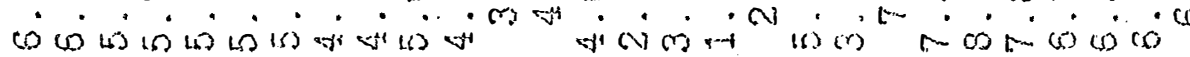

[a

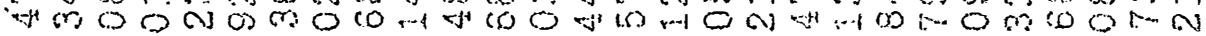

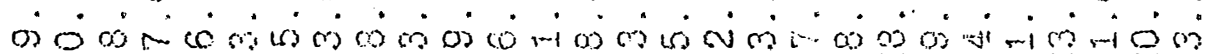

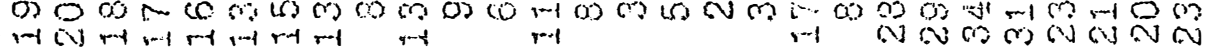

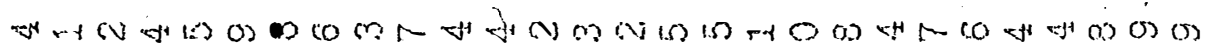
a)

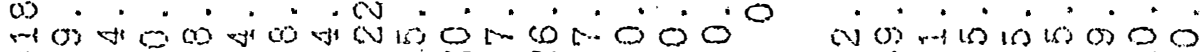
a 40 -

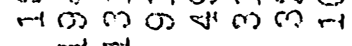

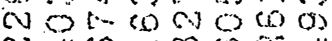
$r+1$ in $10,-1$

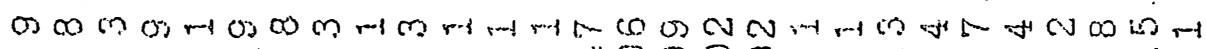
Nم i نं $\dot{0} \dot{0} 0$

Nos 0:0 Hoj

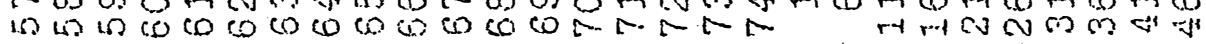




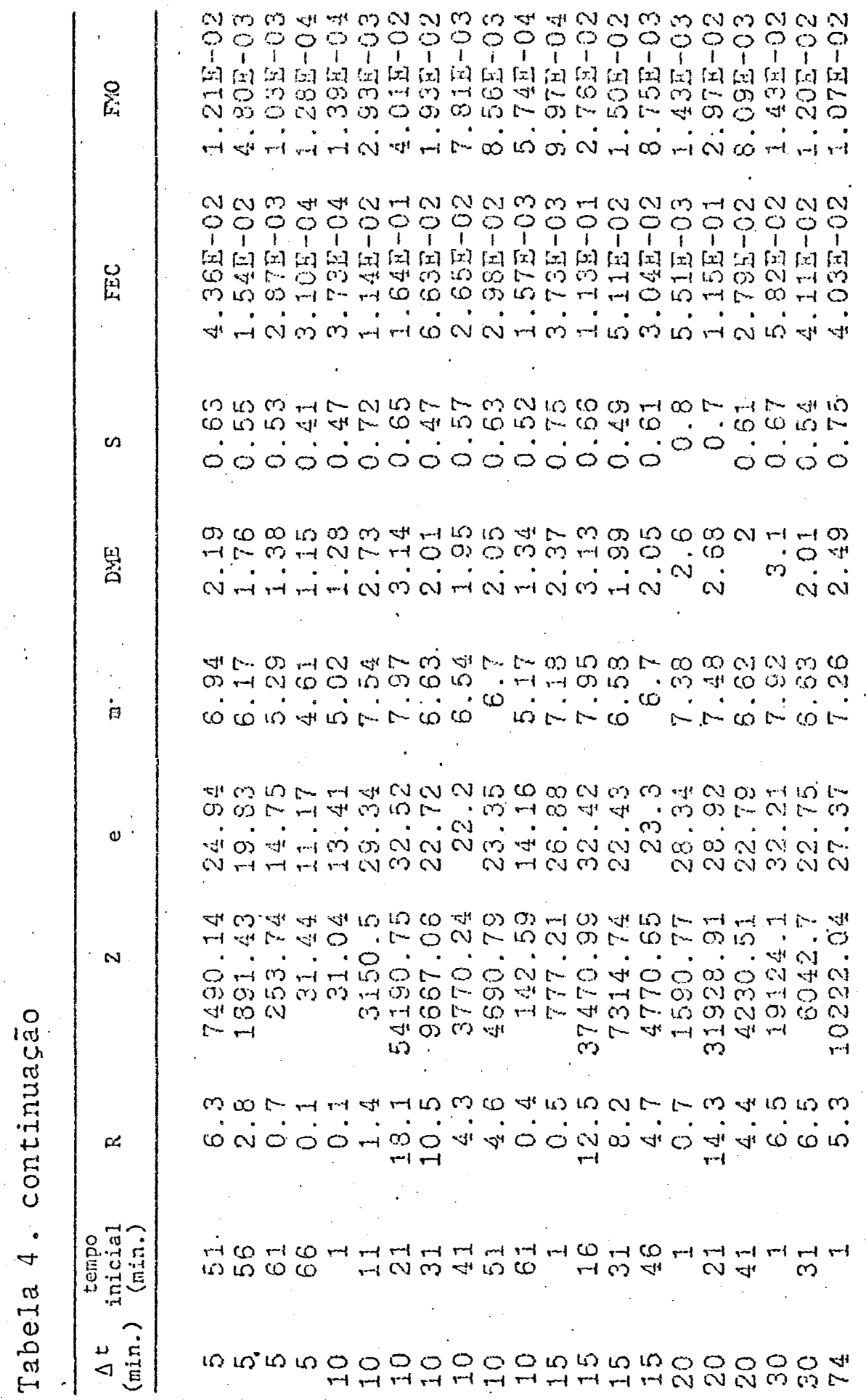

